\title{
Testing, assessment and FRP strengthening of concrete T-beam bridges in Pennsylvania
}

\author{
William C. Sasher \\ West Virginia University
}

Follow this and additional works at: https://researchrepository.wvu.edu/etd

\section{Recommended Citation}

Sasher, William C., "Testing, assessment and FRP strengthening of concrete T-beam bridges in Pennsylvania" (2008). Graduate Theses, Dissertations, and Problem Reports. 1919.

https://researchrepository.wvu.edu/etd/1919

This Thesis is protected by copyright and/or related rights. It has been brought to you by the The Research Repository @ WVU with permission from the rights-holder(s). You are free to use this Thesis in any way that is permitted by the copyright and related rights legislation that applies to your use. For other uses you must obtain permission from the rights-holder(s) directly, unless additional rights are indicated by a Creative Commons license in the record and/ or on the work itself. This Thesis has been accepted for inclusion in WVU Graduate Theses, Dissertations, and Problem Reports collection by an authorized administrator of The Research Repository @ WVU. For more information, please contact researchrepository@mail.wvu.edu. 


\title{
TESTING, ASSESSMENT AND FRP STRENGTHENING of Concrete T-Beam Bridges in Pennsylyania
}

\author{
William C. Sasher \\ Thesis submitted to the \\ College of Engineering and Mineral Resources \\ at \\ West Virginia University \\ in partial fulfillment of the requirements \\ for the degree of \\ Master of Science \\ in \\ Civil and Environmental Engineering \\ Karl E. Barth, Ph. D., Chair \\ Julio F. Davalos, Ph. D., Co-Chair \\ Indrajit Ray, Ph. D. \\ Department of Civil and Environmental Engineering
}

Morgantown, West Virginia

2008

Keywords: fiber reinforced polymer (FRP), concrete t-beam bridge, load testing, load rating, FRP strengthening 


\title{
TESTING, ASSESSMENT AND FRP STRENGTHENING OF CONCRETE T-BEAM BRIDGeS IN PENNSYLVANIA
}

\author{
William Christopher Sasher
}

Dr. Karl E. Barth, Thesis Advisor

\begin{abstract}
The transportation infrastructure of the United States is in urgent need of rehabilitation. The effects of ageing and deterioration, along with increased traffic demands have raised the concern that the deteriorated conditions of highway bridges need to be addressed to insure the safety of the public. Several rehabilitation methods are available to engineers including: bridge replacement, bridge repair, and retrofitting with mechanisms designed to increase the structural capacity of a bridge.

The Pennsylvania Department of Transportation - District 3 (PennDOT-D3) has sponsored a multi-phase project to investigate externally bonded Fiber Reinforced Polymer (FRP) technology on their deteriorated concrete T-Beam bridges. The bridge inventory maintained by PennDOT-D3 includes 128 concrete T-Beam bridges built between 1920 and 1960. Ageing and deterioration effects have caused these bridges to become structurally deficient and/or obsolete. PennDOT-D3 has teamed with researchers from West Virginia University to develop a system to transfer FRP bridge rehabilitation technology to PennDOT's district forces.

The work presented in this thesis focuses on the structural condition assessment and strengthening with externally bonded FRP of bridge \#49-4012-0250-1032 built in 1934 near Sunbury, Pennsylvania. During several field visits, WVU researchers performed destructive and non-destructive testing to investigate the deteriorated condition of the bridge. Load testing was performed using a proof load to attain critical structural behavior characteristic data that could be used to calibrate a computer model of the bridge as well as to determine a bridge performance baseline to compare with the FRP strengthened structural behavior.

During the course of work in this study, a structural analysis program was developed to accurately assess the structural capacity of a simply supported concrete TBeam bridge. The program was designed to be more flexible and easier to use than PennDOT's Bridge Analysis and Rating program (BAR7). The program developed at WVU includes a section for FRP strengthening design. Load rating analysis based on the strengthening design is included in the program.
\end{abstract}




\section{ACKNOWLEDGEMENTS}

The author would like to thank West Virginia University for the endless opportunities that were made available. The classes, professors, student life, and environment created at the university have all provided the author with an unforgettable undergraduate and graduate career. Special thanks go to the civil engineering faculty members at the College of Civil and Environmental Engineering. The attention to detail necessitated by Dr. Zaniewski, Dr. Barth, and Dr. Davalos will always be one of the greatest intangible lessons learned and continually pursued by the author.

The author would like to give particular gratitude to Dr. Barth for his neverending patience and guidance. Dr. Barth was also the one who generously gave the author many of the opportunities that he has been privileged to be a part of throughout his educational career at WVU. The lessons taught by Dr. Barth will never be forgotten.

The author would like to thank Dr. Davalos for the energy and excitement that he exudes as a professor. It has been a privilege and a pleasure to the author to learn from Dr. Davalos. He has been a great professor, advisor, and mentor.

The author would also like to thank his graduate student colleagues for the fun times and the help and support given over the years.

The author would also like to thank his parents for their never-ending guidance, support, and sacrifice. Their encouragement and advice has been invaluable to the author. Words will never make up for the sacrifices that they have made. Remember: “Superhuman effort isn't worth a damn unless it achieves results,”-Ernest Shackleton. 


\section{Table of Contents}

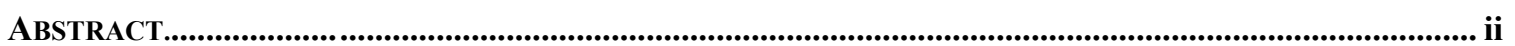

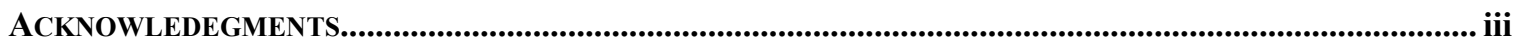

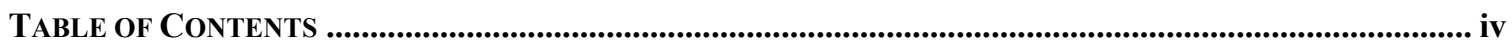

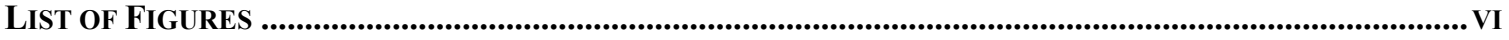

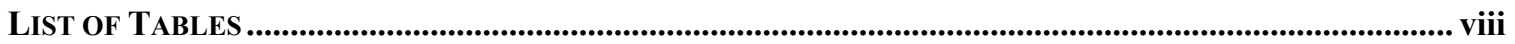

\begin{tabular}{|c|c|}
\hline \multicolumn{2}{|c|}{ CHAPTER 1 - INTRODUCTION } \\
\hline 1.1 & 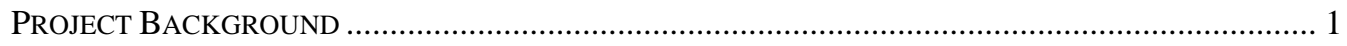 \\
\hline 1.2 & BRIDGE DESCRIPTION ....... \\
\hline 1.3 & OBJECTIVES ......................... \\
\hline 1.4 & SCOPE OF RESEARCH.......................................... \\
\hline 1.4.1 & Destructive and Non-Destructive Evaluation .. \\
\hline 1.4 .2 & Load Testing....................... \\
\hline 1.4 .3 & Structural Analysis \\
\hline 1.4 .4 & FRP Strengthening Design Recommendations.... \\
\hline 1.5 & 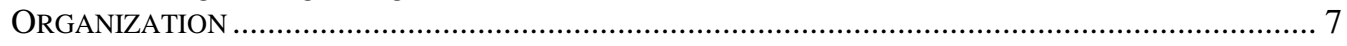 \\
\hline 1.6 & EXPECTED OUTCOMES ................ \\
\hline 1.6.1 & Load Rating .. \\
\hline 1.6.2 & FRP Strengthening Design . \\
\hline 1.6 .3 & Training PennDOT Personn \\
\hline
\end{tabular}

\section{CHAPTER 2 - LITERATURE REVIEW}

\begin{tabular}{|c|c|}
\hline 2.1 & INTRODUCTION.. \\
\hline 2.2 & TRANSPORTATION INFRASTRUCTURE CONDITION ASSESSMENT . \\
\hline .3 & LOAD RATING .......... \\
\hline 2.3 .1 & Current Load Rating Methods . \\
\hline 2.3 .2 & Load Rating Programs .................. \\
\hline 2.3 .3 & Capacity Calculation Methods..... \\
\hline 4 & REHABILITATION STRATEGIES .......... \\
\hline & 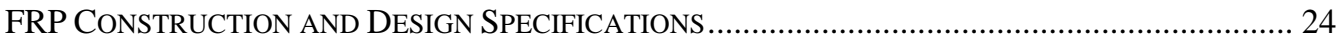 \\
\hline & 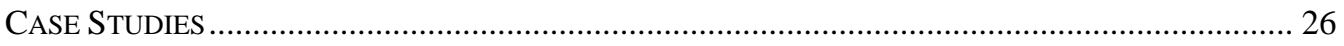 \\
\hline
\end{tabular}

\section{CHAPTER 3 - EXPERIMENTAL WORK}

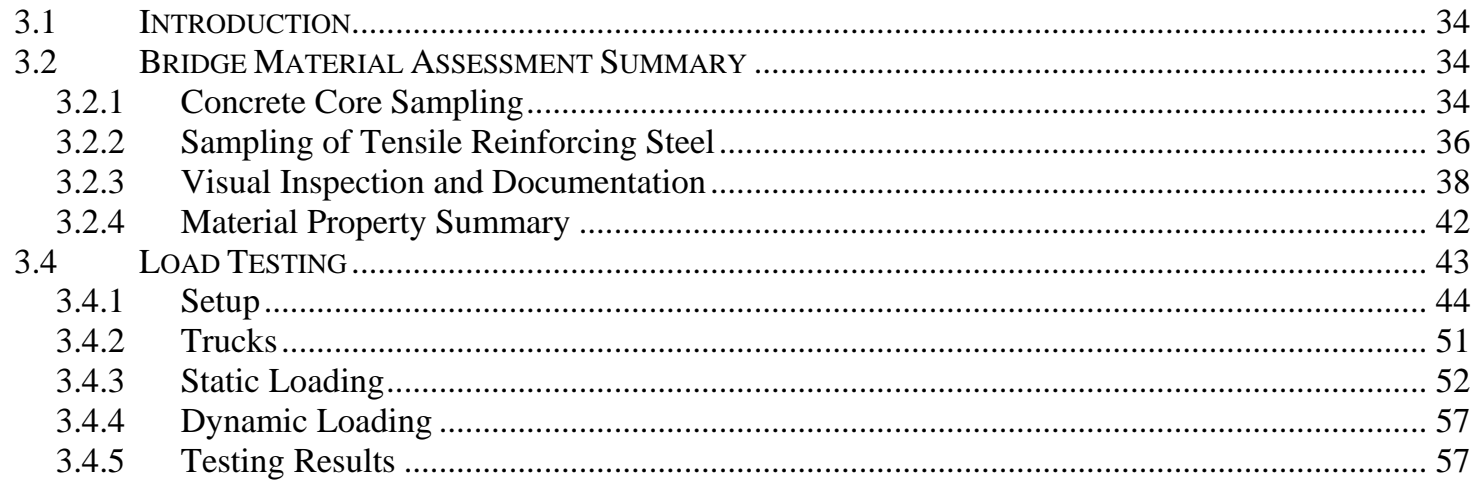



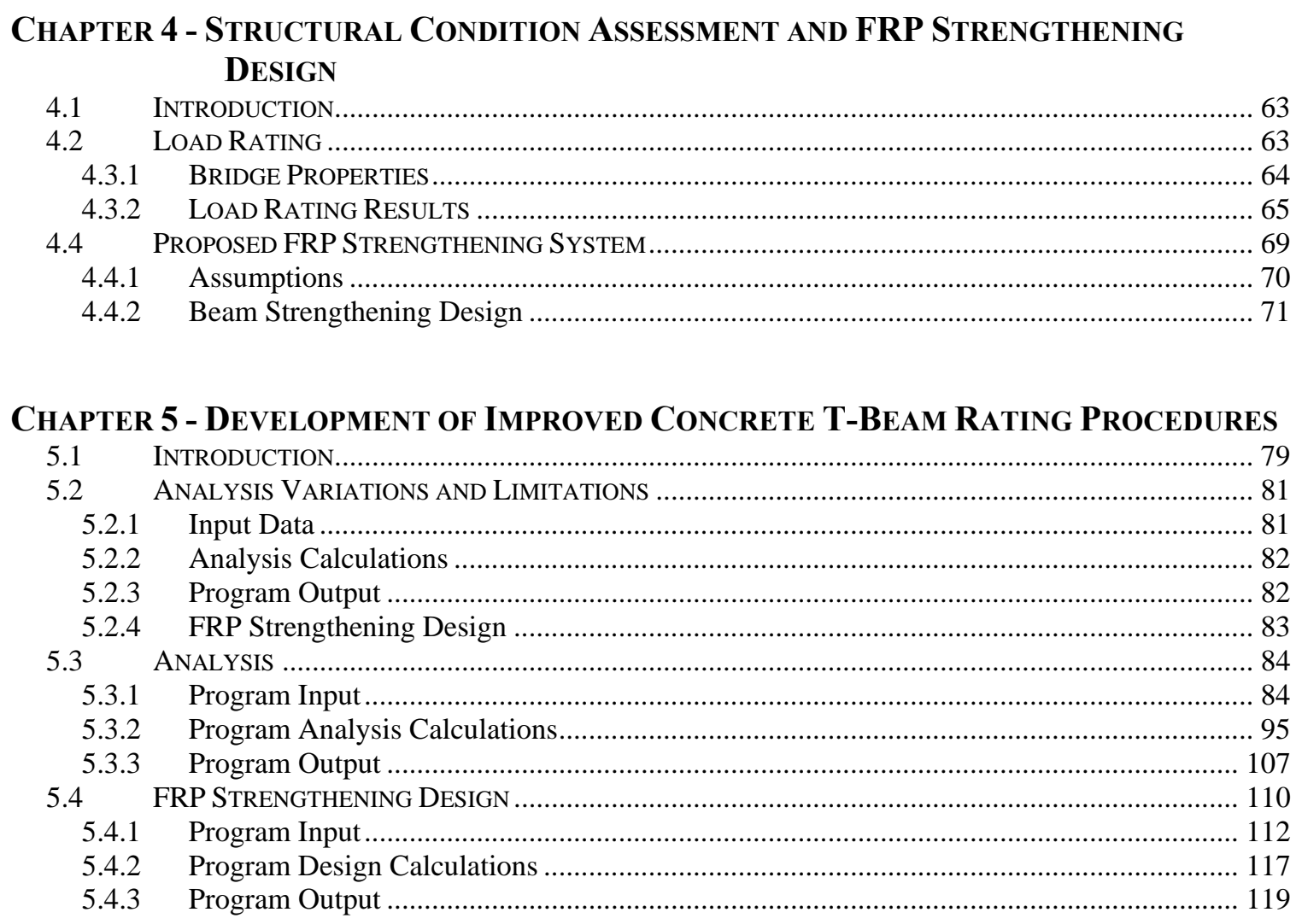

\section{Chapter 6 - CONCLUSions}

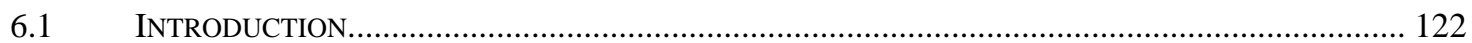

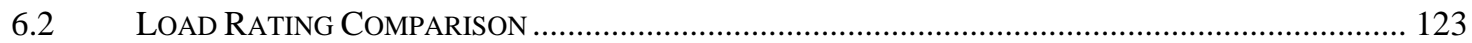

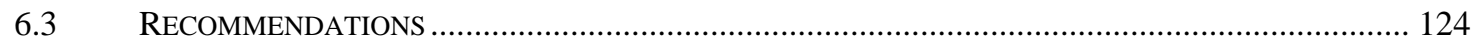

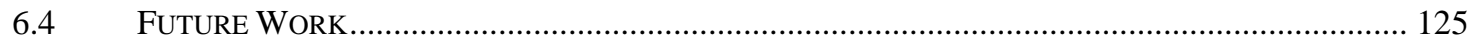

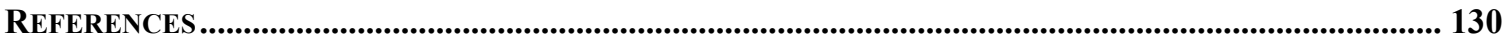

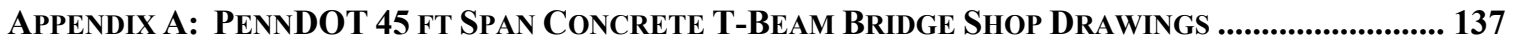

APPENDIX B: MATERIAL EVALUATION TEST RESULTS ................................................................. 140

APPENDIX C: STRUCTURAL ANALYSIS CALCULATIONS ............................................................................ 143

APPENDIX D: STRUCTURAL ANALYSIS CALCULATION RESULTS ................................................................ 150

APPENDIX E: DEAD/LIVE LOAD GENERATOR EQUATIONS......................................................................... 155

APPENDIX F: FRP DESIGN CALCULATIONS..................................................................................... 160

APPENDIX G: FRP DESIGN CALCULATION VARIABLE RESULTS .................................................... 168

APPENDIX H: PROPOSED FRP STRENGTHENING DESIGN DRAWINGS....................................................... 171 


\section{LIST OF FIGURES}

FiguRE 1.1 SELECTEd CANDIDATE BRIDGe REINFORCEMENT LAyout- EleVATION VieW............................. 3

Figure 1.2 Selected Candidate Bridge Reinforcement Layout- Cross SECTION VieW ....................... 3

FigURE 1.3 SELECTED CANDIDATE BRIDGE FOR LEVEL 1 FRP COMPOSITE REPAIR ....................................... 3

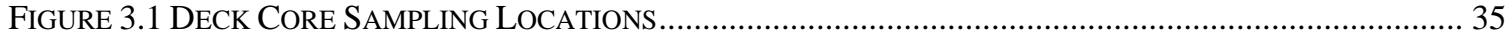

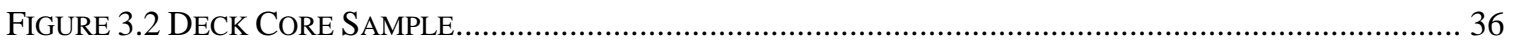

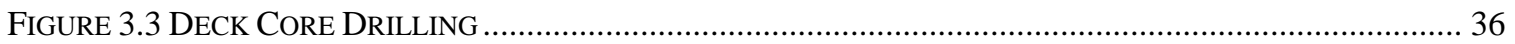

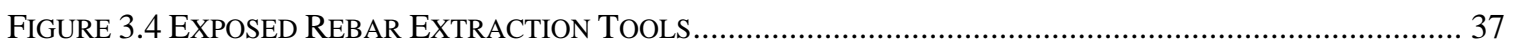

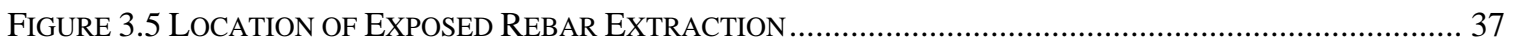

FiguRE 3.6 BEAM 1 - SPALLING, DELAMINATION, AND CRACKING ............................................................... 39

FigURE 3.7 BEAM 6 - SPALLING, DELAMINATION, AND CRACKING ............................................................... 39

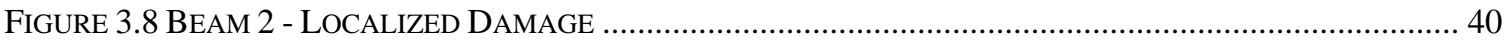

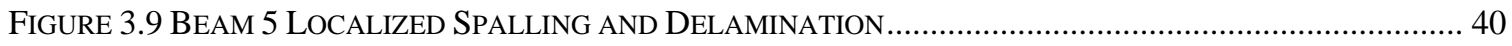

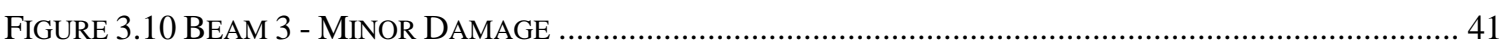

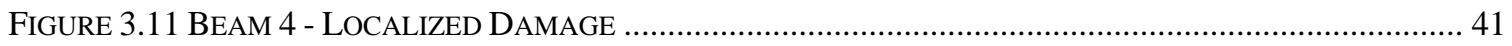

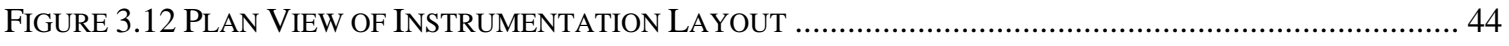

FIGURE 3.13 FIELD PLACEMENTS OF EQUIPMENT AND INSTRUMENTS ........................................................ 45

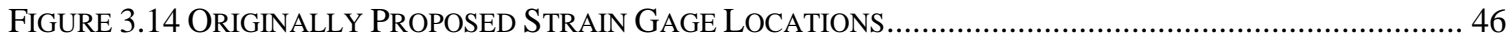

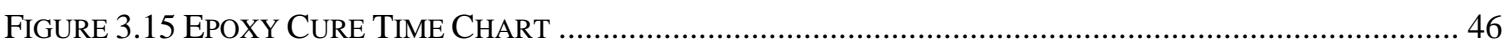

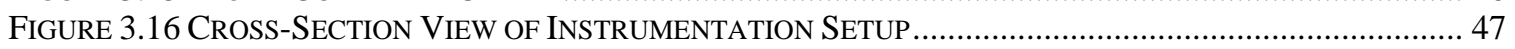

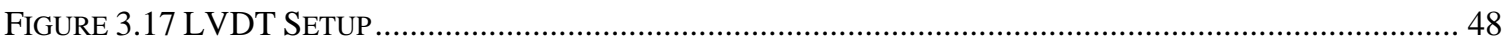

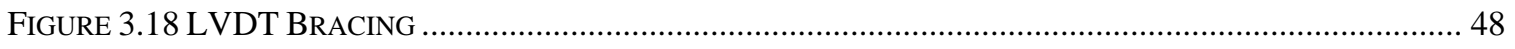

FIGURE 3.19 ACCELEROMETER MOUNTING CONFIGURATION ....................................................................... 49

FIGURE 3.20 COMPUTER AND DATA ACQUISITION SETUP ......................................................................... 50

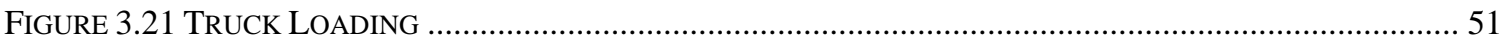

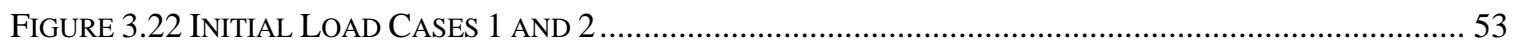

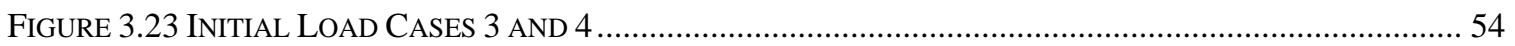

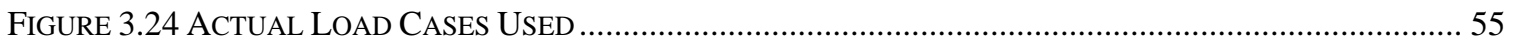

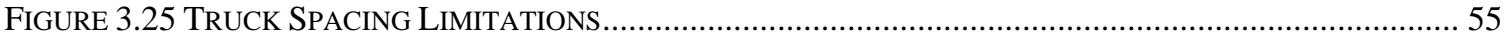

FIGURE 3.26 MODIFIED LOAD CASES .................................................................................................. 56

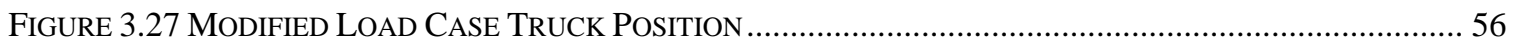

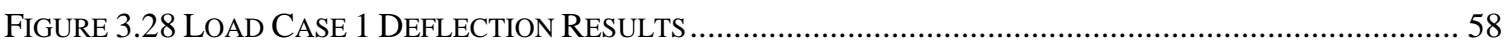

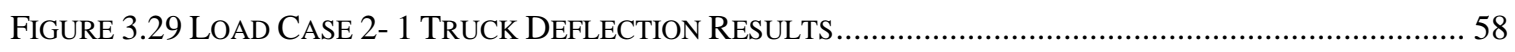

FiguRE 3.30 LoAd CASE 2-2 TRUCKS DEFLECTION RESULTS.................................................................... 59

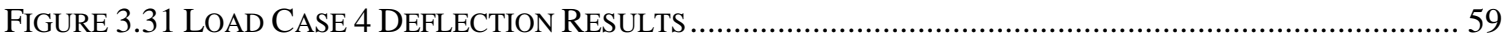

FIGURE 3.32 MODIFIED LOAD CASE DEFLECTION COMPARISON ................................................................ 61

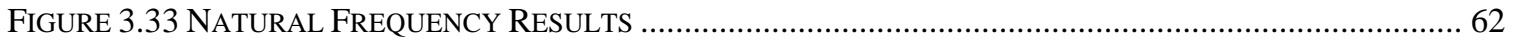

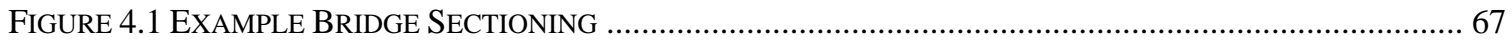

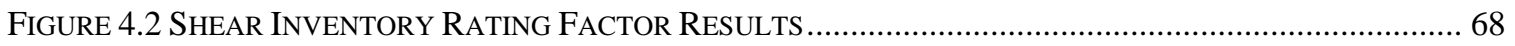

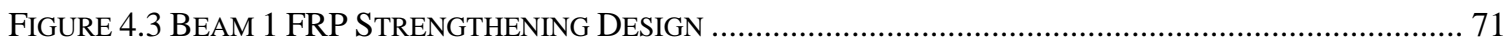

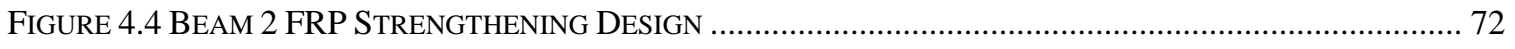

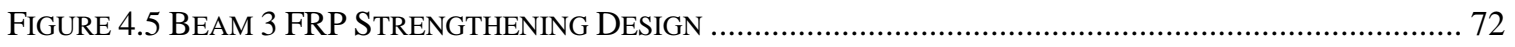

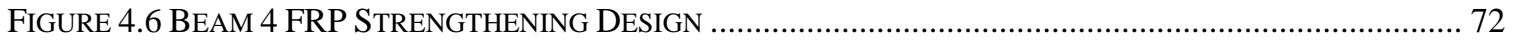

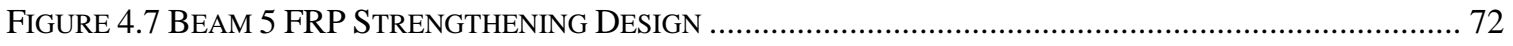

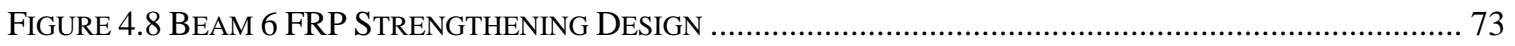

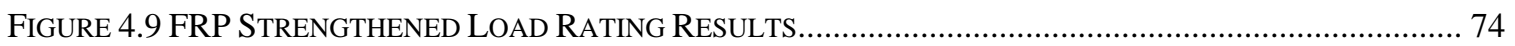

Figure 4.10 PRE- AND POST- SHEAR STRENGTHENING INVENTORY RATING FACTOR COMPARISON............. 78

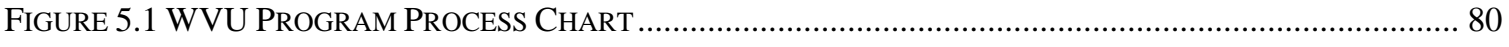

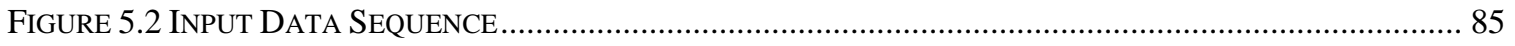

Figure 5.3 SAMPLE SHEAR REMAINING StEEL REINFORCEMENT AREA INPUT DATA TABLES ...................... 92

FIGURE 5.4 CONCRETE T-BEAM ANALYSIS CALCULATION SEQUENCE ........................................................ 96

FigURE 5.6 SAMPLE LIVE LOAD GENERATOR RESULTS TABLE.................................................................. 107 
FigURE 5.7 LOAD RATING ANALYSIS CALCULATION SEQUENCE ........................................................... 108

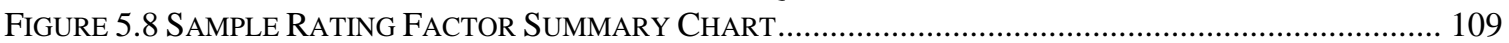

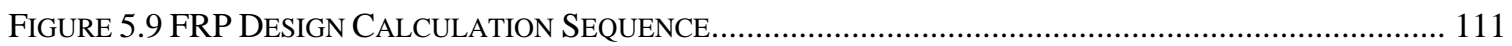

FiguRE 5.10 SAMPLE FLEXURAL FRP TERMINATION PoINT CALCULATION GRAPH ................................... 115

FIGURE 5.11 SAMPLE SHEAR CAPACITY STRENGTHENING ANALYSIS RESULTS GRAPH............................... 117

FigURE 5.12 SAMPLE STRENGTHENED BEAM STRAIN DiSTRIBUTION GRAPH ........................................... 120

FigURE 5.13 SAMPLE EXISTING VS. STRENGTHENED BEAM FLEXURAL LOAD RATING SUMMARY GRAPH. 120

FigURE 5.14 SAMPLE BEAM EXISTING VS. STRENGTHENED LOAD RATING SUMMARY GRAPH.................... 121

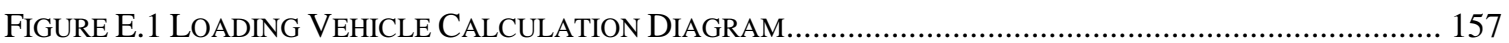

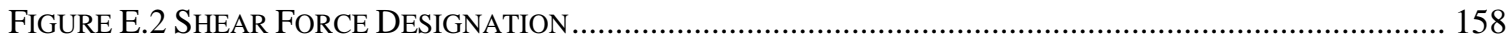

FigURE F.1 SidE FLEXURAL FRP LAMINATE CONTRIBUTION DIAGRAM .................................................... 166 


\section{LIST OF TABLES}

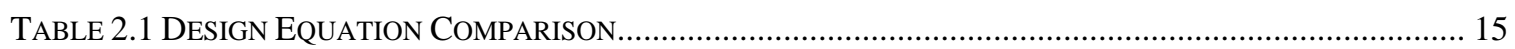

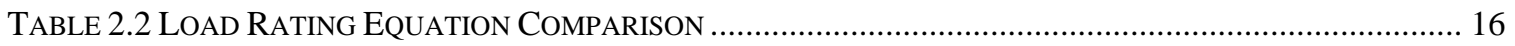

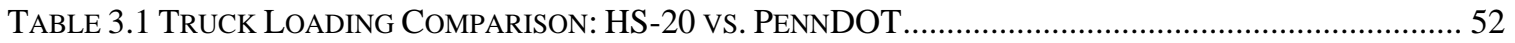

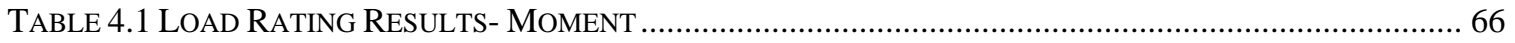

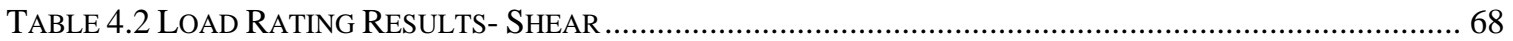

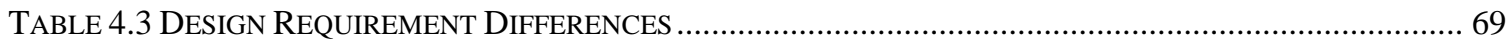

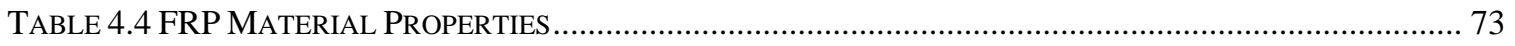

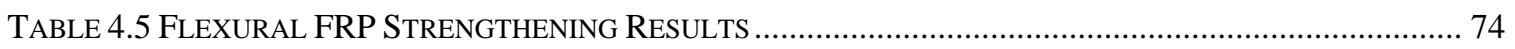

TABLE 4.6 BEAM 1 FRP SHEAR REINFORCEMENT DESIGN RESULTS........................................................... 76

TABLE 4.7 BEAM 2 FRP SHEAR REINFORCEMENT DESIGN RESULTS............................................................... 77

TABLE 4.8 BEAM 3 FRP SHEAR REINFORCEMENT DESIGN RESULTS.............................................................. 77

TABLE 4.9 BEAM 4 FRP SHEAR REINFORCEMENT DESIGN RESULTS........................................................... 77

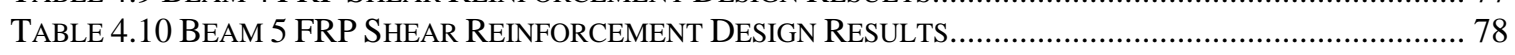

TABLE 4.11 BEAM 6 FRP SHEAR REINFORCEMENT DESIGN RESULTS........................................................... 78

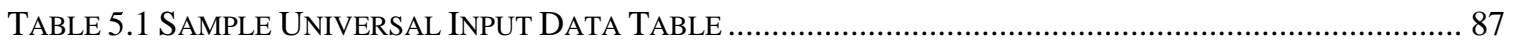

TABLE 5.2 SAMPLE BEAM SPECIFIC FLEXURAL INPUT DATA TABLE ....................................................... 88

TABLE 5.3 SAMPLE BEAM SPECIFIC ShEAR SECTION BREAK INPUT DATA TABLE .......................................... 90

TABLE 5.4 SAMPLE BEAM SPECIFIC SHEAR INVESTIGATION PoINT TABLE ……….......................................... 90

TABLE 5.5 SAMPLE INCLINED STIRRUP INCLUSION BY SECTION INPUT DATA TABLE ................................... 91

TABle 5.6 SAmple Presence of SeVEere Diagonal Cracking By SeCtion InPUt TABle.......................... 92

TABLE 5.7 SAMPLE LoAding VehicLE InPUT Data TABLE ....................................................................... 94

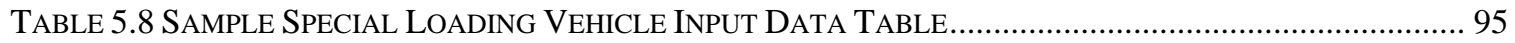

TABLE 5.9 SAMPLE UNIVERSAL VARIABLE ANALYSIS RESULTS................................................................... 97

TABLE 5.10 SAMPLE BEAM SPECIFIC FLEXURAL ANALYSIS RESUlTS ......................................................... 99

TABLE 5.11 SAMPLE LIVE LOAD GENERATOR RESULTS TABLE …........................................................... 100

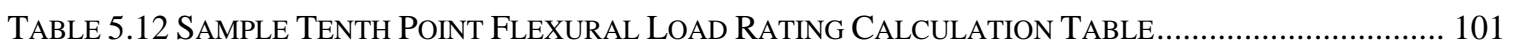

TABLE 5.13 SAMPLE SHEAR ANALYSIS RESULTS TABLE ...................................................................... 102

TABLE 5.14 SAMPLE SECTION SHEAR CAPACITY RESULTS TABLE............................................................ 103

TABLE 5.15 SAMPLE TENTH Point SHEAR CAPACITY RESUltS TABLE ....................................................... 104

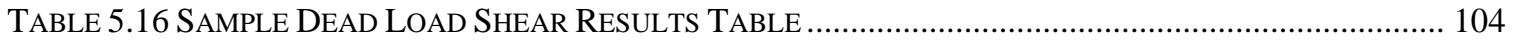

TABLE 5.17 SAMPLE SHEAR LOAD RATING CALCULATION TABLE ............................................................... 105

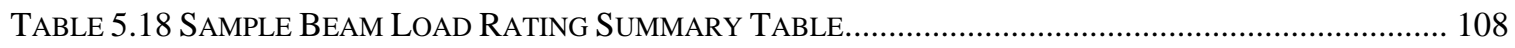

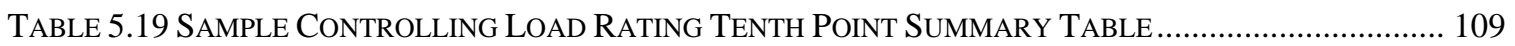

TABLE 5.20 SAMPLE CONTROLLING LOAD RATING FACTOR SUMMARY TABLES ......................................... 110

TABLE 5.21 SAMPLE FRP MANUfaCtURER'S REPORTED SYSTEM PROPERTIES TABLE................................ 112

TABLE 5.22 SAMPLE FRP FLEXURAL STRENGTHENING INPUT/RESULTS TABLE ........................................ 113

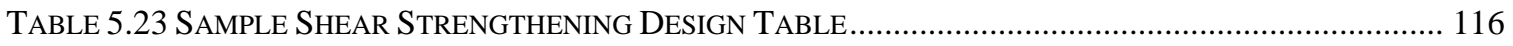

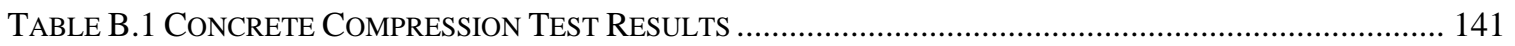

TABLE B.2 Ultra Sonic PUlSE Velocity Test VALUes ....................................................................... 141

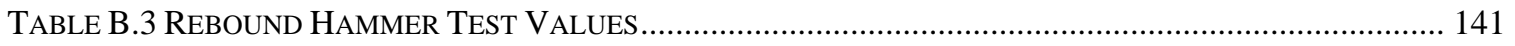

TABLE B.4 StEEL TENSION TEST SAMPLE-AREA CALCULATION ................................................................. 142

TABLE D.1 UNIVERSAL STRUCTURAL ANALYSIS INPUT DATA VARIABLES .................................................. 151

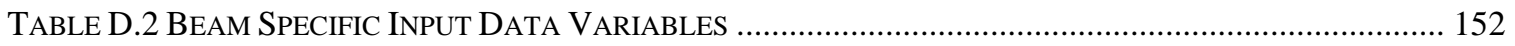

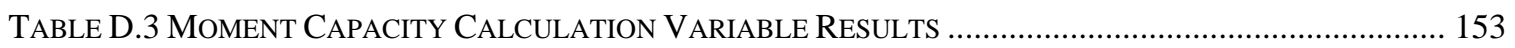

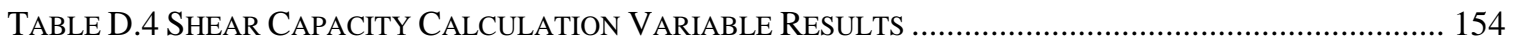

TABLE E.1 DEAD/LiVE LOAD CALCULATION VARIABLE RESULTS ........................................................ 159

TABLE G.1 MANUFACTURER'S REPORTED FRP SYSTEM PROPERTIES ........................................................... 169

TABLE G.2 FLEXURAL FRP DESIGN VARIABLE SUMMARY ..................................................................... 169

TABLE G.3 FRP SHEAR DESIGN VARIABLES- BEAMS 1 AND 6 ................................................................. 170

TABLE G.4 FRP SHEAR DESIGN VARIABLES- BEAMS 3 AND 4 ................................................................. 170

TABLE G.5 FRP SHEAR DESIGN VARIABLES- BEAMS 2 AND 5 ................................................................ 170

- viii - 


\section{CHAPTER 1 - INTRODUCTION}

\subsection{Project BACKGROUND}

The Pennsylvania Department of Transportation - District 3 (PennDOT-D3) has initiated a program to address the current condition of their concrete T-Beam bridges. The district's bridge inventory includes 128 concrete T-Beam bridges built between 1920 and 1960. Deterioration and changing design standards call for these bridges to be updated to conform to current roadway and bridge design specifications.

PennDOT - D3 has developed a plan to deal with the problems posed by these deteriorated concrete T-Beam bridges. The plan involves the use of fiber-reinforced polymers (FRP) to strengthen deteriorated bridges in order to improve the load capacity and remove load restrictions on the bridge in a cost effective manner. The project has been conducted in three phases.

Phase-I has been completed and involved examining the technical and economic feasibility of the different options available and developing a selection process for each bridge rehabilitation option. The selection process developed in Phase-I involved categorizing concrete T-Beam bridges into one of three levels based on several factors. The factors considered when ranking the bridges include: age, span length, average daily traffic and average daily truck traffic (ADT/ADTT), and localized damage based on visual inspection (Brayack, 2005).

Phase-II involves performing a bridge condition assessment and preliminary FRP strengthening design. This phase required load testing before strengthening to compare 
the pre- and post-retrofitting effects. This thesis focuses on the tasks and results of Phase-II activities. Phase-III activities will include the implementation of the FRP strengthening design along with long term testing of the bridge both in the field and in lab scale studies.

The ultimate goal of this project is for PennDOT - D3 to implement a rehabilitation program that will enable district forces to independently identify, analyze, and rehabilitate concrete T-Beam bridges in a cost effective manner using FRP strengthening systems. Depending on the level of repair required, PennDOT will either: contract out all of the work, use a combined approach of an outside contractor and district forces; or all work will be performed by district forces.

\subsection{BRIDGE DESCRIPTION}

The bridge selected to exercise this technology was built in 1934 and is near Sunbury, Pennsylvania (PennDOT Bridge \#49-4012-0250-1032). The simply supported concrete T-Beam bridge spans $48 \mathrm{ft}$ over a small creek and carries two traffic lanes on Creek Road. The deck width is $26 \mathrm{ft}-11$ in. Six beams make up the superstructure with an 8.5 in concrete deck and 2.5 in asphalt overlay. The beam reinforcement layout is shown in Figures 1.1 and 1.2. The bridge can be assumed as a simply supported span of 45 feet from the inside face of the abutments for analysis purposes. Figure 1.3 shows the extensive damage due to deterioration and corrosion. 


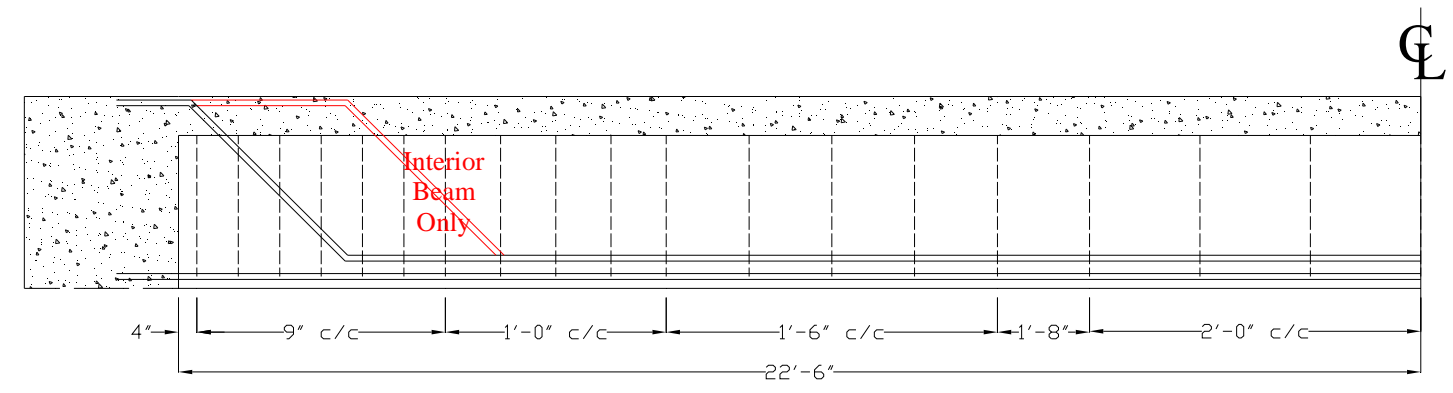

Figure 1.1 Selected Candidate Bridge Reinforcement Layout- Elevation View

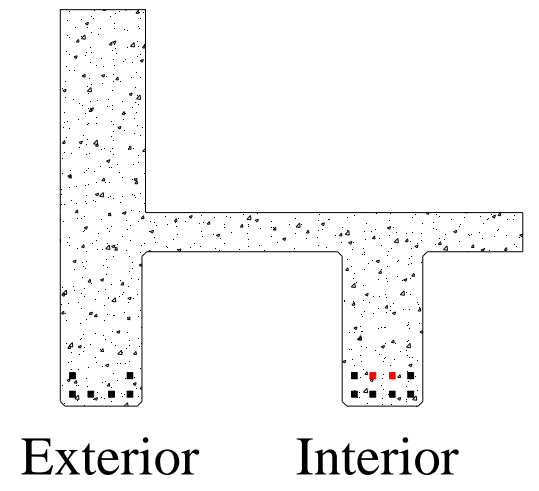

Figure 1.2 Selected Candidate Bridge Reinforcement Layout- Cross Section View

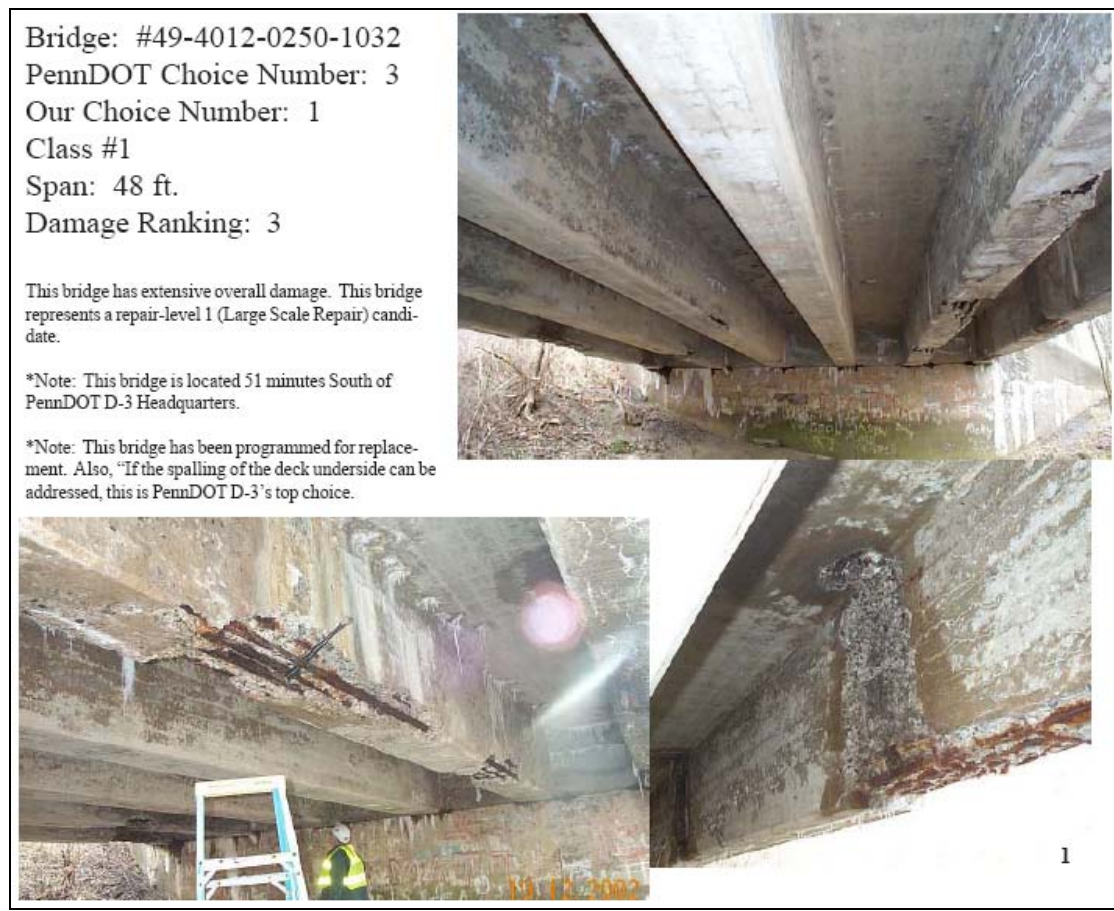

Figure 1.3 Selected Candidate Bridge for Level 1 FRP Composite Repair 


\subsection{OBJECTIVES}

This thesis focuses on the field testing and structural analysis of a selected TBeam bridge prior to rehabilitation and preliminary FRP strengthening designs. The objective of the field testing was to determine the current state of deterioration and its effects throughout the selected bridge. The structural analysis was required to determine the existing load capacity and the additional required resistance that would need to be provided by the FRP reinforcement.

A computer program was developed to facilitate structural analysis calculations and comparisons. The program incorporates many of the analysis and design related issues involved with this type of project. The computer program could be used as an analysis tool to analyze, load rate, and design FRP retrofitting for any concrete T-Beam bridge following American Association of State Highway and Transportation Officials (AASHTO) and American Concrete Institute (ACI) guidelines and specifications (AASHTO 1996, ACI 440.2R-02 2002).

\subsection{SCOPE OF RESEARCH}

This thesis focuses on the rehabilitation of concrete T-Beam bridges and the scope of research consists of four principal components: destructive and non-destructive testing, proof load testing, structural analysis, and FRP strengthening design recommendations.

\subsubsection{Destructive and Non-Destructive Evaluation}

Several testing techniques were employed both in the field and in laboratory testing in order to establish the current health and material strengths of the bridge. The 
non-destructive testing techniques used included: ultrasonic pulse velocity, rebound hammer, concrete carbonation, scanning electron microscope (SEM), Energy Dispersive X-Ray (EDX), chemical analysis of concrete powder, cement content by soluble silica, and acid soluble chloride. Destructive testing techniques included removing core samples of the concrete and removing a section of tensile reinforcing steel in order to determine the in-situ concrete compressive strength and steel yield strength. These testing methods offer a more accurate insight into the condition of the materials in the bridge including the effects of deterioration due to corrosion and aging. It should be noted that the specific work tasks associated with the material characterizations described in 1.4.1 were conducted by a separate investigator. This thesis summarizes these results and then utilizes them as necessary in other items of work. The reader is referred to Parish (2008) for comprehensive descriptions of tasks conducted in 1.4.1.

\subsubsection{Load Testing}

As previous research has shown, load testing is the most accurate method of determining the capacity of a structure. Classic analytical theory of material behavior cannot accurately incorporate all aspects of a complicated structural system.

Assumptions are often made to determine load capacity without in-situ material data lead to overly conservative capacity calculations and inaccurately rated bridges. Load testing is an accurate testing technique that incorporates the primary and secondary load resisting mechanisms. Capacity calculations can then be made by calibrating a computer generated structural analysis model that mimics the load paths, stresses, and strains of the real bridge. Load testing on bridge \#49-4012-0250-1032 was conducted for this project 
to provide a baseline of pre-strengthening data that can be directly compared with poststrengthening data.

\subsubsection{Structural Analysis}

Multiple methods were used to determine the load capacity of the bridge. PennDOT’s Bridge Analysis and Rating program (BAR7) was used to compare new material strength data gathered through destructive and non-destructive testing with previous inspection and load rating reports. To verify BAR7 calculations, a computer program was developed using Microsoft EXCEL that incorporated standard AASHTO analysis calculation methods. This program was also used to compare experimental values with properties suggested by AASHTO guidelines. The program could calculate ultimate capacities, moments, shears, and load rating factors for exterior and interior beams at any point along the span length. Additionally, a computer model of the bridge was built using a commercially available program called ABAQUS.

\subsubsection{FRP Strengthening Design Recommendations}

After a clear picture of the un-strengthened load capacity of the bridge was determined, the amount of FRP composite strengthening could be designed. The FRP strengthening design was performed by a third party under contract with PennDOT-D3 but will be verified by West Virginia University researchers. The design and recommendations follow closely with ACI 440.2R-02 design guidelines as well as NCHRP Report 514 construction specifications. The previously mentioned computer program developed to determine load capacity and load ratings was updated to include FRP rehabilitation design calculations as well as the post-strengthened bridge load rating 
factors. Details of the analysis and design process are described in later chapters and appendices of this thesis.

\subsection{Organization}

This thesis provides the information and research collected in support of Phase-II of this project. Chapter 2 presents a comprehensive literature review of current infrastructure conditions, load rating procedures, rehabilitation strategies, FRP design guidelines, and example case studies. The experimental work and results are presented in Chapter 3 and Chapter 4 respectively. Chapter 5 presents an overview of the load rating analysis and FRP design program developed in this work. The final results and recommendations are presented in Chapter 6.

\subsection{EXPECTED OUTCOMES}

Each of the tasks described in the scope of work are important steps in the accurate capacity and strengthening calculations of any structure. These procedures are small steps towards the ultimate goal of this project. The eventual outcome will be an efficient and effective transfer of FRP strengthening technology to PennDOT-D3 personnel. District forces will be able to independently analyze and strengthen structurally deficient and/or functionally obsolete bridges in a cost effective manner. 


\subsubsection{Load Rating}

Accurate load rating is a critical calculation in determining strengthening requirements of a structure. Several methods presented in the literature review provide proven techniques to improve the load rating of a bridge. Most of the errors encountered during load rating of bridges are a result of inaccurate assumptions in material strengths and load resisting mechanisms within a structure. This research will provide PennDOTD3 with a more accurate load rating analysis of the concrete T-Beam bridge under investigation. The FRP strengthening scheme incorporated will improve the bridges load rating so that no load postings are required. The rehabilitation process should extend the useful service life of the bridge.

\subsubsection{FRP Strengthening Design}

The FRP composite strengthening design should increase the load capacity of the bridge to satisfactory strength levels. The design will follow all recommended design procedures by following guidelines developed and published by ACI Committee 440 . Along with the FRP strengthening design, recommended construction processes and quality control measures are provided to ensure that the FRP strengthening system will maintain long term performance.

\subsubsection{Training PennDOT Personnel}

This project offers an introduction for PennDOT district forces to observe and gain experience on the application of FRP composite strengthening technology. PennDOT personnel will be able to monitor and oversee all aspects of the design and application of FRP technology by beginning the field implementation phase of 
rehabilitation with a Level 1 ranked bridge. At the conclusion of this project, PennDOTD3 personnel will be able to understand unique characteristics, analyze, design, and implement the use of FRP composites strengthening technology in their transportation infrastructure. 


\section{CHAPTER 2 - Literature REVIEW}

\section{$2.1 \quad$ INTRODUCTION}

This research review is dedicated to evaluating bridge condition assessment techniques and FRP strengthening technology for rehabilitation of concrete T-Beam bridges. Accurate structural condition assessments are vital to the rehabilitation of any structure. The conclusions drawn from the literature review will aid WVU researchers in the development of a condition assessment and rehabilitation program for PennDOT. This program involves a selection process for candidate bridges, structural condition assessment techniques, and FRP strengthening guidelines \& specifications.

\subsection{TRANSPORTATION INFRASTRUCTURE CONDITION ASSESSMENT}

Deleterious effects of environmental attacks over time are leading to degradation of highway bridges. This degradation is amplified by the usage of deicing salts, freeze thaw cycles, and dry-wet cyclic environments that accelerate the ageing of structures (Davalos, et al., 2007). These environmental attacks along with inaccurate bridge records, changing design specifications, and heavier design loading vehicles result in poor condition ratings of highway bridges. The poor condition ratings have highlighted the necessity of an improved cost effective process for structural condition assessment and rehabilitation of highway bridges. 
Over $40 \%$ of the nation's bridges are in need of repair or replacement due to poor condition ratings that are often subjective and reported inaccurately (Mayo et al., 1999). The subjectivity is a consequence of visual inspection which is an important element of traditional bridge inspection techniques. Condition ratings based on visual inspection are inaccurate approximately $78 \%$ of the time. Efforts in the research industry are progressing towards the development of less subjective bridge inspection techniques. These techniques involve quantitative representation of deterioration levels in the calculation of a bridges structural capacity.

Pennsylvania is a prime candidate state for implementing FRP rehabilitation technology to their population of aged and deteriorated concrete T-Beam bridges. Their concrete T-beam bridge population is the third largest in the nation. Pennsylvania owns and maintains 2,440 of the 38,170 concrete T-beam bridges in the United States. Approximately $78 \%(1,899)$ of these bridges are simple spans and $60 \%$ of those were built before 1950 with a maximum age of 101 years (Catbas, et al., 2003). Typically, the span lengths range from 20-60 ft. Most of Pennsylvania’s concrete T-beam bridges were assumed to be built using a standard set of design drawings which may not be an accurate representation of the as-built conditions of the structure (Catbas, et al., 2005).

Potential strategies for improving the structural health of Pennsylvania's transportation infrastructure include improving bridge condition ratings and utilizing cost effective strengthening techniques. The first strategy incorporates improving the condition rating factors by developing accurate, non-subjective bridge capacity evaluation methods. The second strategy involves updating the structural capacity of a bridge by applying new technologies that offer quick and cost effective solutions. Both 
methods are used in this research to investigate and strengthen an aged and deteriorated concrete T-Beam bridge in Pennsylvania.

\subsection{LOAD RATING}

The safe load carrying capacity of a highway bridge is expressed through load rating factors. These load ratings are used to evaluate a bridges structural capacity and determine load posting restrictions and permit vehicle allowances (AASHTO, 1994). Load rating calculations are performed with information provided through biennial bridge inspections stored in a database. Load rating factors are calculated using one of three methodologies: Allowable Stress Rating (ASR), Load Factor Rating (LFR), or Load and Resistance Factor Rating (LRFR). Each method calculates ratings based on two levels: inventory and operating.

Inventory ratings are used to express the structural capacity based on standard expected traffic loading for an indefinite period of time. Operating ratings are used to evaluate the maximum permissible live load that the structure can safely carry. These factors are used to evaluate vehicle loadings in excess of standard highway loads that require a special permit. Each member of a structure is analyzed and load rated. The minimum rating factor for any member determines the maximum safe loading capacity of the structure.

Several proven capacity calculation methods have been used for years but new methods are being investigated to improve the accuracy of these calculations. Structural capacity calculations are dependent upon material strength properties. These properties 
can vary due to degradation of the material caused by aging and exposure to harsh environments. Several methods are available to address these issues.

Manuals provided by AASHTO suggest values for unknown material properties that account for reduced material strength over time or lack of specified data. Previous research indicates that these suggested material strength values are often inaccurate. These inaccuracies result in lower load capacity ratings that indicate repair or rehabilitation is necessary.

AASHTO standard analysis procedures do not account for secondary structural elements that could contribute to the ultimate structural capacity. Some assumptions that are commonly made to simplify ultimate capacity calculations include: conservative estimates of load distribution, non-composite action, uniform section loss due to corrosion, and neglecting moment resistance at supports (Chajes, et al., 1999). These secondary structural elements can provide a reserve capacity that is not accounted for in classic structural analysis calculations.

Proof load testing is considered the best practice for structural capacity calculations. Load testing typically involves static or dynamic loading an instrumented bridge. The structural behavior response of the bridge is recorded and used to calibrate a computer model. The structural capacity is calculated from the computer model and classic material property analysis theory. This type of structural capacity calculation can be costly and time consuming. It is not a realistic expectation to perform a proof load test on all structurally deficient or functionally obsolete bridges. Some research argues that these initial costs could be offset by the extension of a bridge's useful life (Phares, et al., 2003). Similarly, it has been proposed to investigate bridges as fleets of statistically 
representative bridges within a population instead of on an individual basis (Catbas, et al., 2003). This method involves load testing and computer modeling a small sample of structures that are statistically representative of the entire bridge population. The results of the study could be used to evaluate structurally similar bridges.

\subsubsection{Current Load Rating Methods}

Changes in load rating methodologies have followed advances in design philosophies. There are three design methodologies that have been or are being used for bridges. The following is a brief overview of the benefits and limitations of each method.

Allowable stress design (ASD) was the standard practice of design for many years because of its simplicity. The allowable or working stress is the maximum stress a member is allowed to experience under design loads. The allowable stress is calculated by dividing the ultimate stress of the material by a safety factor (AASHTO, 1994). This analysis method places no emphasis on the varying certainty of loading types.

Compounding this limitation are the facts that: stress is not an adequate measure of resistance, the factor of safety is subjective, and there is no risk assessment based on reliability theory.

Load Factor Design (LFD) is considered an upgrade to ASD. This design philosophy uses factors to account for the uncertainty in loading types. Higher factors are used for more uncertain loading types such as live loads. Lower factors are used on loading types that can be calculated with more accuracy and lower levels of uncertainty such as dead loads. LFD has the disadvantages of being more complex than ASD and an absence of risk assessment based on reliability analysis. 
Load and Resistance Factor Design (LRFD) accounts for variability and provides a uniform level of safety for all structures based on reliability theory. LRFD philosophy incorporates specific load factors based on reliability analysis that account for variability among unknown structural capacity mechanisms and loading types. Table 2.1 presents a comparison of the design equations.

Table 2.1 Design Equation Comparison

\begin{tabular}{|c|l|l|}
\hline $\begin{array}{c}\text { Allowable Stress Design } \\
\text { (ASD) }\end{array}$ & $\begin{array}{c}\text { Load Factor Design } \\
\text { (LFD) }\end{array}$ & $\begin{array}{c}\text { Load And Resistance } \\
\text { Factor Design (LRFD) }\end{array}$ \\
\hline \hline$\sum D L+\sum L L \leq \frac{R_{u}}{F S}$ & $\gamma\left(\sum \beta_{D L} D L+\sum \beta_{L L} L L\right) \leq \phi R_{u}$ & $\eta\left(\sum \gamma_{D L} D L+\sum \gamma_{L L} L L\right) \leq \phi R_{u}$ \\
& where, & where, \\
where, & $\gamma=$ load factor & $\eta=$ reliability factor \\
$D L=$ dead load force effect & $\beta_{D L}, \beta_{L L}=$ load combination & $\gamma_{D L}=$ dead load factor \\
LL= live load force effect & coefficients & $D L=$ dead load force effect \\
$R_{u}=$ ultimate resistance & $D L=$ dead load force effect & $\gamma_{L L}=$ live load factor \\
$F S=$ factor of safety & $L L=$ live load force effect & LL live load force effect \\
& $\phi=$ resistance factor & $\phi=$ resistance factor \\
& $R_{u}=$ ultimate resitance & $R_{u}=$ ultimate resistance \\
\hline
\end{tabular}

Unique equations are used for each design philosophy. See Table 2.2 for a comparison of the load rating equations. In Allowable Stress Rating (ASR), the safety factor is applied to the allowable stress which is used to calculate the capacity of a member. Load Factor Rating (LFR) applies different factors based on the rating level to the dead load and live load force effects. Load and Resistance Factor Rating (LRFR) applies different factors based on reliability analysis to individual load types and resistance factors.

LRFD philosophy was to be fully implemented in the United States by October 2007. This requires all bridges being designed after that date to be designed and load 
rated using LRFD and LRFR (Jaramilla, Huo, 2005). LRFD and LRFR bring the United States to a design and load rating level consistent with major bridge design codes in Asia, Canada, and Europe. These methods assure a more uniform level of public safety. This design philosophy upgrade should also help reduce maintenance/repair costs and avoid costly over-conservative designs.

LRFR is considered the preferred method of load rating, however, not all bridge load ratings are reported using LRFR methodology. Any existing bridge load rating calculated with ASR or LFR does not have to be reanalyzed using LRFR. LFR is the agreed upon method by the FHWA for reporting load ratings of bridges on the National Highway System to the National Bridge Inventory database.

Table 1.2 Load Rating Equation Comparison

\begin{tabular}{|c|c|c|}
\hline $\begin{array}{c}\text { Allowable Stress Rating } \\
\text { (ASR) }\end{array}$ & $\begin{array}{c}\text { Load Factor Rating } \\
\text { (LFR) }\end{array}$ & $\begin{array}{l}\text { Load and Resistance } \\
\text { Factor Rating (LRFR) }\end{array}$ \\
\hline $\begin{array}{l}R F=\frac{C-D L}{L L(1+I)} \\
\text { where, } \\
\quad R F=\text { rating factor } \\
\quad C=\text { capacity } \\
D L=\text { dead load force effect } \\
L L=\text { live load force effect } \\
I=\text { impact factor }\end{array}$ & $\begin{array}{l}R F=\frac{C-A_{1} D L}{A_{2} L L(1+I)} \\
\text { where, } \\
\qquad R F=\text { rating factor } \\
\quad C=\text { capacity } \\
\qquad \begin{array}{l}A_{1}=\text { factor for dead loads } \\
D L=\text { dead load force effect }\end{array} \\
\quad A_{2}=\text { factor for live loads } \\
\quad L L=\text { live load force effect } \\
\quad I=\text { impact factor }\end{array}$ & $\begin{array}{c}R F=\frac{C-\gamma_{D C} D C-\gamma_{D W} D W \pm \gamma_{P} P}{\gamma_{L L} L L(1+I)} \\
\text { where, } \\
R F=\text { rating factor } \\
C=\text { capacity }=\phi_{c} \phi_{s} \phi R_{n} \\
\phi_{c}=\text { condition factor } \\
\phi_{s}=\text { system factor } \\
\phi=\text { resistance factor } \\
R_{n}=\text { nominal member resist ance } \\
\gamma_{D C}=\text { load factor for structural } \\
\text { components and attachments } \\
D C=\text { dead load force effect due to } \\
\text { structural components } \\
\gamma_{D W}=\text { load factor for wearing } \\
\text { surfaces and utilities } \\
D W=\text { dead load force effect due to } \\
\text { wearing surface and utilities } \\
\gamma_{p}=\text { load factor for permanent loads } \\
\quad \text { other than dead loads } \\
P=\text { permanent load force effect } \\
\gamma_{L L}=\text { live load factor } \\
L L=\text { live load force effects } \\
I=\text { impact factor }\end{array}$ \\
\hline
\end{tabular}


Several research studies have been conducted that compare the design and load rating philosophies to assist engineers in the transition to LRFD/LRFR methodology. These studies include direct comparisons of results using LFR and LRFR on existing bridges. Lichtenstein Consulting Engineers, Inc. investigated several types of bridges and compared the load ratings based on the different philosophies. For concrete T-Beam bridges, LFR generally resulted in higher inventory and operating rating factors than LRFR. However, LRFR resulted in higher legal load ratings. Short span bridges with short beam spacing are considered vulnerable to lower load ratings under LRFD criteria (Lichtenstein Consulting Engineers, Inc., 2001). The incorporation of a condition factor makes LRFR the preferred load rating philosophy for deteriorated bridges. Load Factor Rating is used for this research because of its accepted use on existing bridges.

\subsubsection{Load Rating Programs}

Several computer programs are commercially available that include the different design philosophies. PennDOT uses their independently developed Bridge Analysis and Rating program called BAR7. This program is used to assist with load rating and design of highway bridges. BAR7 analyzes concrete T-Beam, slab, simple span, continuous, and steel bridges. These bridges could be comprised of stringers, floorbeams, girders, or trusses. The program is capable of analyzing hinges, cantilever trusses, influence line ordinates, and estimated fatigue life. It also reports reactions, moments, shears, stresses, deflections, and load rating factors. All calculations are performed in accordance with AASTHO Manual for Maintenance Inspection of Bridges and AASHTO Specifications for Highway Bridges (PennDOT, 2005). BAR7 has not been updated for use with LRFD/LRFR philosophies. 
AASHTO has developed computer programs, called Virtis and Opis, advertised under their AASHTOWare software development division. These programs incorporate LRFD/LRFR philosophies along with Allowable Stress and Load Factor philosophies (AASHTO, 2003). Virtis is a structural analysis tool for rating bridge superstructures in accordance with AASHTO Standard Specifications. The program is a powerful tool for integration of analysis technologies. Bridge data is entered into a database that the user can access to analyze the structure by a variety of line-girder, 2D or 3D analysis packages. Permit/routing systems and other third-party applications are also available to the user.

Virtis uses Bridge Rating and Analysis of Structural Systems (BRASS) as a proven analytical engine for load factor rating. An enhanced version of BAR7, referred to as StdEngine, has been incorporated into the program for LFD/ASD rating. Third party customization and add-ons are encouraged by the developers to enhance the core capabilities of the system. Virtis' data and functionality can be accessed by commercial software packages including: Visual Basic ${ }^{\circledR}$, Excel $^{\circledR}$, AutoCAD ${ }^{\circledR}$, and Microsoft Word ${ }^{\circledR}$.

Opis is a design tool for both superstructures and substructures with specification checking and member optimization abilities. It uses the same database and graphical user interface as Virtis. The greatest attribute of these programs is the bridge database. Once the bridge is described generically, the information is available to a myriad of programs for analysis and comparison using multiple specifications. This capability provides the user with the ability to compare alternative designs using multiple specifications and expedite checking of specifications. Virtis and Opis also have a report writing feature 
that allows the user to customize report documents including bridge description data, analysis results data, graphs of analysis results, and schematics of the bridge description.

Different states use different commercially available programs for their analysis and rating calculations. The Ohio Department of Transportation uses BARS-PC to load rate bridges. For any bridge that exceeds the ability of BARS-PC, they can use AASHTO Virtis, BRASS, DESCUS I, SAP 90/SAP 2000 and STAAD II/Pro. Washington State Department of Transportation uses Bridge Rating and Interactive Display Graphics (BRIDG) for Windows developed by Alan K. Gordon and Associates in Seattle, Washington (Gordon, 2006). Bentley has recently developed programs called Bentley BridgeModeler and Bentley LARS for design and analysis of bridges. These programs are 100\% compatible with AASHTOWare Virtis and other software using BARS format.

\subsubsection{Capacity Calculation Methods}

Aside from the standard calculation methods prescribed by AASHTO, several alternative techniques are being investigated by researchers around the world. These methods implement some form of physical testing of a bridge to determine as-built behavioral characteristics. The analysis techniques involve more accurate depictions of a bridge’s structural behavior by indirectly accounting for secondary structural elements.

Physical testing of bridges generally result in increased strength and stiffness. Bridges that are physically tested often result in higher load rating factors than traditional calculation methods predict. The resulting increase in structural capacity is usually due to secondary structural mechanisms that aid in the bridge’s capacity and are not easily identifiable through classic structural analysis theory. Physical testing entails the 
gathering of experimental data including strains and/or deflections under known loading conditions which can be used to calibrate a computer model. The computer model is then analyzed using a load rating vehicle to determine bridge’s structural behavior characteristics for use in load rating calculations. It is important to note that this type of testing provides information about the bridge behavior under loading and not the structural capacity directly. Capacity calculations are based on design codes and material property theory.

Several states are implementing physical testing for load rating calculations. Delaware has implemented a program for physical testing to gather strain data from the existing bridges. This data is then used to calibrate BRASS input data and gain a more realistic assessment of the bridge condition and capacity (Delaware, 2005). The Iowa and South Carolina Departments of Transportation are both investigating the use of physical testing for more accurate load rating calculations of bridges.

Physical testing costs are dropping as techniques and equipment for nondestructive evaluation becomes more available and more accurate. Bridge Diagnostics, Inc. (BDI) has developed a commercially available system called BDI Structural Testing System (BDI-STS) for load testing bridges. The system correlates structural behavioral response data such as strains, deflections, and accelerations with loading vehicle positions. The BDI-STS system includes supporting software to assist in bridge modeling and load rating. Research conducted in Iowa showed a $42 \%$ increase in the critical load rating factor when using the BDI system.

Dynamic analysis methods are also being researched to aid in accurate structural capacity and load rating calculations. The dynamic signature of a bridge is directly 
related to its stiffness. This method is currently being researched in Australia on timber, concrete, and steel bridges (Samali, et al., 2006). Two dynamic tests are performed on the bridge while acceleration response data is collected. The first test is done with the bridge “as-is" by dropping a weight on the bridge to develop a vibration response recorded by accelerometers and a data acquisition system. The second test adds weight to the center of the bridge increasing the mass and thus decreasing the bending frequency. When the two sets of data are compared, the frequency shift due to the added weight can be utilized to calculate the flexural stiffness of the bridge. The load capacity of the bridge is then estimated from the flexural stiffness using statistically based analysis.

Currently, the cost of physical testing for all structurally deficient or functionally obsolete bridges is not feasible. The cost of physical testing should decrease as computing power improves and physical testing technology develops. The major restriction involved with physical testing is the time requirement. The greatest improvement areas for more rapid analysis involve instrumentation, investigation of computer models, and minimization of traffic disturbances.

\subsection{REHABILITATion Strategies}

Multiple strengthening systems have been developed for rehabilitation of structures. Each system has benefits and limitations that must be considered during the selection process. The goals of this research are aimed at implementing a cost effective strengthening technique for PennDOT-D3. This research focuses on externally applied FRP composites for concrete T-Beam bridges. 
Strengthening techniques include section enlargement, externally bonded systems, external post-tensioning systems, and supplemental supports. Key factors to consider when selecting any strengthening system are: the methods and materials to be used, durability considerations, fire considerations, field applications, and the benefits and limitations of each system. Special considerations for an FRP strengthening system include: the magnitude of strength increase, changes in relative member stiffness, size of the project, environmental conditions, in place concrete strength and substrate integrity, accessibility, operational constraints, construction/maintenance/life-cycle costs, and availability of materials, equipment, and qualified contractors.

The market growth of FRP composite structural strengthening is expected to grow over the next decade (Nanni, 2000). This technology growth is driven by the need for transportation infrastructure rehabilitation. Improved analysis methods and better understanding of FRP technology are expected to be available in the near future.

It is important to understand the benefits of FRP composites to see why this technology is becoming a standard rehabilitation method used in the civil industry. FRP composites have a higher strength to weight ratio than steel and are non-corrosive. Composite materials generally behave linearly until failure. This attribute of FRP must be accounted for during the design process in order to avoid sudden, brittle failure resulting in catastrophic collapse of the structure. Strain limitations limit the useable strength of FRP. Strain compatibility within the strengthened section can be controlled by several factors including substrate condition, epoxy type, and bond strength. Special consideration must be given to the application methods when working with FRP composites. External reinforcement with FRP composites can be accomplished 
using one of three basic methods. Prefabricated elements can be manufactured in a controlled environment, then shipped to the jobsite and applied to the structure using adhesives. This method has been proven to be the most reliable because of the controlled manufacturing conditions and quality control measures. Wet-layup involves the application of resin to the concrete substrate followed by application of the FRP composite laminate. The resin is then impregnated through the fibers of the composite laminate sheet. The composite and the bond are created at the same time in the field. This method provides the maximum flexibility in the field but carries the disadvantages of field mixing of the resin and field fabrication. Uncontrolled field conditions could result in the inclusion of impurities and absorption of moisture in the resin during mixing and application. These impurities could degrade the bond efficiency and possible result in premature failure of the composite-substrate bond. The third method of application involves resin infusion where pressure is applied to the composite laminate and epoxy infusing the fibers with the resin. This method is difficult to use in the field due to cumbersome vacuum equipment.

All of these conditions must be investigated when selecting FRP composites as a structural strengthening method. The FRP strengthening system used during this research may not be the most effective or efficient technique for all bridges. Both the benefits and limitations of multiple structural strengthening systems should be investigated in order to conclude with the best system for any given application. 


\subsection{FRP CONSTRUCTION AND DESIGN SPECIFICATIONS}

FRP composite technology is a proven structural strengthening system with numerous application possibilities. The complexities and sensitivities of the short term behavior of FRP composites have been well investigated over the last few decades by researchers. The results of this research have aided the development of construction and design specifications for several government agencies that are implementing FRP rehabilitation technologies.

A conglomerate of European nations pioneered one of the first field applications of FRP composites for strengthening in 1991 when FRP composites were used to strengthen the Ibach Bridge is Lucerne, Switzerland. A collaborative research program conducted in Europe called EUROCRETE was established in 1993 for the purpose of developing FRP reinforcement for concrete. The research team included members from the United Kingdom, Switzerland, France, Norway and The Netherlands.

In Japan, FRP has been used in construction since the early 1980s. The 1995 Hyogoken Nanbu earthquake spurred the development of FRP technology for retrofitting structures. In 1997, FRP reinforcement applications were led by the Japanese with around 1,000 demonstration/commercial projects. The Japanese were also one of the first countries to develop and implement FRP design guidelines which were incorporated into standard specifications produced by the Japan Society of Civil Engineers (Rizkalla, et al., 2003).

Swedish design guidelines for external strengthening with FRP was incorporated into the Swedish Bridge Code: BRO 94 in 1999 (Taljsten, 2002). Canada has also been a leader in the development and applications of FRP technology. In 1998, the Taylor 
Bridge in Headingley, Manitoba was opened which employed the use of Carbon Fiber Reinforced Polymers (CFRP) in 4 of its 40 precast concrete girders. Canada published FRP design guidelines in their ISIS Design Manual 3 in 2001.

In the United States, a design guideline was published by the American Concrete Institute in 2002 titled Guide for the Design and Construction of Externally Bonded FRP Systems for Strengthening Concrete Structures (ACI 440.2R-02), reported by ACI Committee 440. This document includes material background information, design recommendations, recommended construction specifications, drawing specifications and design examples. This document was used in this research project to develop preliminary FRP strengthening designs.

The short term behavior of FRP composites were investigated under the National Cooperative Highway Research Program (NCHRP) Project 10-59A (Dolan, 2006). This project resulted in a NCHRP Report 514 Bonded Repair and Retrofit of Concrete Structures Using FRP Composites: Recommended Construction Specifications and Process Control Manual in 2004. This document has been submitted to the AASHTO Highway Subcommittee on Bridges and Structures for consideration of adoption into their specifications for highway bridges. It contains in depth recommended construction specifications along with guidelines for submittals, storage, quality assurance, and cost analysis.

Both the ACI 440.2R-02 and NCHRP Report 514 were consulted in the design and construction planning process for the strengthening of the concrete T-Beam bridge under investigation in this research. These documents will be used to develop design and 
construction specifications for incorporation into PennDOT’s Structural Design Manual-4 (DM-4) in a later phase of this research project.

\subsection{CASe Studies}

Due to the multitude of application possibilities of FRP composites, research on almost any issue or application is available. The following are examples of previously conducted research studies that incorporate many similar aspects of this research project. Most of the studies presented focus on the use of externally applied FRP composites as a strengthening technique on conventionally reinforced concrete. These studies used lab scale experiments and/or field experiments on existing bridges. Destructive and nondestructive testing techniques were used to evaluate the effectiveness of the FRP composites and to assess quality control measures. Lab scale experiments are covered first, followed by field investigations, and long term testing methods.

Rahimi and Hutchinson (2001) investigated lab-scale concrete beams of varying reinforcement ratios with bonded external reinforcement. The variables studied include the conventional external bonded reinforcement ratios. The external reinforcements used for comparison were glass FRP (GFRP), carbon FRP (CFRP), and mild steel. Testing results show that the ultimate load-carrying capacity of strengthened beams can increase by as much as $230 \%$ when compared to un-strengthened control beams. From 2D nonlinear finite element analysis the researchers were able to conclude that the limiting principal stress value at ultimate loads of the concrete/external plate interface controls the detachment of bonded external plates from concrete. 
Bonfiglioli, Pascale, and De Mingo (2004) researched lab scale dynamic testing to investigate methods of determining the long term effectiveness of externally bonded FRP composites on beams. The procedure used modal analysis to determine stiffness variation resulting from damage and strengthening of the beams. Damaged areas can be detected and localized by this testing technique but it is not capable of estimating the global behavior of the structure after rehabilitation. The researchers conclusions suggest that modal testing is a viable form of non-destructive testing for interpreting the effectiveness of a strengthening system on damaged reinforced concrete beams.

Sargand and Ball (2000) conducted laboratory tests on fourteen concrete beams and field tests on two reinforced concrete bridges strengthened with externally bonded FRP composites. The laboratory tests indicated a steel strain reduction as high as 53.8\% after strengthening. FRP laminate configurations varied and were layered up to five plies on laboratory beams. Deflections were reduced $8.0-53.1 \%$ when compared to the control beams. Steel strains in the laboratory beams were reduced by $11.5-58.6 \%$ and concrete compressive strains dropped 3.0-33.5\%.

After analyzing the strain readings, it was determined that the neutral axis shifted downward after strengthening, which is similar to the behavior of an overly-reinforced beam design with a higher reinforcement ratio. The ultimate load capacity of laboratory beams increased $47-66 \%$ over the control beam. The bridges used for field testing were simply supported structures with a span length of $40 \mathrm{ft}$ and $30 \mathrm{ft}$ width. All six girders of each bridge were instrumented with strain gages and Linear Variable Displacement Transducers (LVDTs). Up to three layers of FRP composite laminates were used in the strengthening design of the bridges. Different composite types were tested on each 
bridge. Field tested strain readings reduced by $0-15 \%$. Deflections ranged from decreasing $3-11 \%$ and increasing $0-8 \%$. The researchers concluded that it is impossible to determine the contribution of the FRP materials with the relatively limited range of data obtained. However, it is possible to use the data for re-evaluating the loading capacity of the bridges.

Alkhrdaji and Nanni (1999) tested two bonded FRP strengthening methods on two identical bridges. They investigated the overall effectiveness of FRP as a strengthening system including cost, labor requirements, construction processes as well as testing the strengthened structural systems to failure. The two systems used were Near Surface Mounted (NSM) FRP rods and wet layup externally bonded FRP sheets. The bridge being tested was a three-span concrete slab bridge with simply supported spans that was built in 1932. Though the bridge showed no major signs of deterioration, it was slated for demolition due to increasing traffic demands. The two FRP systems were designed to have similar influences on the flexural strength of the bridges. Crews were able to apply the FRP systems in one week with no traffic delays. The test results showed that each of the FRP systems investigated provided significant improvement over the un-strengthened deck.

Research conducted by Hag-Elsafi, Kunin, Alampalli, and Conway (2001) on the strengthening of a simply supported $12.19 \mathrm{~m}$ long concrete T-beam bridge in South Troy, New York closely resemble some of the complications that WVU researchers were faced with on this research project. The structural capacity of the bridge was investigated due to visual signs of deterioration and a lack of proper documentation describing the design of the bridge and materials used during construction. The structural analysis used 
conservative estimates for steel and concrete properties suggested by AASHTO for unknown material properties. The rebar layout was taken from shop drawings that may not have described the as-built conditions of the bridge. The FRP system was designed by a third party under contract. The third party used an estimate of $15 \%$ loss of original steel area due to corrosion.

Comparison of the pre- and post-strengthening structural behavior of the bridge indicate that the FRP has a minimal contribution to reducing flexural tensile steel stresses and moderately aided in the transverse load distribution. Moment resistance at the supports considerably reduced the live load moments. After testing, the FRP was painted to match the color of the concrete for aesthetic purposes. The use of FRP as a strengthening system resulted in a total project cost of $\$ 300,000$ instead of the $\$ 1.2$ million cost for replacing the bridge.

Shahrooz and Boy (2001) used externally bonded FRP composites to strengthen a 45-year old three-span reinforced concrete slab bridge in Ohio with insufficient load capacity. The results of testing showed a $22 \%$ increase in the controlling rating factor and load limits. The load rating was conducted using LFR methods and an HS20-44 loading vehicle. The deflections of the bridge were not altered considerably but the FRP strains suggested participation of the FRP strengthening system. The researchers recommend that future monitoring of long-term behavior of the FRP systems be continually researched.

Destructive and non-destructive testing techniques of FRP strengthening systems were carried out by a team of researchers in Missouri (Alkhrdaji, Nanni, Chen, Barker, 1999). The purpose of this testing was to determine the effectiveness and feasibility of 
two FRP strengthening systems on reinforced concrete bridge decks with the intent of increasing the flexural capacity by 30\%. The tested FRP systems include Carbon NSM rods and externally bonded CFRP sheets. Two of the three bridge decks built in 1932 were strengthened with the FRP systems. All three decks were statically and dynamically tested before and after strengthening. Initial analysis calculations used the Missouri Department of Transportation (MoDOT) suggested material property values of $33 \mathrm{ksi}$ yield strength for steel and $2.5 \mathrm{ksi}$ concrete compressive strength. After failure of the decks, material samples were collected and tested to provide more accurate material property data.

The concrete compressive strength was calculated to be $226 \%$ higher than (8147 psi) MoDOT’s suggested value and the steel yield strength was 31\% higher (43 ksi). The final failure mode was a combination of CFRP rupture and delamination of the sheets which allowed for a pseudo-ductile behavior. Efforts were made to limit the effects of secondary structural elements such as composite action of parapets and continuity at supports. However, the bridge decks exhibited strength characteristics in excess of those predicted by standard design manuals.

Summarized in a second report are the dynamic testing results of the same research project presented above (Alkhrdaji, Barker, Chen, Mu, Nanni, Yang, 1999). The objective of the dynamic tests was to examine any change in the fundamental frequency due to FRP strengthening. Frequency shifts can be examined to evaluate damage levels in reinforced concrete. This research identified an effective indicator for damage level detection that requires no baseline for comparison analysis. The frequency shift is heavily influenced by unstable surface conditions along cracks. This technique it is a 
more sensitive analysis tool to locate damage than the frequently used indicator of change in natural frequency from one damage level to another. Collectively, these methods may be a useful tool for field inspection teams in detection of severe and localized damage within concrete structures. These techniques can be incorporated to develop a more accurate representation of the structural behavior and condition of the bridge as a singular entity.

Mayo, Nanni, Gold, and Barker (1999) studied the effects of using FRP composites to increase the rating factor of a $6.1 \mathrm{~m}$ long, reinforced concrete slab bridge built in 1922 on Route 32 in Iron County, Missouri. Allowable stress and load factor rating analyses were performed using HS20 and MS20 trucks. The analyses resulted in a required 20\% increase in flexural capacity. FRP strengthening was performed using MBrace CF-130 which is a type of commercially available carbon FRP laminate. The field testing was done using only deflection measurements to gather data on the load carrying behavior of the bridge. The average deflection change after strengthening was around 6\%.

Static and dynamic testing techniques were used to investigate the effectiveness of FRP strengthening on an $82 \mathrm{ft}$ long bridge in Cayey, Puerto Rico with the objective of increasing the load rating factor of the bridge. Dynamic tests consisted of using Model 393C accelerometers and a data sampling rate of $100 \mathrm{~Hz}$. Analysis of the dynamic test data was performed using a Fast Fourier Transform with a Hanning window and segments of 1,024 data points. The resulting domain frequency spectra graphs indicated operating modal frequencies from 2-5 Hz and 9-14 Hz. The acceleration data was further analyzed through a Power Spectral Density (PSD) plot to more clearly observe the 
spectral activity. All measured strains and deflections were reduced after the FRP strengthening was installed. Deflections decreased an average of approximately $16 \%$. A $15 \%$ increase in stiffness can be calculated from the natural frequency mode shift of 7.2\%. The rating factor was controlled by shear and increased from 0.44 to 1.02 .

High quality, quantitative non-destructive testing techniques are being developed to aid in monitoring of FRP composites used to strengthen structures. The dependency of the bond between the substrate and FRP composite material is a crucial concern to ensure the long-term reliability of such strengthening systems. Infrared (IR) thermography is being researched as an efficient tool for investigating near-surface defects in composite materials (Starnes, Carino, Kausel, 2003). The New York Department of Transportation and Federal Highway Administration (FHWA) have performed trial inspections using IR thermography for qualitative measurements. These studies should result in a quantitative analysis method using IR thermography to investigate flaw characterization in FRP composite materials.

Lopez and Nanni (2006) conducted research on four concrete T-Beam bridges and one slab bridge in Missouri with the purpose of increasing the load carrying capacity and removing load postings. Load rating analysis was done using LFR methodologies and an HS20-44 truck loading. The externally applied FRP composites were required to resist an increase of up to $30 \%$ in live load capacity. Load testing was performed before and after strengthening. Deflection measurements were taken using a Total Station, which is a commonly used instrument by surveyors. Concrete core samples showed a concrete compressive strength between 4.0 and $6.8 \mathrm{ksi}$. The steel yield strength used was $40 \mathrm{ksi}$ as suggested by AASHTO guidelines. The FRP strengthening system was designed 
following ACI 440.2R-02 guidelines. Based on the results of their study, MoDOT planned to remove the load posting on all of the bridges tested. The researchers decided to conduct semi-annual tests until 2011 to show if stiffness degradation occurs over time. 


\section{CHAPTER 3 - EXPERIMENTAL WORK}

\subsection{INTRODUCTION}

This chapter presents the results of the field inspection visits, material assessment summary, and load testing. Field inspections were performed to collect deteriorated condition assessment data. Material samples were removed from the bridge and studied at West Virginia University laboratories. The results of the studies were used to establish existing material strength properties that were used for accurate structural capacity calculations.

\subsection{Bridge Material Assessment Summary}

One of the first field site visits was conducted on May 24, 2006 in order to collect material strength data through destructive and non-destructive testing. Tests were performed in the field and in WVU laboratories. These tests were conducted to determine a thorough understanding of the deterioration levels within the concrete and reinforcing steel. For an in depth discussion of the testing techniques used for material property testing, refer to George Parish's thesis titled CFRP Repair of Concrete Bridges with Accelerated Ageing by Induced Current.

\subsubsection{Concrete Core Sampling}

Testing of the in-situ concrete compressive strength required removing concrete core samples from the deck. Two 4-inch diameter samples were taken using a Diamond 
Products Model M1 core drilling machine. The samples were taken at the quarter and midpoint of the span length measured from the south abutment and directly in between beams 2 and 3. See Figure 3.1 for the locations of the concrete core samples and beam numeration. Figure 3.2 shows one of the concrete core samples after extraction from the bridge deck. The deck core drilling setup and process are shown in Figure 3.3.

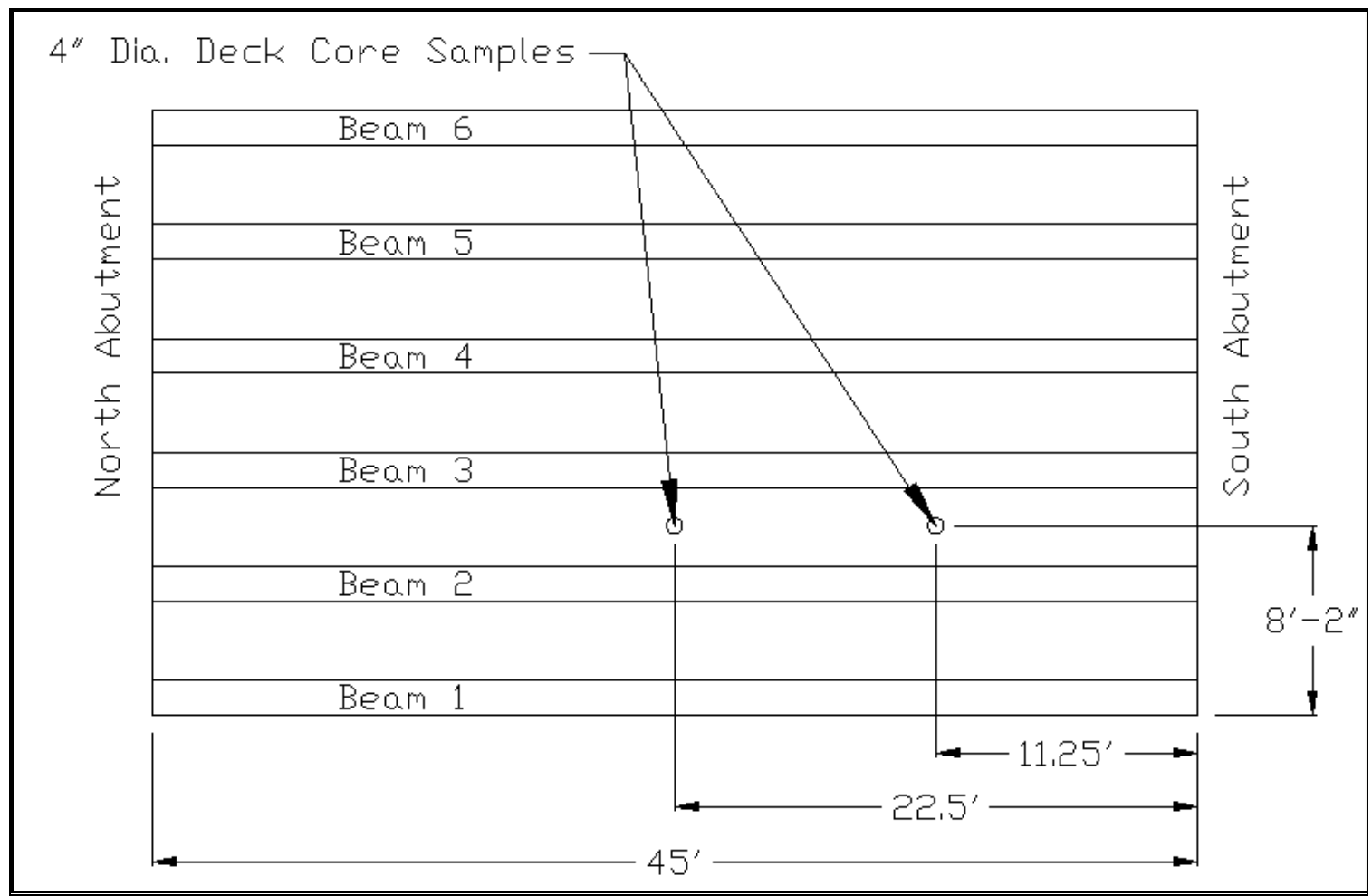

Figure 3.1 Deck Core Sampling Locations 


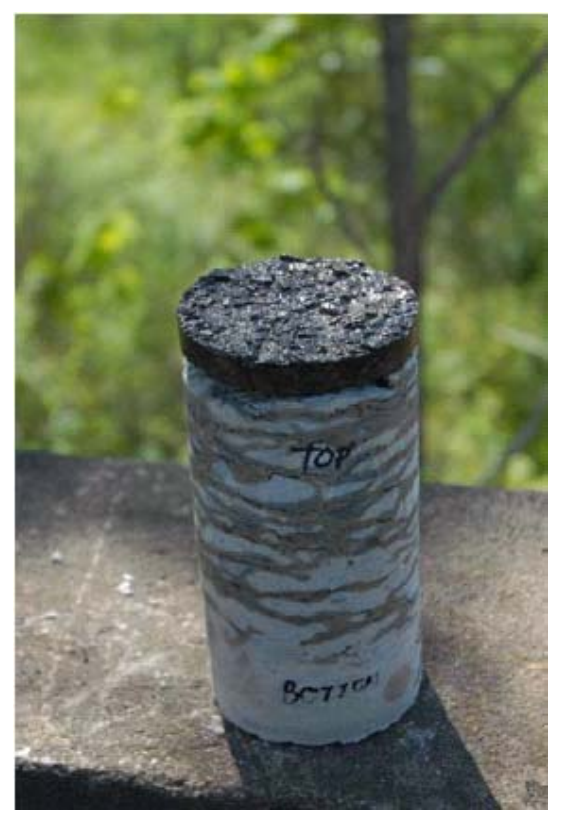

Figure 3.2 Deck Core Sample

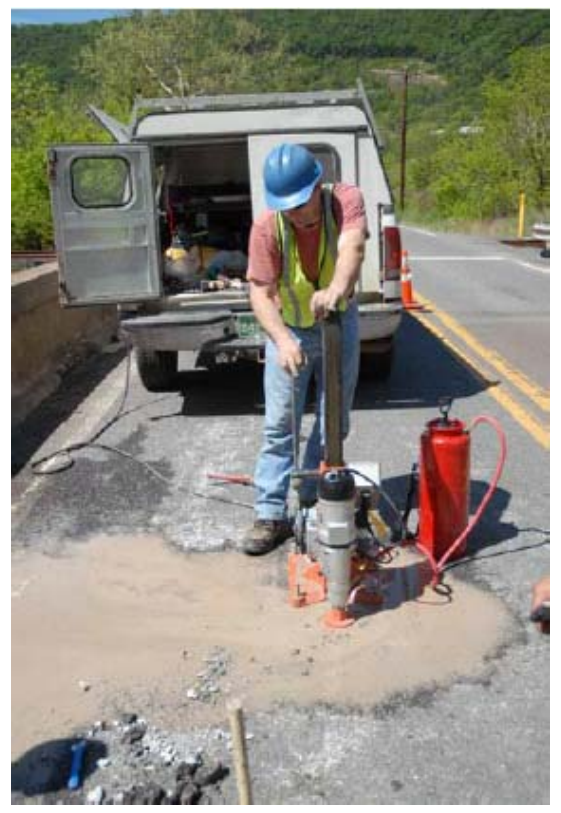

Figure 3.3 Deck Core Drilling

\subsubsection{Sampling of Tensile Reinforcing Steel}

A segment of exposed flexural tension steel on beam 1 was removed to test the steel yield strength. The sample of flexural reinforcement was completely exposed and separated from the concrete over the $8 \mathrm{ft}-6$ in length that was removed. This section of 
steel was chosen because of its ease of extraction and minimal effect on the existing capacity of the bridge. The location and removal procedure of the flexural reinforcing steel are shown in Figures 3.4 and 3.5.

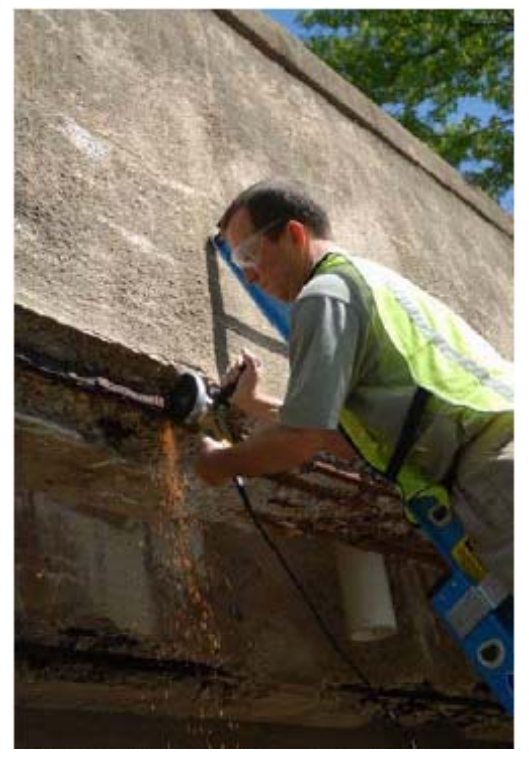

Figure 3.4 Exposed Rebar Extraction Tools

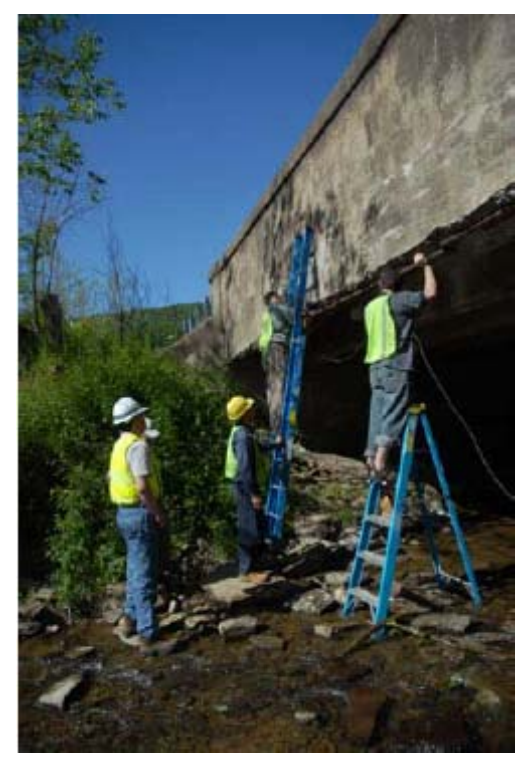

Figure 3.5 Location of Exposed Rebar Extraction 


\subsubsection{Visual Inspection and Documentation}

During the site visit, a detailed visual inspection of the entire bridge was performed and damaged areas were documented with photographs and location measurements. A qualitative measurement analysis was conducted by sketching the areas of concrete delamination, spalling, and severe cracking on each beam. The damage sketches were useful when analyzing deteriorated sections of the bridge.

The exterior beams exhibited the worst deterioration over the entire length of the beam. Each of the exterior beams had localized areas of severe deterioration along the entire interior web face of the beam near the drainage fixtures. This damage was most likely due to the high concentration of deleterious chemicals draining from the road deck. Pictures of some of the damaged areas can be seen in Figures 3.6-3.11.

The beams adjacent to the exterior beams (2 and 5) exhibited the most deterioration of all interior beams. These beams had areas of localized concrete spalling, and cracking. Most of the web concrete cover still remained intact on these beams. Figures 3.8 and 3.9 show example damaged areas of beams 2 and 5. The inner-most beams (3 and 4) had the least amount of damage and exhibited minor localized spalling and delamination. 


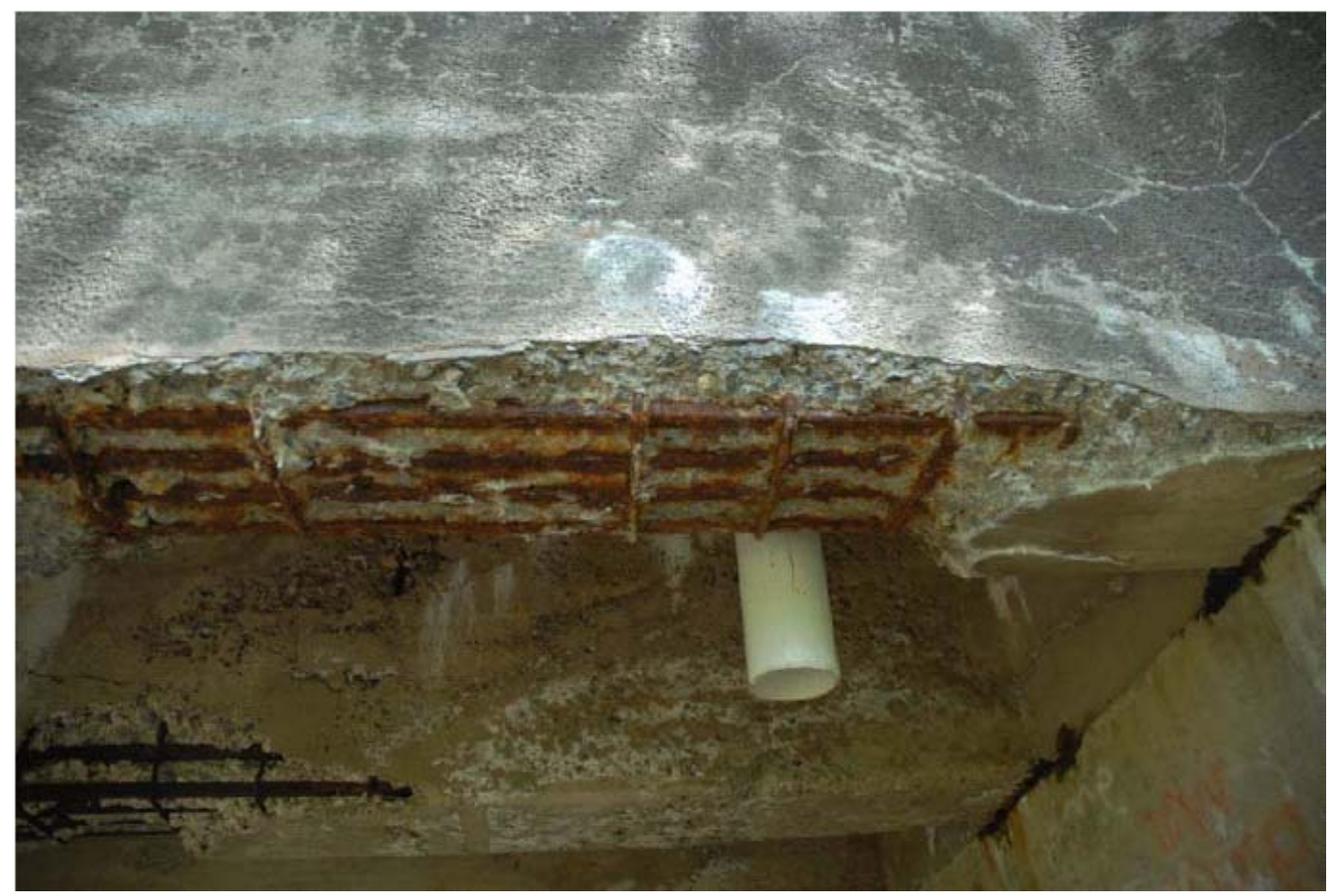

Figure 3.6 Beam 1 - Spalling, Delamination, and Cracking

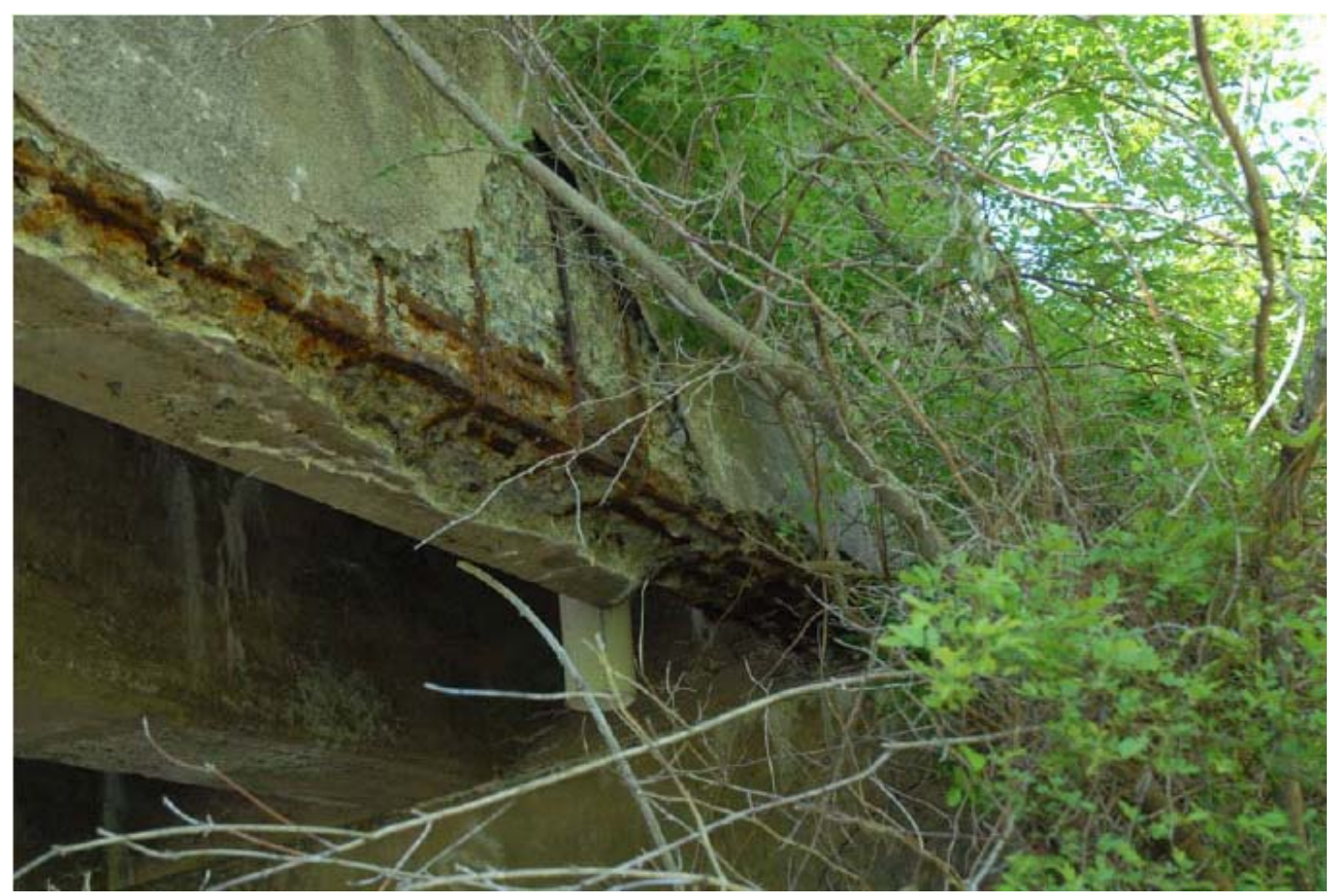

Figure 3.7 Beam 6 - Spalling, Delamination, and Cracking 


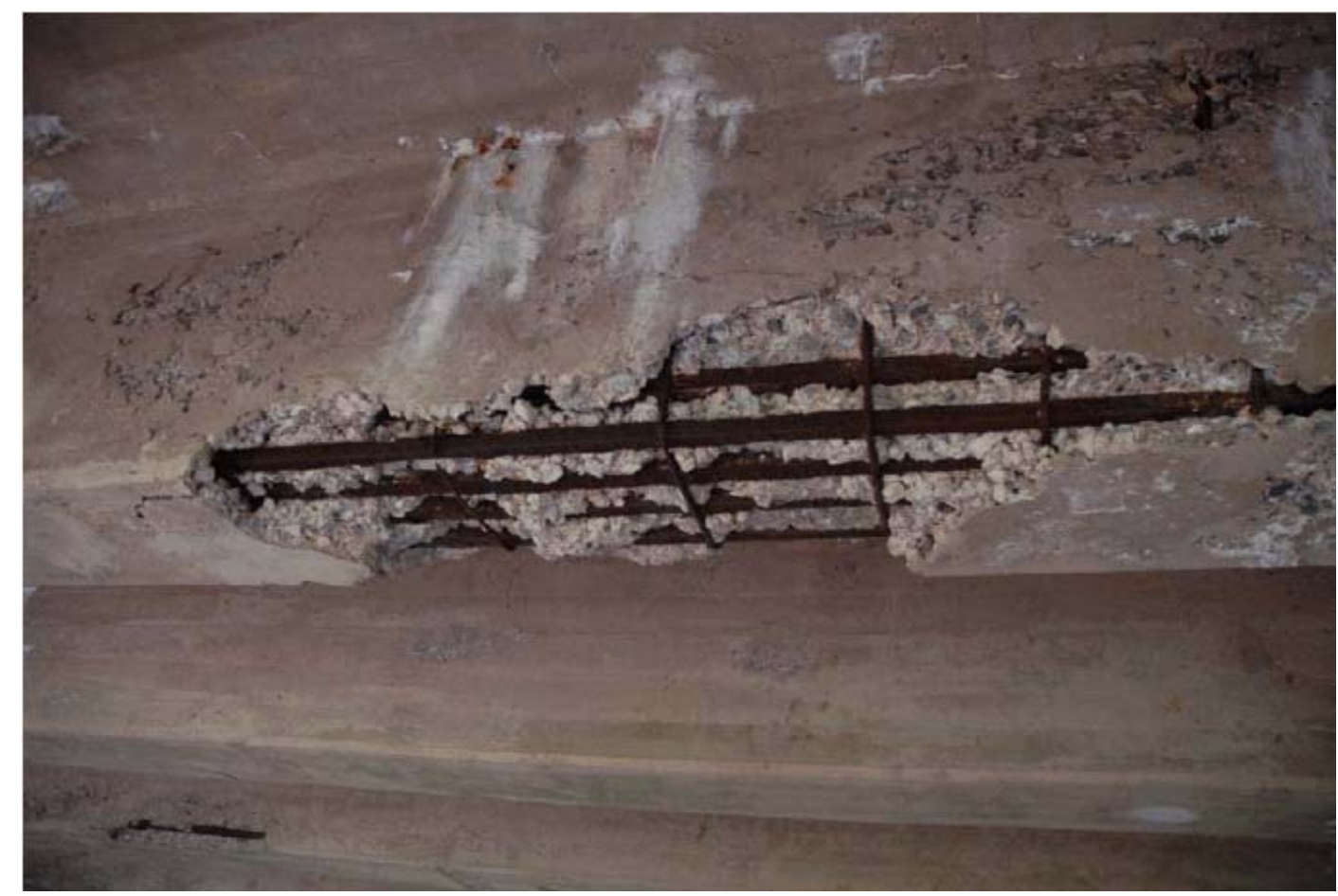

Figure 3.8 Beam 2 - Localized Damage

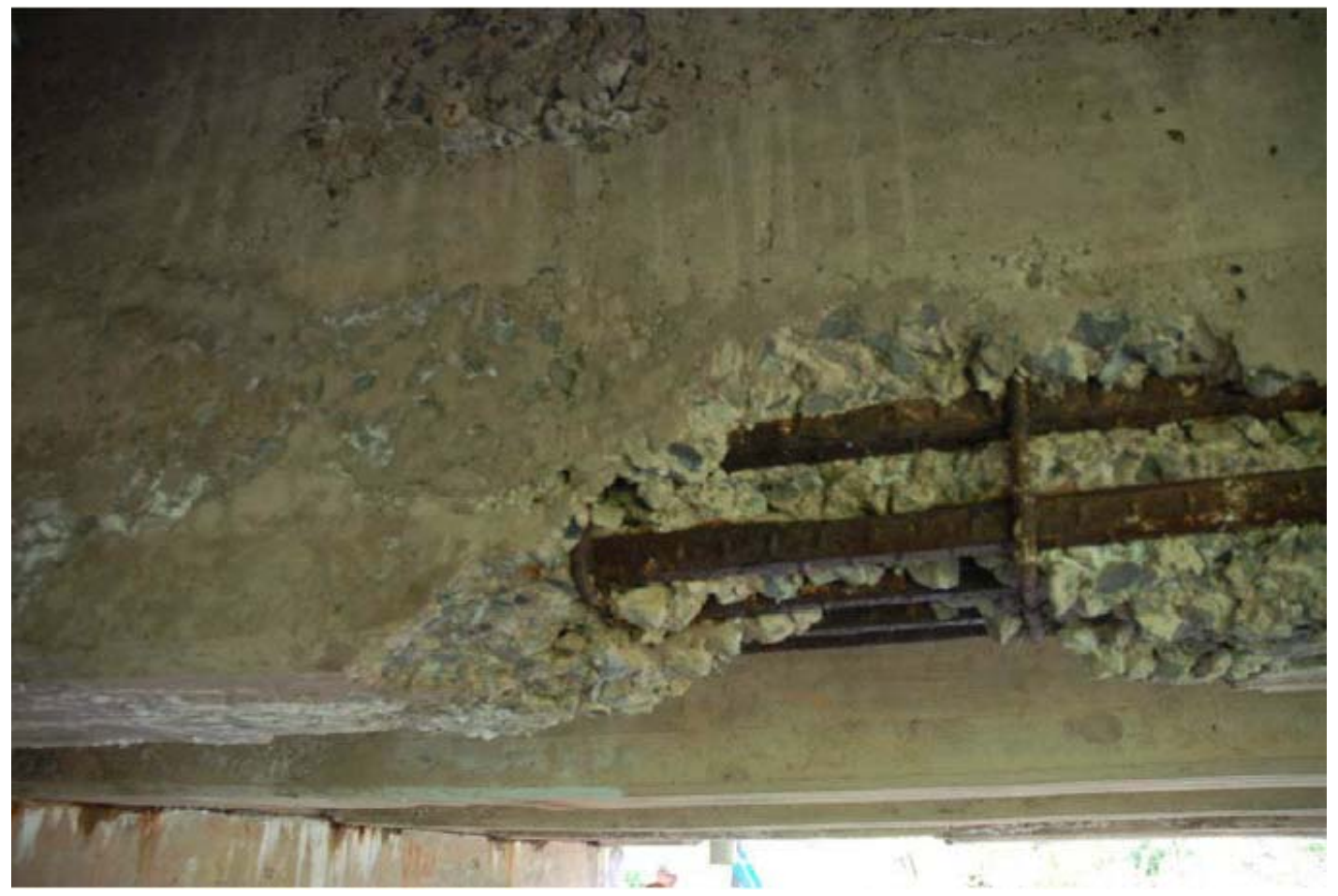

Figure 3.9 Beam 5 Localized Spalling and Delamination 


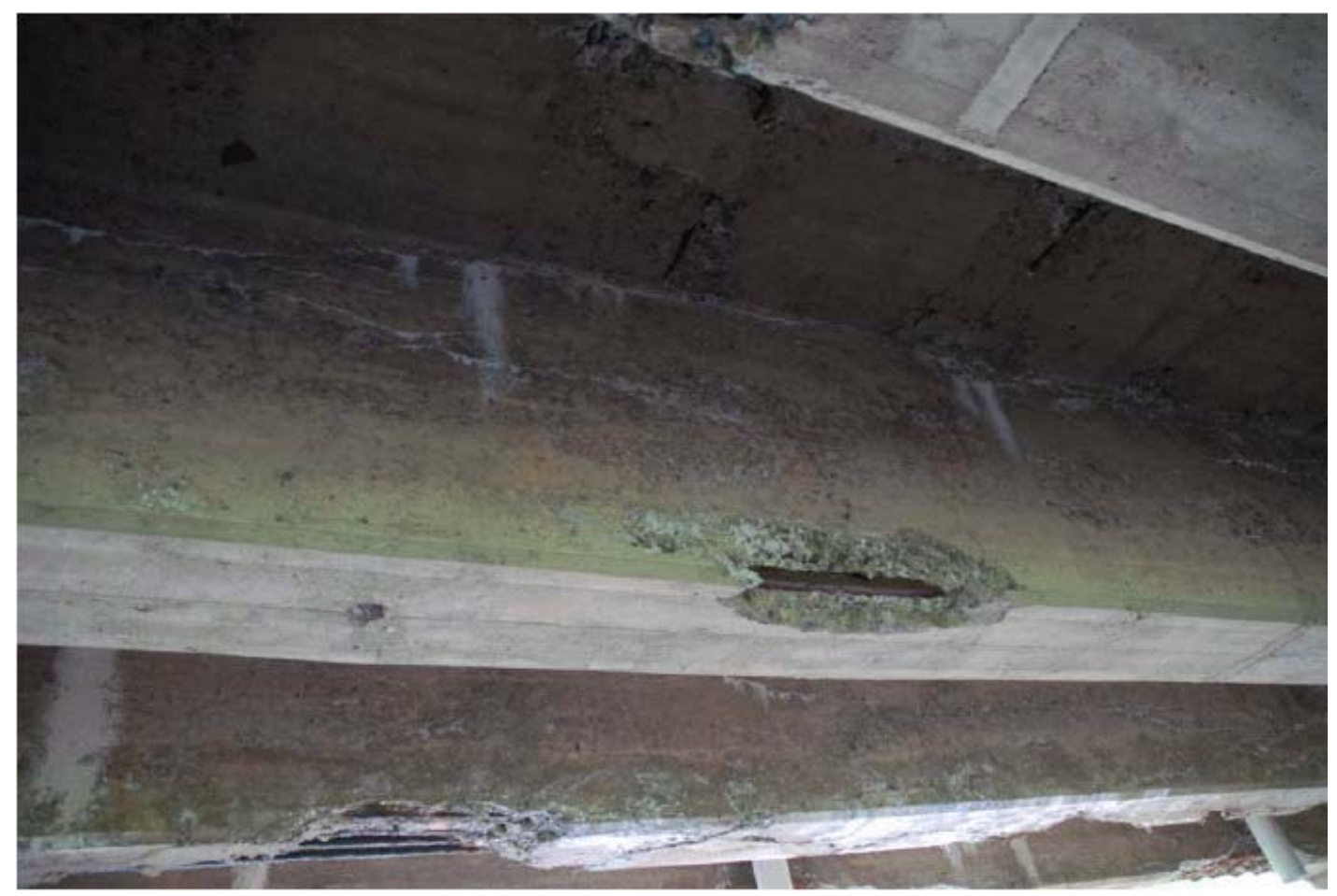

Figure 3.10 Beam 3 - Minor Damage

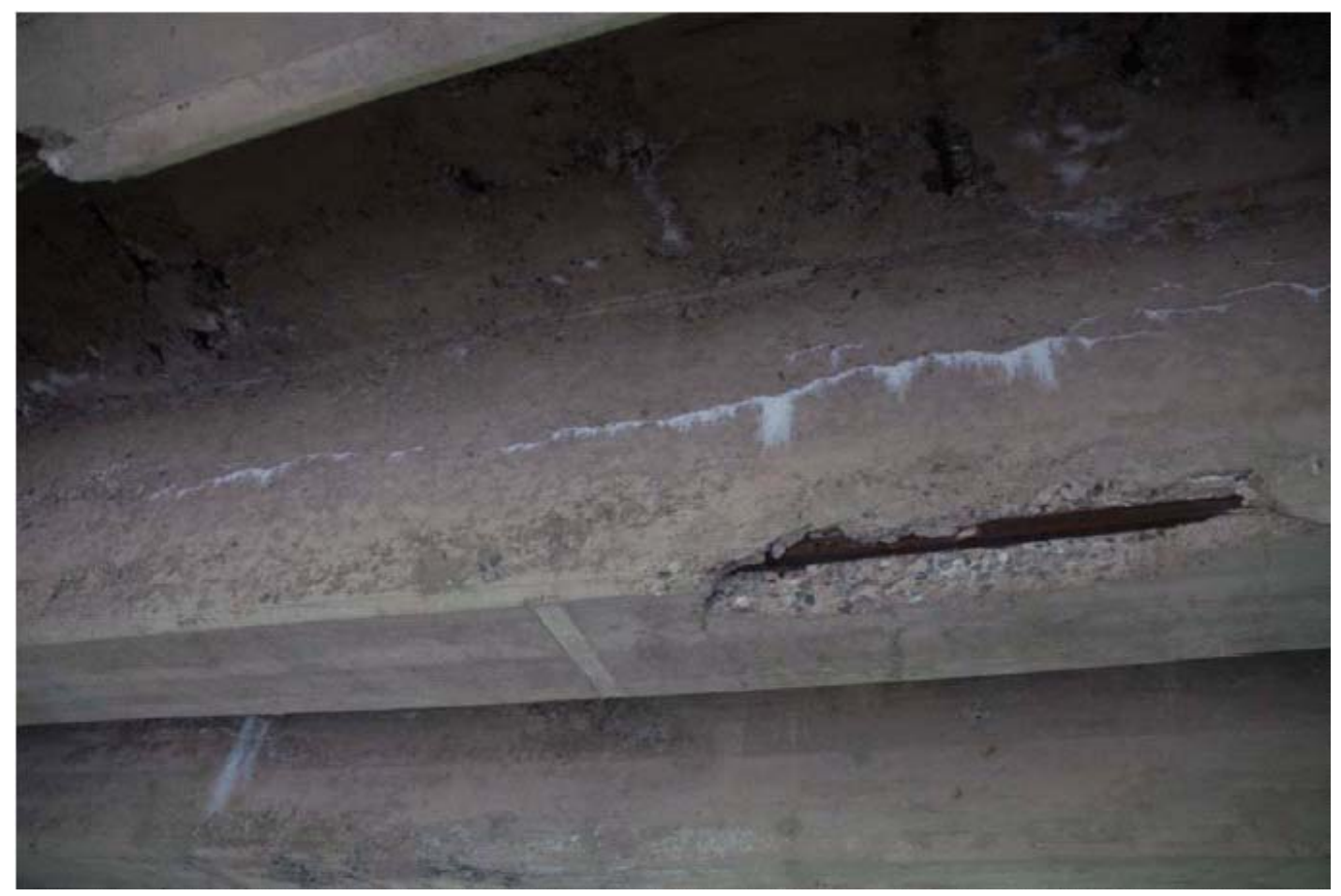

Figure 3.11 Beam 4 - Localized Damage 


\subsubsection{Material Property Summary}

Severe spalling and delamination of the concrete from the bottom faces of the beams were seen through visual inspection. The ultrasonic pulse velocity test indicated the presence of cracks and voids within the beam which can lead to loss of structural integrity. The SEM and EDX analyses confirmed the presence of reaction products caused by severe carbonation and chloride attack which negatively affects the concrete strength.

The $\mathrm{pH}$ level in the concrete, determined by the phenolphthalein test, also indicated the presence of carbonation in the beam and its susceptibility to corrosion of the reinforcing steel. The bridge has a high potential for continued corrosion of the reinforcing steel due to the high chloride content determined through testing.

The high chloride content of the concrete samples can be primarily attributed to the use de-icing salts on the bridge. It is also possible that a chloride based accelerator was used in the concrete at the time of the bridge's construction. It is important to note however, that not all of the chlorides detected under these tests are available for corrosion initiation.

The larger quantities of chloride salt crystals and their reaction products (e.g. chloroaluminate) in the quarter point deck core and beam samples are indicative of a higher porosity when compared to the midpoint deck core sample. The higher porosity of the quarter point deck core sample can also be seen in the compression test. The concrete compressive strength of the quarter point deck core sample was $25 \%$ lower than that of the midpoint deck core sample. The higher porosity indicates decreased durability of the 
concrete within the structure. This result indicates that the susceptibility of the concrete to further carbonation and chloride attack is high.

The steel tension tests conducted at WVU laboratories indicate an average yield stress of $37 \mathrm{ksi}$. The average ultimate strength was determined to be $64 \mathrm{ksi}$. Steel section losses varied between 0 and 20\% for both flexural and shear reinforcement. However, it was observed that one vertical stirrup on exterior beam 1 had completely corroded through the cross section.

It was discovered during the concrete repair stage that the bridge was not built according to the assumed original design drawings. Several sections of steel reinforcement were omitted from this bridge's construction including flexural reinforcement, vertical shear stirrups, and inclined bars. Details of the missing sections are provided in Chapter 4.

\subsection{LOAD TESTING}

Load testing of the bridge was performed to satisfy two objectives. The first objective was to gather sufficient data to correlate results with a finite element model simulation of the bridge. The finite element modeling was not conducted within the scope of this thesis. The second objective was to provide a benchmark for the prestrengthened structural behavior. This benchmark could then be used to compare poststrengthened structural behavior characteristics and determine the effectiveness of the FRP strengthening system. The pre- and post-strengthening testing will consist of similar test configurations. The instrumentation setups and load cases used will parallel each other to facilitate computer modeling comparisons. 


\subsubsection{Setup}

The initial testing plan consisted of recording strain readings, displacements, and accelerations of the bridge. This section covers the instrumentation setup used for load testing the bridge under investigation on October 5, 2006. Figure 3.12 shows the placement of the instruments used in the actual test. Figure 3.13 shows the field instrumentation and equipment setup in the field. The initial plan was altered due to site conditions during the week of instrumentation setup. Details are given in the following sections.

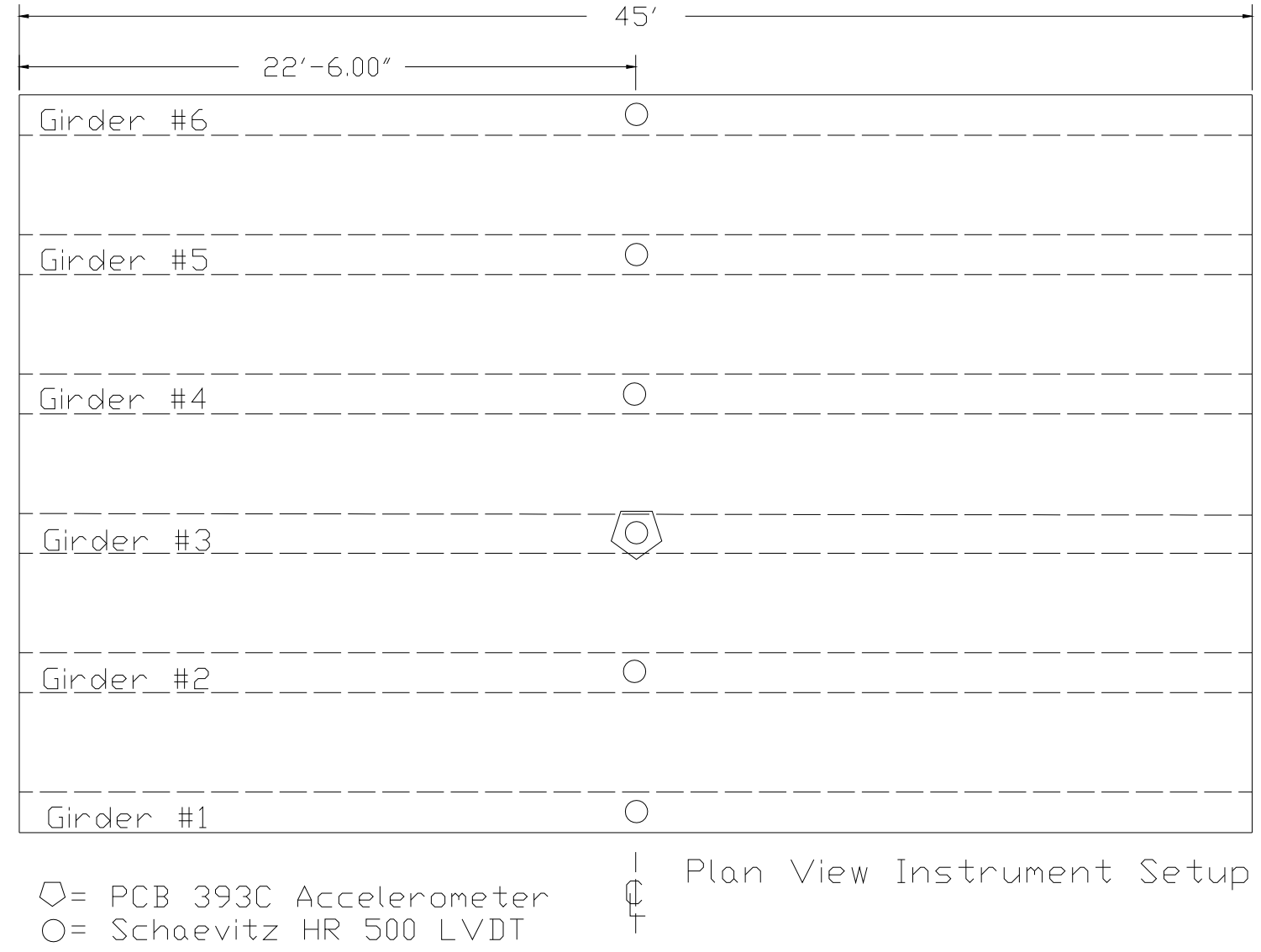

Figure 3.12 Plan View of Instrumentation Layout 


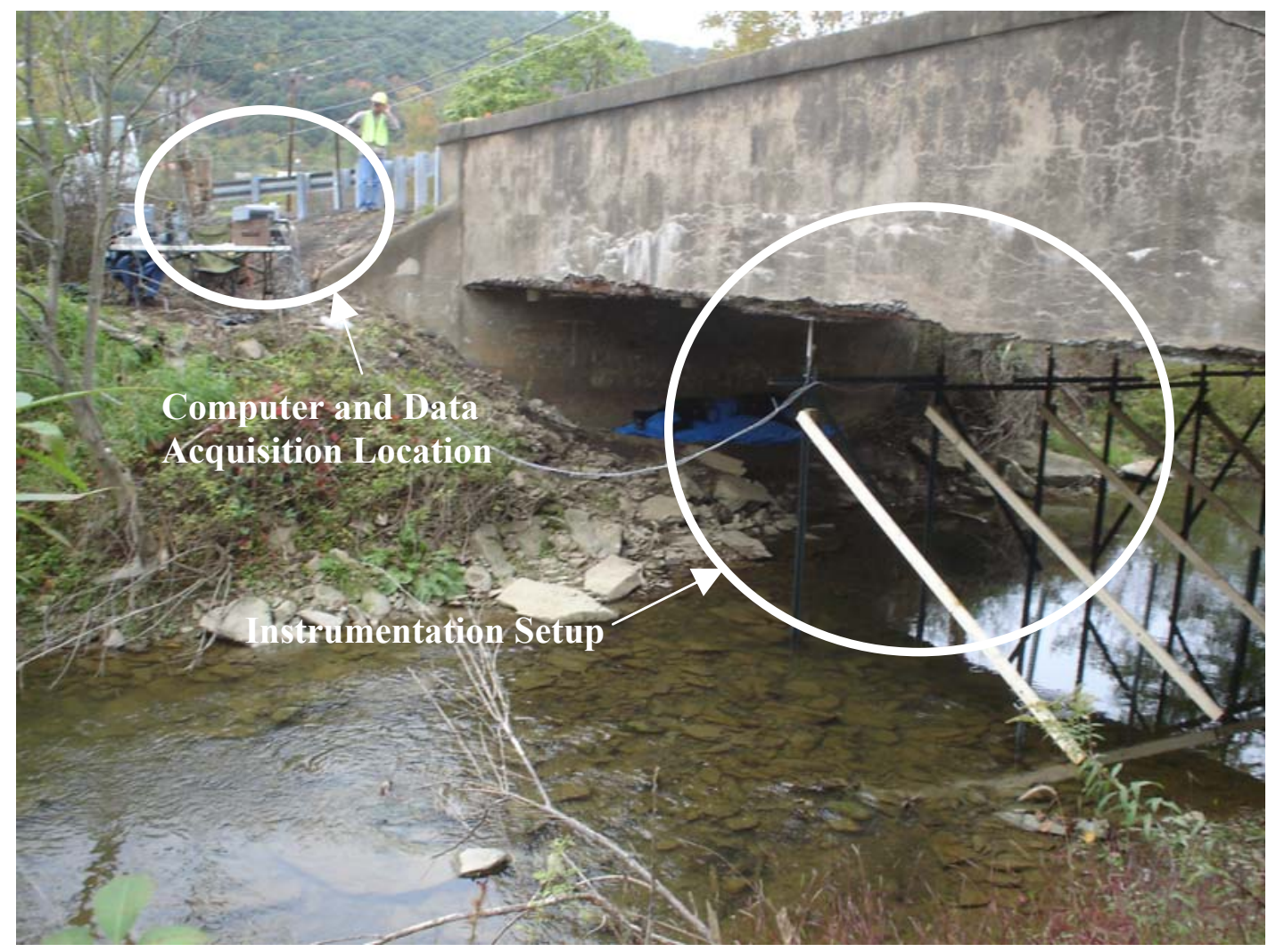

Figure 3.13 Field Placements of Equipment and Instruments

\subsubsection{1- Strain Gages}

The initial instrumentation plan incorporated the use of three Vishay Model N2A06-40CBY350 strain gages. The gages were to be placed at quarter, half, and threequarters height on the inside face of each beam at the midpoint of the span length (Figure 3.14). This positioning would be useful in determining the neutral axis depth of each beam.

Surface preparation of the concrete was required to ensure adequate bond of the gages. The surface preparation consisted of filling voids on the surface of the concrete with a $100 \%$ solid adhesive. Vishay M-Bond AE-10 adhesive was used which required at least six hours to cure at a minimum temperature of $75^{\circ} \mathrm{F}$ as seen in Figure 3.15. Due 
to inclement weather conditions at the bridge site during the instrumentation setup phase, the strain gages could not be placed on the bridge. After three days of curing time at temperatures no higher than $45^{\circ} \mathrm{F}$ in the shade, the epoxy was still tacky and a solid base for strain gage attachment could not be achieved.

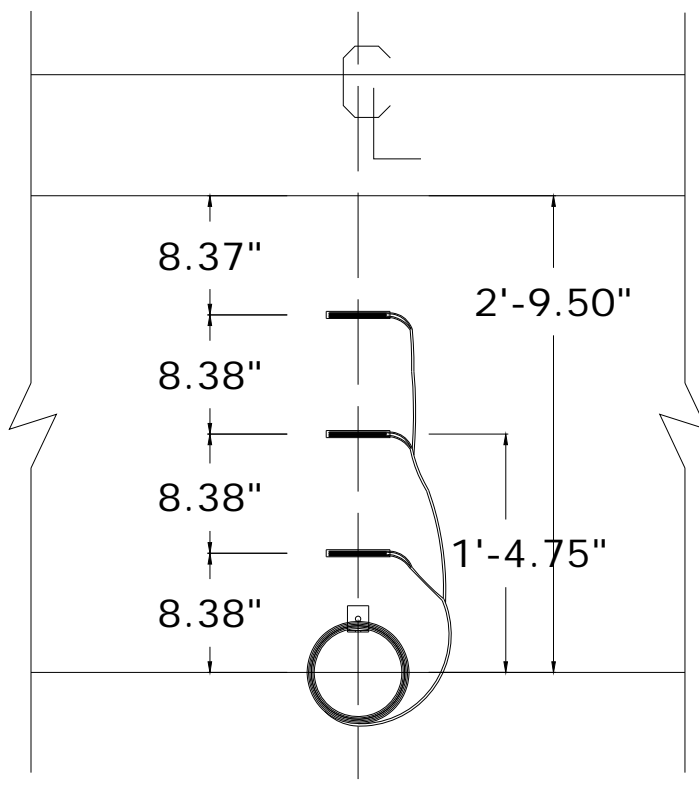

Figure 3.14 Originally Proposed Strain Gage Locations

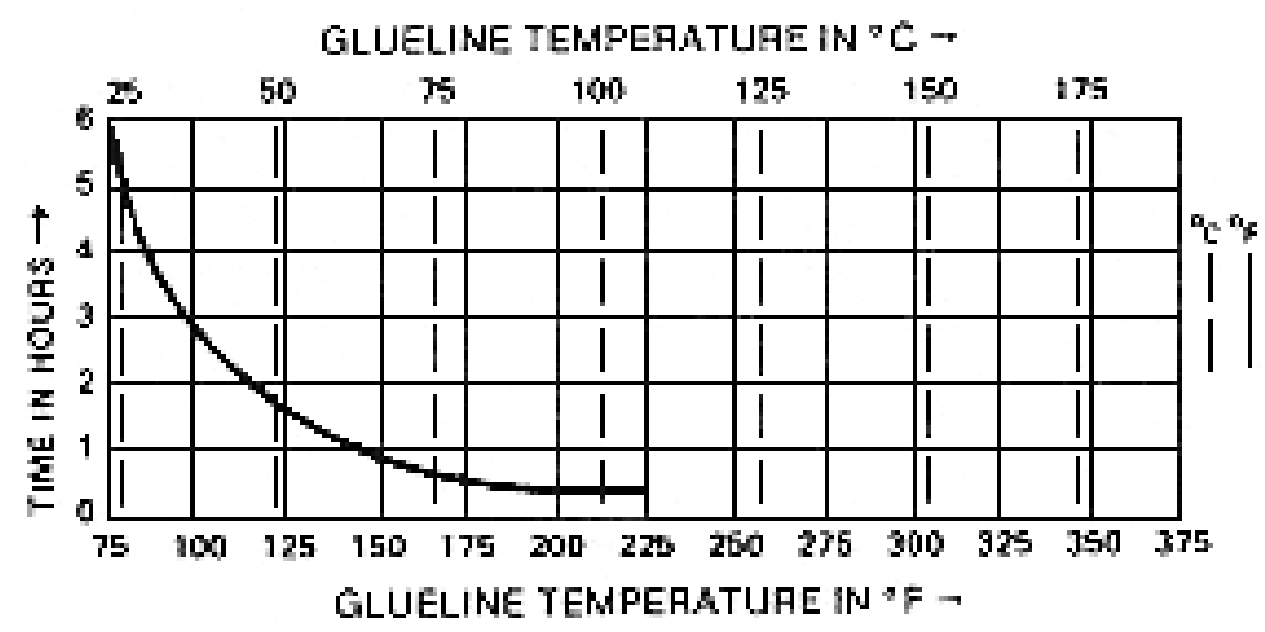

Figure 3.15 Epoxy Cure Time Chart 


\subsubsection{2- Displacement Transducers}

Six Shaevitz HR500 Linear Variable Displacement Transducers (LVDTs) were placed at the bottom-inside face of each beam as shown in Figure 3.16. The range of the LVDTs was \pm 0.5 inches with sensitivity of 0.001 inches. PVC tubing attached to UChannel sign posts supported the LVDTs close to the bottom of the beams. Possible magnetic interference caused by the U-Channel sign posts was limited by inserting the LVDTs into PVC tubing (Figure 3.17). The U-Channel sign posts were driven into the creek bed and tied back with wood 2x4s as shown in Figure 3.18. The sign posts were braced together with inclined and horizontal U-Channel sign posts to limit side-sway movement. Displacement data was taken at a rate of ten scans per second during static load testing.

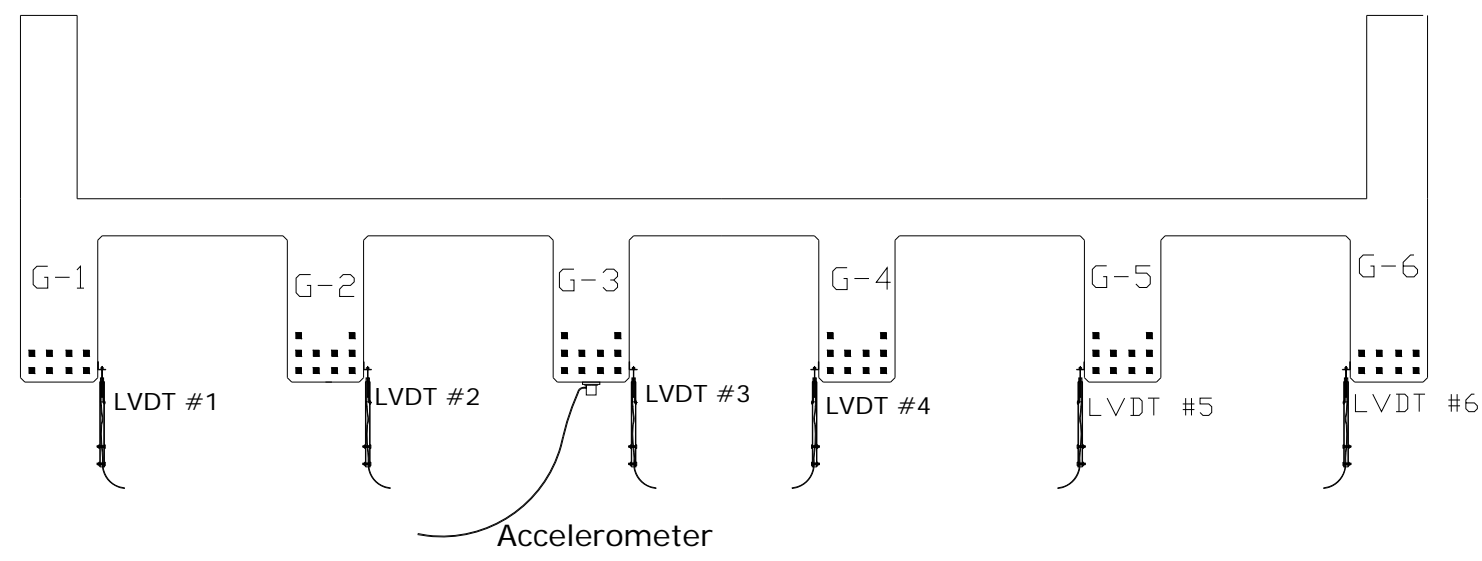

Figure 3.16 Cross-Section View of Instrumentation Setup 


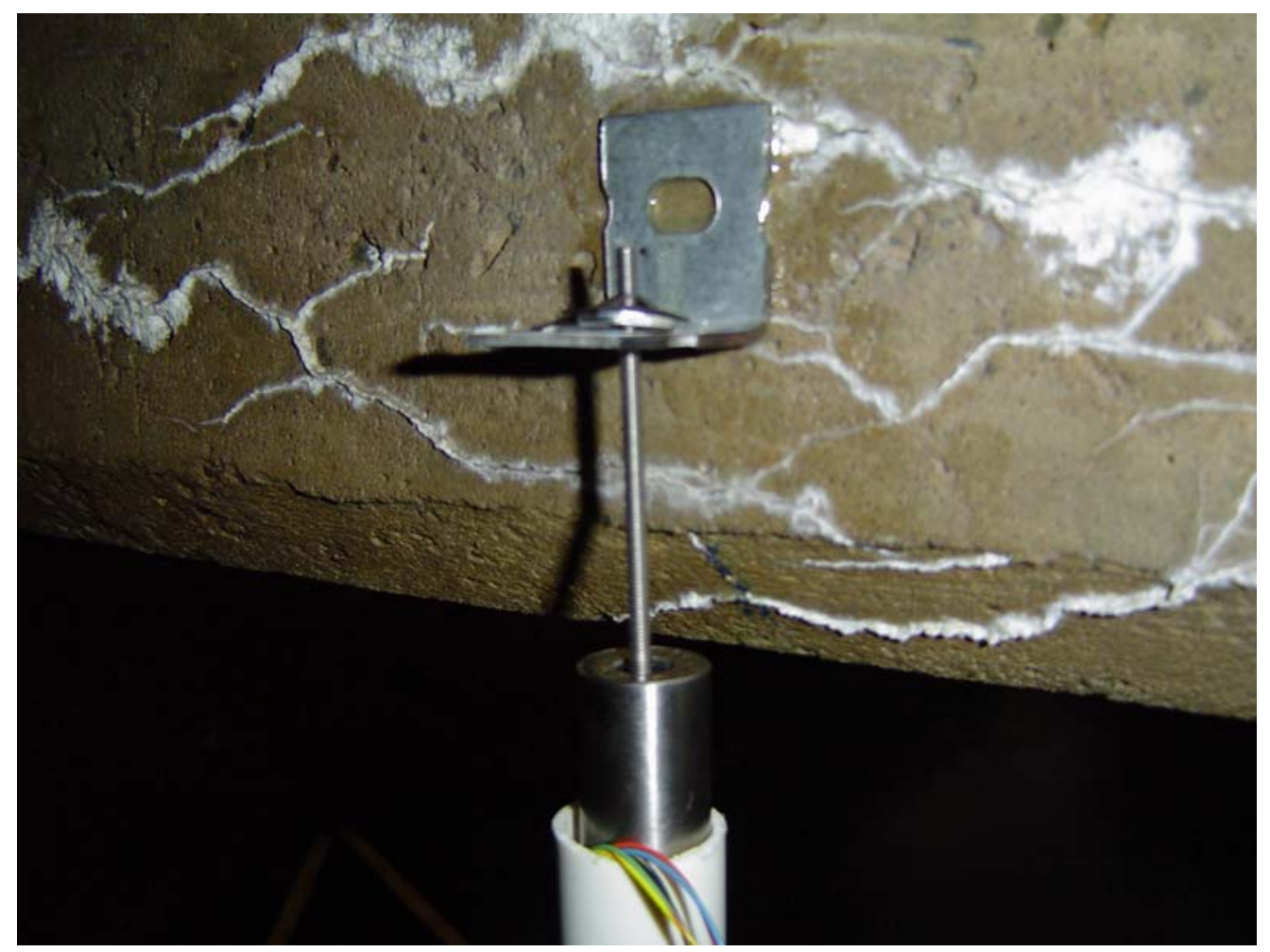

Figure 3.17 LVDT Setup

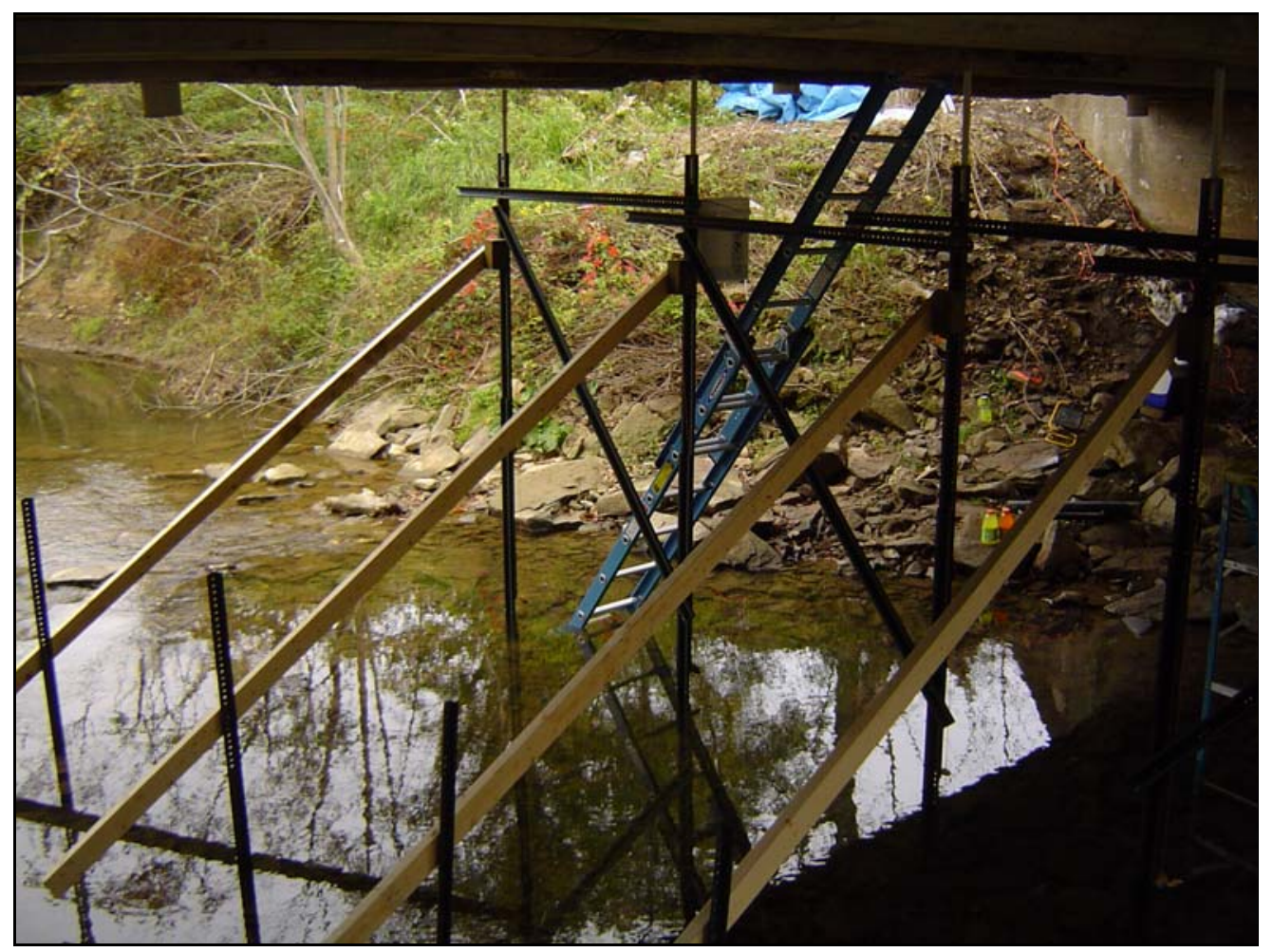

Figure 3.18 LVDT Bracing 


\subsubsection{3- Acceleration Measurement}

The vibration response of the bridge was measured using a PCB Model 393C accelerometer during the dynamic load tests. Due to excessive deterioration on the bottom face of the exterior and adjacent interior beams, the accelerometer was placed on the bottom of beam 3 at the midpoint of the span as shown in Figure 3.19. The accelerometer base plate was mounted to a plywood block which was epoxied to the concrete. This setup assured a solid base for accurate data collection. Acceleration data was collected at a rate of 10,000 scans per second which is the maximum capacity of the data acquisition system.

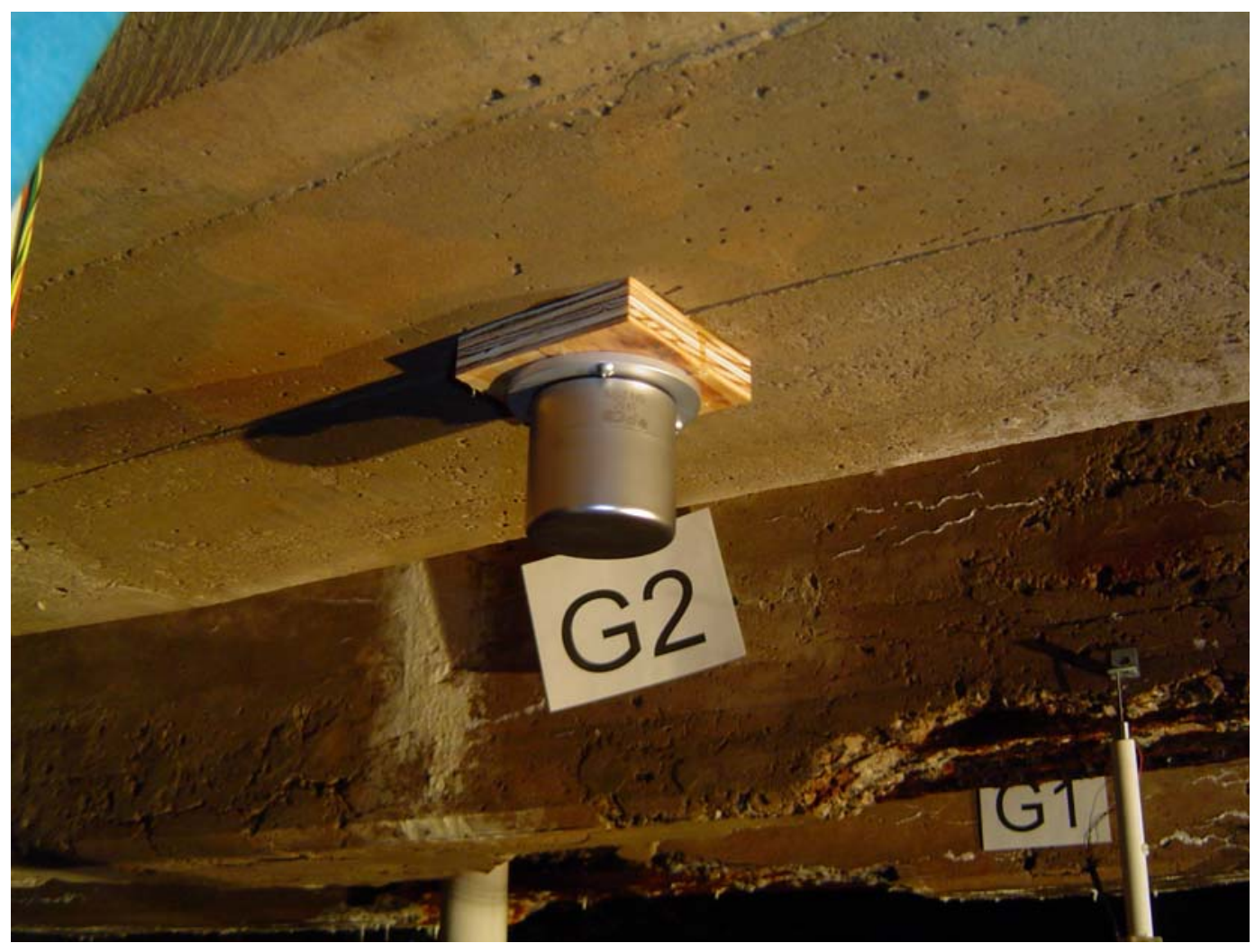

Figure 3.19 Accelerometer Mounting Configuration 


\subsubsection{4- Data Acquisition Setup}

All of the instruments were connected to the data acquisition system and computer setup at the top of the hill near the north abutment as shown previously in Figure 3.20. The field setup consisted of a data acquisition system, computer, printer, and two battery backups. The data processing was handled by a Vishay System 6000 data acquisition system. Strain Smart software version 4.01 produced by Vishay was used to process the data collected during all of the tests. Two APC Smart-UPS 1500 battery back-ups that could provide up to 3.5 hours of battery life were used to insure continuous steady power.

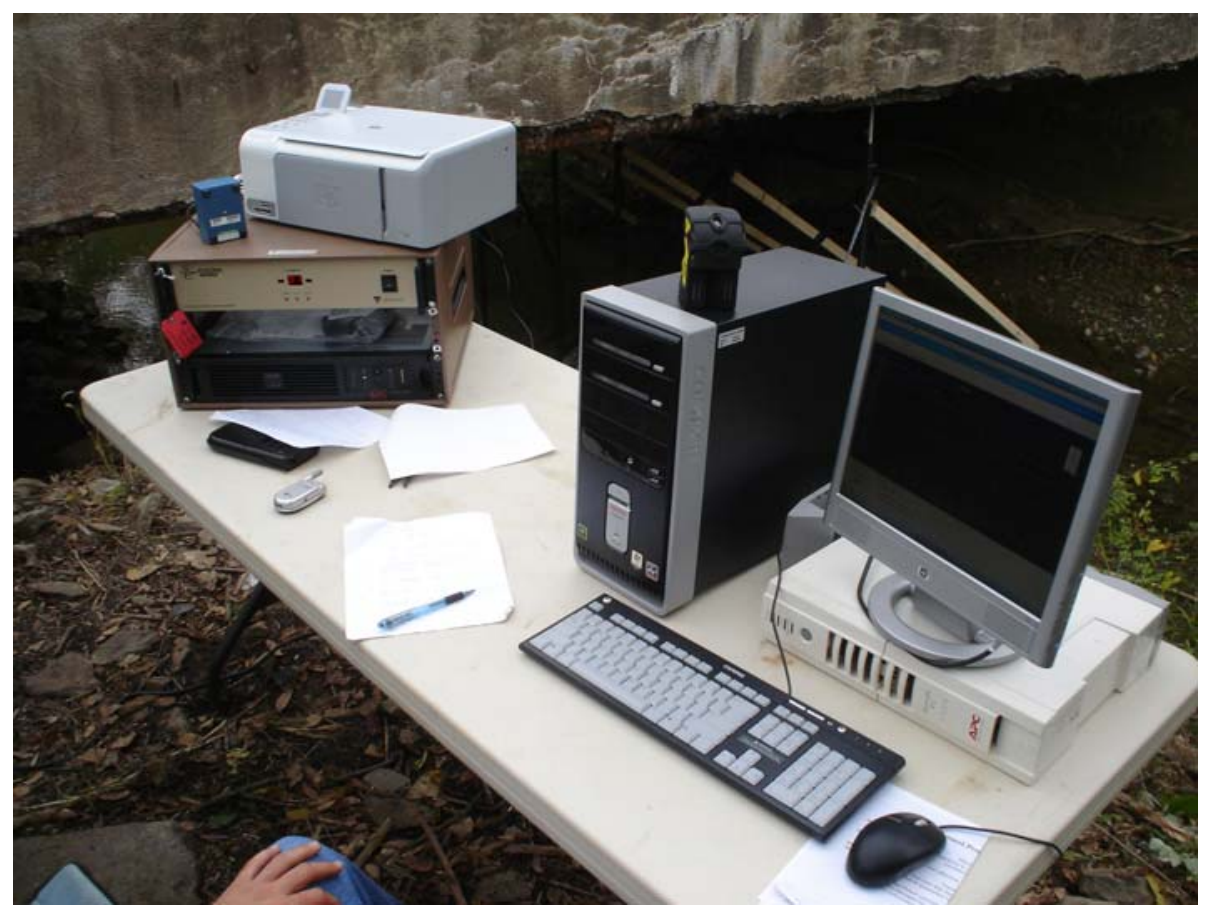

Figure 3.20 Computer and Data Acquisition Setup 


\subsubsection{Trucks}

Two fully loaded tandem dump trucks were provided by PennDOT for use as loading vehicles. The individual wheel loads were measured by PennDOT personnel prior to the load testing (Figure 3.21). The trucks were selected based on their similarity to AASHTO’s standard HS20 loading vehicle. See Table 3.1 for the load comparison between the AASHTO HS20 loading vehicle and the PennDOT provided dump truck used for field testing. Each truck's wheel loading centroid was calculated to determine the truck's placement on the bridge during static load testing. Due to wider tires than expected, both of the trucks could not be placed on the bridge as planned in two of the initial load cases. Some load cases were modified in the field to account for these changes. The initial and actual load cases are described in the following section.

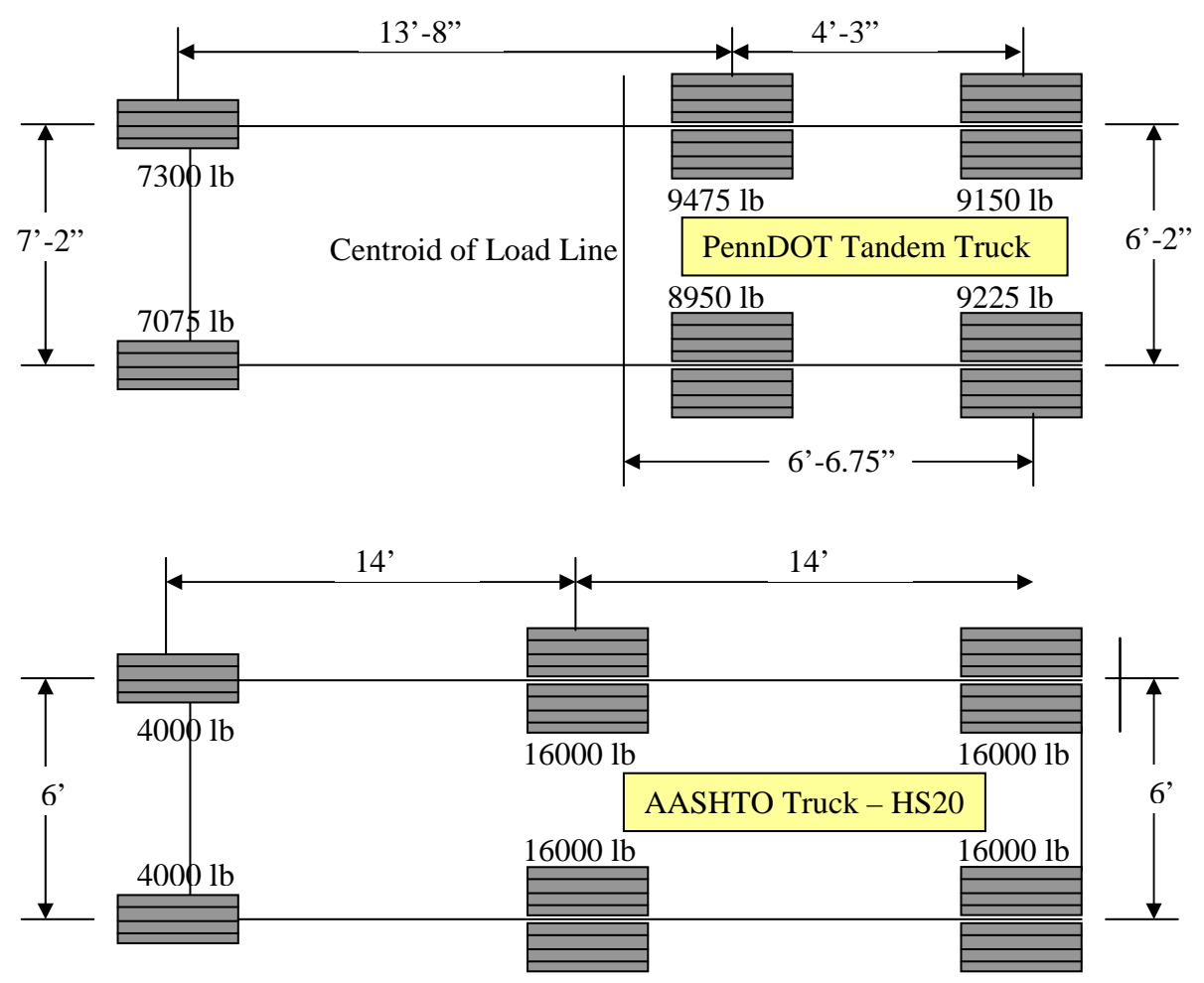

Figure 3.21 Truck Loading 
Table 3.1 Truck Loading Comparison: HS-20 vs. PennDOT

\begin{tabular}{|l|c|c|c|c|c|c|}
\hline \multirow{2}{*}{} & \multicolumn{3}{|c|}{ AASHTO Truck- HS20 } & \multicolumn{2}{c|}{ PennDOT Tandem Truck } \\
\cline { 2 - 7 } & Left & Right & Total & Left & Right & Total \\
\hline \hline Front & 4000 & 4000 & 8000 & 7075 & 7300 & 14375 \\
\hline Rear 1 & 16000 & 16000 & 32000 & 8950 & 9475 & 18425 \\
\hline Rear 2 & 16000 & 16000 & 32000 & 9225 & 9150 & 18400 \\
\hline Total & & & $\mathbf{7 2 0 0 0}$ & & & $\mathbf{5 1 2 0 0}$ \\
\hline
\end{tabular}

\subsubsection{Static Loading}

The initial load cases were designed to place the maximum load onto particular beams as shown in Figures 3.22 and 3.23. Load case 1 was designed to maximize the load effects in the exterior beam by placing the trucks as AASHTO standards would allow to the exterior beam. The maximum load effects in beam 2 were tested by centering a wheel line directly over the beam as shown in load case 2 . Load case 3 was designed to place the maximum load onto beam 3 by placing both trucks as close to the beam as AASHTO standards permit. Both trucks could not fit on the bridge in the configuration shown for load case 3 . In load case 4 a wheel line was placed directly over beam 3. 
Load Case 1
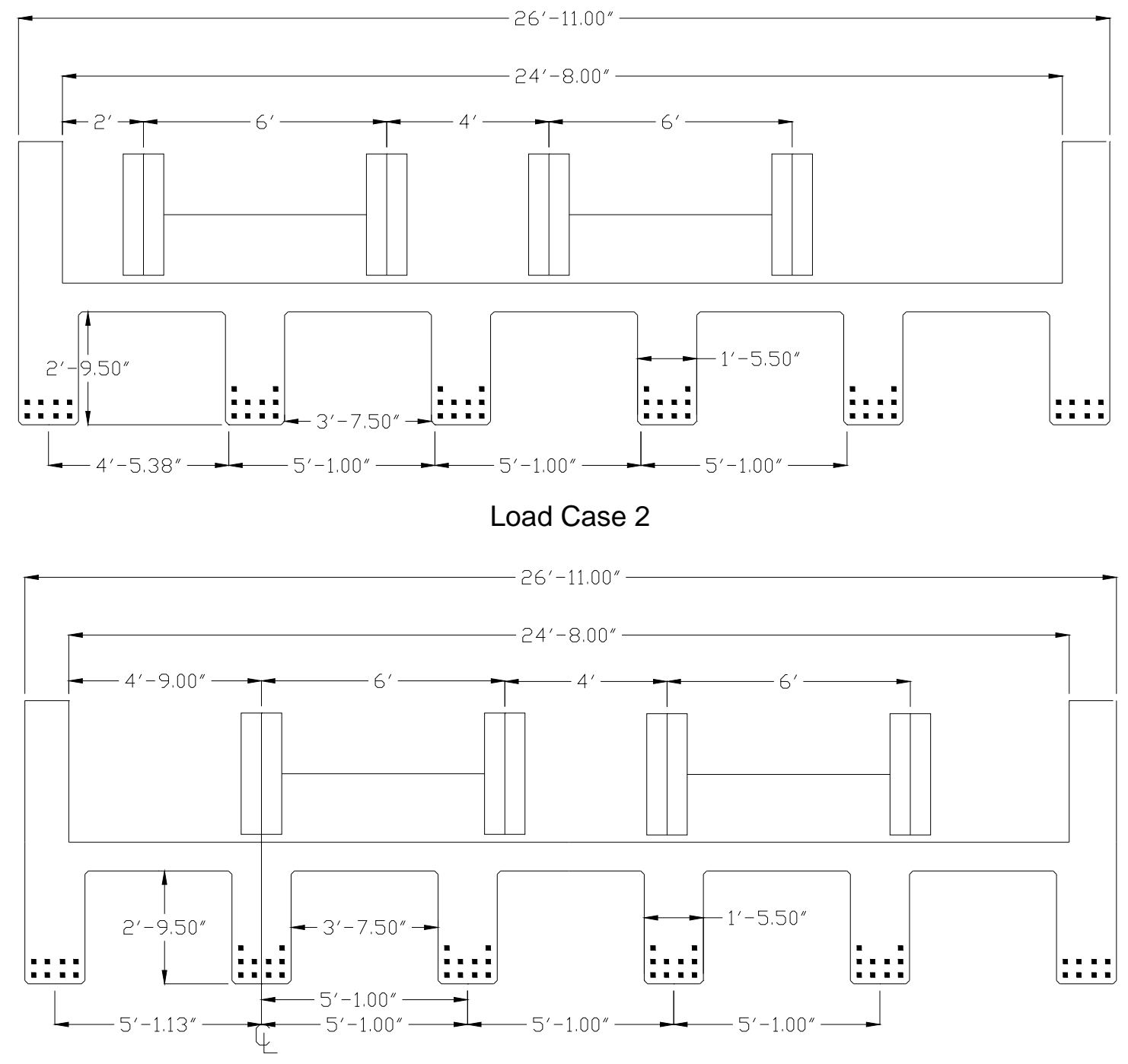

Figure 3.22 Initial Load Cases 1 and 2 
Load Case 3
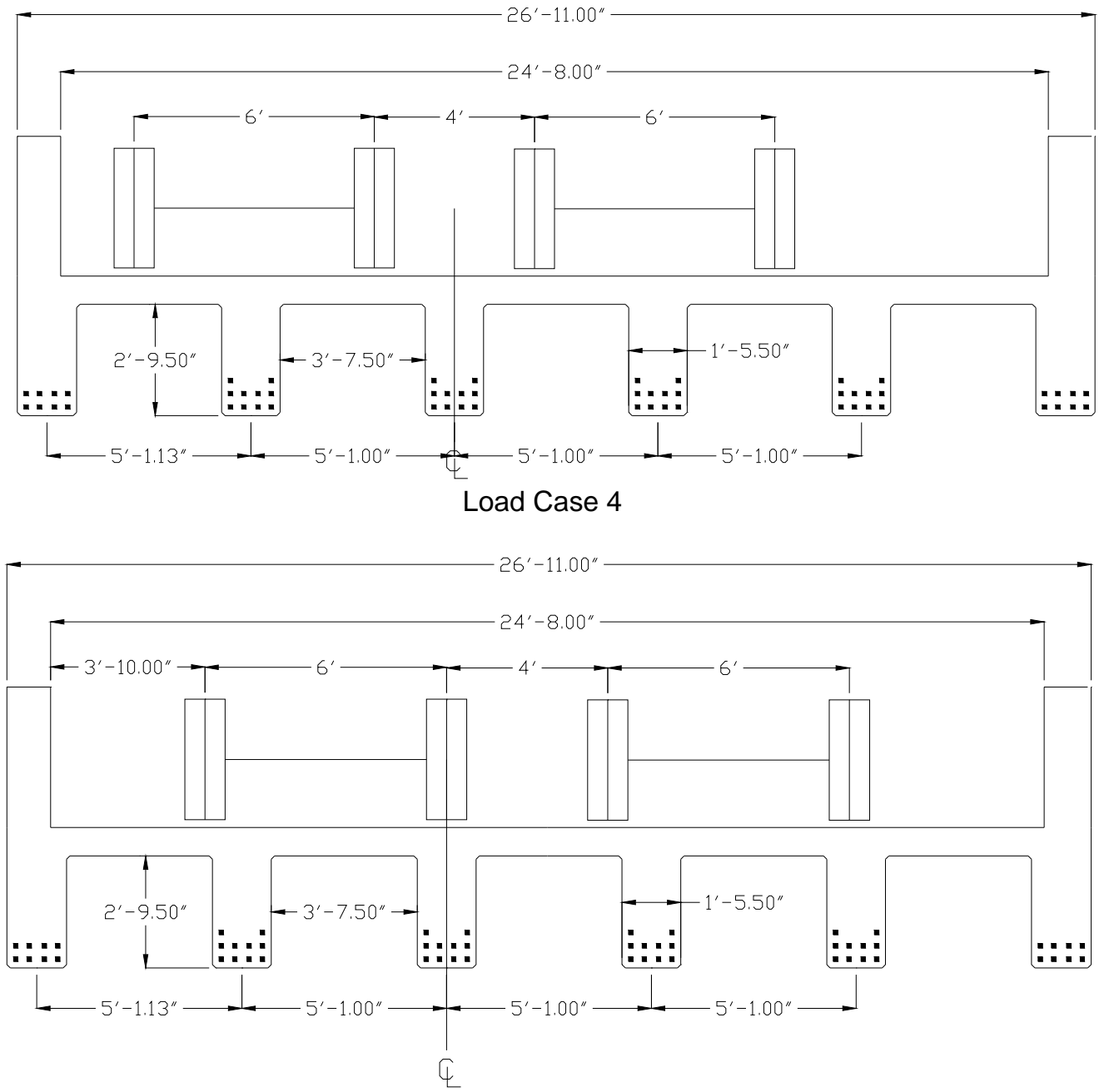

Figure 3.23 Initial Load Cases 3 and 4

The actual load cases used are shown in Figure 3.24. Load case 1 is the same as the initial load case 1 . The maximum force effects in beam 2 were tested twice, once with one truck on the bridge and once with two trucks on the bridge. Load case 2 was not modified. Load case 4 was modified to use only one truck with the wheel line centered over beam 3. Figure 3.25 demonstrates the limiting dimensions of the bridge and the trucks. 

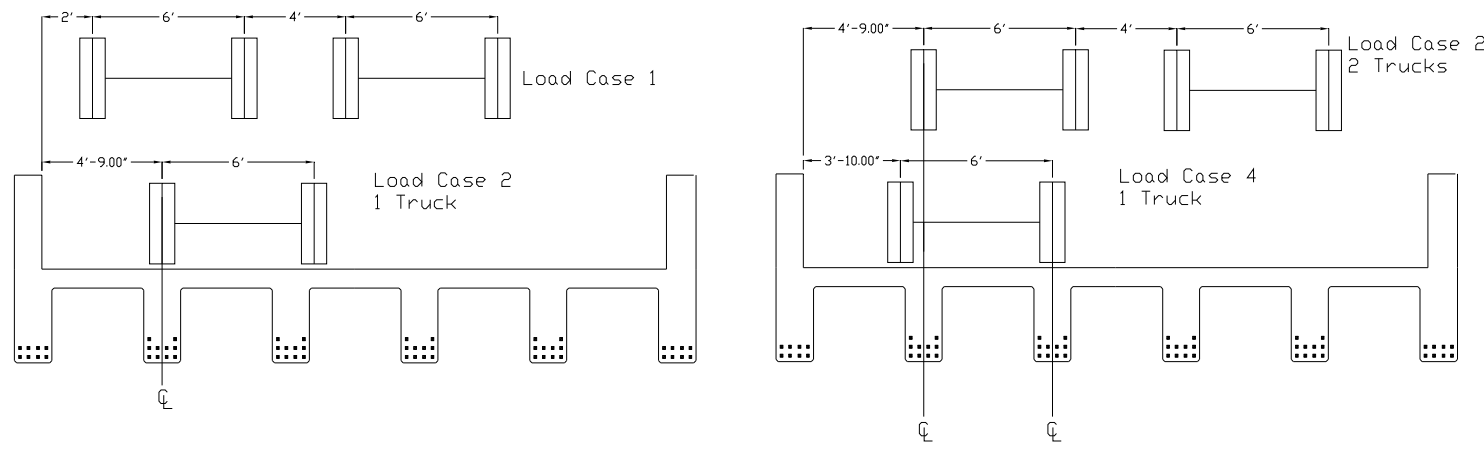

Figure 3.24 Actual Load Cases Used
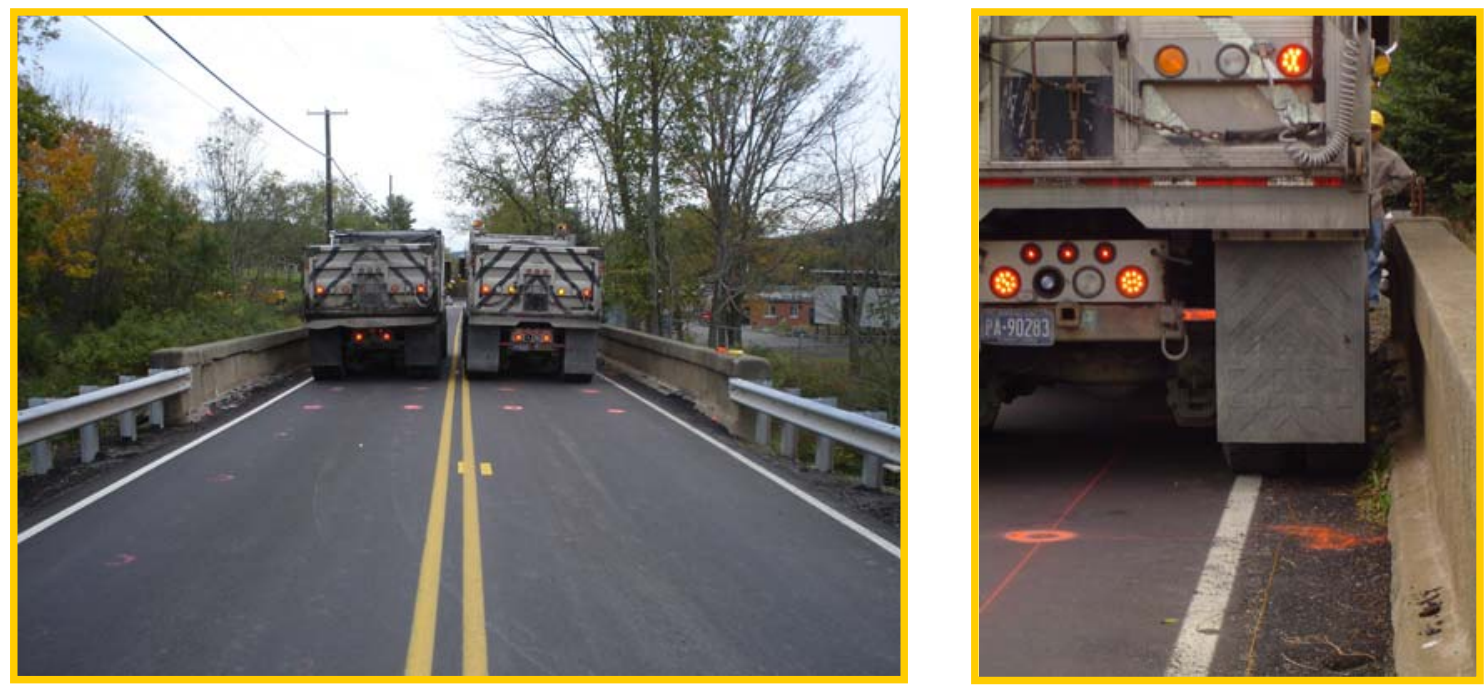

Figure 3.25 Truck Spacing Limitations

Two modified load cases (Figure 3.26) were developed in the field to have an extreme loading even that could be modeled in FE. Each modified load case aligned the trucks back to back over the centerline of the bridge (Figure 3.27). Modified load case 1 consisted of the trucks straddling beam 3. In modified load case 4, the trucks straddled beam 4. It should be noted there are no AASHTO specifications for this type of loading. 

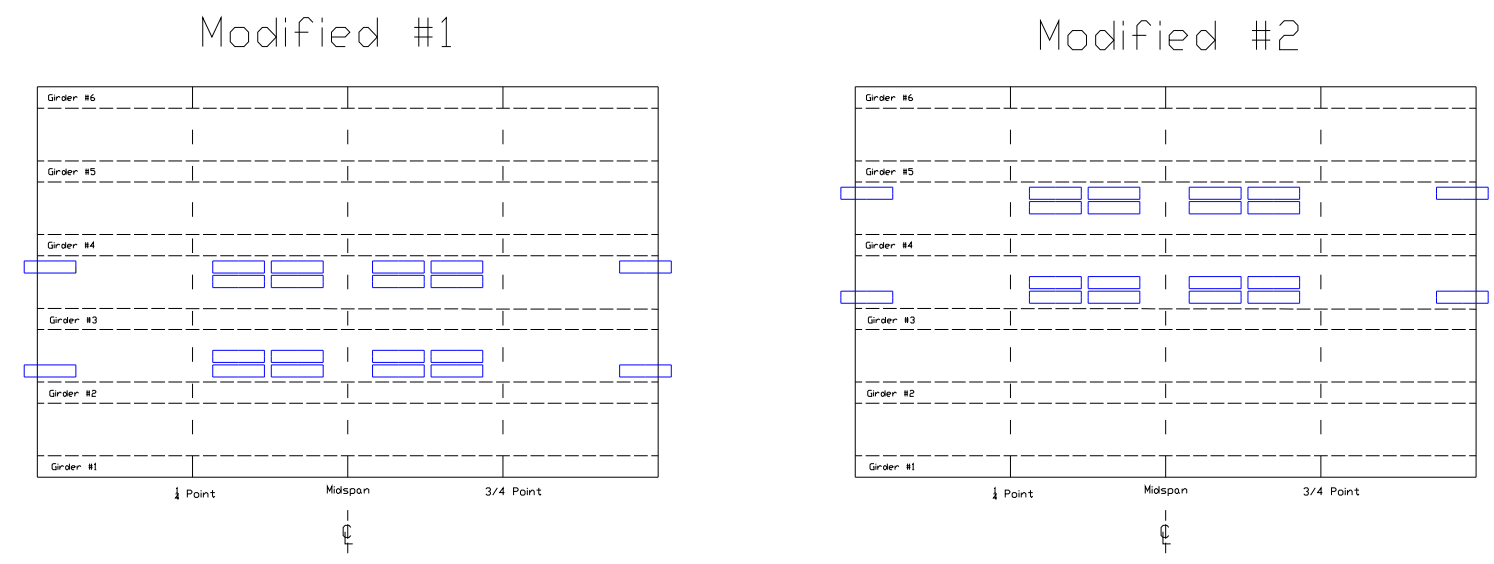

Figure 3.26 Modified Load Cases

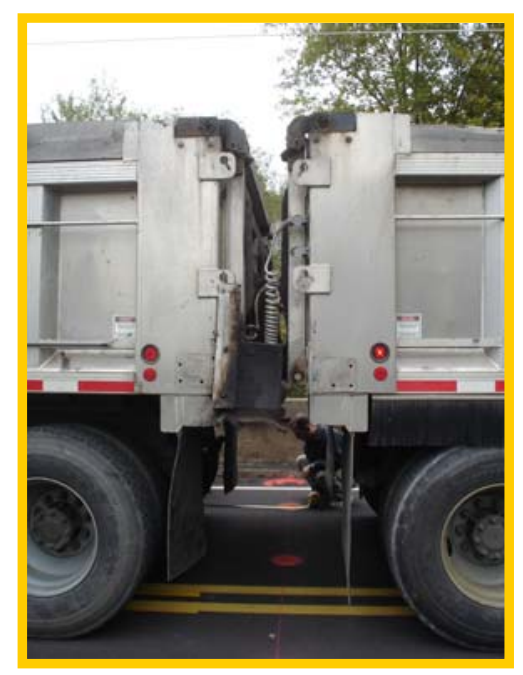

Figure 3.27 Modified Load Case Truck Position

The trucks were lined up on the bridge one at a time and the centroid of the trucks were centered over the quarter, mid, and three-quarters points of the bridge. Data was recorded continuously from the initial time the trucks were moved onto the bridge. Thirty to forty seconds of data were allotted for each truck loading point on the bridge to negate the impact loading response of the bridge caused by truck braking,. Once the deflection measurements leveled off, the truck was moved to the next point until the test was completed. 


\subsubsection{Dynamic Loading}

The bridge was tested under dynamic loading six times. Data for the dynamic tests were recorded at 10,000 scans per second. The first three dynamic tests incorporated a $2 \times 4$ placed at the north support of the bridge. This was done to excite the trucks suspension system as it drove over the bridge approximately 30 miles per hour. A forced vibration was induced in the bridge that enabled the accelerometer to capture the vibration frequencies and damping effects of the bridge once the truck was off the bridge. The second set of dynamic load tests consisted of driving the truck at speeds of 30-50 mph and slamming the brakes once the truck reached the center of the bridge. The damping curve was much clearer in all of the braking tests when compared to the tests using the $2 \times 4$.

\subsubsection{Testing Results}

The load testing deflection results are presented in Figures 3.28-3.31 for the first four load cases. Each line in the figures represent the deflection of the bridge when the positioning of the truck(s) centroid is either at quarter, mid, or three-quarters along the span. The transverse load placement can also be seen in each figure. The maximum deflection in the first four AASHTO allowed load cases was approximately 0.038 inches under beam 3 during load case 1 and beam 4 during load case 2 with two trucks. 


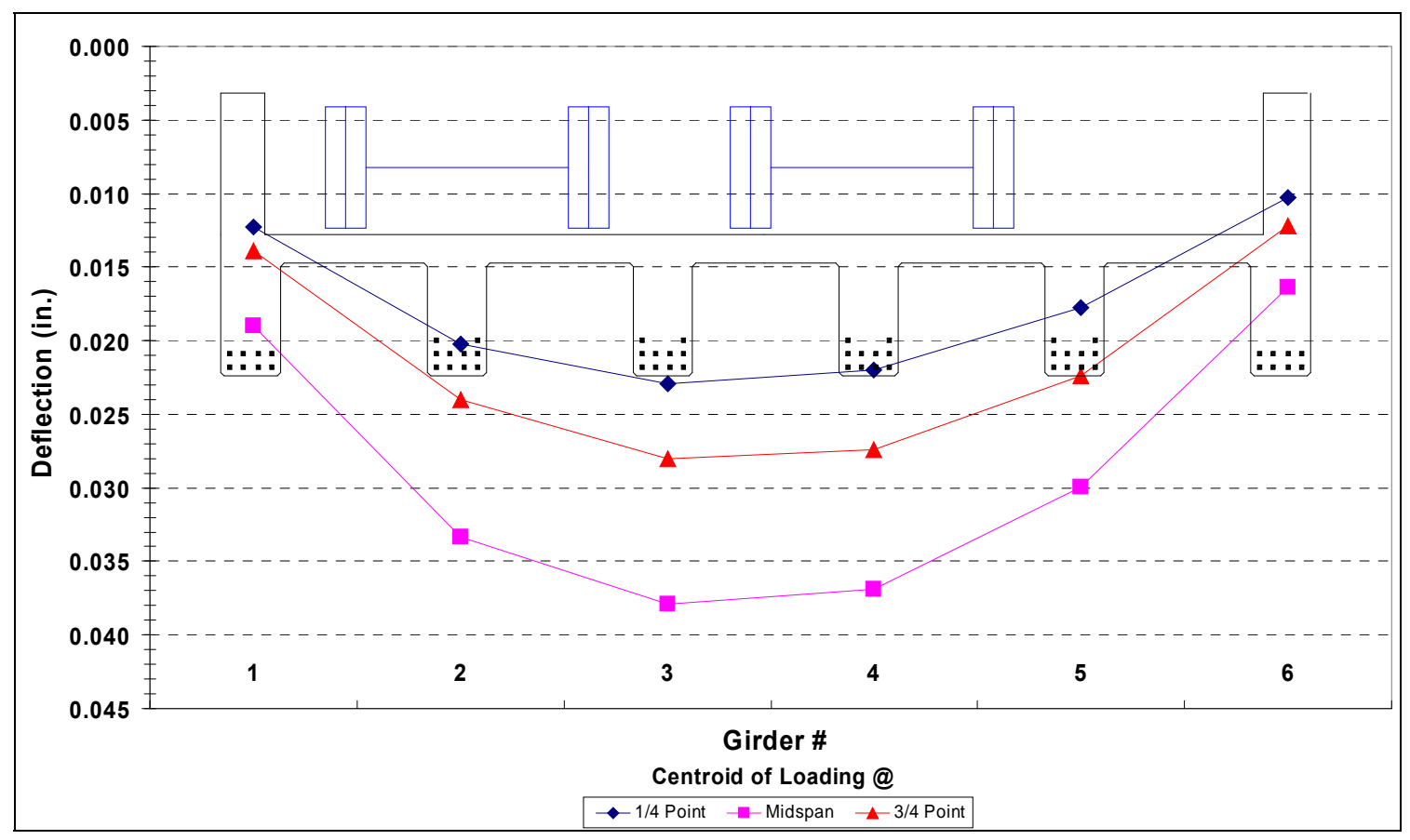

Figure 3.28 Load Case 1 Deflection Results

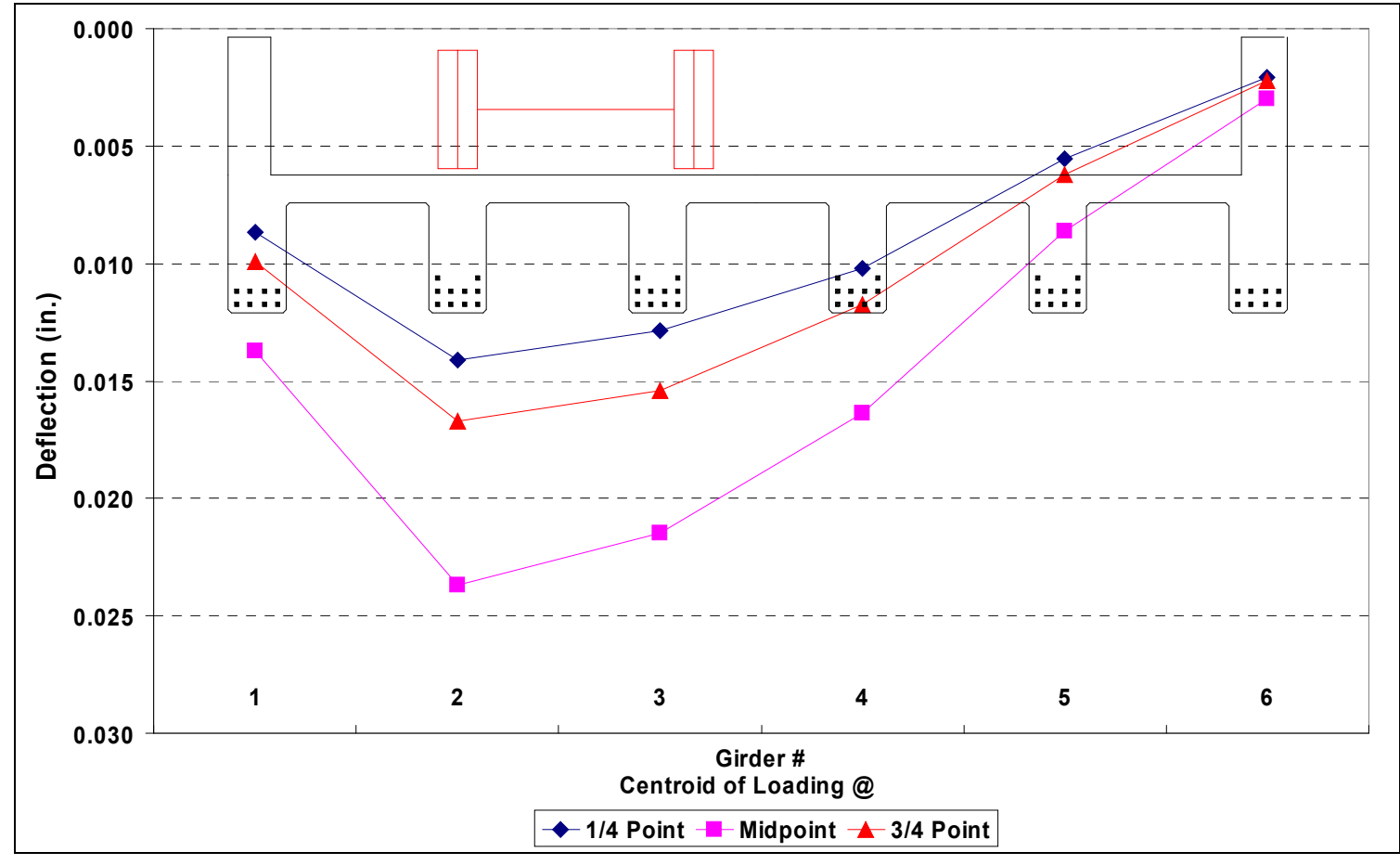

Figure 3.29 Load Case 2- 1 Truck Deflection Results 


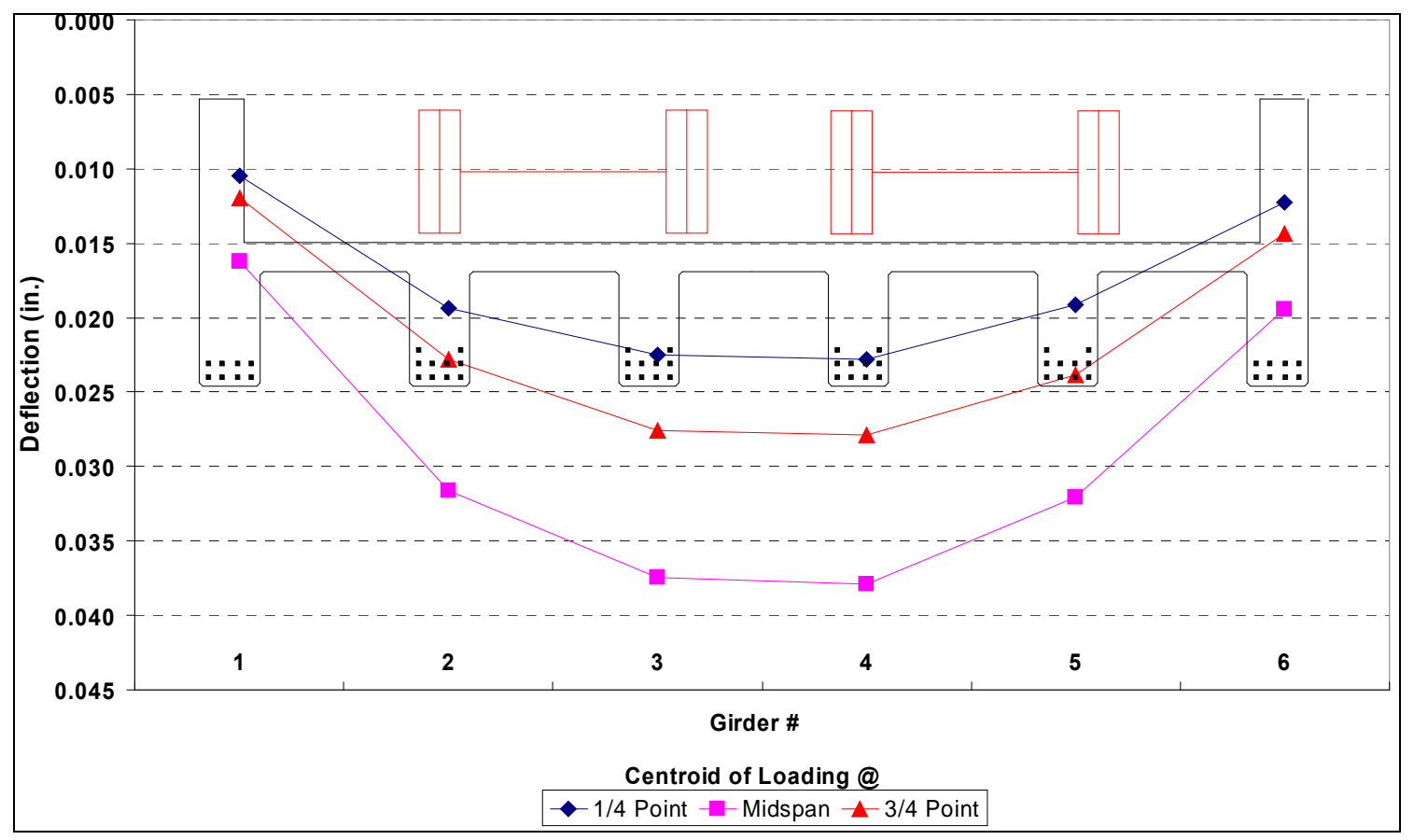

Figure 3.30 Load Case 2-2 Trucks Deflection Results

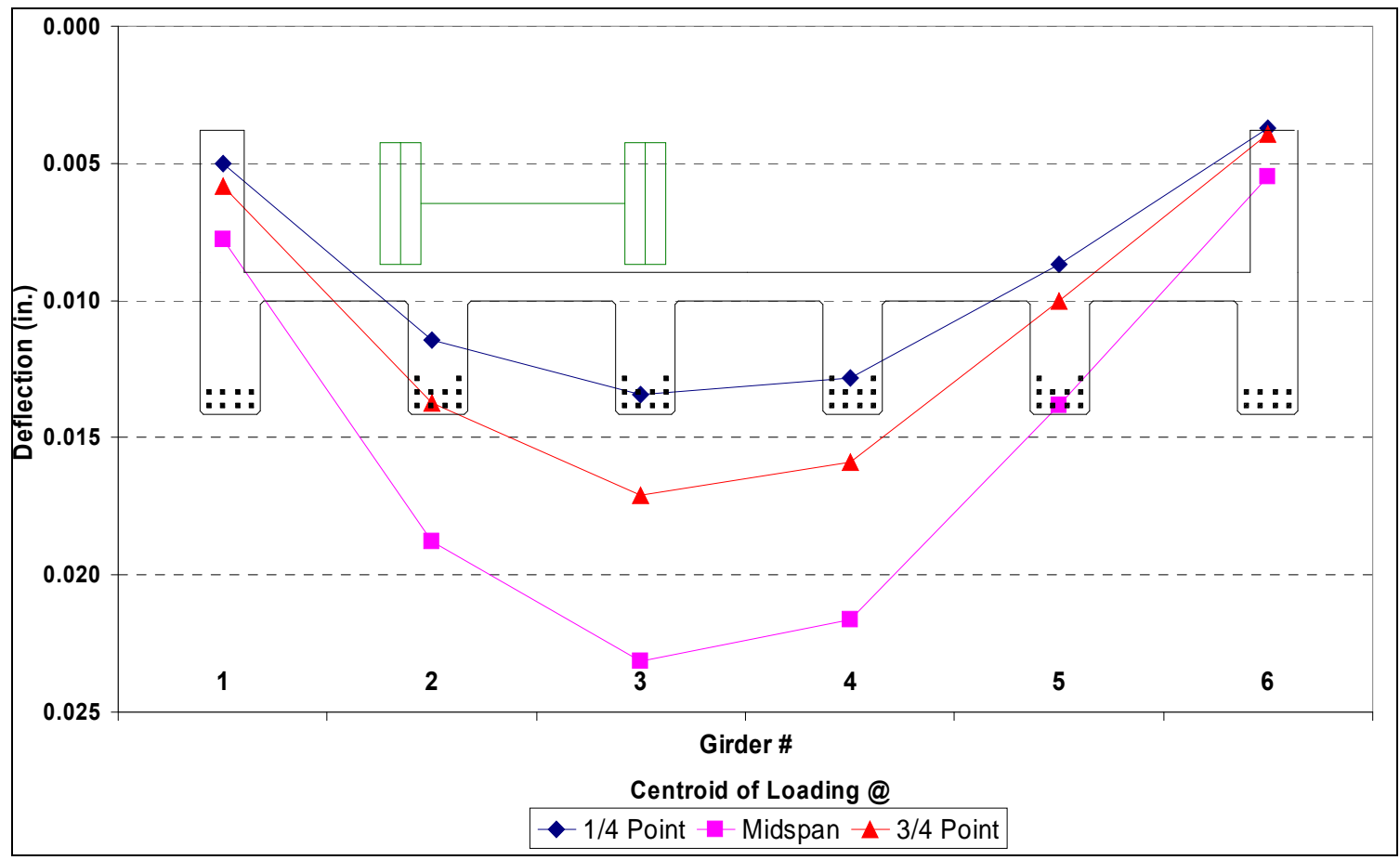

Figure 3.31 Load Case 4 Deflection Results 
The deflection results of modified load cases 1 and 2 are presented in Figure 3.32. The modified load cases are identical except for the beam in which the truck straddled. Beam 1 in modified load case 1 should experience the same loading effects as beam 6 in modified load case 2. This method is also applicable to compare beam 2 with 5 and beam 3 with 4 . Figure 3.32 compares the modified load cases by comparing the beams that are under similar loading conditions. If the beams possess similar strength and stiffness characteristics, they should exhibit similar structural behavioral responses. Any difference in response could indicate variations in strength and stiffness characteristics. Those variations could be caused by uneven levels of deterioration.

Beams 1 and 6 and beams 3 and 4 have very similar deflection responses under an equivalent loading condition. Beams 2 and 5 have very similar deflection responses when the trucks are placed farthest away. When the trucks are closer to either beam 2 or 5, the deflection results differ by approximately 12\%. It can be deduced from Figure 3.32 that opposite beams in the bridge have undergone similar deterioration levels over time. 


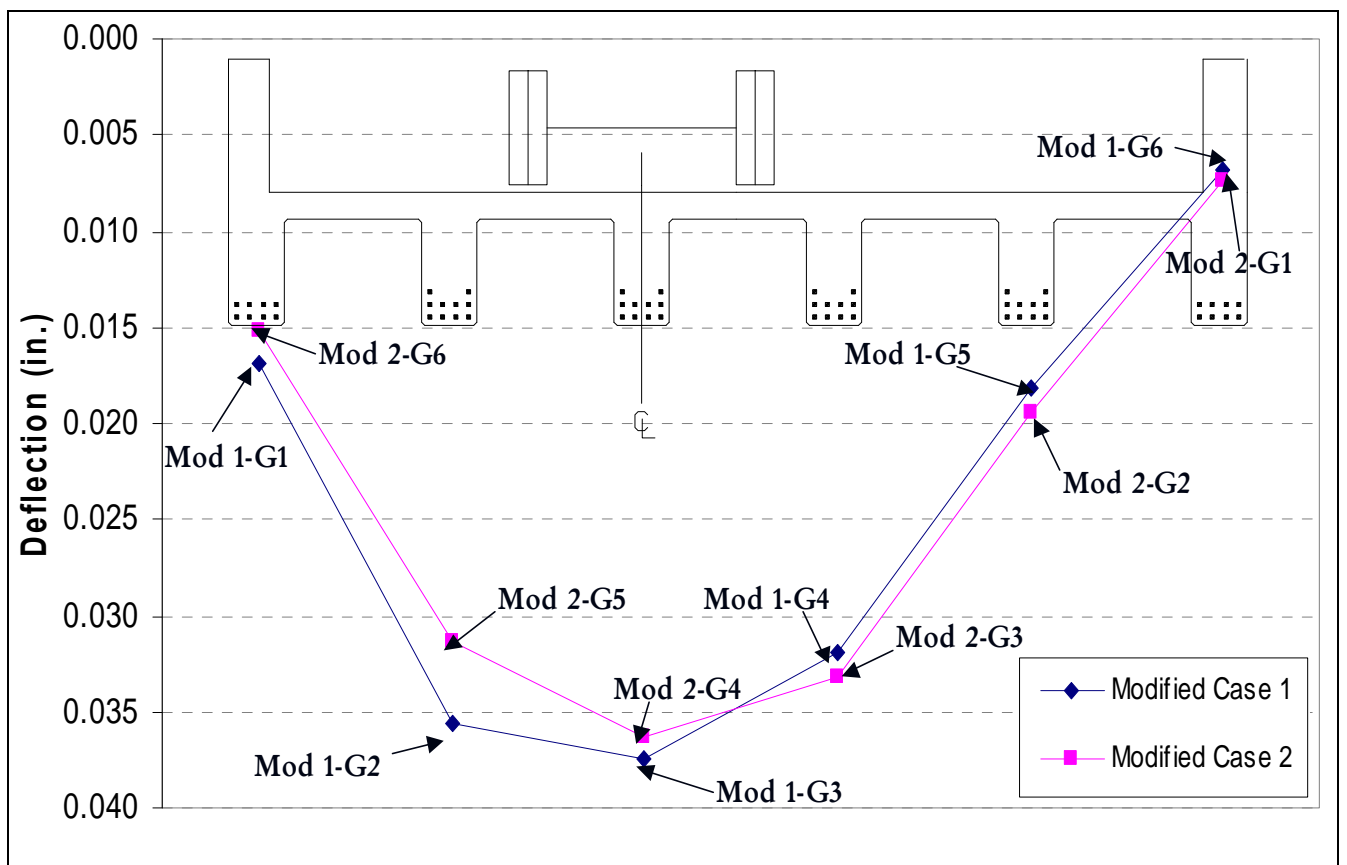

Figure 3.32 Modified Load Case Deflection Comparison

The acceleration response data was analyzed using a Fast Fourier Transform (FFT) program provided within the Strain Smart software. The natural frequency can be extracted from the resulting frequency spectrum analysis graph shown in Figure 3.33. The field tests showed a first mode natural frequency of $14.66 \mathrm{~Hz}$ and a second mode frequency of $21.96 \mathrm{~Hz}$. These results will be compared with the post-strengthened bridge load test data to help determine the effectiveness of the FRP strengthening system. 


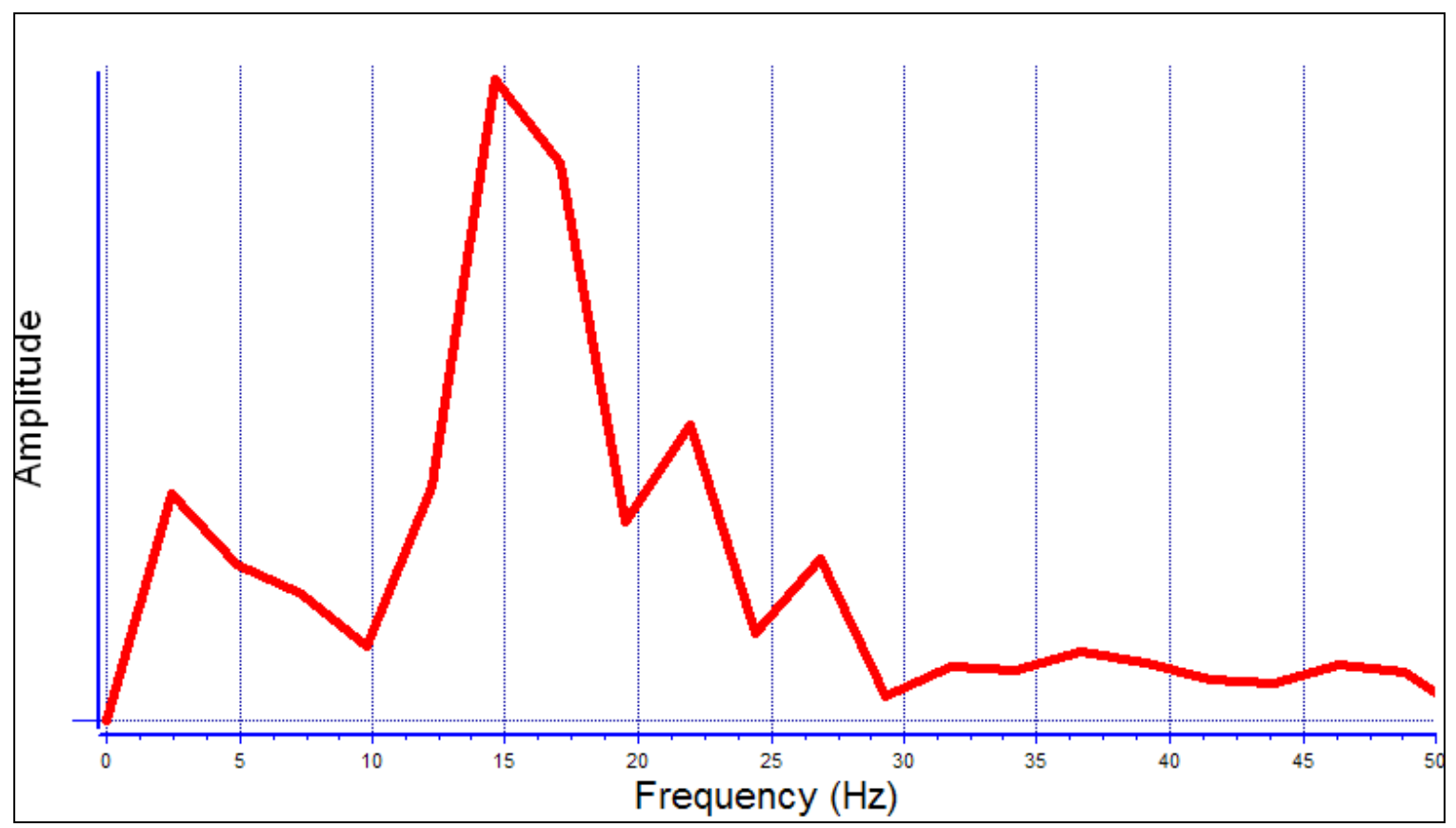

Figure 3.33 Natural Frequency Results 


\section{ChaPTER 4 - STRuCTURAl CONDition ASSESSMENT AND FRP STRENGTHENING DESIGN}

\subsection{INTRODUCTION}

The framework of this chapter is based upon fulfilling two of the tasks included in Phase II of the project as directed by PennDOT-D3. These tasks consist of establishing the bridge's existing structural capacity and determining the required structural capacity. The simplest method of expressing the structural is through load rating analysis. The existing structural capacity is calculated using experimental data and observed site conditions. Strengthened structural capacity requirements are based on a minimum inventory rating factor equal to 1.0 using an HS-20 loading vehicle. With the existing and required capacity established, the FRP strengthening system can be designed.

\subsection{LOAD RATING}

All strength investigations presented in this thesis are based on the bridge's load rating. Load rating factors are used because they directly relate the bridge's structural capacity to the intended required structural capacity. In order to determine a required capacity, a minimum strengthening level must be decided. The HS-20 loading vehicle was selected because of its representation of traditional traffic loadings.

Desirable rating factors are greater than or equal to 1.0. This value indicates the bridge's structural capacity meets or exceeds required structural capacity. In order to 
meet minimum desirable strength levels, the preferred lowest rating factor based on an HS-20 loading vehicle was set at 1.0 for this research.

\subsubsection{BRIdGe Properties}

A realistic representation of the bridge's material strength and geometric properties is necessary to accurately determine the bridge's existing structural capacity. Documentation of the original material properties used during construction was not available for the bridge investigated in this research. Material strength values are suggested by AASHTO for unknown material properties in the Manual for Condition Evaluation of Bridges according to the year it was built. However, AASHTO guidelines allow for the use of experimental values when available.

The experimental values for concrete compressive strength ranged from 2,000 to 5,000 psi. The deck core samples resulted in an average concrete compressive strength of approximately 5,000 psi. However, the beam concrete appeared to be in a much more deteriorated state. Field tests indicated a beam concrete compressive strength close to 2,000 psi. The AASHTO Manual for Condition Evaluation of Bridges suggests a value of 2,500 psi for bridges built prior to 1954 (AASHTO, 1994). In the interest of conservatism and safety, a concrete compressive strength of 3,000 psi was used in this research.

The AASHTO Manual suggests a yield strength of 33 ksi for unknown structural steel grades on bridges built prior to 1954. However, the experimental value for steel yield strength was approximately $37 \mathrm{ksi}$. Since the steel yield strength was directly tested and the section loss could be measured, a value of $36 \mathrm{ksi}$ was used. This value allows for conservatism while accurately depicting the steel yield strength. 
Section loss measurements were documented in areas of exposed steel reinforcement. In areas where reinforcement section losses could not be measured, an assumed $10 \%$ reduction in cross sectional area was used. The section loss assumption was used for all steel reinforcement in beams 3 and 4 as well as the shear reinforcement for the remaining beams.

\subsubsection{LOAD RATING RESUltS}

The load ratings reported in this research are based on AASHTO Load Factor Rating methodologies using an HS-20 truck loading. The calculations follow procedures and guidelines suggested by AASHTO Standard Specifications for Highway Bridges (1996) and AASHTO Manual for Condition Evaluation of Bridges (1994). Each beam’s flexural and shear load rating factors were calculated to investigate the deteriorated capacity of the bridge.

\subsubsection{Beam Flexural Load Rating}

The flexural load rating calculations are based on the assumption that the flexural reinforcement configuration near the midspan region of the bridge is constant throughout the entire span length. This assumption is valid because the maximum moment is always located near the midspan region for simply supported structures. This assumption follows PennDOT’s BAR7 analysis methods.

Table 4.1 shows the results of the flexural capacity load rating analysis. The inventory rating factors based on moment capacity for all of the beams are less than 1.0 due to the lack of tensile reinforcing steel and deteriorated section losses. Beam 5 has the lowest flexural inventory load rating factor at 0.58 . The flexural operating rating factor 
of beam 5 is also below 1.0 which could suggest that load posting is required. The existing moment capacity and required moment capacity are also reported in Table 4.1.

Table 4.1 Load Rating Results- Moment

\begin{tabular}{|l|c|c|c|c|c|c|c|}
\hline \multicolumn{2}{|c|}{} & \multicolumn{7}{|c|}{ Beam \# } \\
\cline { 3 - 9 } \multicolumn{2}{c|}{} & 1 & 2 & 3 & 4 & 5 & 6 \\
\hline \hline Existing Inventory Rating Factor & & 0.72 & 0.91 & 0.90 & 0.90 & 0.58 & 0.91 \\
\hline Existing Operating Rating Factor & & 1.20 & 1.52 & 1.50 & 1.50 & 0.96 & 1.52 \\
\hline Existing Moment Capacity & (kip·ft) & 614 & 1107 & 1101 & 1101 & 909 & 673 \\
\hline Required Resisting Moment Strength & (kip·ft) & 701 & 1163 & 1163 & 1163 & 1163 & 701 \\
\hline
\end{tabular}

Beams 2, 3, 4 and 6 require an increase in flexural capacity of approximately 5\% to achieve an inventory rating of 1.0. Beams 1 and 5 require an increase in flexural capacity of approximately $14 \%$ and $30 \%$ respectively. While these figures are inherently conservative based on AASHTO standards, these results suggest that this bridge is a prime candidate for flexural FRP strengthening. Higher, less conservative forms of analysis (e.g. FEM) could result in flexural load rating factors that suggest no strengthening is required.

\subsubsection{Beam Shear Load Rating}

The shear reinforcement layout in a beam is typically varied along the span length according to required shear capacities at different section. For analysis purposes, the beams were broken into section depending on different spacing arrangements of vertical and inclined shear reinforcement as shown in Figure 4.1. The required structural demands and capacities at the section breaks were computed and used for load rating calculations. 


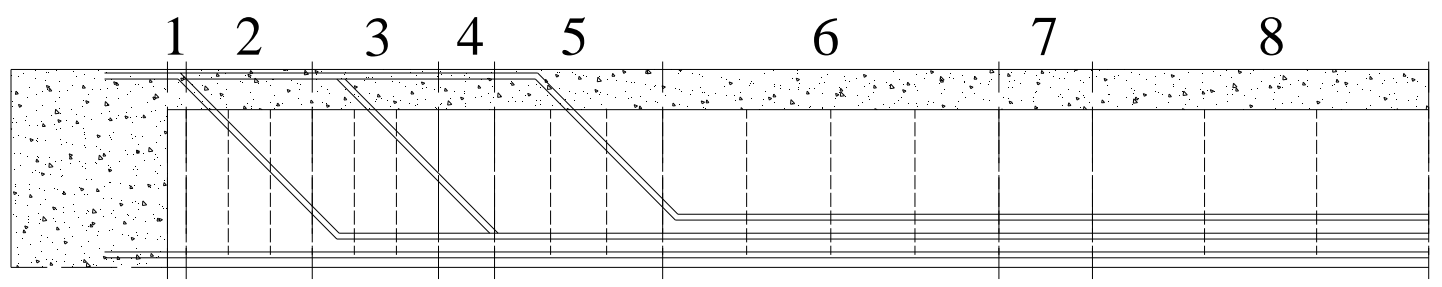

Figure 4.1 Example Bridge Sectioning

During the concrete repair stage of rehabilitating this bridge, PennDOT officials noted that minimal deterioration effects were present on the exposed shear reinforcement. WVU researchers applied a loss of $10 \%$ to the cross sectional area in all sections of shear reinforcement to be conservative. This method accounts for the conservatism inherent in AASHTO guidelines and specifications.

Table 4.2 shows the results of the shear analysis and load rating calculations. The existing capacity of the exterior beams is sufficient to satisfy the loading requirement of an HS-20 truck. No further strengthening is required for exterior beams to account for the section where the original shear reinforcement was omitted.

Identical sections for each interior beam require shear strengthening to achieve the minimum satisfactory load rating. As shown in Figure 4.2, the interior beam existing shear inventory rating factors for sections 5, 6, and 8 are inadequate. Shear strengthening is required in section 5 to account for the incline bars omitted from the original design. Section 6 was built according to the original design plan. However, it required strengthening to meet HS20 loading vehicle demands. Additional reinforcement is needed to reach the required shear capacity in Section 8. The required shear resistance would have been provided by the missing vertical stirrups that were included in the original design plans. 
Table 4.2 Load Rating Results- Shear

\begin{tabular}{|c|c|c|c|c|c|c|c|c|c|c|}
\hline & \multicolumn{8}{|c|}{ Stirrup Section \# } \\
\hline & & & 1 & 2 & 3 & 4 & 5 & 6 & 7 & 8 \\
\hline \multirow{4}{*}{$\begin{array}{c}\text { Beam } \\
1\end{array}$} & Exsiting Inventory Rating Factor & & 4.17 & 5.86 & 2.48 & 2.38 & 2.52 & 2.54 & 3.45 & 2.92 \\
\hline & Existing Operating Rating Factor & & 6.96 & 9.78 & 4.14 & 3.98 & 4.20 & 4.24 & 5.75 & 4.87 \\
\hline & Existing Shear Capacity & (kips) & 163.2 & 228.6 & 107.1 & 96.0 & 96.0 & 85.0 & 79.0 & 62.0 \\
\hline & Required Shear Resistance & (kips) & 65.3 & 67.2 & 61.4 & 56.0 & 53.5 & 46.1 & 31.3 & 27.3 \\
\hline \multirow{4}{*}{$\begin{array}{c}\text { Beam } \\
2\end{array}$} & Exsiting Inventory Rating Factor & & 1.32 & 1.93 & 2.13 & 2.20 & 0.75 & 0.77 & 1.12 & 0.95 \\
\hline & ting Rating Factor & & 2.20 & 3.22 & 3.56 & 3.67 & 1.24 & 1.28 & 1.88 & 1.59 \\
\hline & Existing Shear Capacity & (kips) & 163.3 & 227.9 & 227.9 & 216.9 & 95.3 & 84.3 & 78.3 & 61.3 \\
\hline & Required Shear Resistance & (kips) & 136.0 & 141.9 & 130.3 & 120.0 & 115.2 & 100.6 & 71.5 & 63.9 \\
\hline \multirow{4}{*}{$\begin{array}{c}\text { Beam } \\
3\end{array}$} & Exsiting Inventory Rating Factor & & 1.32 & 1.93 & 2.13 & 2.20 & 0.75 & 0.77 & 1.12 & 0.95 \\
\hline & Existing Operating Rating Factor & & 2.20 & 3.22 & 3.56 & 3.67 & 1.24 & 1.28 & 1.88 & 1.59 \\
\hline & Existing Sh & (kips) & 163.3 & 227.9 & 227.9 & 216.9 & 95.3 & 84.3 & 78.3 & 61.3 \\
\hline & Requ & (kips) & 136.0 & 141.9 & 130.3 & 120.0 & 115.2 & 100.6 & 71.5 & 63.9 \\
\hline \multirow{4}{*}{$\begin{array}{c}\text { Beam } \\
4\end{array}$} & Exsiting Inventory Rating Factor & & 1.32 & 1.93 & 2.13 & 2.20 & 0.75 & 0.77 & 1.12 & 0.95 \\
\hline & Existing Operating Rating Factor & & 2.20 & 3.22 & 3.56 & 3.67 & 1.24 & 1.28 & 1.88 & 1.59 \\
\hline & Existing Shear Capacity & (kips) & 163.3 & 227.9 & 227.9 & 216.9 & 95.3 & 84.3 & 78.3 & 61.3 \\
\hline & $\operatorname{Req}$ & (kips) & 136.0 & 141.9 & 130.3 & 120.0 & 115.2 & 100.6 & 71.5 & 63.9 \\
\hline \multirow{4}{*}{$\begin{array}{c}\text { Beam } \\
5\end{array}$} & g Factor & & 1.32 & 1.93 & 2.13 & 2.20 & 0.75 & 0.77 & 1.12 & 0.95 \\
\hline & ting Rating Factor & & 2.20 & 3.22 & 3.56 & 3.67 & 1.24 & 1.28 & 1.88 & 1.59 \\
\hline & Existing Shear Capacity & (kips) & 163.3 & 227.9 & 227.9 & 216.9 & 95.3 & 84.3 & 78.3 & 61.3 \\
\hline & Required Shear Resistance & (kips) & 136.0 & 141.9 & 130.3 & 120.0 & 115.2 & 100.6 & 71.5 & 63.9 \\
\hline \multirow{4}{*}{$\begin{array}{c}\text { Beam } \\
6\end{array}$} & Exsiting Inventory Rating Factor & & 4.17 & 5.86 & 2.48 & 2.38 & 2.52 & 2.54 & 3.45 & 2.92 \\
\hline & ing Factor & & 6.96 & 9.78 & 4.14 & 3.98 & 4.20 & 4.24 & 5.75 & 4.87 \\
\hline & Exist & (kips) & 163.2 & 228.6 & 107.1 & 96.0 & 96.0 & 85.0 & 79.0 & 62.0 \\
\hline & Required Shear Resistance & (kips) & 65.3 & 67.2 & 61.4 & 56.0 & 53.5 & 46.1 & 31.3 & 27.3 \\
\hline
\end{tabular}

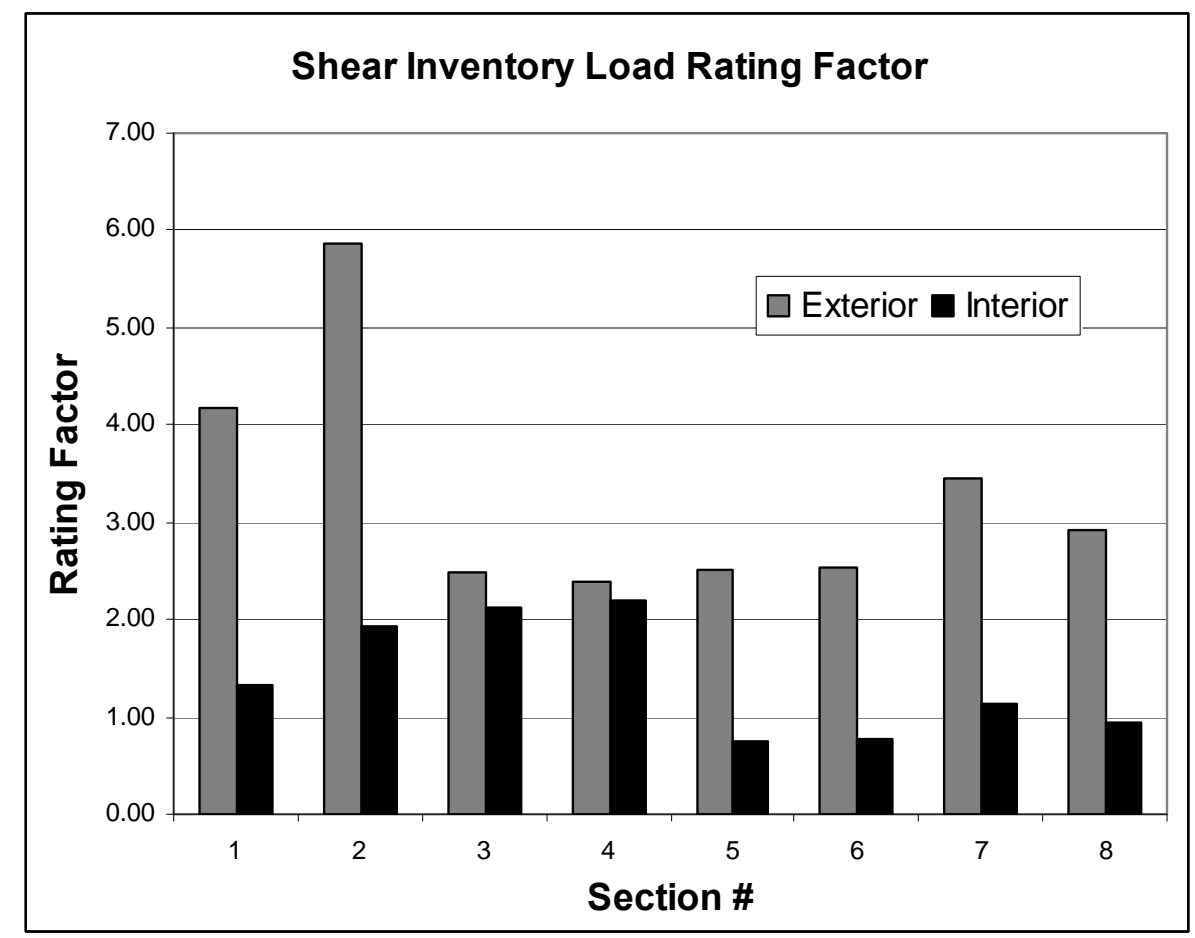

Figure 4.2 Shear Inventory Rating Factor Results 


\subsection{Proposed FRP StREngThENING System}

The FRP design presented in this section satisfy the original objective of developing a strengthening system for PennDOT bridge \#49-4012-0250-1032. These designs meet or exceed all required strength and serviceability levels. The original design capacity requirements of the bridge were unknown. Several target baselines were investigated including restoring the original capacity, an HS-25 truck loading, and the current LRFD loading of an HL-93 truck. Table 4.3 shows the differences in maximum required force effects based on the investigated alternative strengthening design requirements.

Table 4.3 Design Requirement Differences

\begin{tabular}{|l|c|c|}
\hline $\begin{array}{c}\text { Design } \\
\text { Requirement }\end{array}$ & $\begin{array}{c}\text { Mu } \\
\text { (kip·ft) }\end{array}$ & $\begin{array}{c}\mathbf{V}_{\mathbf{u}} \text { Sec. 1 } \\
\text { (kips) }\end{array}$ \\
\hline \hline HS-20 Truck & 1163.3 & 136.1 \\
\hline Original Design & 1456.5 & 163 \\
\hline HS-25 & 1313.5 & 165.7 \\
\hline HL-93 Truck & 1345.2 & 166.4 \\
\hline
\end{tabular}

The designs presented in this thesis are preliminary designs. The final designs may differ from WVU's suggested designs. It should also be noted that engineering judgment was used to determine the sheet widths, spacing and placement of the FRP strengthening system to provide the most economical and practical design possible. Some of the FRP shear reinforcement layouts are altered slightly from the program output to allow for consistent spacing and elimination of overlaps between the FRP sheets. Some of the placements of the strips (for shear strengthening) are altered slightly from the program output to allow for consistency of spacing and minimization of overlaps between the FRP sheets. 


\subsubsection{Assumptions}

Several basic assumptions are made in the FRP strengthening design using externally applied composites. Conditions of equilibrium based on internal stresses and strain compatibility are used as the basis for strength analysis and design. The assumptions made in the analysis are:

- Design calculations are based on actual dimensions, internal reinforcing steel layout, and material properties of the existing member under analysis.

- The material properties used are constant throughout the cross-section of the member.

- Plane sections remain plane under loading. The resulting strains in the reinforcement and concrete are directly proportional to the distance from the neutral axis.

- The maximum usable concrete strain is $0.003 \mathrm{in} / \mathrm{in}$.

- The tensile strength of the concrete is neglected.

- There is no relative slip between the external reinforcement and the concrete.

- The shear deformation within the adhesive layer is neglected.

- The FRP reinforcement has a linear elastic stress-strain relationship up to failure.

These assumptions follow guidelines set forth in ACI 440.2R-02 and classical beam theory assumptions. 


\subsubsection{Beam Strengthening Design}

This section summarizes the results of the beam FRP strengthening design. The calculations used are presented in Appendix F and the detailed results of the calculations are presented in Appendix G.

As stated previously, the goals of the rehabilitation design were to provide a safe, efficient, economical and practical FRP strengthening system. The strengthening level used updates the bridge’s structural capacity to current design standard requirements.

Attention was paid to the strip widths and spacing within a section to provide room for contaminants to escape the concrete. The final strip widths of the recommended designs also considered the FRP strengthening construction process. The designs try to use similar strip widths to ease fabrication and maximize the usable FRP within a roll.

The final recommended FRP strengthening designs are given in Figures 4.3-4.8. These figures show a simple qualitative representation of the suggested FRP strengthening design. For a complete description of the FRP strengthening scheme, consult Appendix H. The calculation steps for FRP strengthening are presented in Chapter 5. The equations used for FRP design are shown in Appendix F. The flexural and shear variable results used for FRP strengthening are tabulated in Appendix G.

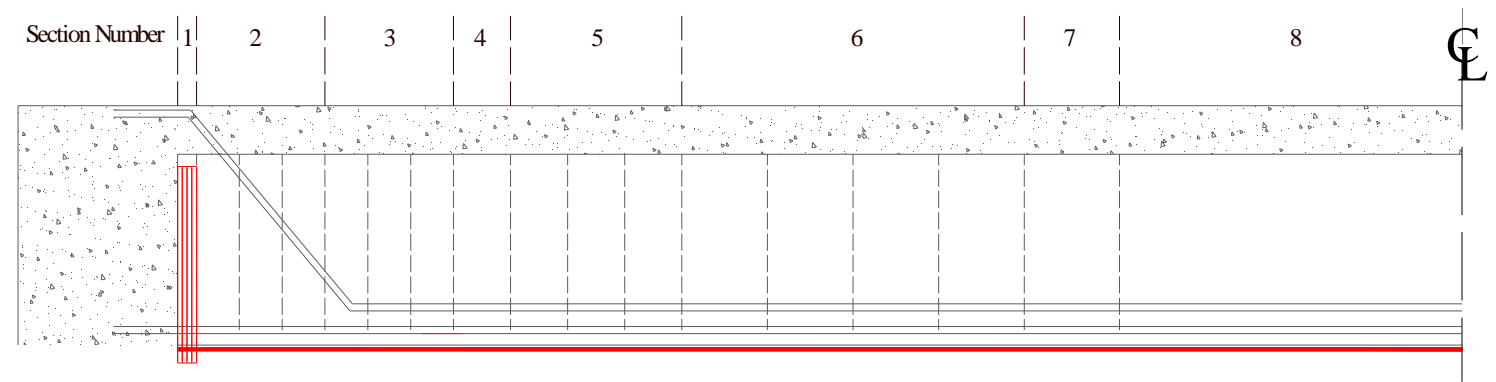

Figure 4.3 Beam 1 FRP Strengthening Design 


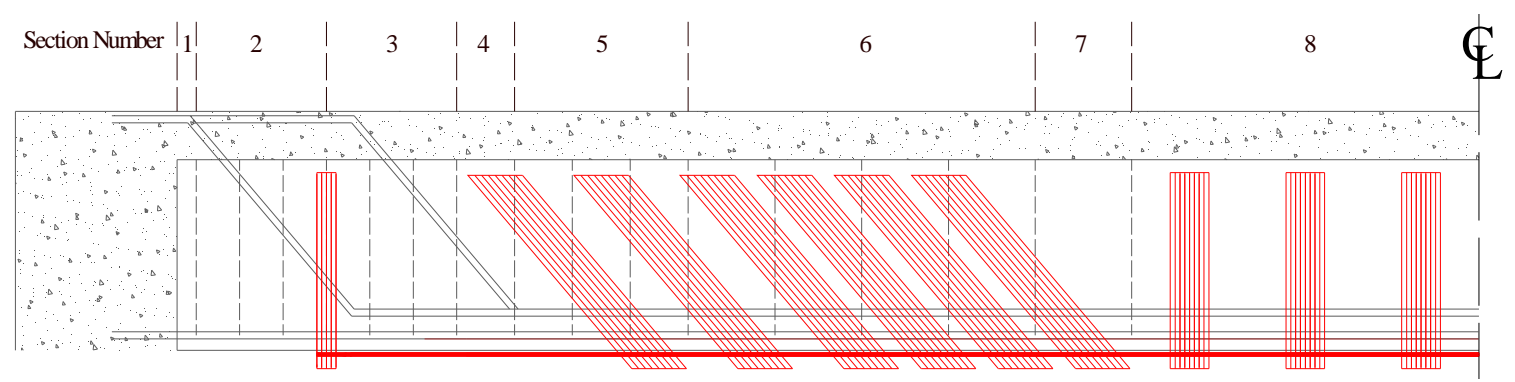

Figure 4.4 Beam 2 FRP Strengthening Design

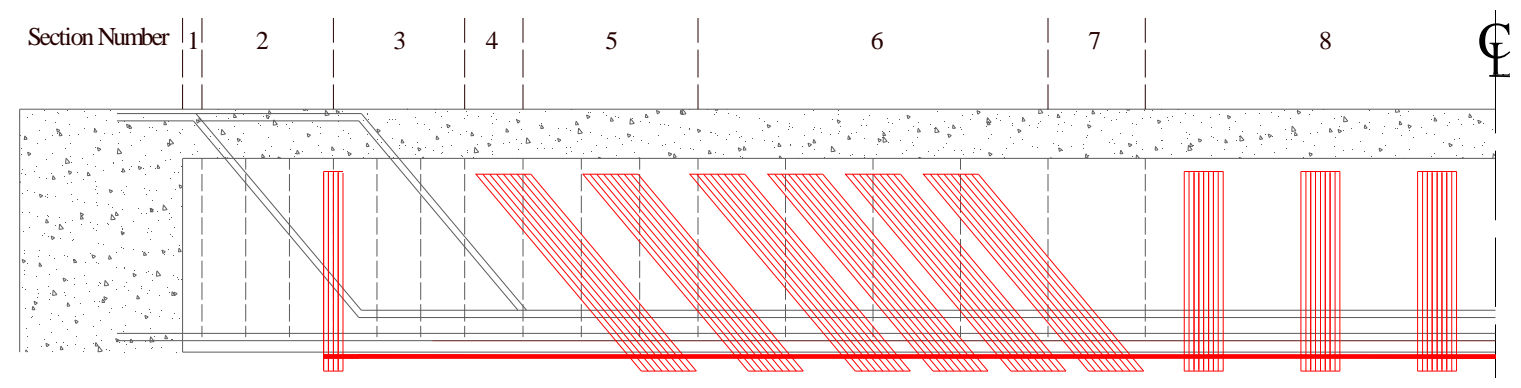

Figure 4.5 Beam 3 FRP Strengthening Design

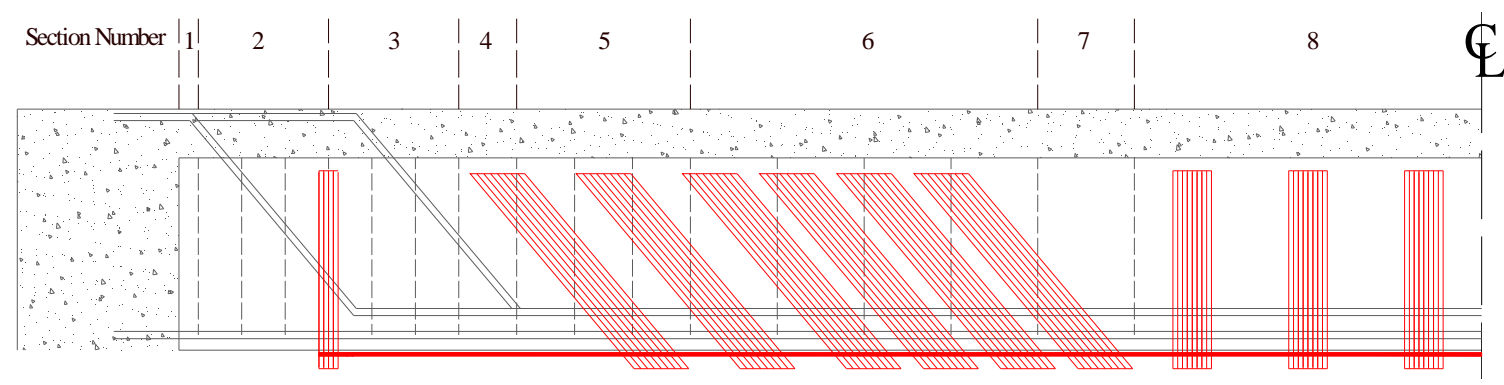

Figure 4.6 Beam 4 FRP Strengthening Design

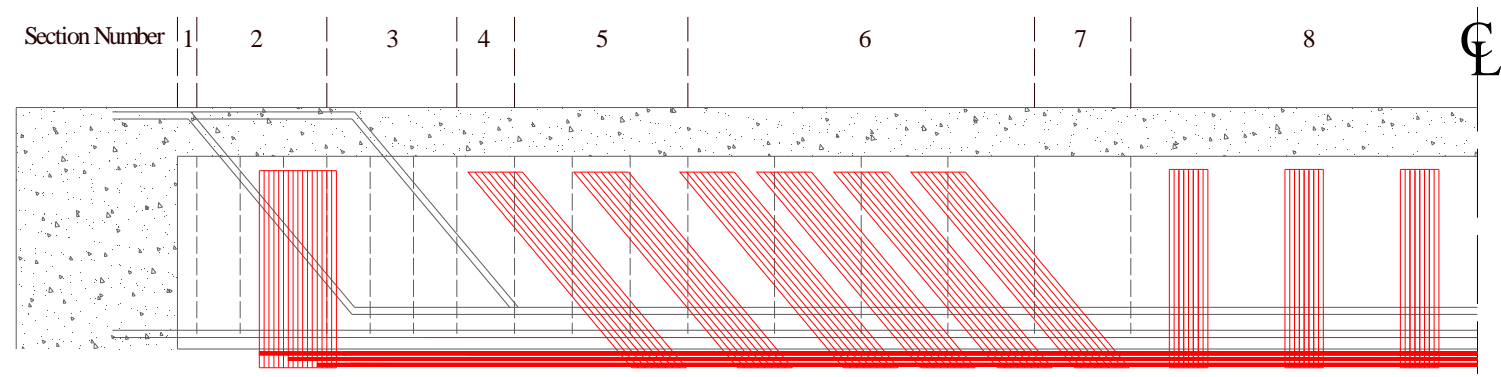

Figure 4.7 Beam 5 FRP Strengthening Design 


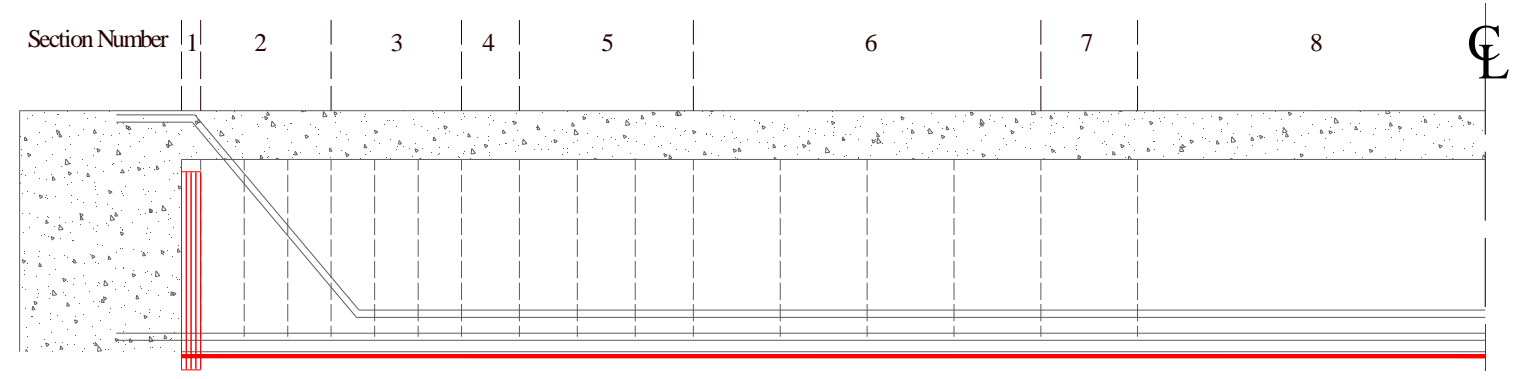

Figure 4.8 Beam 6 FRP Strengthening Design

\subsubsection{FRP Material Properties}

The FRP manufacturer's reported minimum guaranteed material property values are presented in Table 4.4. The values are modified in accordance with ACI 440.2R-02 to account for environmental degradation over time.

Table 4.4 FRP Material Properties

\begin{tabular}{|l|c|c|c|}
\hline Tensile Strength & $\boldsymbol{f}_{f u}{ }^{*}$ & (ksi) & 550 \\
\hline Modulus of Elsticity & $\boldsymbol{E}_{f}$ & (ksi) & 33000 \\
\hline Thickness & $\boldsymbol{t}_{f}$ & (in) & 0.0065 \\
\hline Ultimate Strain & $\varepsilon_{f u}{ }^{*}$ & (in/in) & 0.0167 \\
\hline
\end{tabular}

\subsubsection{Flexural Strengthening}

As shown in Figures 4.3-4.8 and tabulated in Table 4.5, all of the beams require at least one layer of FRP for flexural strengthening. Beam 5 requires the maximum allowable three layers of FRP on the bottom face of the beam. It does not require flexural FRP reinforcement on the sides of the beam. FRP sheets are the minimum area required for a flexural inventory load rating factor equal to or greater than 1.0. Figure 4.9 shows the pre- and post-strengthened flexural load rating factors of each beam. It should be noted that using these suggested FRP designs, any further deterioration of flexural reinforcement will result in a minimum inventory load rating factor less than 1.0. 
The desired failure mode for an FRP strengthened structure is ductile failure through FRP rupture. This failure mode allows adequate response time for bridge owners to take appropriate action to ensure the safety of the public before bridge failure occurs. Brittle failures caused by concrete crushing are sudden and could result in a catastrophic failure of the bridge without prior warning.

Service level stresses are checked for the FRP and steel according to ACI.440.2R02 guidelines. Steel service level stresses are checked to prohibit inelastic deformations due to steel yielding under service level loads. The FRP service level stress check is used to avoid creep-rupture of the FRP reinforcement or failure due to fatigue of the reinforcement.

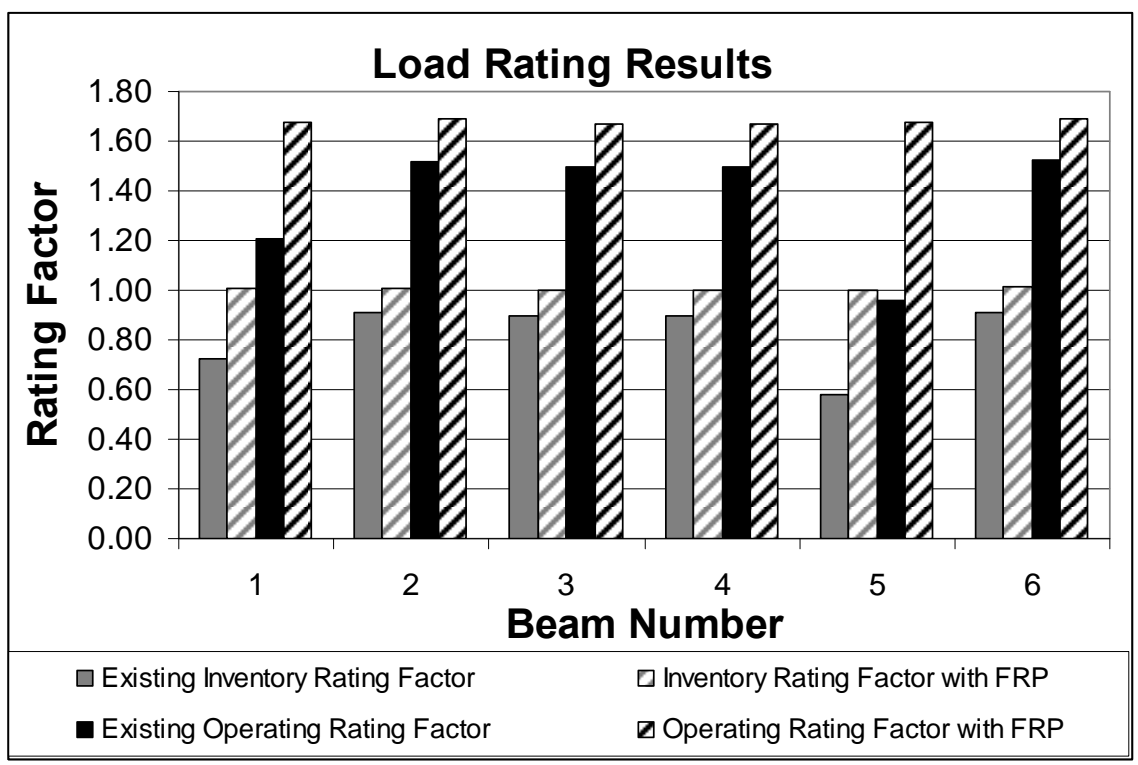

Figure 4.9 FRP Strengthened Load Rating Results 
Table 4.5 Flexural FRP Strengthening Results

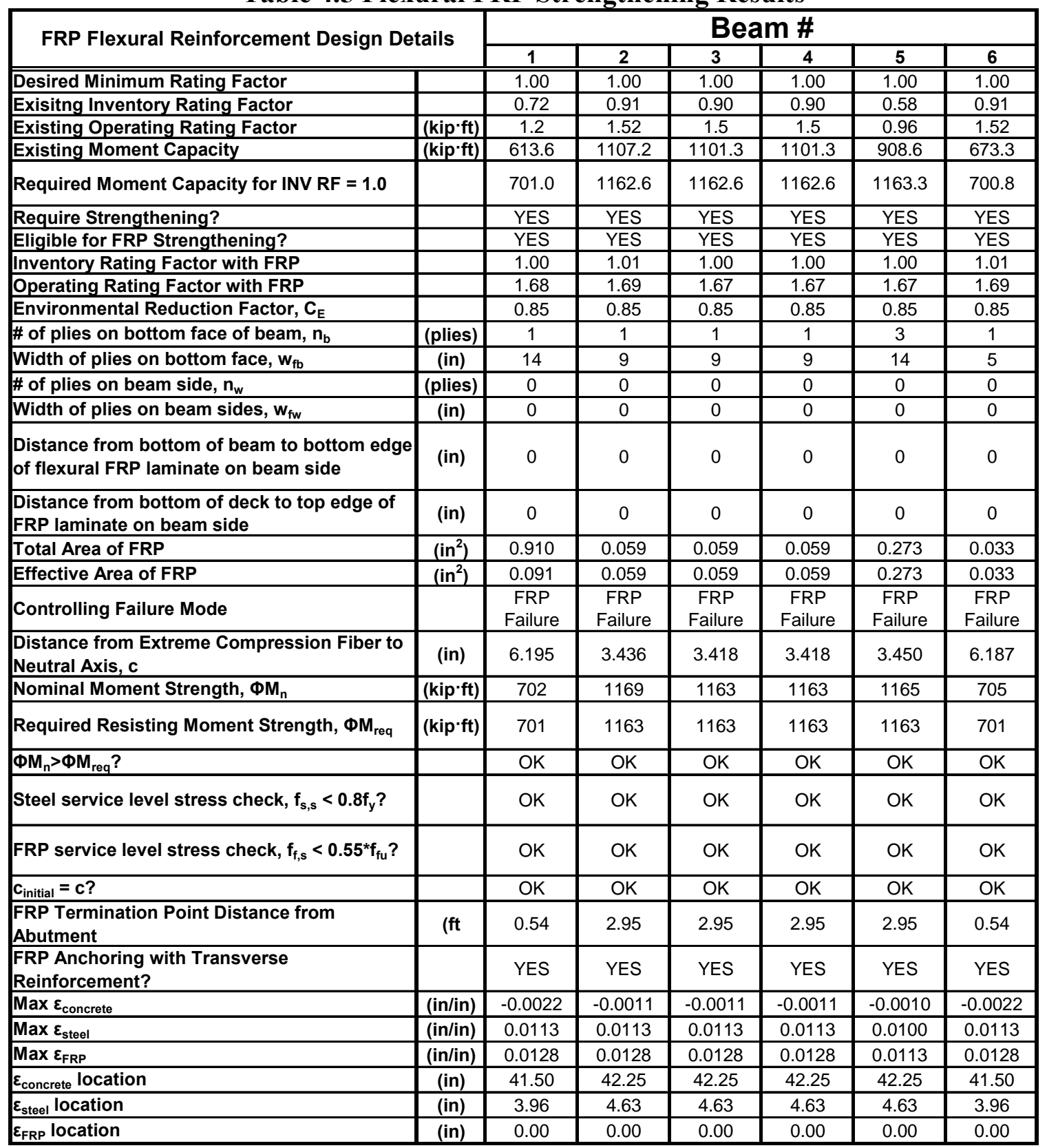

\subsubsection{Shear Strengthening}

The FRP shear strengthening design results for each section are summarized in

Tables 4.6-4.11. These tables show the existing and strengthened shear load rating

factors along with the shear FRP design details and design check results. 
The only beams that required shear strengthening were the interior beams. The interior beam shear inventory load rating factors for each section are shown in Figure 4.10. The figure shows that Sections 5, 6, and 8 required shear strengthening to improve the inventory load rating factor to an acceptable value.

Section 5 required the most strengthening with three layers of 8 inch FRP strip widths at a $45^{\circ}$ angle and 22 inch center-to-center spacing. In order to provide adequate room for contaminants to escape the concrete, three layers were used with wider spacing than that required for two layers.

The FRP strengthening of section 6 requires one layer of 8 inch wide FRP strips at a $45^{\circ}$ angle and 16 inch center-to-center spacing. Section 8 requires one layer of 8 inch wide FRP strips at a $90^{\circ}$ angle and 24 inch center-to-center spacing are required to achieve an inventory load rating factor greater than 1.0.

Table 4.6 Beam 1 FRP Shear Reinforcement Design Results

\begin{tabular}{|l|c|c|c|c|c|c|c|c|c|}
\multicolumn{1}{|c|}{} & \multicolumn{7}{|c|}{ Beam $\mathbf{1}$} \\
\hline Section \# & & $\mathbf{1}$ & $\mathbf{2}$ & $\mathbf{3}$ & $\mathbf{4}$ & $\mathbf{5}$ & $\mathbf{6}$ & $\mathbf{7}$ & $\mathbf{8}$ \\
\hline Section Start Distance from Abutment & (ft) & 0.00 & 0.33 & 2.58 & 4.83 & 5.83 & 8.83 & 14.83 & 16.50 \\
\hline Existing Shear Inventory Rating Factor & & 4.17 & 5.86 & 2.48 & 2.38 & 2.52 & 2.54 & 3.45 & 2.92 \\
\hline Existing Shear Oprerating Rating Factor & & 6.96 & 9.78 & 4.14 & 3.98 & 4.20 & 4.25 & 5.75 & 4.87 \\
\hline Strenghtened Shear Inventory Rating Factor & & 4.17 & 5.86 & 2.48 & 2.38 & 2.52 & 2.54 & 3.45 & 2.92 \\
\hline Strenghtened Shear Operating Rating Factor & & 6.96 & 9.78 & 4.14 & 3.98 & 4.20 & 4.24 & 5.75 & 4.87 \\
\hline Number of FRP layers/strip & (layers) & & & & & & & & \\
\hline Angle of Primary Fiber Orientation & (degrees) & & & & & & & & \\
\hline Strip Width & (in) & & & & & & & & \\
\hline Center-to-Center spacing of Strips & (in) & & & & & & & & \\
\hline V Required & (kips) & 65.3 & 67.2 & 61.4 & 56.0 & 53.5 & 46.1 & 31.3 & 27.3 \\
\hline Strengthened Shear Capacity & (kips) & 163.2 & 228.6 & 107.1 & 96.0 & 96.0 & 85.0 & 79.0 & 62.0 \\
\hline FRP Shear Contribution Limit Check & (kips) & & & & & & & & \\
\hline Stregthened V > V Required? & & $Y E S$ & $Y E S$ & $Y E S$ & $Y E S$ & $Y E S$ & $Y E S$ & $Y E S$ & $Y E S$ \\
\hline
\end{tabular}


Table 4.7 Beam 2 FRP Shear Reinforcement Design Results

\begin{tabular}{|l|c|c|c|c|c|c|c|c|c|}
\cline { 2 - 9 } \\
\hline Section \# & \multicolumn{7}{|c|}{ Beam $\mathbf{2}$} \\
\hline Section Start Distance from Abutment & $\mathbf{f t})$ & $\mathbf{1}$ & $\mathbf{2}$ & $\mathbf{3}$ & $\mathbf{4}$ & $\mathbf{5}$ & $\mathbf{6}$ & $\mathbf{7}$ & $\mathbf{8}$ \\
\hline Existing Shear Inventory Rating Factor & & 1.32 & 1.93 & 2.13 & 2.20 & $\mathbf{0 . 7 5}$ & $\mathbf{0 . 7 7}$ & 1.12 & 0.95 \\
\hline Existing Shear Oprerating Rating Factor & & 2.20 & 3.22 & 3.56 & 3.67 & 1.24 & 1.28 & 1.88 & 1.59 \\
\hline Strenghtened Shear Inventory Rating Factor & & 1.32 & 1.93 & 2.13 & 2.20 & 1.05 & 1.05 & 1.12 & 1.04 \\
\hline Strenghtened Shear Operating Rating Factor & & 2.20 & 3.22 & 3.56 & 3.67 & 1.76 & 1.76 & 1.88 & 1.74 \\
\hline Number of FRP layers/strip & (layers) & & & & & 3 & 1 & & 1 \\
\hline Angle of Primary Fiber Orientation & (degrees) & & & & & 45 & 45 & & 90 \\
\hline Strip Width & (in) & & & & & 8 & 8 & & 4 \\
\hline Center-to-Center spacing of Strips & (in) & & & & & 22 & 16 & & 24 \\
\hline V Required & (kips) & 136.0 & 141.9 & 130.3 & 120.0 & 115.2 & 100.6 & 71.5 & 63.9 \\
\hline Strengthened Shear Capacity & (kips) & 163.3 & 227.9 & 227.9 & 216.9 & 119.3 & 104.3 & 78.3 & 66.0 \\
\hline FRP Shear Contribution Limit Check & (kips) & $O K$ & $O K$ & $O K$ & $O K$ & $O K$ & $O K$ & $O K$ & $O K$ \\
\hline Stregthened V > V Required? & & $Y E S$ & $Y E S$ & $Y E S$ & $Y E S$ & $Y E S$ & $Y E S$ & $Y E S$ & $Y E S$ \\
\hline
\end{tabular}

Table 4.8 Beam 3 FRP Shear Reinforcement Design Results

\begin{tabular}{|l|c|c|c|c|c|c|c|c|c|}
\cline { 3 - 9 } \\
\cline { 2 - 10 }
\end{tabular}

Table 4.9 Beam 4 FRP Shear Reinforcement Design Results

\begin{tabular}{|l|c|c|c|c|c|c|c|c|c|}
\cline { 3 - 9 } & \multicolumn{7}{|c|}{ Beam $\mathbf{4}$} \\
\hline Section \# & & $\mathbf{1}$ & $\mathbf{2}$ & $\mathbf{3}$ & $\mathbf{4}$ & $\mathbf{5}$ & $\mathbf{6}$ & $\mathbf{7}$ & $\mathbf{8}$ \\
\hline Section Start Distance from Abutment & (ft) & 0.00 & 0.33 & 2.58 & 4.83 & 5.83 & 8.83 & 14.83 & 16.50 \\
\hline \hline Existing Shear Inventory Rating Factor & & 1.32 & 1.93 & 2.13 & 2.20 & $\mathbf{0 . 7 5}$ & $\mathbf{0 . 7 7}$ & 1.12 & $\mathbf{0 . 9 5}$ \\
\hline Existing Shear Oprerating Rating Factor & & 2.20 & 3.22 & 3.56 & 3.67 & 1.25 & 1.28 & 1.88 & 1.59 \\
\hline Strenghtened Shear Inventory Rating Factor & & 1.32 & 1.93 & 2.13 & 2.20 & 1.05 & 1.05 & 1.12 & 1.06 \\
\hline Strenghtened Shear Operating Rating Factor & & 2.20 & 3.22 & 3.56 & 3.67 & 1.76 & 1.76 & 1.88 & 1.77 \\
\hline Number of FRP layers/strip & (layers) & & & & & 3 & 1 & & 1 \\
\hline Angle of Primary Fiber Orientation & (degrees) & & & & & 45 & 45 & & 90 \\
\hline Strip Width & (in) & & & & & 8 & 8 & & 4 \\
\hline Center-to-Center spacing of Strips & (in) & & & & & 22 & 16 & & 20 \\
\hline V Required & (kips) & 136.0 & 141.9 & 130.3 & 120.0 & 115.2 & 100.6 & 71.5 & 63.9 \\
\hline Strengthened Shear Capacity & (kips) & 163.3 & 227.9 & 227.9 & 216.9 & 119.3 & 104.3 & 78.3 & 67.0 \\
\hline FRP Shear Contribution Limit Check & (kips) & $O K$ & $O K$ & $O K$ & $O K$ & $O K$ & $O K$ & $O K$ & $O K$ \\
\hline Stregthened V > V Required? & & $Y E S$ & $Y E S$ & $Y E S$ & $Y E S$ & $Y E S$ & $Y E S$ & $Y E S$ & $Y E S$ \\
\hline
\end{tabular}


Table 4.10 Beam 5 FRP Shear Reinforcement Design Results

\begin{tabular}{|l|c|c|c|c|c|c|c|c|c|}
\cline { 2 - 9 } \\
\cline { 2 - 9 }
\end{tabular}

Table 4.11 Beam 6 FRP Shear Reinforcement Design Results

\begin{tabular}{|l|c|c|c|c|c|c|c|c|c|}
\cline { 3 - 10 } \\
\cline { 2 - 10 }
\end{tabular}

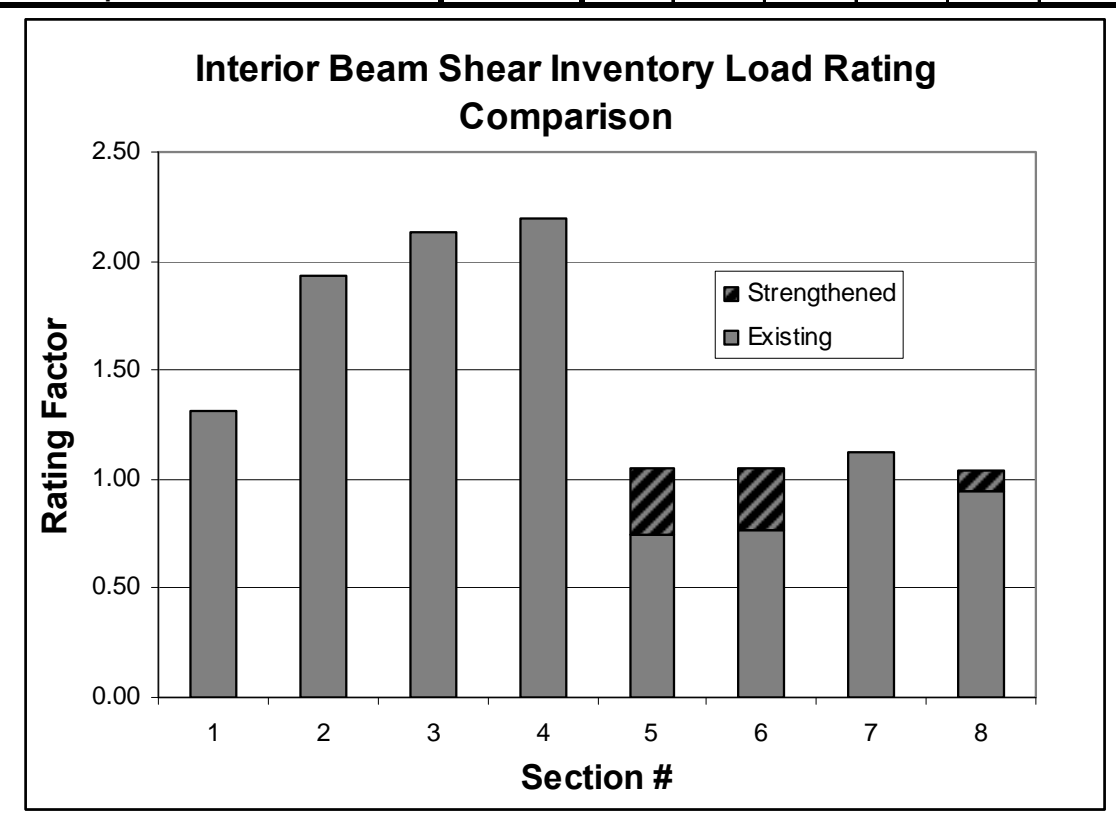

Figure 4.10 Pre- and Post- Shear Strengthening Inventory Rating Factor Comparison 


\section{CHAPTER 5 - DEVELOPMENT OF IMPROVED CONCRETE T-Beam Rating Procedures}

\section{$5.1 \quad$ INTRODUCTION}

WVU researchers developed a program for concrete T-Beam analysis, load rating, and FRP strengthening design. The objective of the program is to provide PennDOT district forces with a self-contained simply-supported concrete T-Beam bridge rehabilitation package. This program provides the user with a simple analysis package for accurately and efficiently investigating critical structural characteristics following AASHTO protocols. All structural analysis and FRP strengthening design calculations reported in this thesis are results from the program.

The program analysis and strengthening design process is shown in Figure 5.1. The major steps involved in the analysis and design process are: user input, structural capacity analysis, dead/live load generation, load rating analysis, and FRP strengthening design. The analysis results are tabulated and presented graphically to facilitate any required post processing of the data. 


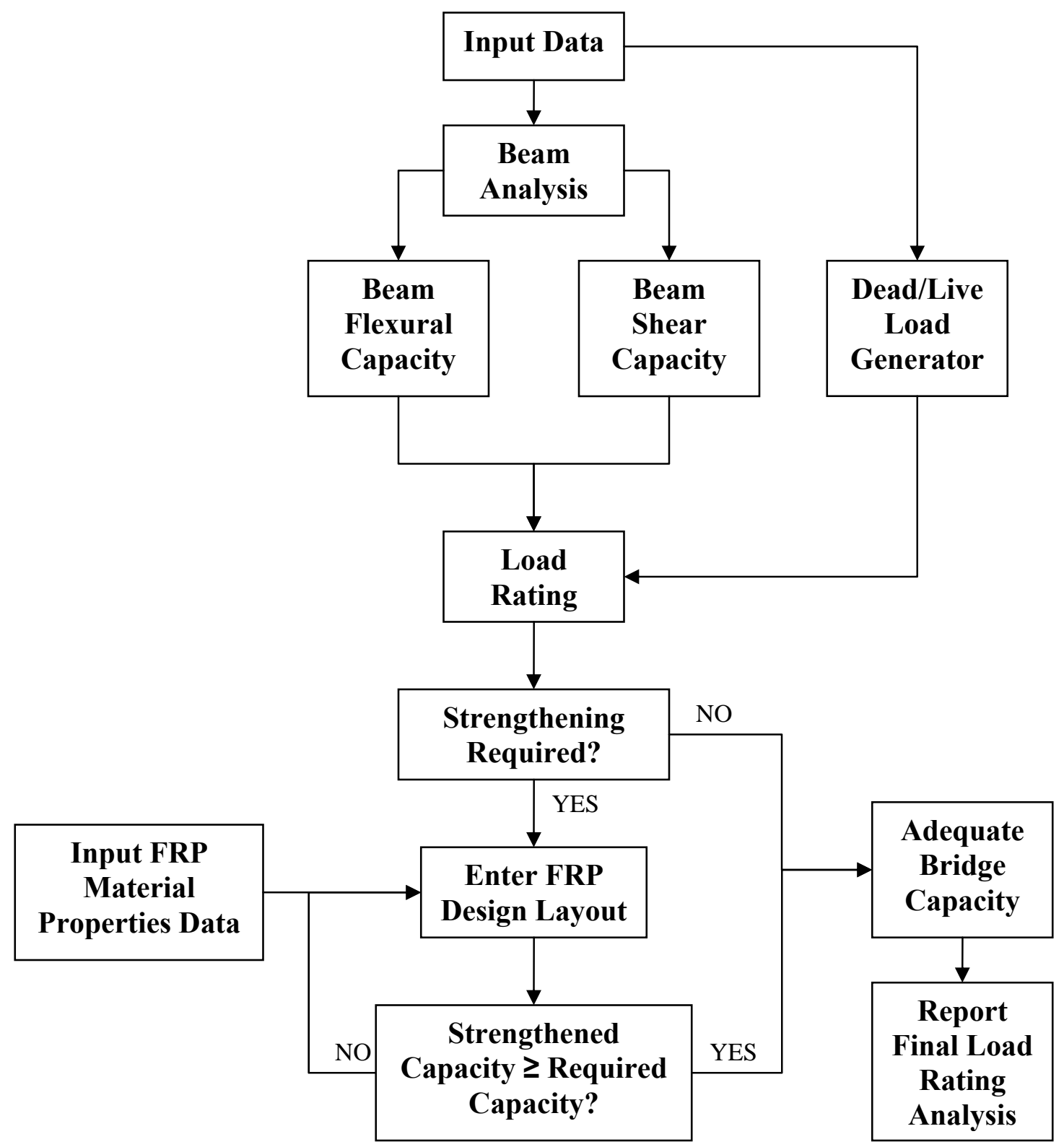

Figure 5.1 WVU Program Process Chart

The initial purpose of designing this program was to follow and understand the calculations used in PennDOT’s BAR7 program. Furthermore, this program allowed the comparison of variable input data and verification of PennDOT's calculation procedures. As the program developed, it was expanded to include FRP strengthening design calculations and load rating analysis of the rehabilitated bridge. 


\subsection{ANALYSIS VARIATIONS AND Limitations}

This section compares and contrasts the differences between PennDOT’s BAR7 and WVU's analysis programs. The program developed at WVU is intended to be more facilitating to the user and provide a more accurate structural analysis. The most notable distinction is WVU's simplification of input data.

\subsubsection{Input Data}

WVU’s program incorporates several modifications to BAR7 input data requirements. The modifications were made to simplify user interface and increase the accuracy of the structural capacity analysis. The input data required for WVU's program can be obtained solely from the bridge design drawings and/or site bridge inspection records. BAR7 requires the user to input dead loads, distribution factors, etc. which can require reference to design specifications and/or bridge inspection manuals.

The two programs account for bridge geometric property input data in the same way except for the reinforcement layout. BAR7 requires the user to indirectly account for inclined shear reinforcement by modifying vertical stirrup spacing. This method requires supplemental calculations by the rating engineer which can be confusing and incorrectly computed. WVU's analysis program allows the user to directly account for inclined shear reinforcement by entering the number of inclined bars effective in each section. The user defines the bridge’s sections based on vertical stirrup spacing and locations of inclined bars.

The area of steel for each reinforcement type (e.g. flexural, vertical stirrups, and inclined bars) is assumed constant throughout the bridge for BAR7 analysis. This does not allow the user to account for varying levels of deterioration. WVU's analysis 
program allows the user to define the percentage of remaining steel for each reinforcement type in every section and beam. This method of accounting for deterioration losses provides a more accurate structural analysis.

\subsubsection{Analysis Calculations}

BAR7 is a powerful program with the ability to analyze multiple bridge types and span arrangements. However, there are multiple limitations in BAR7 concerning concrete T-Beam bridge analysis. WVU's analysis program is intended to be a more functional expansion of BAR7's simply supported concrete T-Beam analysis.

WVU's program can analyze multiple beams during one analysis session. This feature facilitates investigating multiple beam types and the effects of varying material property input data. The beam types could vary in location (interior or exterior) and/or reinforcement layout. The percentage of parapet dead load distribution to each beam is also defined by the user.

\subsubsection{Program Output}

The analysis results for WVU's program are modeled after BAR7's program output. In both programs, the load rating factors at each tenth point are summarized in table format for every loading vehicle investigated. The tables include the load rating factors, load capacities, and controlling force type (e.g. moment or shear). The programs also present a table that summarizes the controlling tenth point load rating factors and capacities.

BAR7 reports the load rating results based on Allowable Stress Rating and Load Factor Rating methodologies. WVU's analysis program is currently limited to Load 
Factor Rating analysis. However, the program can be easily upgraded to include Allowable Stress Design and Rating procedures. LRFD/LRFR methodologies are relatively new and are not mandated for aged concrete T-Beam bridges. WVU's program has been developed with future upgrades in mind. The load rating vehicles used in LRFD/LRFR procedures have been included in the live load vehicle inventory. It should be noted that WVU's program was built using EXCEL which allows for relatively simple modifications.

\subsubsection{FRP Strengthening Design}

The latest version of BAR7 is limited to bridge analysis and load rating. WVU's analysis program is specially designed for simply-supported concrete T-Beam analysis and rehabilitation. The program incorporates FRP strengthening design procedures. The load ratings based on the FRP strengthening design are reported in the same table format as for the existing bridge condition assessment. The combination of FRP strengthening design and load rating with deteriorated structural condition assessment in a single program should be a valuable analysis tool for rehabilitation of bridges.

WVU researchers chose to build the program in EXCEL for its simplicity. It should be noted that BAR7 can be updated to include strengthening design procedures and strengthened load rating analysis. The FRP rehabilitation design procedures could be expanded to include various bridge types and the use of different strengthening techniques. 


\subsection{ANALYSIS}

The analysis calculations follow AASHTO and ACI prescribed guidelines and procedures for load factor based designs. The program structural analysis steps can be split into three separate phases: user input, structural analysis, and load rating results.

The user is required to input the geometric properties of the concrete T-Beam(s) under investigation. Several options are available to the user to provide a more accurate analysis during the data entering stage. The program modifies itself to account for variable user input options. Further details on these options are provided in the following section.

The program analyzes and reports the load rating factors for the beam at tenth points. It should be noted that combined moment and shear effects are not considered in the structural analysis calculations. This is considered a valid analysis procedure for simply-supported structures.

The maximum dead and live load effects are calculated through the dead/live load generator. The load generator analyzes all of the standard loading vehicles in PennDOT's inventory. The user has the option of entering one special loading vehicle with up to ten axels. The program will only report analysis results for the loading vehicles that are selected by the user.

\subsubsection{Program Input}

The required structural analysis input data is entered by the user on one sheet within EXCEL. The user input can be split into three separate parts: universal input data, beam specific input data, and live load generator options. All input data is either a 
geometric or material property of the bridge or analysis option. The program input data process is shown in Figure 5.2.

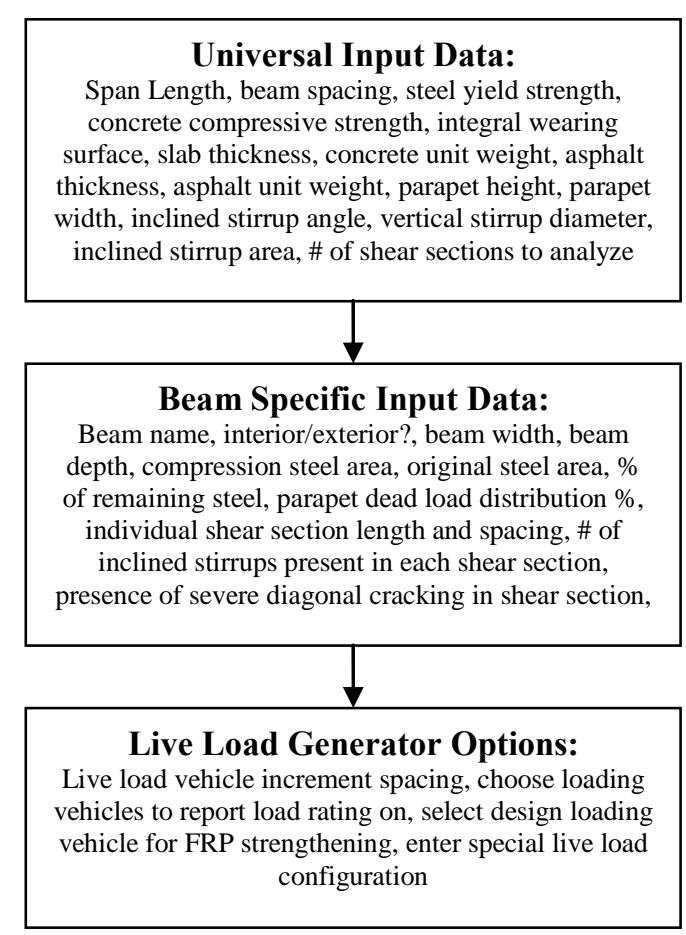

Figure 5.2 Input Data Sequence

\subsubsection{Universal Input Data}

The universal input data section covers all of the structural variables that are applicable to the flexural and shear resistance analyses of the beam. The section also provides analysis options to the user such as removing the clear cover on the sides of the beam for concrete shear resistance calculations to account for concrete deterioration.

The global geometric properties of the bridge are entered in the universal input data table. These include: span length, center-to-center spacing, steel yield stress, concrete compressive strength (original design and existing), integral wearing surface thickness, flange thickness, concrete unit weight, asphalt unit weight, asphalt thickness, 
parapet height, parapet width, inclined stirrup angle with respect to the horizontal, vertical stirrup diameter, and original inclined stirrup area.

The user has the option of analyzing a single universal beam or two variable beams. The program will modify itself to leave cells blank that are devoted to analyzing the second beam. This option makes it easier for the user to analyze the results and track down calculations within the program if a single beam analysis is desired.

The user has several options to determine a strengthening level. The strengthening philosophy options include increasing the structural capacity to: the original design capacity, loading vehicle requirements, or a user defined minimum load rating factor.

A sample universal input data table is presented in Table 5.1. The user input fields are colored light blue. This enables the user to easily decipher which cells require input data and which cells are calculation results. Some calculation result cells are incorporated within the user input data tables to provide a quick check for input data accuracy. 
Table 5.1 Sample Universal Input Data Table

\begin{tabular}{|c|c|c|c|}
\hline Span Length & $\mathrm{L}$ & $(\mathrm{ft})$. & 45 \\
\hline c/c spacing & $\mathrm{s}$ & (in.) & 58 \\
\hline Yield Stress for Steel & $f_{y}$ & (psi) & 36000 \\
\hline Original Design Concrete Compressive Strength & $f_{c o}^{\prime}$ & (psi) & 3000 \\
\hline Existing Concrete Compressive Strength & $f_{c}^{\prime}$ & (psi) & 3000 \\
\hline Integral Wearing Surface & $t_{\text {iws }}$ & (in.) & 0.5 \\
\hline Slab Thickness & $t_{s}$ & (in.) & 8.5 \\
\hline Flange Thickness & $\mathrm{t}$ & (in.) & 8 \\
\hline Concrete Unit Weight & $\gamma_{c}$ & $\left(\mathrm{k} / \mathrm{ft}^{3}\right)$ & 0.150 \\
\hline Asphalt Unit Weight & $\gamma_{\mathrm{a}}$ & $\left(\mathrm{k} / \mathrm{ft}^{3}\right)$ & 0.150 \\
\hline Asphalt Thickness & $t_{a}$ & (in.) & 4.5 \\
\hline Parapet Height & $h_{p}$ & (in.) & 44.0 \\
\hline Parapet Width & $b_{p}$ & (in.) & 18.5 \\
\hline Analyze Universal Girder only? & \multicolumn{2}{|c|}{ (YES or NO) } & NO \\
\hline Inclined Stirrup Angle with Respect to Horizontal & \multicolumn{2}{|c|}{ (degrees) } & 45 \\
\hline Diameter of Vertical Stirrups & $\phi_{\mathrm{V}}$ & (in.) & 0.5 \\
\hline Original Area of Single Inclined Stirrup & $A_{\text {vi1 }}{ }^{0}$ & $\left(\right.$ in. $\left.^{2}\right)$ & 1.563 \\
\hline Remove Clear Cover on Web for Shear Calcs? & \multicolumn{2}{|c|}{ (YES or NO) } & $\mathrm{NO}$ \\
\hline \multirow{2}{*}{\multicolumn{3}{|c|}{$\begin{array}{l}\text { \# of Sections of Vertical Stirrup Spacing Changes for the } 3 \text { Girder } \\
\text { \# of Sections of Vertical Stirrup Spacing Changes for the } 4 \text { Girder } \\
\text { Select Desired Load Rating Method: Enter } 1 \text { for Allowable Stress Design Rating, Enter } \\
2 \text { for Load Factor Design Rating, Enter } 3 \text { for Load and Resistance Factor Design } \\
\text { Rating }\end{array}$}} & 8 \\
\hline & & & 8 \\
\hline \multicolumn{3}{|c|}{$\begin{array}{l}\text { Select Required Capacity for Design of FRP Strengthening: Enter } 1 \text { for Original } \\
\text { Design Capacity, Enter } 2 \text { for Loading Vehicle Capacity, Enter } 3 \text { for Maximum of Design } \\
\text { Vehicle Loading or Original Design Capacity, Enter } 4 \text { for Design Based on Minimum } \\
\text { Rating Factor }\end{array}$} & 4 \\
\hline
\end{tabular}

\subsubsection{Beam Specific Input Data}

The beam specific input data entry is covered in several input tables. Sample

beam specific data entry tables are shown in Tables 5.2, 5.3, 5.5, 5.6 and Figure 5.3. The first beam specific table (Table 5.2) is largely related to the beam geometric and flexural analysis properties. The user has the option of giving names to the beam(s) being analyzed in this table which are then carried throughout the program. The number of varying shear reinforcement layout sections is entered at this point. The user can enter up to eight separate sections for analysis. The table also requires the user to enter the percentage of a single parapet dead load distributed to each beam. 
Table 5.2 Sample Beam Specific Flexural Input Data Table

\begin{tabular}{|c|c|c|c|c|c|}
\hline Name the Girder/s to Analyze & & & 3 & 4 & <---Enter Data \\
\hline Analyze as Interior Girder? & \multicolumn{2}{|c|}{ (YES or NO) } & YES & YES & \\
\hline Width & $\mathrm{b}$ & (in.) & 17.50 & 17.50 & <---Enter Data \\
\hline Depth of Girder & $\mathrm{h}$ & (in.) & 42.25 & 42.25 & $<---$ Enter Data \\
\hline Compression Steel & $A_{s}^{\prime}$ & $\left(\right.$ in. $\left.^{2}\right)$ & 0.00 & 0.00 & $<---E n t e r$ Data \\
\hline Original Flexural Tension Steel & $A_{s}{ }^{0}$ & $\left(\right.$ in. $\left.{ }^{2}\right)$ & 15.625 & 15.625 & \\
\hline Estimate of $\%$ of Remaining Flexural Steel & & $(\%)$ & 72 & 72 & \\
\hline Flexural Tension Steel Remaining & $A_{s}$ & $\left(\right.$ in. $\left.^{2}\right)$ & 11.250 & 11.250 & \\
\hline$\%$ of Single Parapet DL distribution & & $(\%)$ & 33.0 & 33.0 & <---Enter Data \\
\hline Centroid Distance of Tension Steel at $1^{\text {st }}$ level, from bottom of girder & $\mathrm{y}_{1}$ & (in.) & 2.6 & 2.6 & $<---E n t e r$ Data \\
\hline Original Area of Tension Steel at $1^{\text {st }}$ level, from bottom of girder & $A_{s 1}{ }^{0}$ & $\left(\right.$ in. $\left.^{2}\right)$ & 6.3 & 6.3 & $<---E n t e r$ Data \\
\hline Estimate of $\%$ of Remaining Flexural Steel at $1^{\text {st }}$ level, from bottom & & $(\%)$ & 90.0 & 90.0 & $<---E n t e r$ Data \\
\hline Flexural Tension Steel Remaining at $1^{\text {st }}$ level, from bottom & $A_{s 1}$ & $\left(\right.$ in. $\left.^{2}\right)$ & 5.6 & 5.6 & \\
\hline Centroid Distance of Tension Steel at $2^{\text {nd }}$ level, from bottom of girder & $\mathrm{y}_{2}$ & (in.) & 6.6 & 6.6 & $<---E n t e r$ Data \\
\hline Original Area of Tension Steel at $2^{\text {nd }}$ level, from bottom of girder & $\mathrm{A}_{\mathrm{s} 2}{ }^{0}$ & $\left(\right.$ in. $\left.{ }^{2}\right)$ & 6.3 & 6.3 & $<---E n t e r$ Data \\
\hline Estimate of $\%$ of Remaining Flexural Steel at $2^{\text {nd }}$ level, from bottom & & $(\%)$ & 90.0 & 90.0 & $<---E n t e r$ Data \\
\hline Flexural Tension Steel Remaining at $2^{\text {nd }}$ level, from bottom & $\overline{A_{s 2}}$ & $\left(\right.$ in. $\left.{ }^{2}\right)$ & 5.6 & 5.6 & \\
\hline Centroid Distance of Tension Steel at $3^{\text {rd }}$ level, from bottom of girder & $\overline{y_{3}}$ & (in.) & 10.6 & 10.6 & $<---E n t e r$ Data \\
\hline Original Area of Tension Steel at $3^{\text {rd }}$ level, from bottom of girder & $\mathrm{A}_{\mathrm{s} 3}{ }^{0}$ & $\left(\right.$ in. $\left.^{2}\right)$ & 3.1 & 3.1 & $<---E n t e r$ Data \\
\hline Estimate of $\%$ of Remaining Flexural Steel at $3^{\text {rd }}$ level, from bottom & & $(\%)$ & 0.0 & 0.0 & $<---E n t e r$ Data \\
\hline Flexural Tension Steel Remaining at $3^{\text {rd }}$ level, from bottom & $\overline{A_{s 1}}$ & (in. $\left.{ }^{2}\right)$ & 0.0 & 0.0 & \\
\hline Original Ext. Comp. Fiber- $A_{s}$ Centroid Dist. & $\mathrm{d}$ & (in.) & 36.43 & 36.43 & \\
\hline As Built Ext. Comp. Fiber- $A_{s}$ Centroid Dist. & $d$ & (in.) & 37.63 & 37.63 & \\
\hline
\end{tabular}

The beam specific geometries entered into the table shown in Table 5.2 are the beam width and depth. The user has the option of accounting for the compression steel within the beam for flexural analysis. The original flexural tension steel and deterioration amounts are accounted for in example Table 5.2. The program allows for up to three layers of tensile reinforcing steel. The original area of each layer must be entered along with the distance from the centroid of that layer to the bottom face of the beam. The deterioration of each layer can be accounted for by entering a percentage of remaining steel at each level.

The remaining area of flexural tension steel at each level is calculated and reported in the table. The total original area, percentage of remaining steel, and remaining flexural tension steel areas are calculated and reported in the same table. The 
distance from the extreme compression fiber to the original and existing steel area are calculated in the program and reported at the bottom of the same table. This method of entering the flexural tension steel properties allows the user to analyze the original and existing capacity of the beam while accounting for varying levels of corrosion and deterioration between the levels of steel reinforcement.

Table 5.3 shows a sample table where the different shear reinforcement layout sections are entered. The user must input the individual section lengths and the vertical stirrup spacing within each section. Since symmetry is assumed about the centerline of the bridge, the section distances should add up to half of the bridge span.

Table 5.3 also shows one method of how the program directs the user to the required input data fields. The program will indicate each required input data field by stating "Enter Data" and pointing to the cell(s) that require data. Table 22 shows the calculation results for each section break across the bridge to aid the user in accurate data entry. The shear investigation points show the distance from the abutment at which the dead/live load generator will calculate required resistances. The program will automatically update the number of shear investigation points depending on the amount of sections to be analyzed. 
Table 5.3 Sample Beam Specific Shear Section Break Input Data Table

\begin{tabular}{|c|c|c|c|c|}
\hline $\begin{array}{c}\text { Vertical } \\
\text { Stirrup } \\
\text { Section \# }\end{array}$ & \multicolumn{3}{|c|}{ Beam 2} & \\
\hline \multirow{2}{*}{1} & Section 1 Distance & (in.) & 4 & $<----E n t e r$ Data \\
\hline & Section 1 Spacing & (in.) & 4 & $<----E n t e r$ Data \\
\hline \multirow{2}{*}{2} & Section 2 Distance & (in.) & 27 & $<---$ Enter Data \\
\hline & Section 2 Spacing & (in.) & 9 & $<----E n t e r$ Data \\
\hline \multirow{2}{*}{3} & Section 3 Distance & (in.) & 27 & $<----$ Enter Data \\
\hline & Section 3 Spacing & (in.) & 9 & $<---$ Enter Data \\
\hline \multirow{2}{*}{4} & Section 4 Distance & (in.) & 12 & $<---$ Enter Data \\
\hline & Section 4 Spacing & (in.) & 12 & $<---$-Enter Data \\
\hline \multirow{2}{*}{5} & Section 5 Distance & (in.) & 36 & $<---$ Enter Data \\
\hline & Section 5 Spacing & (in.) & 12 & $<----E n t e r$ Data \\
\hline \multirow{2}{*}{6} & Section 6 Distance & (in.) & 72 & $<---$-Enter Data \\
\hline & Section 6 Spacing & (in.) & 18 & $<---$-Enter Data \\
\hline \multirow{2}{*}{7} & Section 7 Distance & (in.) & 20 & <----Enter Data \\
\hline & Section 7 Spacing & (in.) & 20 & $<----E n t e r$ Data \\
\hline \multirow{2}{*}{8} & Section 8 Distance & (in.) & 72 & $<---$-Enter Data \\
\hline & Section 8 Spacing & (in.) & 24 & <----Enter Data \\
\hline
\end{tabular}

Table 5.4 Sample Beam Specific Shear Investigation Point Table

\begin{tabular}{|c|c|c|c|}
\hline \multicolumn{2}{|c|}{ Beam 2} & \multicolumn{2}{|c|}{ Beam 5} \\
\hline $\begin{array}{c}\text { Shear } \\
\text { Investigation } \\
\text { Points } \\
\end{array}$ & Distance (ft) & \begin{tabular}{|c|} 
Shear \\
Investigation \\
Points \\
\end{tabular} & Distance (ft) \\
\hline 1 & 0.0 & 1 & 0.0 \\
\hline 2 & 0.3 & 2 & 0.3 \\
\hline 3 & 2.6 & 3 & 2.6 \\
\hline 4 & 4.8 & 4 & 4.8 \\
\hline 5 & 5.8 & 5 & 5.8 \\
\hline 6 & 8.8 & 6 & 8.8 \\
\hline 7 & 14.8 & 7 & 14.8 \\
\hline 8 & 16.5 & 8 & 16.5 \\
\hline 9 & 28.5 & 9 & 28.5 \\
\hline 10 & 30.2 & 10 & 30.2 \\
\hline 11 & 36.2 & 11 & 36.2 \\
\hline 12 & 39.2 & 12 & 39.2 \\
\hline 13 & 40.2 & 13 & 40.2 \\
\hline 14 & 42.4 & 14 & 42.4 \\
\hline 15 & 44.7 & 15 & 44.7 \\
\hline 16 & 45.0 & 16 & 45.0 \\
\hline
\end{tabular}


The inclined reinforcement layout is accounted for by direct inclusion of the bars in each section. The number of inclined stirrups effective in each section is entered into the table shown in Table 5.5. The program does not assume multiple inclined bars at a given point. The user must enter the total number of bars inclined within a given section. This method does not require separate hand calculations that cannot be quickly verified by a third party and is therefore a much easier method of accounting for the inclined bars than BAR7 procedures.

Table 5.5 Sample Inclined Stirrup Inclusion by Section Input Data Table
\begin{tabular}{|l|l|c|c|c|}
\hline Number of Inclined Stirrups Effective in Section 1 & Enter Data---> & 0 & 0 & <---Enter Data \\
\hline Number of Inclined Stirrups Effective in Section 2 & Enter Data---> & 2 & 2 & <---Enter Data \\
\hline Number of Inclined Stirrups Effective in Section 3 & Enter Data---> & 2 & 2 & $<---$ Enter Data \\
\hline Number of Inclined Stirrups Effective in Section 4 & Enter Data---> & 2 & 2 & $<---$ Enter Data \\
\hline Number of Inclined Stirrups Effective in Section 5 & Enter Data---> & 2 & 2 & $<---$ Enter Data \\
\hline Number of Inclined Stirrups Effective in Section 6 & Enter Data---> & 0 & 0 & $<---$ Enter Data \\
\hline Number of Inclined Stirrups Effective in Section 7 & Enter Data---> & 0 & 0 & $<---$ Enter Data \\
\hline Number of Inclined Stirrups Effective in Section 8 & Enter Data---> & 0 & 0 & $<---$ Enter Data \\
\hline
\end{tabular}

The table shown in Table 5.6 allows the user to account for severe diagonal cracking within each section. AASHTO states that if severe diagonal cracking is present, analysis calculations should assume that the shear resistance provided by the concrete is equal to zero. 
Table 5.6 Sample Presence of Severe Diagonal Cracking by Section Input Table

\begin{tabular}{|c|c|c|}
\hline \multicolumn{1}{c|}{} & Beam 2 & Beam 5 \\
\hline $\mathbf{2}$ & $N O$ & $N O$ \\
\hline $\mathbf{3}$ & $N O$ & $N O$ \\
\hline $\mathbf{4}$ & $N O$ & $N O$ \\
\hline $\mathbf{5}$ & $N O$ & $N O$ \\
\hline $\mathbf{6}$ & $N O$ & $N O$ \\
\hline $\mathbf{7}$ & $N O$ & $N O$ \\
\hline $\mathbf{8}$ & $N O$ & $N O$ \\
\hline
\end{tabular}

The deterioration percentages of steel shear reinforcement are accounted for in the table shown in Figure 5.3. The user can select one of three methods for calculating the remaining shear steel reinforcement. The user may choose to analyze using a universal percentage of remaining steel. This method will reduce each section of shear reinforcing steel (vertical and inclined) by the same amount regardless of what section it is in.

\begin{tabular}{l}
\hline Enter 1 to use Universal Est. of Stirrup \\
Area Remaining \\
\hline Enter 2 to use Stirrup Area Remianing by \\
Section \\
\hline $\begin{array}{l}\text { Enter } 3 \text { to modify Estimate of Stirrup Area } \\
\text { Remaining Individually by Section and } \\
\text { Girder }\end{array}$ \\
\hline
\end{tabular}
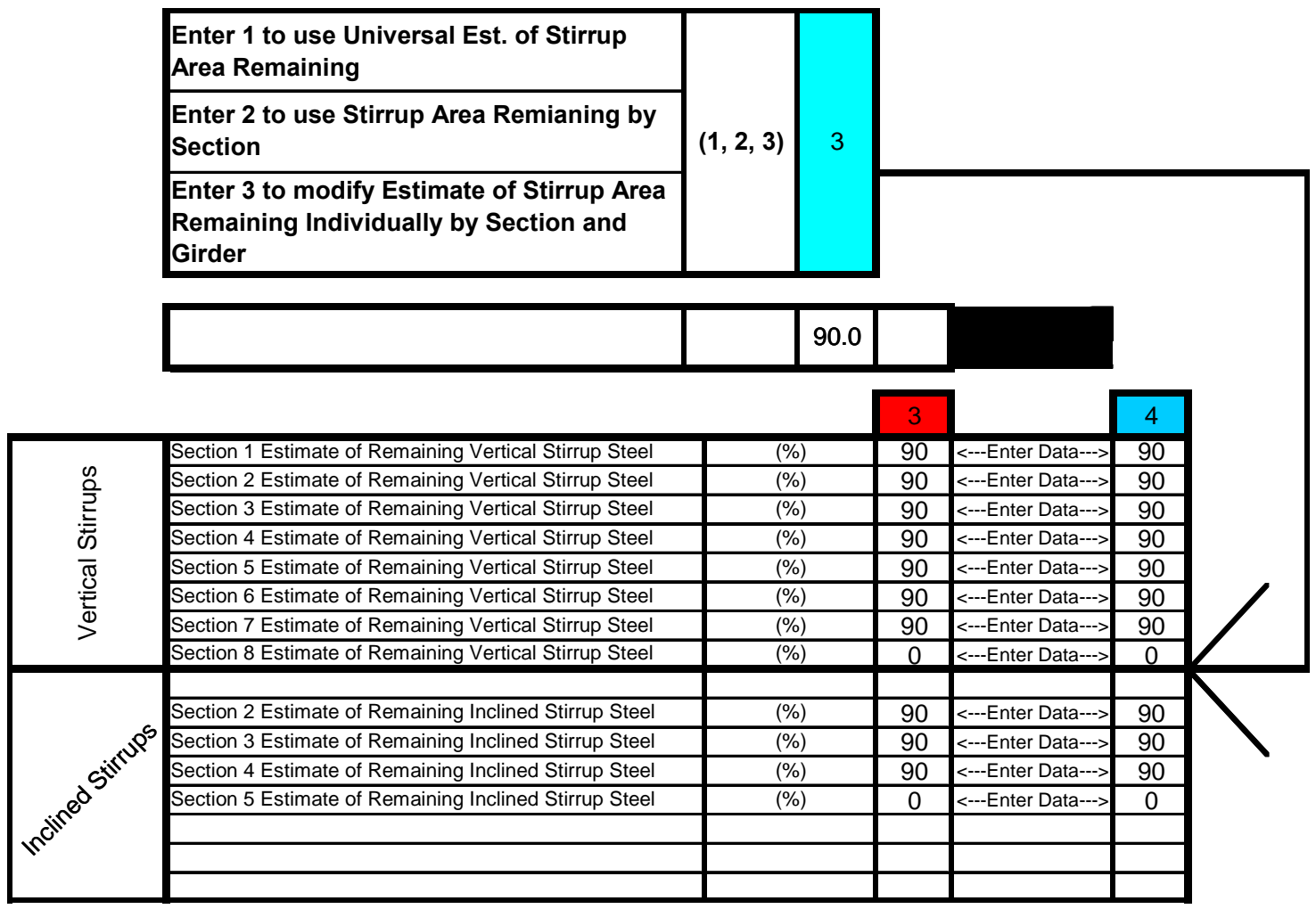

Figure 5.3 Sample Shear Remaining Steel Reinforcement Area Input Data Tables 
The second method reduces the steel by individual sections. This method allows for a more accurate analysis approach than BAR7. The third analysis option for remaining shear steel reinforcement allows the user to account for corrosion loss by individual beam and section. This option allows for the most accurate and detailed structural analysis calculation.

Figure 5.3 shows a second method of how the program directs the user to the correct data entry fields. The program directs the user to the appropriate table that requires data entry depending on the selected method of accounting for corrosion loss in the shear resisting steel reinforcement,. The program is designed to be user friendly. Future program updates will incorporate user interface changes to tailor the program to PennDOT requirements.

\subsubsection{Live Load Generator Options}

The live load generator was necessary to provide a stand-alone program for structural analysis and load rating. The program analyzes all eleven of PennDOT's standard live loading vehicles and allows the user to enter one special live loading vehicle. The program also calculates the loading results for the LRFD standard loading vehicles of an HL-93 truck and HL-93 tandem.

The user must enter a span length and live load increment spacing. The increment spacing must be long enough to allow the program to analyze all loading vehicles until they have crossed the entire length of the bridge. If the user selects an increment spacing that is too short, the program will tell the user to increase the increment. The program is capable of analyzing the load steps at an increment of about $0.65 \%$ of the span length. 
The best practice is to use an increment spacing that will result in the wheel loads being placed directly on the investigation points. This will result in the maximum force effect at the investigation point.

The load rating results desired for each loading vehicle must be entered by placing an " $\mathrm{x}$ " in the appropriate cell(s) under "Choose Loads to Investigate." The unfactored and undistributed maximum force effects in the bridge due each selected loading vehicle are displayed in a table to the right of the live load selection table as shown in Table 5.7.

Table 5.7 Sample Loading Vehicle Input Data Table Choose which loadings to calculate by placing an $(x)$ in the box

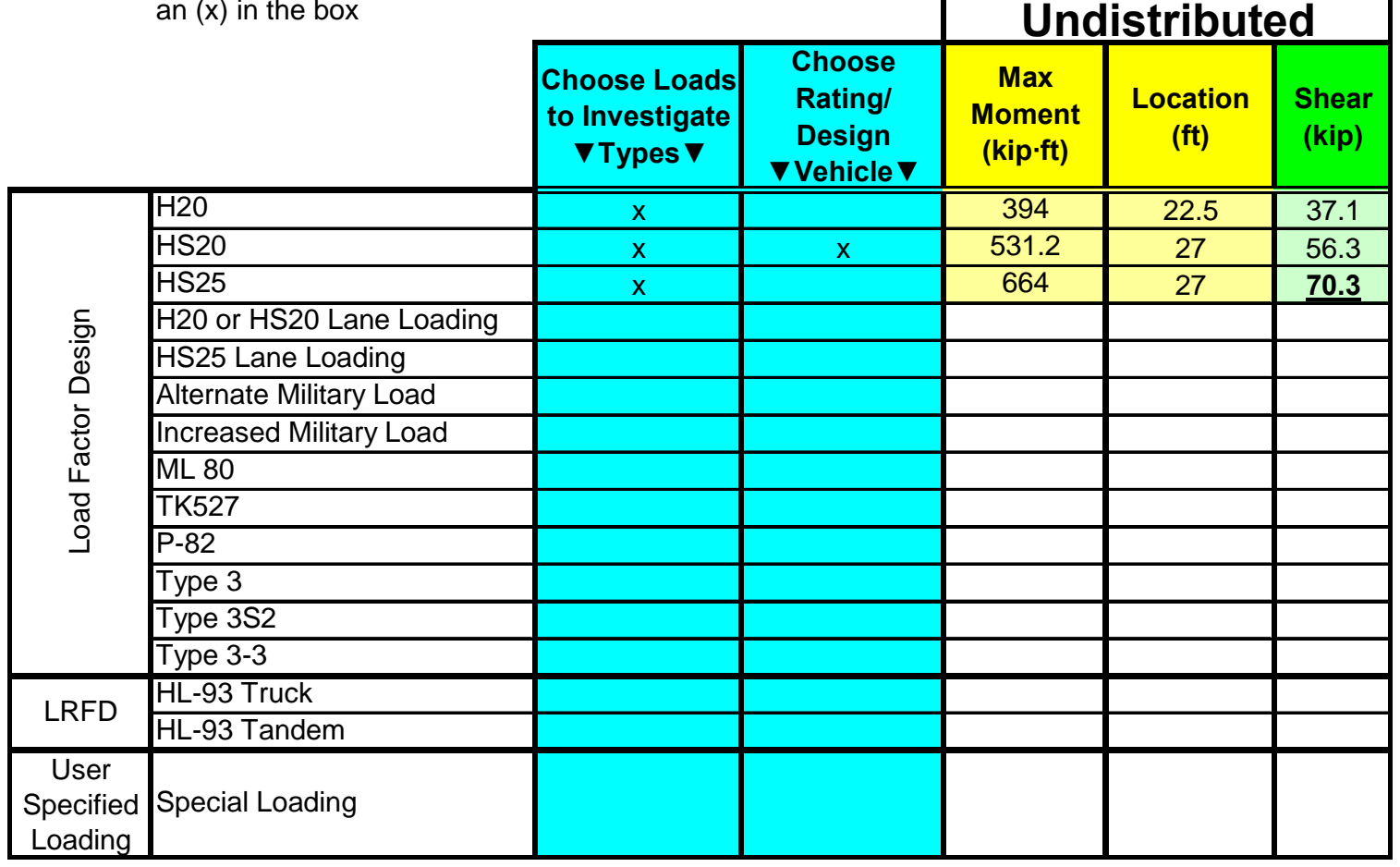

If strengthening based on a loading vehicle requirement is desired, the user must select the loading vehicle(s) to design for by placing an " $\mathrm{x}$ " in the appropriate cell under “Choose Rating/Design Vehicle.” The program will select the maximum force effect at 
each investigation point resulting from the selected design vehicles during strengthening analysis.

The user specified live load vehicle information is entered into the table shown in Table 5.8. The user can enter a vehicle with up to ten axles and name the vehicle loading. The program modifies the table to account for different axles and directs the user where to input the information. The axle load and spacing must be entered into each required cell.

Table 5.8 Sample Special Loading Vehicle Input Data Table If User Specified Loading is Chosen, fill in the following

\begin{tabular}{|c|c|c|c|c|}
\hline $\begin{array}{r}\# \text { of Axle Loads = } \\
\text { Name of Loading = }\end{array}$ & 10 & \multicolumn{2}{|l|}{$(\max 10)$} & \\
\hline Axle \# & & $\begin{array}{l}\text { Axle Load } \\
\text { (kip) }\end{array}$ & $\begin{array}{c}\text { Axle } \\
\text { Spacing (ft) }\end{array}$ & \\
\hline 1 & Enter Data--> & 4 & 0 & $<---A l w a y s 0$ \\
\hline 2 & Enter Data--> & 4 & 4 & <--Enter Data \\
\hline 3 & Enter Data--> & & & <--Enter Data \\
\hline 4 & Enter Data--> & & & <--Enter Data \\
\hline 5 & Enter Data--> & & & <--Enter Data \\
\hline 6 & Enter Data--> & & & <--Enter Data \\
\hline 7 & Enter Data--> & & & <--Enter Data \\
\hline 8 & Enter Data--> & & & <--Enter Data \\
\hline 9 & Enter Data--> & & & <--Enter Data \\
\hline 10 & Enter Data--> & & & <--Enter Data \\
\hline
\end{tabular}

\subsubsection{Program Analysis Calculations}

The structural analysis calculations follow AASHTO Manual, AASHTO Specifications, and ACI Manual analysis protocol. The detailed analysis calculation equations are presented in Appendix C. There are two identical sheets within the program dedicated to the structural analysis and load rating of the beams. One of the sheets covers the as-built or deteriorated analysis and the other sheet calculates the 
original design capacity. The calculation tables are separated in a similar manner as the input data tables. The general sequence of analysis is shown in Figure 5.4. The program calculates three values at each investigation point that are required for load rating analysis: the ultimate capacity, dead load force effect, and live load force effect.

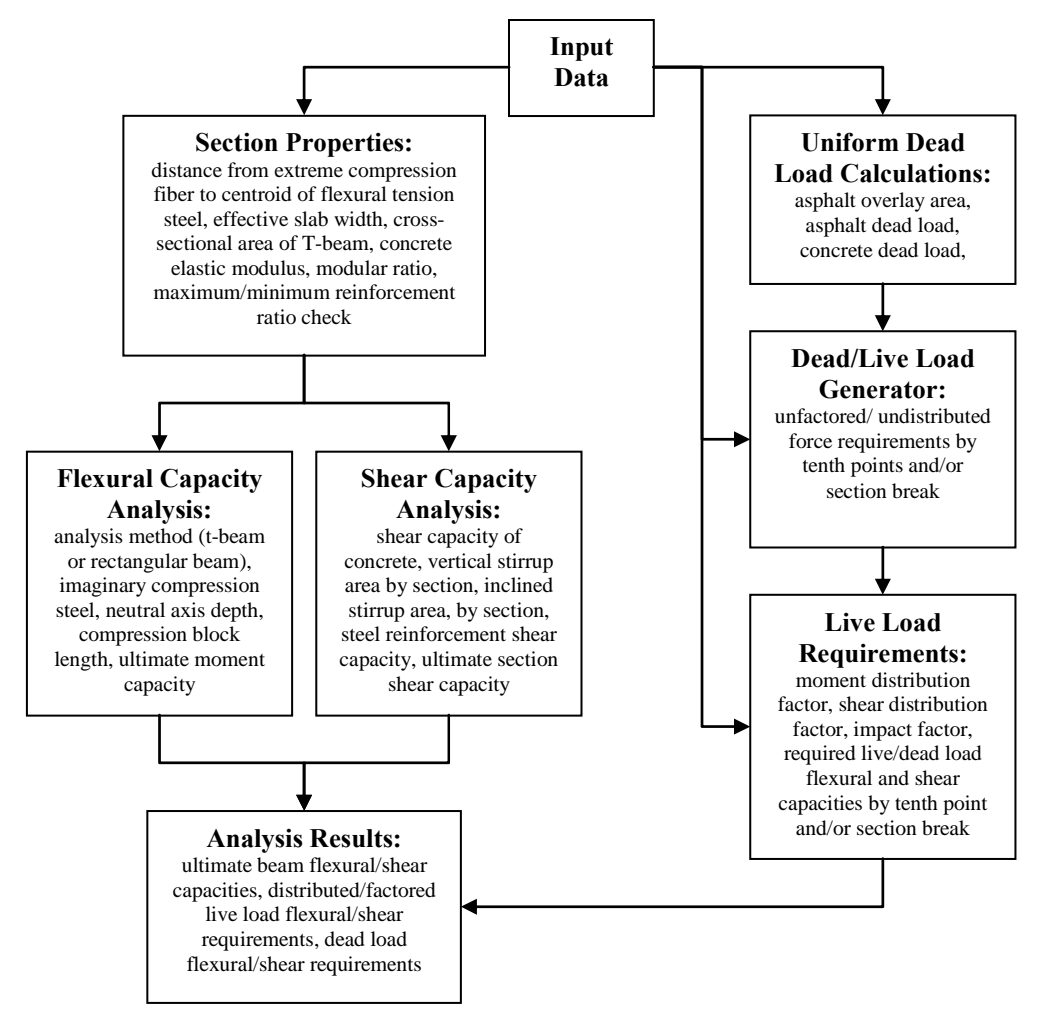

Figure 5.4 Concrete T-Beam Analysis Calculation Sequence

Universal variables that are applicable to any beam are shown in Table 5.9. These variables include the: concrete elastic modulus, steel elastic modulus, modular ratio, beta factor, impact factor, allowable shear stress in concrete, inclined stirrup angle with respect to horizontal in radians, original area of vertical stirrup, and shear phi factor. 
Table 5.9 Sample Universal Variable Analysis Results

\begin{tabular}{|c|c|c|c|}
\hline Elastic Modulus for Concrete & $E_{c}$ & (psi) & 3321000 \\
\hline Elastic Modulus for Steel & $E_{s}$ & (psi) & 29000000 \\
\hline Beta & $\bar{\beta}$ & & 0.85 \\
\hline Modular Ratio & $\mathrm{n}$ & & 9 \\
\hline Impact Factor & $\mathrm{I}$ & & 0.3 \\
\hline Shear Stress Taken by Concrete & $\mathrm{v}_{\mathrm{c}}$ & (psi) & 71.20 \\
\hline Inclined Stirrup Angle with Respect to Horizontal & \multicolumn{2}{|c|}{ (radians) } & 0.785 \\
\hline Original Area of Single Vertical Stirrup & $A_{v v 1}{ }^{0}$ & $\left(\right.$ in. $\left.^{2}\right)$ & 0.393 \\
\hline Shear Phi Factor & \multicolumn{2}{|c|}{$\overline{\Phi_{\mathrm{v}}}$} & 0.85 \\
\hline
\end{tabular}

Load rating calculations are based on Load Factor Design philosophy. The inventory and operating ratings are calculated for each selected loading vehicle at every tenth point and shear investigation point. The bridge capacity calculations are also performed and displayed to the user in the program load rating summary tables. The load rating and bridge capacity equations used are from the AASHTO Manual for Condition Evaluation of Bridges (1994).

Load Rating Equation:

$$
R F=\frac{C-A_{1} D L}{A_{2} L L(1+I)} \quad \text { (AASHTO Manual Eqn. 6-1a) }
$$

where:

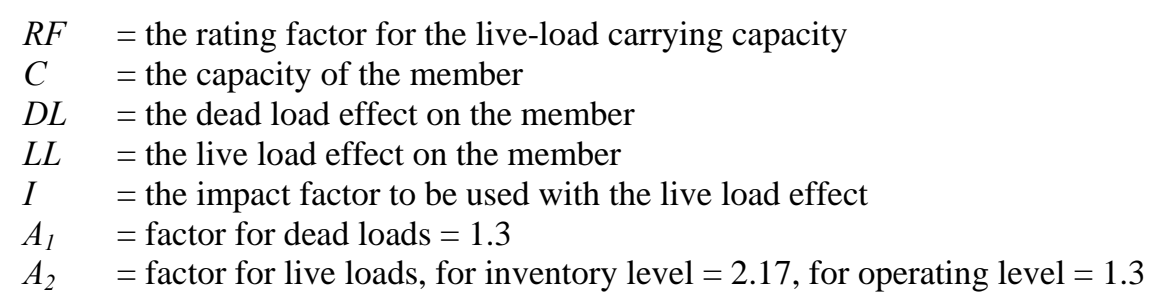


Bridge Capacity:

$$
R T=(R F) W
$$

(AASHTO Manual Eqn. 6-1b)

where:

$$
\begin{array}{ll}
R T & =\text { bridge member capacity rating } \\
W & =\text { weight of the nominal truck used in determining the live load effect }
\end{array}
$$

\subsubsection{Beam Flexural Capacity Analysis}

The flexural properties of the beam are calculated in the table shown in Table 5.10. Ultimate capacity calculation variables computed in the table are the: distance from extreme compression fiber to the centroid of flexural tension steel reinforcement, effective slab width, maximum and minimum reinforcement ratio check, steel tension force capacity, concrete compressive force capacity, T-Beam behavior possibility, analysis approach, neutral axis depth, compression block length, and the ultimate moment capacity of the beam. The program modifies itself to account for T-Beam behavior and incorporates imaginary compression steel area if necessary. 
Table 5.10 Sample Beam Specific Flexural Analysis Results

\begin{tabular}{|c|c|c|c|c|}
\hline & \\
\hline & & & 3 & 4 \\
\hline Ext. Comp. Fiber- $A_{s}$ Centroid Dist. & $d$ & (in.) & 37.63 & 37.63 \\
\hline Effective Slab Width & $b_{\text {eff }}$ & (in.) & 58.00 & 58.00 \\
\hline Cross-sectional Area of T-Beam & $\mathrm{A}_{\mathrm{T}-\mathrm{Beam}}$ & $\left(\right.$ in. $\left.^{2}\right)$ & 1072 & 1072 \\
\hline Asphalt Overlay Area & $\mathrm{A}_{\mathrm{AC}}$ & $\left(\right.$ in. $\left.^{2}\right)$ & 261.00 & 261.00 \\
\hline Asphalt Dead Load & $\mathrm{w}_{\mathrm{A}}$ & (kip/ft) & 0.272 & 0.272 \\
\hline Concrete Dead Load & $\mathrm{w}_{\mathrm{C}}$ & (kip/ft) & 1.117 & 1.117 \\
\hline Uniform Dead Load & $W_{D L}$ & (kip/ft) & 1.707 & 1.707 \\
\hline Moment Distribution Factor & $\mathrm{DF}_{\mathrm{M}}$ & & 0.403 & 0.403 \\
\hline Maximum Dead Load Moment & $\mathrm{M}_{\mathrm{DL}}$ & (kip-ft) & 432.1 & 432.1 \\
\hline Max Undistributed LL Moment/Truck & $\mathrm{M}_{\mathrm{LL}}{ }^{0}$ & (kip-ft) & 664.00 & 664.00 \\
\hline Maximum Distributed LL + Impact Factor & $\mathrm{M}_{\mathrm{LL+1}}$ & (kip-ft) & 346.10 & 346.10 \\
\hline Maximum Reinforcement Ratio Check & $\rho_{\max }$ & OK/FAIL & OK & OK \\
\hline Minimum Reinforcement Ratio Check & $\rho_{\min }$ & OK/FAIL & OK & OK \\
\hline Imaginary Compression Steel & $A_{s f}$ & $\left(\right.$ in. $\left.^{2}\right)$ & 22.95 & 22.95 \\
\hline Tension Force Capacity & $\mathrm{T}$ & Ibs & 405000 & 405000 \\
\hline Flange Compression Force Capacity & $\mathrm{C}$ & Ibs & 357000 & 1183200 \\
\hline \multirow[t]{2}{*}{ T-Beam Behavior Possibility? T>C } & \multicolumn{2}{|c|}{ YES/NO } & YES & NO \\
\hline & $\omega$ & & 0.062 & 0.062 \\
\hline Neutral Axis Depth & $\mathrm{c}$ & (in.) & 3.23 & 3.23 \\
\hline Analysis Approach & & & $\begin{array}{c}\text { Rectangular } \\
\text { Beam }\end{array}$ & $\begin{array}{c}\text { Rectangular } \\
\text { Beam }\end{array}$ \\
\hline Compression Block Length & $\mathrm{a}$ & (in.) & 2.74 & 2.74 \\
\hline Ultimate Moment Capacity & $\mathrm{M}_{U}$ & (kip-ft) & 1101 & 1101 \\
\hline
\end{tabular}

The variables concerning the maximum dead and live load moment of the beam are also displayed in the table shown in Table 5.11. The asphalt area, asphalt uniform dead load, concrete uniform dead load, and maximum dead load moment calculations are handled within the table. The moment distribution factor, unfactored/undistributed maximum loading vehicle moment, and distributed live load moment with impact factor calculation results are shown in the table. Table 5.11 allows the user to check which loading vehicle selected is controlling the maximum moment values at each tenth point. 
A similar table is used to calculate the unfactored and undistributed moment for the strengthening design vehicle(s) chosen.

Table 5.11 Sample Live Load Generator Results Table

\begin{tabular}{|c|c|c|c|c|c|c|c|c|c|c|c|c|}
\hline & & \multicolumn{11}{|c|}{ Tenth Point Maximum Moment Values (kip·ft) } \\
\hline & Section \# & 0.0 & 0.1 & $\overline{0.2}$ & 0.3 & $\overline{0.4}$ & 0.5 & 0.6 & 0.7 & 0.8 & 0.9 & $\overline{1.0}$ \\
\hline & Distance $(\mathrm{ft})$ & 0.0 & 4.5 & 9.0 & 13.5 & 18.0 & 22.5 & 27.0 & 31.5 & 36.0 & 40.5 & 45.0 \\
\hline \multirow{16}{*}{ 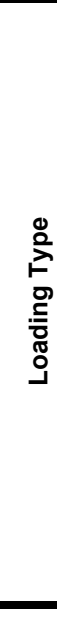 } & $\mathrm{H} 20$ & $\overline{0}$ & 150.8 & 265.6 & 344.4 & 387.2 & 394 & $\begin{array}{l}364.8 \\
\end{array}$ & 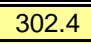 & 230.4 & $\begin{array}{l}129.6 \\
\end{array}$ & 0 \\
\hline & $\mathrm{HS} 2 \mathrm{O}$ & 0 & 224.4 & 384 & 478.8 & 512 & 530 & 531.2 & 470.4 & 371.2 & 214.4 & 0 \\
\hline & HS25 & 0 & 280.5 & 480 & 598.5 & 640 & 662.5 & 664 & 588 & 464 & 268 & 0 \\
\hline & & & & & & & & & & & & \\
\hline & & & & & & & & & & & & \\
\hline & & & & & & & & & & & & \\
\hline & & & & & & & & & & & & \\
\hline & & & & & & & & & & & & \\
\hline & & & & & & & & & & & & \\
\hline & & & & & & & & & & & & \\
\hline & & & & & & & & & & & & \\
\hline & & & & & & & & & & & & \\
\hline & & & & & & & & & & & & \\
\hline & & & & & & & & & & & & \\
\hline & & & & & & & & & & & & \\
\hline & Maximum (kips) & 0 & 280.5 & 4880 & 598.5 & 6440 & 662.5 & 6664 & 588 & 464 & 268 & $\overline{0}$ \\
\hline
\end{tabular}

A sample load rating analysis for each selected loading vehicle is shown in Table 5.12. The program displays the maximum force effect results at each tenth for each selected loading vehicle and calculates the inventory and operating rating factors. An example of the use of colors within the program to keep track of data within large tables can be seen in Table 5.12. The empty data cells shown in the table represent the unselected loading vehicles. This data is not shown so as to only present the user with the information that is desired. 
Table 5.12 Sample Tenth Point Flexural Load Rating Calculation Table Tenth Point Moment Analysis

\begin{tabular}{|c|c|c|c|c|c|c|c|}
\hline & \multirow{3}{*}{$\begin{array}{c}3 \\
0.0\end{array}$} & \multirow{3}{*}{$\begin{array}{c}4 \\
0.0 \\
\end{array}$} & \multirow{3}{*}{$\begin{array}{c}3 \\
0.0 \\
\end{array}$} & \multirow{3}{*}{$\begin{array}{c}4 \\
0.0\end{array}$} \\
\hline & & & & & & & \\
\hline \multirow{6}{*}{0} & Maximum Moment @ $0 \mathrm{ft}$ Due to Dead Load & $\mathrm{M}_{\mathrm{DL}, 0}$ & (kips) & & & & \\
\hline & Max. Moment @ 0 ft Due to Undist. Live Load & $\mathrm{M}_{\mathrm{LL}, 0}{ }^{0}$ & (kips) & 0.0 & 0.0 & 0.0 & 0.0 \\
\hline & Max. Moment @ 0 ft Due to Dist. Live Load & $\mathrm{M}_{\mathrm{LL}, 0}$ & (kips) & 0.0 & 0.0 & 0.0 & 0.0 \\
\hline & Ultimate Moment Capacity @ 0 ft & $\mathrm{M}_{\mathrm{U}, 0}$ & (kips) & 1101.3 & 1101.3 & 1101.3 & 1101.3 \\
\hline & Moment Inventory Rating Factor @ 0 ft & $\mathrm{RF}_{\mathrm{MIR}, 0}$ & & - & - & - & - \\
\hline & Moment Operating Rating Factor @ 0 ft & $\mathrm{RF}_{\mathrm{MOR}, 0}$ & & - & - & - & - \\
\hline \multirow{6}{*}{4.5} & Maximum Moment @ $4.5 \mathrm{ft}$ Due to Dead Load & $\mathrm{M}_{\mathrm{DL}, 0.1}$ & (kips) & 155.6 & 155.6 & 155.6 & 155.6 \\
\hline & Max. Moment @ 4.5 ft Due to Undist. Live Load & $\mathrm{M}_{\mathrm{LL}, 0.1}{ }^{0}$ & (kips) & 150.8 & 150.8 & 224.4 & 224.4 \\
\hline & Max. Moment @ $4.5 \mathrm{ft}$ Due to Dist. Live Load & $\mathrm{M}_{\mathrm{LL}, 0.1}$ & (kips) & 78.6 & 78.6 & 117.0 & 117.0 \\
\hline & Ultimate Moment Capacity @ $4.5 \mathrm{ft}$ & $M_{U, 0.1}$ & (kips) & 1101.3 & 1101.3 & 1101.3 & 1101.3 \\
\hline & Moment Inventory Rating Factor @ $4.5 \mathrm{ft}$ & $\mathrm{RF}_{\mathrm{MIR}, 0.1}$ & & 5.27 & 5.27 & 3.54 & 3.54 \\
\hline & Moment Operating Rating Factor @ $4.5 \mathrm{ft}$ & $\mathrm{RF}_{\mathrm{MOR}, 0.1}$ & & 8.80 & 8.80 & 5.91 & 5.91 \\
\hline \multirow{6}{*}{9} & Maximum Moment @ $9 \mathrm{ft}$ Due to Dead Load & $\mathrm{M}_{\mathrm{DL}, 0.2}$ & (kips) & 276.5 & 276.5 & 276.5 & 276.5 \\
\hline & ft Due to Undist. Live Load & $\mathrm{M}_{\mathrm{LL}, 0.2^{0}}$ & (kips) & 265.6 & 265.6 & 384.0 & 384.0 \\
\hline & Max. Moment @ $9 \mathrm{ft}$ Due to Dist. Live Load & $\mathrm{M}_{\mathrm{LL}, 0.2}$ & (kips) & 138.4 & 138.4 & 200.2 & 200.2 \\
\hline & Ultimate Moment Capacity @ 9 ft & $\mathrm{M}_{\mathrm{U}, 0.2}$ & (kips) & 1101.3 & 1101.3 & 1101.3 & 1101.3 \\
\hline & Moment Inventory Rating Factor @ 9 ft & $\mathrm{RF}_{\mathrm{MIR}, 0.2}$ & & 2.47 & 2.47 & 1.71 & 1.71 \\
\hline & Moment Operating Rating Factor @ $9 \mathrm{ft}$ & $\mathrm{RF}_{\mathrm{MOR}, 0.2}$ & & 4.12 & 4.12 & 2.85 & 2.85 \\
\hline \multirow{6}{*}{13.5} & Maximum Moment @ $13.5 \mathrm{ft}$ Due to Dead Load & $\mathrm{M}_{\mathrm{DL}, 0.3}$ & (kips) & 363.0 & 363.0 & 363.0 & 363.0 \\
\hline & Max. Moment @ 13.5 ft Due to Undist. Live Load & $\mathrm{M}_{\mathrm{LL}, 0.3^{0}}$ & (kips) & 344.4 & 344.4 & 478.8 & 478.8 \\
\hline & Max. Moment @ 13.5 ft Due to Dist. Live Load & $\mathrm{M}_{\mathrm{LL}, 0.3}$ & (kips) & 179.5 & 179.5 & 249.6 & 249.6 \\
\hline & Ultimate Moment Capacity @ $13.5 \mathrm{ft}$ & $\mathrm{M}_{\mathrm{U}, 0.3}$ & (kips) & 1101.3 & 1101.3 & 1101.3 & 1101.3 \\
\hline & Moment Inventory Rating Factor @ $13.5 \mathrm{ft}$ & $\mathrm{RF}_{\mathrm{MIR}, 0.3}$ & & 1.62 & 1.62 & 1.16 & 1.16 \\
\hline & Moment Operating Rating Factor @ $13.5 \mathrm{ft}$ & $\mathrm{RF}_{\mathrm{MOR}, 0.3}$ & & 2.70 & 2.70 & 1.94 & 1.94 \\
\hline \multirow{6}{*}{1} & Maximum Moment @ $18 \mathrm{ft}$ Due to Dead Load & $\mathrm{M}_{\mathrm{DL}, 0.4}$ & (kips) & 414.8 & 414.8 & 414.8 & 414.8 \\
\hline & Max. Moment @ 18 ft Due to Undist. Live Load & $\mathrm{M}_{\mathrm{LL}, 0.4^{0}}$ & (kips) & 387.2 & 387.2 & 531.2 & 531.2 \\
\hline & Max. Moment @ $18 \mathrm{ft}$ Due to Dist. Live Load & $\mathrm{M}_{\mathrm{LL}, 0.4}$ & (kips) & 201.8 & 201.8 & 276.9 & 276.9 \\
\hline & Ultimate Moment Capacity @ $18 \mathrm{ft}$ & $\mathrm{M}_{\mathrm{U}, 0.4}$ & (kips) & 1101.3 & 1101.3 & 1101.3 & 1101.3 \\
\hline & Moment Inventory Rating Factor @ $18 \mathrm{ft}$ & $\mathrm{RF}_{\mathrm{MIR}, 0.4}$ & & 1.28 & 1.28 & 0.94 & 0.94 \\
\hline & Moment Operating Rating Factor @ $18 \mathrm{ft}$ & $\mathrm{RF}_{\mathrm{MOR}, 0.4}$ & & 2.14 & 2.14 & 1.56 & 1.56 \\
\hline \multirow{6}{*}{22.5} & Maximum Moment @ $22.5 \mathrm{ft}$ Due to Dead Load & $\mathrm{M}_{\mathrm{DL}, 0.5}$ & (kips) & 432.1 & 432.1 & 432.1 & 432.1 \\
\hline & Max. Moment @ 22.5 ft Due to Undist. Live Load & $\mathrm{M}_{\mathrm{LL}, 0.5}{ }^{0}$ & (kips) & 394.0 & 394.0 & 530.0 & 530.0 \\
\hline & Max. Moment @ 22.5 ft Due to Dist. Live Load & $\mathrm{M}_{\mathrm{LL}, 0.5}$ & (kips) & 205.4 & 205.4 & 276.3 & 276.3 \\
\hline & Ultimate Moment Capacity @ $22.5 \mathrm{ft}$ & $\mathrm{M}_{\mathrm{U}, 0.5}$ & (kips) & 1101.3 & 1101.3 & 1101.3 & 1101.3 \\
\hline & Moment Inventory Rating Factor @ $22.5 \mathrm{ft}$ & $\mathrm{RF}_{\mathrm{MIR}, 0.5}$ & & 1.21 & 1.21 & 0.90 & 0.90 \\
\hline & Moment Operating Rating Factor @ 22.5 ft & $\mathrm{RF}_{\mathrm{MOR}, 0.5}$ & & 2.02 & 2.02 & 1.50 & 1.50 \\
\hline
\end{tabular}

\subsubsection{Beam Shear Capacity Analysis}

The shear capacity calculations are split into separate tables. The sample table

shown in Table 5.13 displays the results that are applicable to each shear section being 
analyzed. The shear capacity of the concrete, original vertical stirrup area, and shear distribution factor for each beam are displayed in this table.

Table 5.13 Sample Shear Analysis Results Table
\begin{tabular}{|l|c|c|c|}
\cline { 3 - 4 } & \multicolumn{1}{c}{} & 3 & 4 \\
\hline Shear Capacity of Concrete & (lbs) & 72128 & 72128 \\
\hline Original Vertical Stirrup Area & (in. $\left.{ }^{2}\right)$ & 0.393 & 0.393 \\
\hline Shear Distribution Facor & & 0.586 & 0.586 \\
\hline
\end{tabular}

The ultimate shear capacity calculation of each section is computed in the table shown in Table 5.14. The program calculates the effective vertical and inclined shear reinforcement steel area then calculates its capacity and the beam's ultimate shear capacity at each section. Once the shear capacity of each section has been calculated, the program calculates the ultimate shear capacity at each tenth point as shown in Table 5.15. 
Table 5.14 Sample Section Shear Capacity Results Table

\begin{tabular}{|c|c|c|c|c|}
\hline Section \# & & & 3 & 4 \\
\hline \multirow{4}{*}{1} & Vertical Stirrup Area in Section 1 & $\left(\right.$ in. $\left.^{2}\right)$ & 0.353 & 0.353 \\
\hline & Inclined Stirrup Area in Section 1 & $\left(\right.$ in. $\left.^{2}\right)$ & 0.00 & 0.00 \\
\hline & Shear Reinforcement Capacity in Section 1 & (lbs) & 120000 & 120000 \\
\hline & Ultimate Shear Capacity in Section 1 & (lbs) & 163000 & 163000 \\
\hline \multirow{4}{*}{2} & Vertical Stirrup Area in Section 2 & $\left(\right.$ in. $\left.^{2}\right)$ & 0.353 & 0.353 \\
\hline & Inclined Stirrup Area in Section 2 & $\left(\right.$ in. $\left.^{2}\right)$ & 2.81 & 2.81 \\
\hline & Shear Reinforcement Capacity in Section 2 & (lbs) & 196000 & 196000 \\
\hline & Ultimate Shear Capacity in Section 2 & (lbs) & 228000 & 228000 \\
\hline \multirow{4}{*}{3} & Vertical Stirrup Area in Section 3 & $\left(\right.$ in. $\left.^{2}\right)$ & 0.353 & 0.353 \\
\hline & Inclined Stirrup Area in Section 3 & $\left(\right.$ in. $\left.^{2}\right)$ & 2.81 & 2.81 \\
\hline & Shear Reinforcement Capacity in Section 3 & (lbs) & 196000 & 196000 \\
\hline & Ultimate Shear Capacity in Section 3 & (lbs) & 228000 & 228000 \\
\hline \multirow{4}{*}{4} & Vertical Stirrup Area in Section 4 & $\left(\right.$ in. $\left.^{2}\right)$ & 0.353 & 0.353 \\
\hline & Inclined Stirrup Area in Section 4 & $\left(\right.$ in. $\left.^{2}\right)$ & 2.81 & 2.81 \\
\hline & Shear Reinforcement Capacity in Section 4 & (lbs) & 183000 & 183000 \\
\hline & Ultimate Shear Capacity in Section 4 & (lbs) & 217000 & 217000 \\
\hline \multirow{4}{*}{5} & Vertical Stirrup Area in Section 5 & $\left(\right.$ in. $\left.^{2}\right)$ & 0.353 & 0.353 \\
\hline & Inclined Stirrup Area in Section 5 & $\left(\right.$ in. $\left.^{2}\right)$ & 0.00 & 0.00 \\
\hline & Shear Reinforcement Capacity in Section 5 & $(\mathrm{lbs})$ & 40000 & 40000 \\
\hline & Ultimate Shear Capacity in Section 5 & (lbs) & 95000 & 95000 \\
\hline \multirow{4}{*}{6} & Vertical Stirrup Area in Section 6 & $\left(\right.$ in. $\left.^{2}\right)$ & 0.353 & 0.353 \\
\hline & Inclined Stirrup Area in Section 6 & $\left(\right.$ in. $\left.^{2}\right)$ & 0.00 & 0.00 \\
\hline & Shear Reinforcement Capacity in Section 6 & (lbs) & 27000 & 27000 \\
\hline & Ultimate Shear Capacity in Section 6 & (lbs) & 84000 & 84000 \\
\hline \multirow{4}{*}{7} & Vertical Stirrup Area in Section 7 & $\left(\right.$ in. $\left.^{2}\right)$ & 0.353 & 0.353 \\
\hline & Inclined Stirrup Area in Section 7 & $\left(\right.$ in. $\left.^{2}\right)$ & 0.00 & 0.00 \\
\hline & Shear Reinforcement Capacity in Section 7 & $(\mathrm{lbs})$ & 20000 & 20000 \\
\hline & Ultimate Shear Capacity in Section 7 & (lbs) & 78000 & 78000 \\
\hline \multirow{4}{*}{8} & Vertical Stirrup Area in Section 8 & $\left(\right.$ in. $\left.^{2}\right)$ & 0.000 & 0.000 \\
\hline & Inclined Stirrup Area in Section 8 & $\left(\right.$ in. $\left.^{2}\right)$ & 0.00 & 0.00 \\
\hline & Shear Reinforcement Capacity in Section 8 & (lbs) & 0 & 0 \\
\hline & Ultimate Shear Capacity in Section 8 & (lbs) & 61000 & 61000 \\
\hline
\end{tabular}


Table 5.15 Sample Tenth Point Shear Capacity Results Table

\begin{tabular}{|c|c|c|c|c|c|c|c|}
\hline & \multicolumn{9}{|c|}{3} & \multicolumn{2}{|c|}{3} & \multicolumn{3}{|c|}{4} \\
$\mathbf{x}$ & $\begin{array}{c}\text { Tenth } \\
\text { Point }\end{array}$ & $\begin{array}{c}\text { In Section } \\
\#\end{array}$ & $\begin{array}{c}\text { Shear } \\
\text { Stirrup } \\
\text { Capacity } \\
\text { (lbs) }\end{array}$ & $\begin{array}{c}\text { Shear } \\
\text { Capacity } \\
\text { (Ibs) }\end{array}$ & $\begin{array}{c}\text { Shear } \\
\text { Stirrup } \\
\text { Capacity } \\
\text { (lbs) }\end{array}$ & $\begin{array}{c}\text { Shear } \\
\text { Capacity } \\
\text { (Ibs) }\end{array}$ \\
\hline \hline 0 & 1 & 1 & 120000 & 163000 & 1 & 120000 & 163000 \\
\hline 4.5 & 2 & 3 & 196000 & 228000 & 3 & 196000 & 228000 \\
\hline 9 & 3 & 6 & 27000 & 84000 & 6 & 27000 & 84000 \\
\hline 13.5 & 4 & 6 & 27000 & 84000 & 6 & 27000 & 84000 \\
\hline 18 & 5 & 8 & 0 & 61000 & 8 & 0 & 61000 \\
\hline 22.5 & 6 & 8 & 0 & 61000 & 8 & 0 & 61000 \\
\hline
\end{tabular}

The required dead load resistance at each shear investigation point is displayed in Table 34. The results from the live load generator analysis, dead load analysis, and ultimate shear capacity are displayed in the table shown in Table 35. This table is where the shear load rating analysis for each loading vehicle is performed. A similar table is used to calculate the shear load ratings at each tenth point.

Table 5.16 Sample Dead Load Shear Results Table

\begin{tabular}{|c|c|c|c|c|c|c|c|c|}
\multicolumn{1}{c|}{} & \multicolumn{7}{c|}{3 Girder Shear Values Due to Dead Load } \\
\hline Point \# & $\mathbf{1}$ & $\mathbf{2}$ & $\mathbf{3}$ & $\mathbf{4}$ & $\mathbf{5}$ & $\mathbf{6}$ & $\mathbf{7}$ & $\mathbf{8}$ \\
\hline Distance (ft) & $\mathbf{0 . 0 0}$ & $\mathbf{0 . 3 3}$ & $\mathbf{2 . 5 8}$ & $\mathbf{4 . 8 3}$ & $\mathbf{5 . 8 3}$ & $\mathbf{8 . 8 3}$ & $\mathbf{1 4 . 8 3}$ & $\mathbf{1 6 . 5 0}$ \\
\hline \hline $\begin{array}{c}\text { Dead Load } \\
\text { Shear (kips) }\end{array}$ & 38.4 & 37.8 & 34.0 & 30.2 & 28.5 & 23.3 & 13.1 & 10.2 \\
\hline
\end{tabular}


Table 5.17 Sample Shear Load Rating Calculation Table By Section Break

\begin{tabular}{|c|c|c|c|c|c|c|c|c|}
\hline & & (kips & 38.4 & 38.4 & 38.4 & 38.4 & 38.4 & 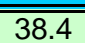 \\
\hline & Max. Shear in Section 1 Due to Undist. Live Load & (kips) & 37.1 & 37.1 & 52.3 & 52.3 & 70.3 & 70.3 \\
\hline & Max. Shear in Section 1 Due to Dist. Live Load & (kips) & 28.1 & 28.1 & 39.7 & 39.7 & 53.3 & 53.3 \\
\hline & Ultimate Shear Capacity of Section 1 & (kips) & 163.0 & 163.0 & 163.0 & 163.0 & 163.0 & 163.0 \\
\hline & Shear Inventory Rating Factor of Section 1 & & 1.85 & 1.85 & 1.31 & 1.31 & 0.98 & 0.98 \\
\hline & Shear Operating Rating Factor of Section 1 & & 3.09 & 3.09 & 2.19 & 2.19 & 1.63 & 1.63 \\
\hline & Maximum Shear in Section 2 Due to Dead Load & (kips) & 37.8 & 37.8 & 37.8 & 37.8 & 37.8 & 37.8 \\
\hline & Max. Shear in Section 2 Due to Undist. Live Load & (kips) & 37.1 & 37.1 & 56.3 & 56.3 & 70.3 & 70.3 \\
\hline & Max. Shear in Section 2 Due to Dist. Live Load & (kips) & 28.1 & 28.1 & 42.7 & 42.7 & 53.3 & 53.3 \\
\hline 2 & Ultimate Shear Capacity of Section 2 & (kips) & 228.0 & 228.0 & 228.0 & 228.0 & 228.0 & 228.0 \\
\hline & Shear Inventory Rating Factor of Section 2 & & 2.93 & 2.93 & 1.93 & 1.93 & 1.55 & 1.55 \\
\hline & Shear Operating Rating Factor of Section 2 & & 4.89 & 4.89 & 3.22 & 3.22 & 2.58 & 2.58 \\
\hline & Maximum Shear in Section 3 Due to Dead Load & (kips) & 34.0 & 34.0 & 34.0 & 34.0 & 34.0 & 34.0 \\
\hline & Max. Shear in Section 3 Due to Undist. Live Load & (kips) & 34.8 & 34.8 & 52.3 & 52.3 & 65.3 & 65.3 \\
\hline 3 & Max. Shear in Section 3 Due to Dist. Live Load & (kips) & 26.4 & 26.4 & 39.7 & 39.7 & 49.5 & 49.5 \\
\hline & Ultimate Shear Capacity of Section 3 & (kips) & 228.0 & 228.0 & 228.0 & 228.0 & 228.0 & 228.0 \\
\hline & Shear Inventory Rating Factor of Section 3 & & 3.21 & 3.21 & 2.13 & 2.13 & 1.71 & 1.71 \\
\hline & Shear Operating Rating Factor of Section 3 & & 5.36 & 5.36 & 3.56 & 3.56 & 2.85 & 2.85 \\
\hline & Maximum Shear in Section 4 Due to Dead Load & (kips) & 30.2 & 30.2 & 30.2 & 30.2 & 30.2 & 30.2 \\
\hline & Max. Shear in Section 4 Due to Undist. Live Load & (kips) & 33.1 & 33.1 & 49.1 & 49.1 & 61.3 & 61.3 \\
\hline & Max. Shear in Section 4 Due to Dist. Live Load & (kips) & 25.1 & 25.1 & 37.2 & 37.2 & 46.5 & 46.5 \\
\hline 4 & Ultimate Shear Capacity of Section 4 & (kips) & 217.0 & 217.0 & 217.0 & 217.0 & 217.0 & 217.0 \\
\hline & Shear Inventory Rating Factor of Section 4 & & 3.26 & 3.26 & 2.20 & 2.20 & 1.76 & 1.76 \\
\hline & Shear Operating Rating Factor of Section 4 & & 5.45 & 5.45 & 3.67 & 3.67 & 2.94 & 2.94 \\
\hline & Maximum Shear in Section 5 Due to Dead Load & (kips) & 28.5 & 28.5 & 28.5 & 28.5 & 28.5 & 28.5 \\
\hline & Max. Shear in Section 5 Due to Undist. Live Load & (kips) & 32.2 & 32.2 & 47.5 & 47.5 & 59.3 & 59.3 \\
\hline & Max. Shear in Section 5 Due to Dist. Live Load & (kips) & 24.4 & 24.4 & 36.0 & 36.0 & 45.0 & 45.0 \\
\hline 5 & Ultimate Shear Capacity of Section 5 & (kips) & 95.0 & 95.0 & 95.0 & 95.0 & 95.0 & 95.0 \\
\hline & Shear Inventory Rating Factor of Section 5 & & 1.09 & 1.09 & 0.74 & 0.74 & 0.59 & $\underline{\underline{0.59}}$ \\
\hline & Shear Operating Rating Factor of Section 5 & & 1.83 & 1.83 & 1.24 & 1.24 & 0.99 & 0.99 \\
\hline & Maximum Shear in Section 6 Due to Dead Load & (kips) & 23.3 & 23.3 & 23.3 & 23.3 & 23.3 & 23.3 \\
\hline & Max. Shear in Section 6 Due to Undist. Live Load & (kips) & 29.5 & 29.5 & 42.7 & 42.7 & 53.3 & 53.3 \\
\hline & Max. Shear in Section 6 Due to Dist. Live Load & (kips) & 22.4 & 22.4 & 32.4 & 32.4 & 40.4 & 40.4 \\
\hline 6 & Ultimate Shear Capacity of Section 6 & (kips) & 84.0 & 84.0 & 84.0 & 84.0 & 84.0 & 84.0 \\
\hline & Shear Inventory Rating Factor of Section 6 & & 1.11 & 1.11 & 0.76 & 0.76 & 0.61 & 0.61 \\
\hline & Shear Operating Rating Factor of Section 6 & & 1.84 & 1.84 & 1.27 & 1.27 & 1.02 & 1.02 \\
\hline & Maximum Shear in Section 7 Due to Dead Load & (kips) & 13.1 & 13.1 & 13.1 & 13.1 & 13.1 & 13.1 \\
\hline & Max. Shear in Section 7 Due to Undist. Live Load & (kips) & 24.2 & 24.2 & 33.1 & 33.1 & 41.3 & 41.3 \\
\hline & Max. Shear in Section 7 Due to Dist. Live Load & (kips) & 18.4 & 18.4 & 25.1 & 25.1 & 31.3 & 31.3 \\
\hline & Ultimate Shear Capacity of Section 7 & (kips) & 78.0 & 78.0 & 78.0 & 78.0 & 78.0 & 78.0 \\
\hline & Shear Inventory Rating Factor of Section 7 & & 1.53 & 1.53 & 1.12 & 1.12 & 0.90 & 0.90 \\
\hline & Shear Operating Rating Factor of Section 7 & & 2.56 & 2.56 & 1.87 & 1.87 & 1.50 & 1.50 \\
\hline & Maximum Shear in Section 8 Due to Dead Load & (kips) & 10.2 & 10.2 & 10.2 & 10.2 & 10.2 & 10.2 \\
\hline & Max. Shear in Section 8 Due to Undist. Live Load & (kips) & 22.8 & 22.8 & 30.7 & 30.7 & 38.3 & 38.3 \\
\hline & Max. Shear in Section 8 Due to Dist. Live Load & (kips) & 17.3 & 17.3 & 23.3 & 23.3 & 29.1 & 29.1 \\
\hline & Ultimate Shear Capacity of Section 8 & (kips & 61.0 & 61.0 & 61.0 & 61.0 & 61.0 & 61.0 \\
\hline & Shear Inventory Rating Factor of Section 8 & & 1.27 & 1.27 & 0.94 & 0.94 & 0.76 & 0.76 \\
\hline & Shear Operating Rating Factor of Section 8 & & 2.12 & 2.12 & 1.57 & 1.57 & 1.26 & 1.26 \\
\hline
\end{tabular}




\subsubsection{Dead/Live Load Generator}

Though only one bridge span was investigated during this project, the same structural analysis and load rating calculations are used for any concrete T-Beam span length. The EXCEL live load generator analysis was verified by CONSYS results for multiple span lengths. CONSYS is a commercially available live load generator.

The live load analysis is based on the theory of superposition. The force effects from individual axle loads are calculated at each investigation point. These force effects are then superimposed together to attain the total force effect due to the loading vehicle as it crosses the bridge.

The maximum force effect results are summarized at the top of each loading vehicle analysis sheet as shown in Figure 5.6. The results include the maximum positive moment and location, and the maximum shear to the left and right of each investigation point. 


\section{HS20 Truck}

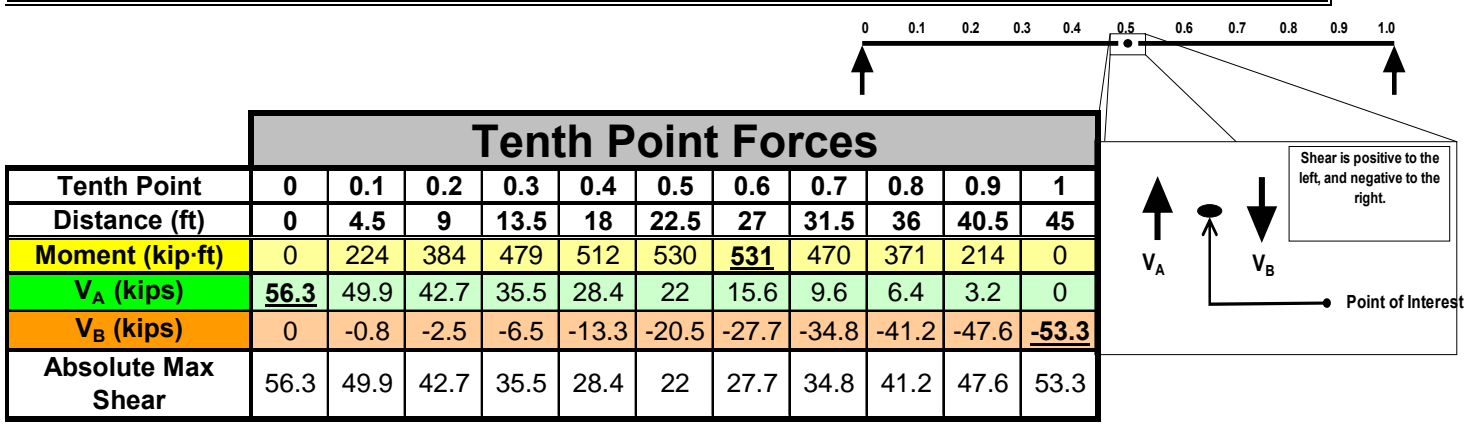

\begin{tabular}{|c|c|c|c|c|c|c|c|c|c|c|c|c|c|c|c|c|}
\hline & & te & 10 & $\mathrm{G}$ & $\mathrm{E}$ & & I & & & & & & & & & \\
\hline Point \# & 1 & 2 & 3 & 4 & 5 & 6 & 7 & 8 & 9 & 10 & 11 & 12 & 13 & 14 & 15 & 16 \\
\hline Distance (ft) & 0.0 & 0.3 & 2.6 & 4.8 & 5.8 & 8.8 & \begin{tabular}{|l|}
14.8 \\
\end{tabular} & 16.5 & 28.5 & 30.2 & 36.2 & 39.2 & 40.2 & 42.4 & 44.7 & 45.0 \\
\hline$V_{A}$ (kips) & 56.3 & 56.3 & 52.3 & \begin{tabular}{|l|l|}
49.1 \\
\end{tabular} & \begin{tabular}{|l|}
47.5 \\
\end{tabular} & 42.7 & 33.1 & 30.7 & 13.5 & 10.7 & 6 & 3.9 & 3.2 & 1.8 & $\overline{0}$ & 0 \\
\hline$V_{B}$ (kips) & 0 & 0 & \begin{tabular}{|l|}
-0.4 \\
\end{tabular} & -0.8 & -1 & -2 & -7.7 & -10.9 & -30.1 & -32.5 & $\mid-41.2$ & -45.5 & -46.9 & -49.8 & -53.3 & -53.3 \\
\hline $\begin{array}{l}\text { Abs Max Used for } \\
\text { Analysis }\end{array}$ & 56.3 & 56.3 & 52.3 & \begin{tabular}{|l|}
$\mid 49.1$ \\
\end{tabular} & 47.5 & 42.7 & 33.1 & \begin{tabular}{|l|}
30.7 \\
\end{tabular} & 30.1 & 32.5 & 41.2 & $\mid 45.5$ & 46.9 & 49.8 & 53.3 & 53.3 \\
\hline
\end{tabular}

\begin{tabular}{|c|c|c|c|c|c|c|c|c|c|c|c|c|c|c|c|c|}
\hline & \multicolumn{16}{|c|}{ Interior Girder Shear Values to Be Used for Analysis } \\
\hline Point \# & 1 & 2 & 3 & 4 & 5 & 6 & 7 & 8 & 9 & 10 & 11 & 12 & 13 & 14 & 15 & \\
\hline Distance (ft) & 0.0 & 0.3 & 2.6 & 4.8 & 5.8 & 8.8 & 14.8 & 16.5 & 28.5 & 30.2 & 36.2 & \begin{tabular}{|l|}
39.2 \\
\end{tabular} & 40.2 & 42.4 & 44.7 & 45.0 \\
\hline $\mathrm{V}_{\mathrm{A}}$ (kips) & 56.3 & 56.3 & \begin{tabular}{|l|l|}
52.3 \\
\end{tabular} & \begin{tabular}{|l|l|}
49.1 \\
\end{tabular} & 47.5 & 42.7 & 33.1 & 30.7 & 13.5 & 10.7 & 6 & 3.9 & 3.2 & 1.8 & 0 & \\
\hline $\mathrm{V}_{B}$ (kips) & 0 & 0 & \begin{tabular}{|l|}
-0.4 \\
\end{tabular} & \begin{tabular}{|l|}
-0.8 \\
\end{tabular} & -1 & -2 & -7.7 & -10.9 & -30.1 & -32.5 & \begin{tabular}{|l|}
-41.2 \\
\end{tabular} & -45.5 & \begin{tabular}{|l|}
-46.9 \\
\end{tabular} & -49.8 & -53.3 & -53. \\
\hline $\begin{array}{l}\text { bs Max Used for } \\
\text { Analysis }\end{array}$ & 56.3 & 56.3 & 52.3 & 49.1 & 47.5 & $\mid 42.7$ & 33.1 & 30.7 & 30.1 & 32.5 & 41.2 & 45.5 & \begin{tabular}{|l|l|}
46.9 & \\
\end{tabular} & \begin{tabular}{|l|}
49.8 \\
\end{tabular} & 53.3 & \\
\hline
\end{tabular}

Figure 5.6 Sample Live Load Generator Results Table

\subsubsection{Program Output}

The program follows the calculation procedure shown in Figure 5.7. Inventory

and operating rating factors and capacities for each loading vehicle selected are

calculated for every tenth point and summarized in the table shown in Table 5.18 for

flexure and shear. The controlling rating factor is also summarized on the left side of the

table. The table has been color formatted to easily recognize moment and shear results.

Moment results are shown in yellow and shear results are shown in green. 


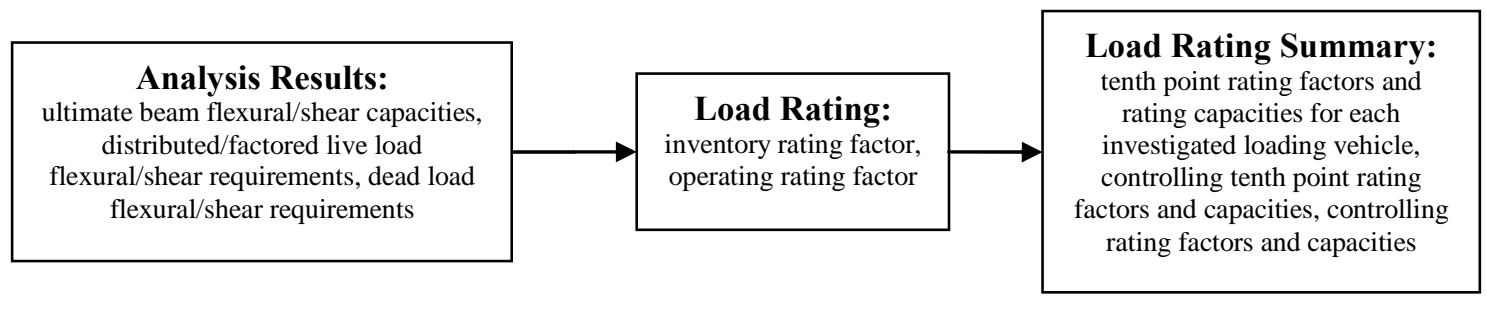

Figure 5.7 Load Rating Analysis Calculation Sequence

Table 5.18 Sample Beam Load Rating Summary Table

\begin{tabular}{|c|c|c|c|c|c|c|c|c|c|c|c|c|c|c|c|c|}
\hline \multirow[b]{3}{*}{$\begin{array}{c}\text { Loading } \\
\text { Vehicle }\end{array}$} & \multirow[b]{3}{*}{$x(f t)$} & & \multicolumn{6}{|c|}{ Controlling } & \multicolumn{4}{|c|}{ Moment } & \multicolumn{4}{|c|}{ Shear } \\
\hline & & & \multicolumn{3}{|c|}{1 Girder } & \multicolumn{3}{|c|}{5 Girder } & \multicolumn{2}{|c|}{1 Girder } & \multicolumn{2}{|c|}{5 Girder } & \multicolumn{2}{|c|}{1 Girder } & \multicolumn{2}{|c|}{5 Girder } \\
\hline & & & Factor & $\begin{array}{l}M \\
\text { or } \\
V\end{array}$ & $\begin{array}{c}\text { Capacity } \\
\text { (kips) }\end{array}$ & Factor & $\begin{array}{l}M \\
\text { or } \\
V\end{array}$ & $\begin{array}{l}\text { Capacity } \\
\text { (kips) }\end{array}$ & Factor & $\begin{array}{l}\text { Capacity } \\
\text { (kips) }\end{array}$ & Factor & $\begin{array}{l}\text { Capacity } \\
\text { (kips) }\end{array}$ & Factor & $\begin{array}{l}\text { Capacity } \\
\text { (kips) }\end{array}$ & Factor & $\begin{array}{c}\text { Capacity } \\
\text { (kips) }\end{array}$ \\
\hline \multirow{12}{*}{ H20 } & \multirow{2}{*}{0} & Inventory & 5.86 & $\mathrm{~V}$ & 234.6 & 1.80 & $\mathrm{~V}$ & 72.0 & - & - & 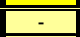 & 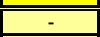 & 5.86 & 234.6 & 1.80 & 72.0 \\
\hline & & Operating & 9.79 & $\mathrm{~V}$ & 391.5 & 3.01 & $\mathrm{~V}$ & 120.3 & - & - & - & - & 9.79 & 391.5 & 3.01 & 120.3 \\
\hline & \multirow{2}{*}{4.5} & Inventory & 4.01 & $\mathrm{~V}$ & 160.5 & 3.37 & $\mathrm{~V}$ & 134.9 & 5.32 & 212.8 & 4.39 & 175.6 & 4.01 & 160.5 & 3.37 & 134.9 \\
\hline & & Operating & 6.70 & $\mathrm{~V}$ & 267.9 & 5.63 & $\mathrm{~V}$ & 225.2 & 8.88 & 355.2 & 7.33 & 293.1 & 6.70 & 267.9 & 5.63 & 225.2 \\
\hline & \multirow{2}{*}{9} & Inventory & 2.32 & $\mathrm{M}$ & 93.0 & 1.07 & $\mathrm{~V}$ & 42.8 & 2.32 & 93.0 & 1.97 & 78.7 & 3.69 & 147.6 & 1.07 & 42.8 \\
\hline & & Operating & 3.88 & $\mathrm{M}$ & 155.2 & 1.79 & $\mathrm{~V}$ & 71.5 & 3.88 & 155.2 & 3.28 & 131.4 & 6.16 & 246.3 & 1.79 & 71.5 \\
\hline & \multirow{2}{*}{13.5} & Inventory & 1.41 & $M$ & 56.4 & 1.23 & $M$ & 49.2 & 1.41 & 56.4 & 1.23 & 49.2 & 4.73 & 189.1 & 1.48 & 59.1 \\
\hline & & Operating & 2.35 & $M$ & 94.1 & 2.05 & $M$ & 82.0 & 2.35 & 94.1 & 2.05 & 82.0 & 7.89 & 315.7 & 2.47 & 98.6 \\
\hline & \multirow{2}{*}{18} & Inventory & 1.05 & $M$ & 42.0 & 0.94 & $M$ & 37.6 & 1.05 & 42.0 & 0.94 & 37.6 & 4.34 & 173.6 & 1.41 & 56.5 \\
\hline & & Operating & 1.75 & $M$ & 70.0 & 1.57 & $M$ & 62.7 & 1.75 & 70.0 & 1.57 & 62.7 & 7.25 & 289.9 & 2.36 & 94.3 \\
\hline & \multirow{2}{*}{22.5} & Inventory & 0.96 & $M$ & 38.5 & 0.87 & $M$ & 34.9 & 0.96 & 38.5 & 0.87 & 34.9 & 6.00 & 240.2 & 2.08 & 83.3 \\
\hline & & Operating & 1.61 & $\mathrm{M}$ & 64.3 & 1.46 & $M$ & 58.2 & 1.61 & 64.3 & 1.46 & 58.2 & 10.02 & 400.9 & 3.48 & 139.1 \\
\hline \multirow{12}{*}{ HS20 } & \multirow{2}{*}{0} & Inventory & 3.86 & $\mathrm{~V}$ & 278.2 & 1.19 & $\mathrm{~V}$ & 85.5 & - & - & - & - & 3.86 & 278.2 & 1.19 & 85.5 \\
\hline & & Operating & 6.45 & $\mathrm{~V}$ & 464.4 & 1.98 & $\mathrm{~V}$ & 142.6 & - & - & - & - & 6.45 & 464.4 & 1.98 & 142.6 \\
\hline & \multirow{2}{*}{4.5} & Inventory & 2.69 & $\mathrm{~V}$ & 193.9 & 2.26 & $\mathrm{~V}$ & 163.0 & 3.57 & 257.4 & 2.95 & 212.4 & 2.69 & 193.9 & 2.26 & 163.0 \\
\hline & & Operating & 4.50 & $\mathrm{~V}$ & 323.7 & 3.78 & $\mathrm{~V}$ & 272.1 & 5.97 & 429.6 & 4.92 & 354.5 & 4.50 & 323.7 & 3.78 & 272.1 \\
\hline & & Inventory & 1.61 & $\mathrm{M}$ & 115.7 & 0.74 & $\mathrm{~V}$ & 53.3 & 1.61 & 115.7 & 1.36 & 98.0 & 2.55 & 183.5 & 0.74 & 53.3 \\
\hline & $y$ & Operating & 2.68 & $\mathrm{M}$ & 193.2 & 1.23 & $\mathrm{~V}$ & 88.9 & 2.68 & 193.2 & 2.27 & 163.6 & 4.25 & 306.3 & 1.23 & 88.9 \\
\hline & 135 & Inventory & 1.01 & $\mathrm{M}$ & 73.0 & 0.88 & $\mathrm{M}$ & 63.6 & 1.01 & 73.0 & 0.88 & 63.6 & 3.40 & 244.5 & 1.06 & 76.4 \\
\hline & & Operating & 1.69 & $\mathrm{M}$ & 121.8 & 1.48 & $\mathrm{M}$ & 106.2 & 1.69 & 121.8 & 1.48 & 106.2 & 5.67 & 408.2 & 1.77 & 127.5 \\
\hline & 18 & Inventory & 0.76 & $\mathrm{M}$ & 55.0 & 0.68 & $\mathrm{M}$ & 49.3 & 0.76 & 55.0 & 0.68 & 49.3 & 3.29 & 236.6 & 1.07 & 77.0 \\
\hline & 8 & Operating & 1.28 & $\mathrm{M}$ & 91.9 & 1.14 & $M$ & 82.2 & 1.28 & 91.9 & 1.14 & 82.2 & 5.49 & 395.0 & 1.79 & 128.5 \\
\hline & 5 & Inventory & 0.72 & $\mathrm{M}$ & 51.6 & 0.65 & $M$ & 46.7 & 0.72 & 51.6 & 0.65 & 46.7 & 4.78 & 343.9 & 1.66 & 119.3 \\
\hline & & Operating & 1.20 & $\mathrm{M}$ & 86.1 & 1.08 & $M$ & 77.9 & 1.20 & 86.1 & 1.08 & 77.9 & 7.97 & 574.0 & 2.77 & 199.1 \\
\hline & 0 & Inventory & 3.09 & $\mathrm{~V}$ & 278.5 & 0.95 & $\mathrm{~V}$ & 85.5 & - & - & - & - & 3.09 & 278.5 & 0.95 & 85.5 \\
\hline & & Operating & 5.17 & $\mathrm{~V}$ & 464.9 & 1.59 & $\mathrm{~V}$ & 142.8 & - & - & - & - & 5.17 & 464.9 & 1.59 & 142.8 \\
\hline & 45 & Inventory & 2.16 & $\mathrm{~V}$ & 194.1 & 1.81 & $\mathrm{~V}$ & 163.2 & 2.86 & 257.4 & 2.36 & 212.4 & 2.16 & 194.1 & 1.81 & 163.2 \\
\hline & 4.5 & Operating & 3.60 & $\mathrm{~V}$ & 324.1 & 3.03 & $\mathrm{~V}$ & 272.5 & 4.77 & 429.6 & 3.94 & 354.5 & 3.60 & 324.1 & 3.03 & 272.5 \\
\hline & 9 & Inventory & 1.29 & $\mathrm{M}$ & 115.7 & 0.59 & $\mathrm{~V}$ & 53.3 & 1.29 & 115.7 & 1.09 & 98.0 & 2.04 & 183.8 & 0.59 & 53.3 \\
\hline & y & Operating & 2.15 & $M$ & 193.2 & 0.99 & $\mathrm{~V}$ & 89.0 & 2.15 & 193.2 & 1.82 & 163.6 & 3.41 & 306.8 & 0.99 & 89.0 \\
\hline & 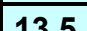 & Inventory & 0.81 & $M$ & 73.0 & 0.71 & $M$ & 63.6 & 0.81 & 73.0 & 0.71 & 63.6 & 2.72 & 245.0 & 0.85 & 76.5 \\
\hline & & Operating & 1.35 & $\mathrm{M}$ & 121.8 & 1.18 & $M$ & 106.2 & 1.35 & 121.8 & 1.18 & 106.2 & 4.54 & 408.9 & 1.42 & 127.7 \\
\hline & 18 & Inventory & 0.61 & $\mathrm{M}$ & 55.0 & 0.55 & $M$ & 49.3 & 0.61 & 55.0 & 0.55 & 49.3 & 2.62 & 236.0 & 0.85 & 76.8 \\
\hline & & Operating & 1.02 & $\mathrm{M}$ & 91.9 & 0.91 & $M$ & 82.2 & 1.02 & 91.9 & 0.91 & 82.2 & 4.38 & 393.9 & 1.42 & 128.2 \\
\hline & 225 & Inventory & 0.57 & $\mathrm{M}$ & 51.6 & 0.52 & $M$ & 46.7 & 0.57 & 51.6 & 0.52 & 46.7 & 3.81 & 342.6 & 1.32 & 118.9 \\
\hline & 22. & Operating & 0.96 & $M$ & 86.1 & 0.87 & $M$ & 77.9 & 0.96 & 86.1 & 0.87 & 77.9 & 6.35 & 571.9 & 2.20 & 198.4 \\
\hline
\end{tabular}

The tenth point summary table, shown in Table 5.19, displays the controlling load rating factors and loading vehicle at each tenth point. Similar summary tables are shown in the program for moment and shear load rating results. The controlling tenth point load 
rating analysis results are shown in Figure 5.8 which presents a graphical representation of the rating factors across the span length of the bridge.

Table 5.19 Sample Controlling Load Rating Tenth Point Summary Table

\begin{tabular}{|c|c|c|c|c|c|c|c|c|c|}
\hline \multicolumn{2}{|c|}{ Tenth Point } & \multicolumn{4}{|c|}{ Beam 3} & \multicolumn{4}{|c|}{ Beam 4} \\
\hline$x(f t)$ & & Factor & Mor V & $\begin{array}{c}\text { Capacity } \\
\text { (kips) }\end{array}$ & $\begin{array}{c}\text { Controlling } \\
\text { Load Vehicle }\end{array}$ & Factor & Mor V & $\begin{array}{c}\text { Capacity } \\
\text { (kips) }\end{array}$ & $\begin{array}{c}\text { Controlling } \\
\text { Load Vehicle }\end{array}$ \\
\hline \multirow{2}{*}{$\mathbf{0}$} & Inventory & 0.97 & V & 97.9 & HL-93 Truck & 0.97 & V & 97.9 & HL-93 Truck \\
\hline & Operating & 1.62 & V & 163.5 & HL-93 Truck & 1.62 & V & 163.5 & HL-93 Truck \\
\hline \multirow{2}{*}{4.5} & Inventory & 1.83 & V & 165 & $H S 25$ & 1.83 & V & 165 & $H S 25$ \\
\hline & Operating & 3.06 & V & 275.5 & $H S 25$ & 3.06 & V & 275.5 & $H S 25$ \\
\hline \multirow{2}{*}{9} & Inventory & 0.62 & V & 55.4 & $H S 25$ & 0.62 & V & 55.4 & $H S 25$ \\
\hline & Operating & 1.03 & V & 92.5 & $H S 25$ & 1.03 & V & 92.5 & $H S 25$ \\
\hline \multirow{2}{*}{13.5} & Inventory & 0.88 & V & 79 & $H S 25$ & 0.88 & V & 79 & $H S 25$ \\
\hline & Operating & 1.47 & V & 131.9 & $H S 25$ & 1.47 & V & 131.9 & $H S 25$ \\
\hline \multirow{2}{*}{18} & Inventory & 0.72 & M & 72.9 & HL-93 Truck & 0.72 & M & 72.9 & HL-93 Truck \\
\hline & Operating & 1.21 & $M$ & 121.7 & HL-93 Truck & 1.21 & $M$ & 121.7 & HL-93 Truck \\
\hline \multirow{2}{*}{22.5} & Inventory & 0.69 & M & 69.5 & HL-93 Truck & 0.69 & $M$ & 69.5 & HL-93 Truck \\
\hline & Operating & 1.15 & M & 116 & HL-93 Truck & 1.15 & $M$ & 116 & HL-93 Truck \\
\hline
\end{tabular}

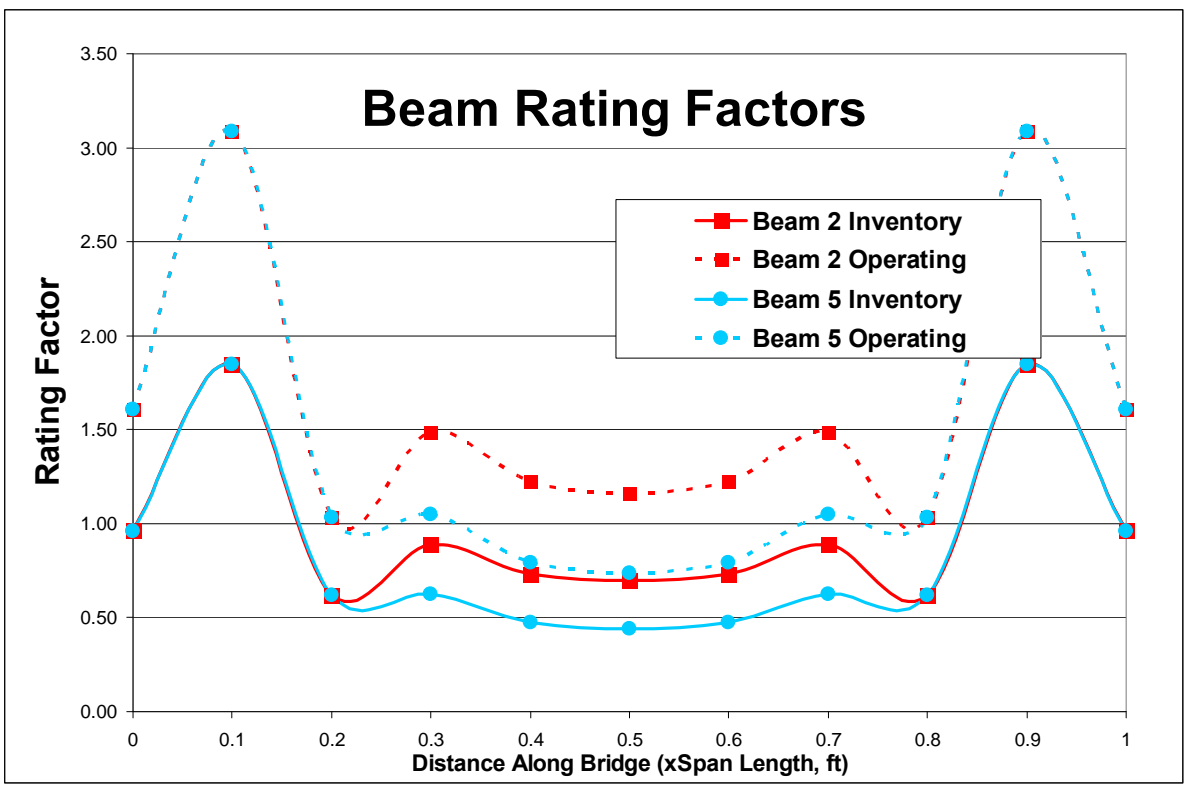

Figure 5.8 Sample Rating Factor Summary Chart 
The overall controlling inventory and operating load rating factors for moment and shear are shown in a table similar to Table 5.20. This table summarizes the controlling load rating factor for each beam and the corresponding section, bridge capacity, and loading vehicle.

Table 5.20 Sample Controlling Load Rating Factor Summary Tables

\begin{tabular}{|c|l|c|c|c|c|c|c|}
\hline \multicolumn{2}{|c|}{ Controlling Summary } & Factor & $M$ or V & $\begin{array}{c}\text { Capacity } \\
\text { (kips) }\end{array}$ & $\begin{array}{c}\text { Controlling } \\
\text { Section }\end{array}$ & $\begin{array}{c}\text { Controlling } \\
\text { Load }\end{array}$ & $\boldsymbol{x}$ (ft) \\
\hline \hline \multirow{2}{*}{ 1 Girder } & Inventory & 1.14 & $\mathrm{M}$ & 103 & 8 & $\mathrm{HS} 25$ & 22.5 \\
\cline { 2 - 9 } & Operating & 1.91 & $\mathrm{M}$ & 172 & 8 & $\mathrm{HS} 25$ & 22.5 \\
\hline \multirow{2}{*}{5 Girder } & Inventory & 0.59 & $\mathrm{~V}$ & 27 & 6 & $\mathrm{HS} 25$ & 9 \\
\cline { 2 - 9 } & Operating & 0.99 & $\mathrm{~V}$ & 45 & 6 & $\mathrm{HS} 25$ & 9 \\
\hline
\end{tabular}

\begin{tabular}{|c|l|c|c|c|c|c|}
\hline \multicolumn{2}{|c|}{ Moment } & Factor & $\begin{array}{c}\text { Capacity } \\
\text { (kips) }\end{array}$ & $\begin{array}{c}\text { Controlling } \\
\text { Section }\end{array}$ & $\begin{array}{c}\text { Controlling } \\
\text { Load }\end{array}$ & $\boldsymbol{x}(\mathrm{ft})$ \\
\hline \hline \multirow{2}{*}{ 1 Girder } & Inventory & 1.14 & 103 & 8 & $\mathrm{HS} 25$ & 22.5 \\
\cline { 2 - 8 } & Operating & 1.91 & 172 & 8 & $\mathrm{HS} 25$ & 22.5 \\
\hline \multirow{2}{*}{5 Girder } & Inventory & 1.03 & 93 & 8 & $\mathrm{HS} 25$ & 22.5 \\
\cline { 2 - 7 } & Operating & 1.73 & 155 & 8 & $\mathrm{HS} 25$ & 22.5 \\
\hline
\end{tabular}

\begin{tabular}{|c|l|c|c|c|c|c|}
\hline \multicolumn{2}{|c|}{ Shear } & Factor & $\begin{array}{c}\text { Capacity } \\
\text { (kips) }\end{array}$ & $\begin{array}{c}\text { Controlling } \\
\text { Section }\end{array}$ & $\begin{array}{c}\text { Controlling } \\
\text { Load }\end{array}$ & $\boldsymbol{x}(\mathrm{ft})$ \\
\hline \hline \multirow{2}{*}{1 Girder } & Inventory & 2.04 & 92 & 6 & HS25 & 9 \\
\cline { 2 - 8 } & Operating & 3.41 & 153 & 6 & HS25 & 9 \\
\hline \multirow{2}{*}{5 Girder } & Inventory & 0.59 & 27 & 6 & HS25 & 9 \\
\cline { 2 - 8 } & Operating & 0.99 & 45 & 6 & HS25 & 9 \\
\hline
\end{tabular}

\subsection{FRP STRENGTHENING DESIGN}

The procedures, equations, and suggestions contained within ACI 440.2R-02 were strictly adhered to for the FRP strengthening designs. The FRP strengthening design process is shown in Figure 5.9. All of the FRP design information is contained on one sheet in EXCEL. All of the necessary information (input data, existing analysis results, strengthened analysis results, design checks) for FRP design iteration is contained in a separate section at the top of the sheet. The analysis is split into two phases: flexural 
strengthening and shear strengthening. The equations used for each phase are presented in Appendix F.

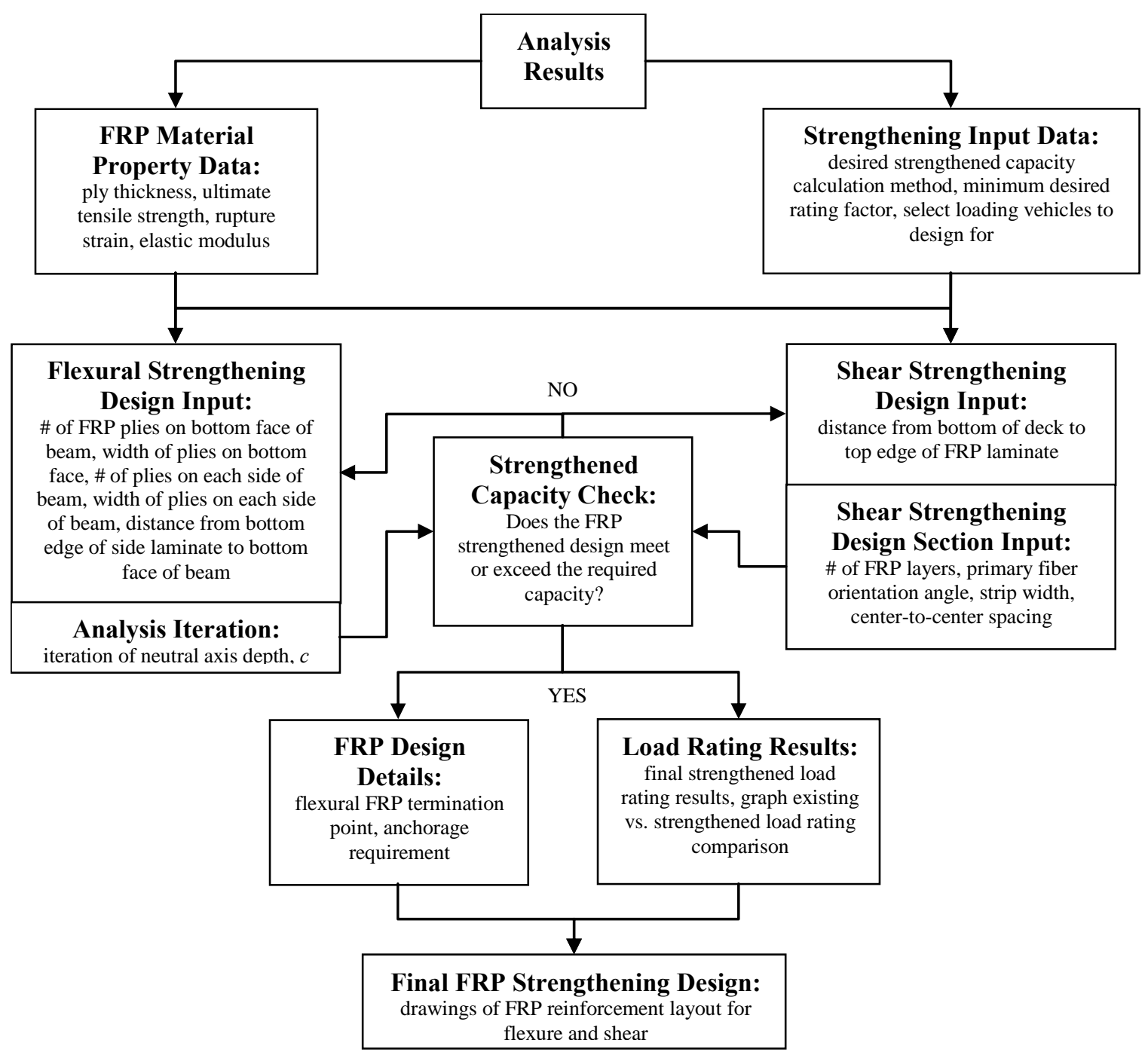

Figure 5.9 FRP Design Calculation Sequence 


\subsubsection{Program Input}

The user must enter and update data based on the results of the previous analysis. The required strengthening input data is incorporated into the necessary results tables so that the user can easily see the effects of any updates entered.

The user must first enter the manufacturer's reported system properties in the table shown in Table 5.21. These values are applicable to both flexural and shear strengthening. The ultimate tensile strength and rupture strain are reduced according to the appropriate factors. Depending on the strengthening requirement philosophy selected, the user must enter the desired minimum load rating factor at the top of sheet.

Table 5.21 Sample FRP Manufacturer's Reported System Properties Table

\begin{tabular}{|l|c|c|}
\hline Thickness per ply, $\boldsymbol{t}_{\boldsymbol{f}}$ & 0.0065 & in \\
\hline Ultimate Tensile Strength, $\boldsymbol{f}_{\boldsymbol{f} \boldsymbol{u}} *$ & 550 & ksi \\
\hline Rupture Strain, $\boldsymbol{\varepsilon}_{\boldsymbol{f} \boldsymbol{u}}{ }^{*}$ & 0.0167 & in/in \\
\hline Modulus of Elasticity of FRP Laminates, $\boldsymbol{E}_{\boldsymbol{f}}$ & 33000 & ksi \\
\hline
\end{tabular}

\subsubsection{Flexural Strengthening}

All of the information required for FRP flexural strengthening is presented to the user in the table shown in Table 5.22. The environmental reduction factor must be entered into the table. A table which suggests environmental reduction factors for different conditions from ACI 440.2R-02 has been copied into the sheet to aid the user in selection. 
Table 5.22 Sample FRP Flexural Strengthening Input/Results Table

\begin{tabular}{|c|c|c|c|}
\hline & Beam 3 & Beam 4 & \\
\hline Environmental Reduction Factor, $\mathrm{C}_{\mathrm{E}}$ & 0.85 & 0.85 & $<---$ Input \\
\hline$\#$ of plies on bottom face of girder, $n_{b}$ & 1 & 1 & $<---$ Input \\
\hline Width of FRP plies on bottom face, $w_{f b}$ & 9 & 9 & <---Input \\
\hline$\#$ of plies each web face of girder, $n_{w}$ & 0 & 0 & <---Input \\
\hline Width of FRP plies on webs, $w_{\mathrm{fw}}$ & 4 & 4 & <---Input \\
\hline $\begin{array}{l}\text { Distance from bottom face of beam to bottom edge } \\
\text { of flexural FRP laminate on beam side }\end{array}$ & 2 & 2 & $<---$ Input \\
\hline $\begin{array}{l}\text { Distance from bottom of deck to top edge of shear } \\
\text { FRP laminate on web }\end{array}$ & 2 & 2 & $<---$ Input \\
\hline Total Area of FRP & 0.059 & 0.059 & in $^{2}$ \\
\hline Effective Area of FRP & 0.059 & 0.059 & in $^{2}$ \\
\hline Controling Failure Mode? & FRP Failure & FRP Failure & \\
\hline $\begin{array}{l}\text { Initial Distance from Extreme Compression Fiber } \\
\text { to Neutral Axis, } c_{\text {initial }}\end{array}$ & 3.418 & 3.418 & in \\
\hline $\begin{array}{l}\text { Distance from Extreme Compression Fiber to } \\
\text { Neutral Axis, c }\end{array}$ & 3.418 & 3.418 & in \\
\hline Nominal Moment Strength, $\Phi M_{n}$ & 1162.9 & 1162.9 & $k \cdot f t$ \\
\hline Required Resisting Moment Strength, $\Phi M_{\text {req }}$ & 1162.6 & 1162.6 & $k \cdot f t$ \\
\hline$\Phi M_{\mathrm{n}}>\Phi M_{\mathrm{req}} ?$ & $O K$ & $O K$ & \\
\hline Steel service level stress check, $\mathrm{f}_{\mathrm{s}, \mathrm{s}}<\mathbf{0 . 8 f}_{\mathrm{y}}$ ? & $O K$ & $O K$ & \\
\hline Service Level FRP stress check, $\mathrm{f}_{\mathrm{f}, \mathrm{s}}<0.55 * \mathrm{f}_{\mathrm{fu}}$ ? & $O K$ & $O K$ & \\
\hline $\mathrm{c}_{\text {initial }}=\mathrm{c} ?$ & $O K$ & $O K$ & \\
\hline FRP Termination Point Distance from Abutment & 2.95 & 2.95 & (ft) \\
\hline FRP Anchoring with Transverse Reinforcement? & $Y E S$ & $Y E S$ & \\
\hline
\end{tabular}

If strengthening is required, the user must enter the flexural FRP layout. The user must enter the number of layers and width of the sheets that are required on the sides and bottom face of the beam. The maximum number of layers of FRP is limited to three because the bond dependent coefficient starts to break down if more layers are used.

The flexural FRP is most efficiently used when the maximum required amount is applied to the bottom face of the beam. If the maximum amount of flexural FRP on the bottom face is not enough to attain the desired capacity, FRP layers can be applied to the sides of the beam. The program assumes that the same number of layers and width of sheets is used on both sides of the beam. The user must enter the distance from the 
bottom face of the beam to the bottom edge of the flexural FRP laminate on the side of the beam. This is required to calculate the flexural resistance provided by the FRP. Details on the calculation method for the side FRP flexural resistance contribution are presented in Appendix F. The distance from the bottom of the deck to top edge of shear FRP laminate on the web is entered in this table if shear strengthening is necessary.

Several analysis results are presented to the user in the table shown in Table 5.22 to facilitate the flexural strengthening design process. The user must iterate the initial neutral axis depth based on the computed neutral axis depth (gray cells in Table 5.22). Once the computed neutral axis is equal to the initial neutral axis, the user can see if the FRP layout satisfies the required capacity and design checks. If not, the user must update the FRP design layout and re-iterate the neutral axis until the required capacity and design checks are satisfied.

The program has four design checks that must be satisfied. The first design check confirms that the required moment capacity is less than the nominal moment strength of the strengthened beam. The service level stresses of the FRP and steel are checked to ensure that inelastic deformations of the concrete and creep-rupture or failure due to cyclic stresses are avoided. After all designs checks have been satisfied, the program displays a message indicating that the beam flexural design is satisfactory.

Once the FRP flexural design is satisfactory, the user must enter the coefficients from the equation shown in the bottom of the graph, shown in Figure 5.10, into the appropriate cells. The program guides the user with arrows to indicate which cells to enter the equation into. This step is necessary to determine the flexural FRP termination point and if anchorage of the flexural FRP is necessary. 


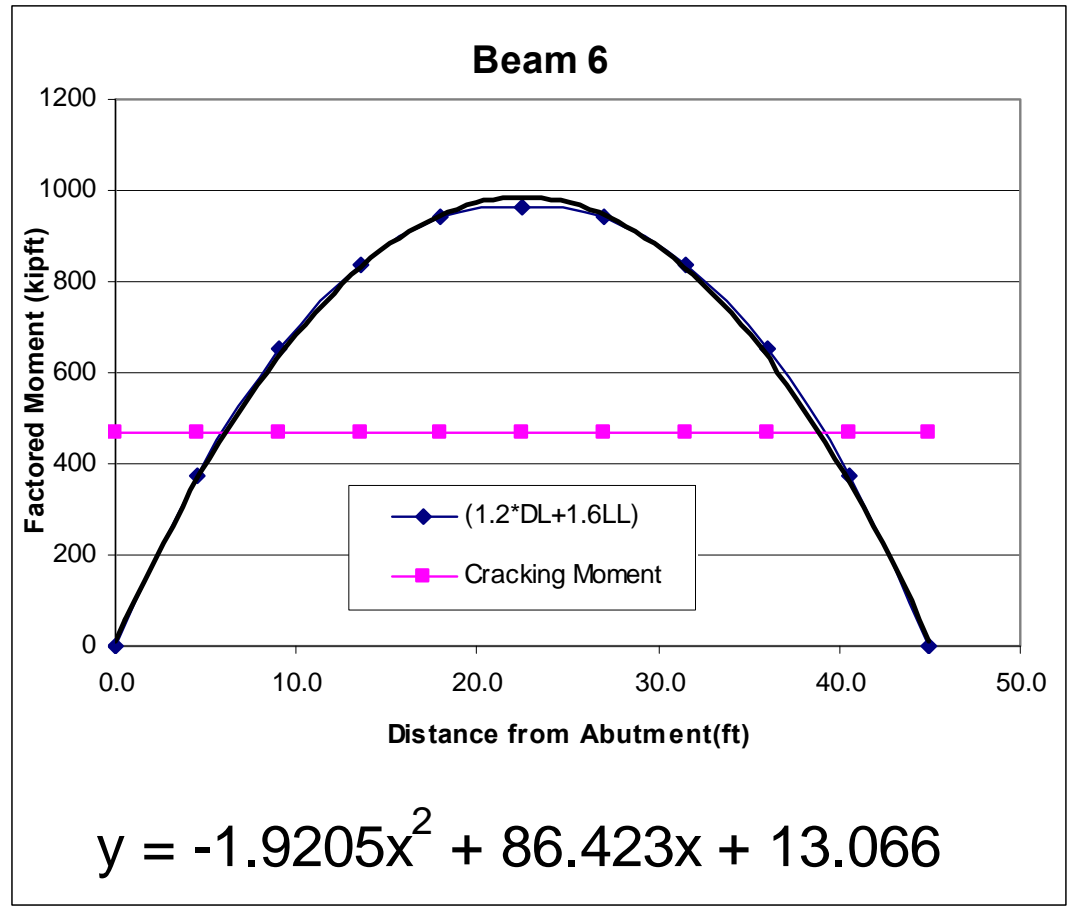

Figure 5.10 Sample Flexural FRP Termination Point Calculation Graph

\subsubsection{Shear Strengthening}

The shear strengthening input table, shown in Table 5.23, presents the user with all of the necessary information to complete an FRP shear strengthening design for each section within a given beam. The existing and required shear strength at each section is used to determine if FRP strengthening is required. The user must enter the number of FRP layers, angle of primary fiber orientation, strip width, and center-to-center spacing of the strips for each section where strengthening is required. 
Table 5.23 Sample Shear Strengthening Design Table

\begin{tabular}{|c|c|c|c|c|c|c|c|c|}
\hline & \multicolumn{8}{|c|}{ Beam 3} \\
\hline & \multicolumn{8}{|c|}{ Section } \\
\hline & $\overline{1.1}$ & 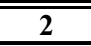 & 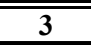 & 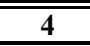 & 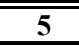 & 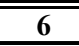 & 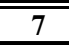 & 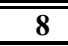 \\
\hline Section Distance from Abument (ft) & 0.0 & 0.3 & 2.6 & 4.8 & 5.8 & 8.8 & 14.8 & 16.5 \\
\hline Require FRP Strengthening & $\mathrm{NO}$ & $\mathrm{NO}$ & $\mathrm{NO}$ & $\mathrm{NO}$ & $\underline{Y E S}$ & $\underline{Y E S}$ & $\mathrm{NO}$ & $\underline{Y E S}$ \\
\hline V Existing (kips) & 163.3 & 227.9 & 227.9 & 216.9 & $\overline{95.3}$ & $\overline{84.3}$ & 78.3 & $\overline{61.3}$ \\
\hline V Required (kips) & 136.0 & 141.9 & 130.3 & 120.0 & 115.2 & 100.6 & 71.5 & 63.9 \\
\hline FRP strip length, in & & & & & 35.9 & 71.8 & & 72.0 \\
\hline Number of FRP layers/strip & & & & & 3 & 1 & & 1 \\
\hline \begin{tabular}{|l} 
Angle of Primary Fiber Orientation (deg) \\
\end{tabular} & & & & & 45 & 45 & & 90 \\
\hline \begin{tabular}{|l} 
Strip Width (in) \\
\end{tabular} & & & & & 8 & 8 & & 8 \\
\hline Center-to-Center spacing of Strips (in) & & & & & 22 & 16 & & 24 \\
\hline V FRP Required (kips) & & & & & 19.9 & 16.4 & & 2.5 \\
\hline V FRP Provided (kips) & 0.0 & 0.0 & 0.0 & 0.0 & 23.9 & 20.0 & 0.0 & 9.4 \\
\hline Strengthened INV RF & 1.32 & 1.93 & 2.13 & 2.20 & 1.05 & 1.05 & 1.12 & 1.14 \\
\hline Strengthened OPR RF & 2.20 & 3.22 & 3.56 & 3.67 & 1.76 & 1.76 & 1.88 & 1.90 \\
\hline FRP Sheets in Section & & & & & 2 & 5 & & 3 \\
\hline FRP Shear Contribution Limit (kips) & $O K$ & $O K$ & $O K$ & $O K$ & $O K$ & $O K$ & $O K$ & $O K$ \\
\hline \begin{tabular}{|l} 
Strengthened Shear Capacity (kips) \\
\end{tabular} & 163.3 & 227.9 & 227.9 & 216.9 & 119.3 & 104.3 & 78.3 & 70.7 \\
\hline Stregthened V > V Required? & $Y E S$ & $Y E S$ & $Y E S$ & $Y E S$ & $Y E S$ & $Y E S$ & $Y E S$ & $Y E S$ \\
\hline
\end{tabular}

The shear strength provided by the FRP is then compared to the required shear strength contribution of FRP. The FRP layout must be altered until the shear strength provided by the FRP meets or exceeds the required shear strength. The design limits checked at each section include the FRP shear contribution limit and if required shear strength capacities are satisfied. The strengthened inventory and operating rating factors are also reported in the table shown in Table 5.23.

The graph shown in Figure 5.11 displays the shear strengthening synopsis of the beam. This graph is a useful design tool to see what areas require FRP and what amount is required for each section. The shear capacities for each section shown in Figure 5.11 include: existing, ultimate required, required by FRP, and strengthened. 


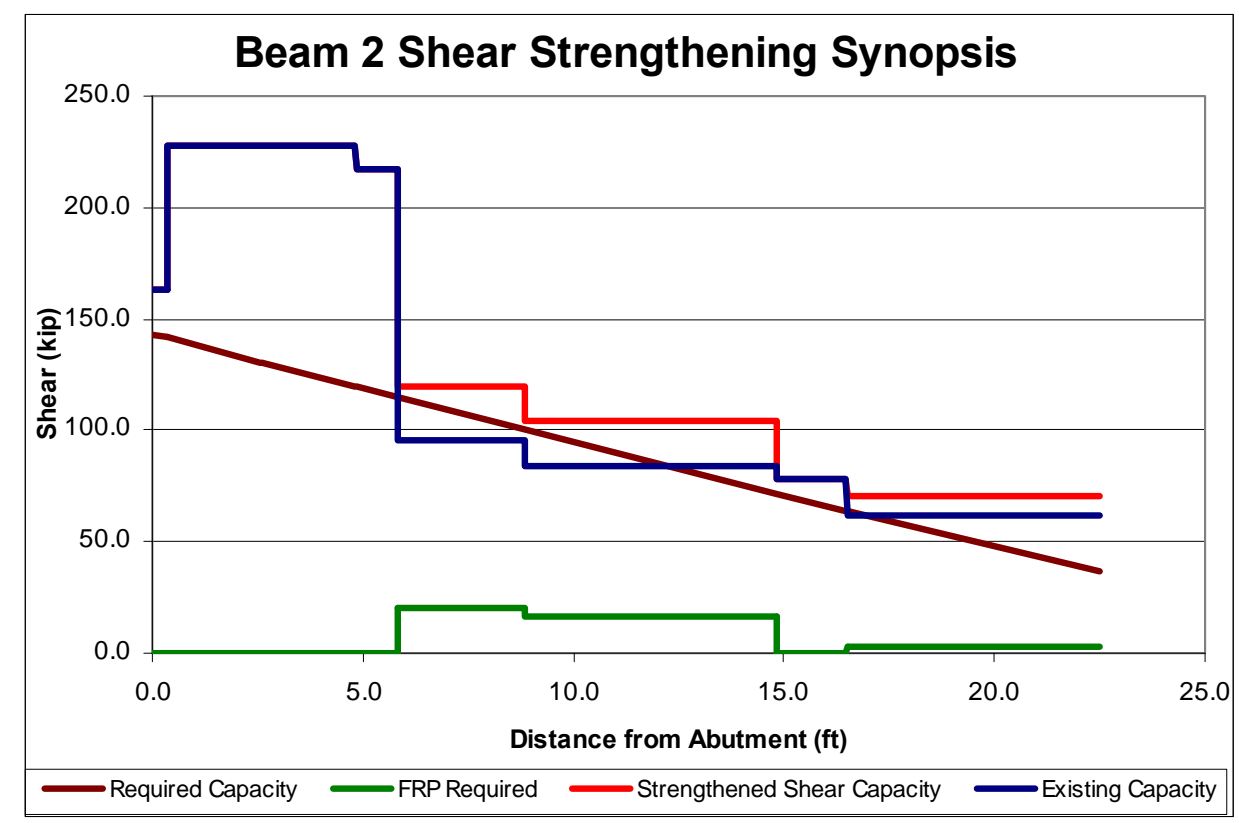

Figure 5.11 Sample Shear Capacity Strengthening Analysis Results Graph

\subsubsection{Program Design Calculations}

The flexural and shear strengthening design calculations are carried out in a separate part of the spreadsheet from the input and design summary section. The calculations follow the same steps as ACI 440.2R-02 design examples. The design equations used are presented in Appendix F.

\subsubsection{Flexural Strengthening}

The flexural FRP strengthening design is carried out in thirteen steps. Each step follows ACI 440.2R-02 protocol except the calculation for the strengthened design flexural capacity. Some of the variables used had to be modified to account for any flexural FRP reinforcement on the sides of the beam. A brief overview of the program's calculation method is given in this section. The required steps for flexural FRP analysis are as follows: 
1. Calculate the FRP-system properties.

2. Calculate the section properties.

3. Determine the existing state of strain on the soffit.

4. Determine the bond-dependent coefficient of the FRP system.

5. Estimate the depth to the neutral axis

6. Determine the effective level of strain in the FRP reinforcement.

7. Calculate the strain in the existing reinforcing steel.

8. Calculate the stress level in the reinforcing steel and FRP.

9. Calculate the internal force resultants and check equilibrium.

10. Adjust the neutral axis depth until force equilibrium is satisfied.

11. Calculate the design flexural strength of the section.

12. Check the service level stresses in the reinforcing steel and the FRP.

13. Compute the cracking moment.

After all of the design checks are satisfied, the program reports to the user that the flexural FRP design is satisfactory. Step 11 was modified to account for the effective area of FRP. The effective area has to be calculated since the entire width of the FRP strips on the side of the beam is not at the failure strain. Assuming that plane sections remain plane under loading, a linear strain gradient is developed across the width of the flexural FRP strip. The FRP areas closer to the neutral axis do not act at the same strain level as the FRP areas near the bottom face of the beam. This effect reduces the force contribution from the FRP on the sides of the beam. To account for this, an effective area of FRP is used which is assumed to act at the ultimate strain for the entire effective area of FRP. Also, the distance from the neutral axis to the force resultant of the FRP due to the strain gradient is calculated and used as the moment arm.

\subsubsection{Shear Strengthening}

The FRP shear strengthening design is carried out in four steps that follow ACI 440.2R-02 design examples. No modifications had to be made to the design equations. The design steps are as follows:

1. Calculate the FRP-system design and material properties.

2. Calculate the effective strain level in the FRP shear reinforcement. 
3. Calculate the contribution of the FRP reinforcement to the shear strength.

4. Calculate the shear strength in the section.

Several calculations are carried out within each step. The equations are presented in Appendix F. It should be noted that the most effective use of FRP strips is at a $45^{\circ}$ angle with respect to the horizontal. However, this application method is more cumbersome and time consuming than applying the strips at a $90^{\circ}$ angle. Strips applied at a $90^{\circ}$ angle can be wrapped around the beam to cover both sides of the beam. If the strips are angled, the strips must be cut and applied to each side of the beam separately.

\subsubsection{Program Output}

The program is designed to be user-friendly throughout the design process. The user is presented with all of the information that is required for design in table format as well as useful information in a graphical format during the design process. The load rating summary tables shown in Tables 5.18-5.20 are also calculated for the strengthened bridge. These tables are useful in comparing the strengthened load rating results based different loading vehicles.

\subsubsection{Flexural Strengthening}

The controlling existing and strengthened design results are displayed to the user in the tables previously shown on the FRP design sheet. A sample strain distribution graph is shown in Figure 5.12. The points on the graph (from top to bottom) indicate the strain at the top of the concrete deck, tensile reinforcement steel centroid, and flexural FRP laminates on the bottom face of the beam. An example of the graph showing the existing vs. FRP strengthened flexural inventory and operating load rating factors for both beams is shown in Figure 5.13. 


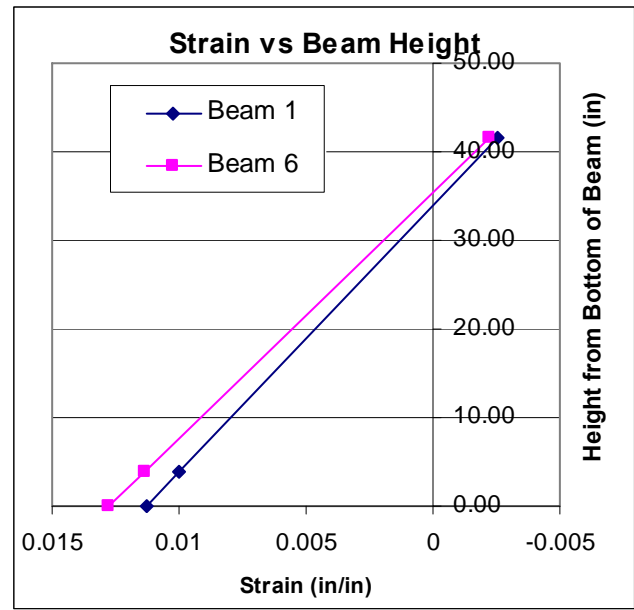

Figure 5.12 Sample Strengthened Beam Strain Distribution Graph

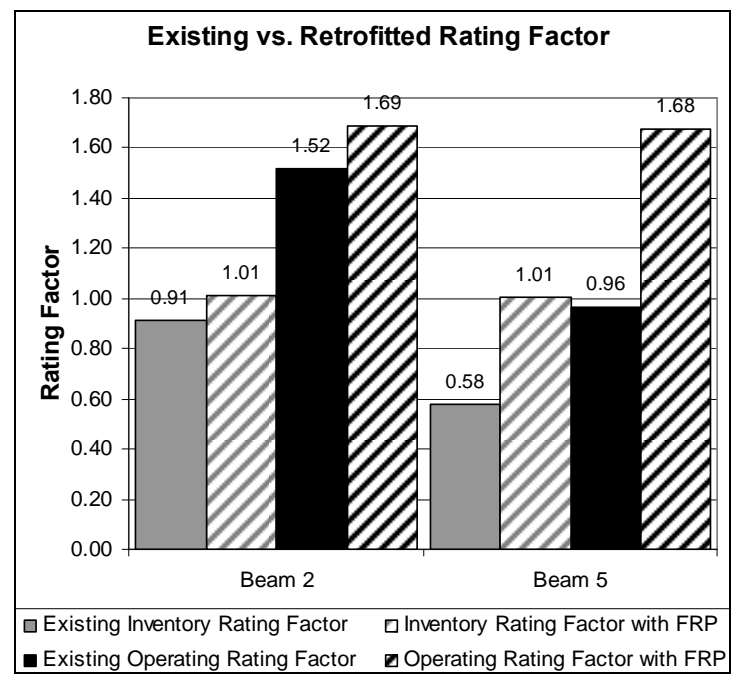

Figure 5.13 Sample Existing vs. Strengthened Beam Flexural Load Rating Summary Graph

\subsubsection{Shear Strengthening}

The shear strengthening results are presented in table format for each section as shown in Table 5.23. The program displays the strengthened bridge load rating factors for the selected loading vehicles in a separate sheet (Table 5.24). Graphical displays of the existing vs. strengthened inventory and operating rating factors are also made available to the user. A sample strengthening design load rating summary graph is shown 
in Figure 5.14. The existing and strengthened load rating factors depend on the design loading vehicle selected.

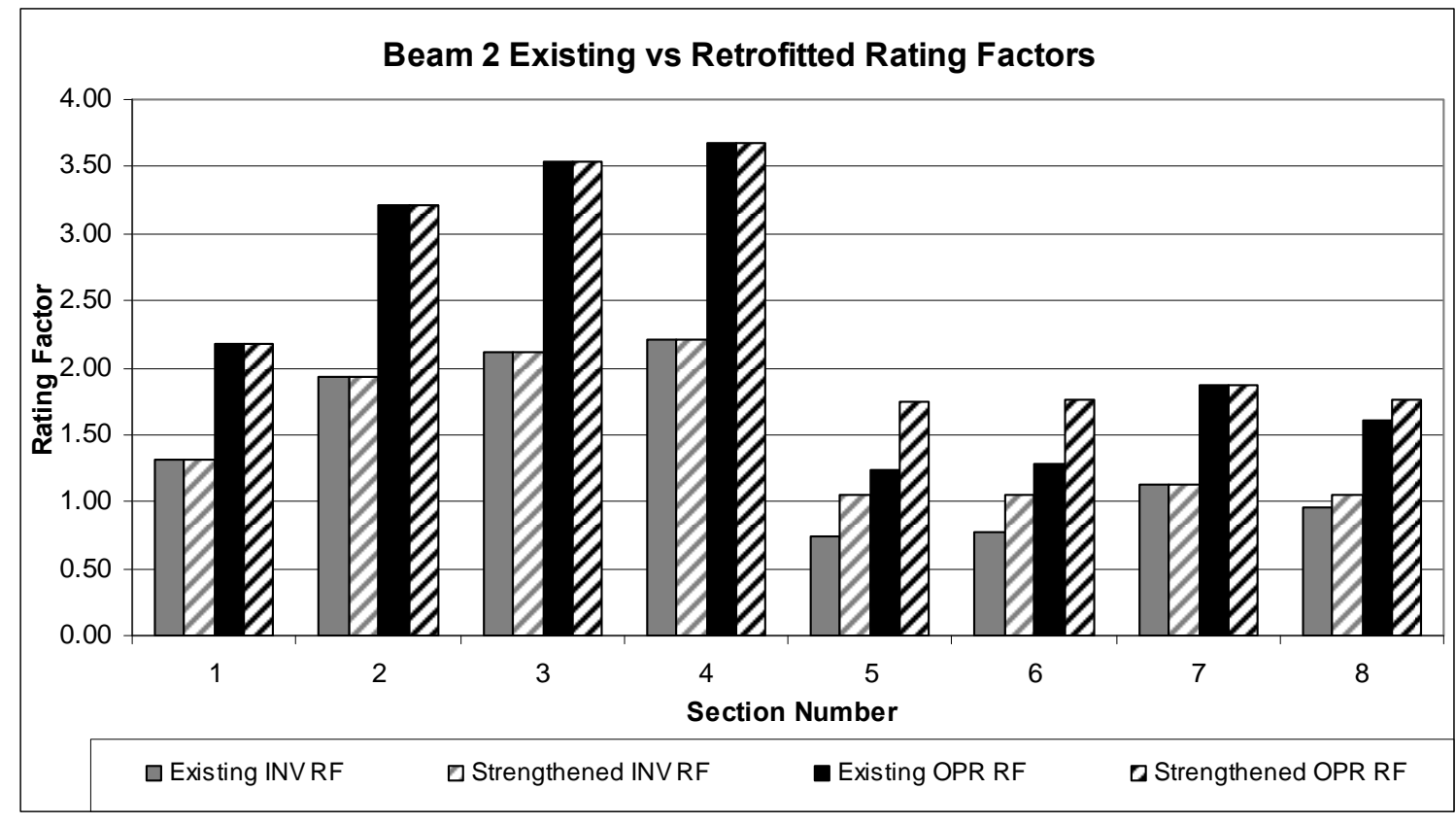

Figure 5.14 Sample Beam Existing vs. Strengthened Load Rating Summary Graph 


\section{ChAPTER 6 - CONCLUSIONS}

\subsection{INTRODUCTION}

The research presented in this thesis encompasses the results from Phase-II of a three phase project performed for PennDOT-D3 by a research team at West Virginia University. Phase-II involved the condition assessment and preliminary FRP strengthening design for concrete T-Beam bridge \#49-4012-0250-1032 near Sunbury, Pennsylvania. The work contained in this thesis is a step towards successful transfer of FRP strengthening technology to PennDOT-D3.

The scope of work covered in this thesis included: (1) establishing the need for bridge rehabilitation, bridge condition assessment techniques, load rating methods, structural strengthening methods, FRP design specifications, and successful case studies incorporating the use of FRP for structural strengthening (Chapter 2); (2) investigation of the existing deteriorated structural condition of PennDOT bridge \#49-4012-0250-1032 through destructive and non-destructive testing techniques, proof load testing of the deteriorated structure (Chapter 3); (3) load rating analysis and preliminary FRP strengthening design (Chapter 4); development of an improved concrete T-Beam rating procedure and FRP strengthening design program (Chapter 5).

Detailed results have been presented for each chapter including difficulties incurred during the research work and suggested methods of solution. This chapter covers conclusions from the load rating analysis summary based on the existing and 
proposed strengthening designs. The resulting recommendations developed during the project and suggestions for future work are also presented in this chapter.

\subsection{LOAD RATING COMPARISON}

The most recent load rating report for the investigated bridge was obtained from PennDOT and evaluated to determine the accuracy and limitations of the BAR7. A program was developed by WVU researchers to mimic BAR7 analysis using EXCEL. The program was enhanced to be more flexible and user friendly than BAR7 while providing more accurate results. WVU's program is limited to analyzing simple span concrete T-Beam bridges. The program is a unique load rating and FRP strengthening design tool that adheres to AASHTO and ACI guidelines and specifications. Several questions were raised during the review of PennDOT's BAR7 load rating report involving the input data and calculation methods. The methods used for WVU's analysis were summarized and justified using AASHTO guidelines.

It was discovered that the bridge reinforcement layout did not match the original design layout. Several flexural reinforcing bars and vertical stirrup bars shown in the original design plans were omitted during the construction of the bridge. The initial structural analysis performed during Phase-II had to be re-calculated in order to re-design the FRP strengthening system. This discovery also meant that PennDOT's load rating report for this bridge had been erroneous by accounting for non-existent steel reinforcement.

The as-built and deteriorated structural capacities of the bridge were calculated using WVU's analysis program. PennDOT-D3 and WVU researchers agreed to 
strengthen the bridge based on an HS-20 truck loading requirement. Preliminary

proposed FRP strengthening designs were presented. The proposed rehabilitation plan results in an inventory load rating factor of 1.0 or greater for any section of the bridge requiring FRP strengthening based on standard AASHTO analysis protocol. This thesis also presented the capabilities and explanation of the analysis and design program developed by WVU researchers.

\subsection{RECOMMENDATIONS}

During the course of research for this project, several recommendations were developed by WVU researchers. The following are the recommendations to PennDOTD3 personnel that relate to bridge inspection, structural analysis, FRP strengthening design, and guidelines of FRP rehabilitation systems.

\section{Set a minimum strengthening level based on HS-20 loading vehicle}

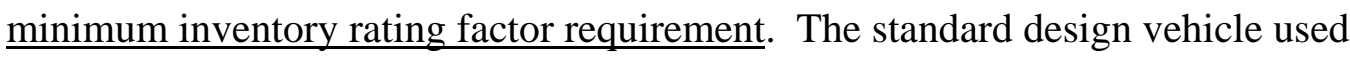
in Load Factor Design is the HS-20 truck. PennDOT-D3 bases their load ratings on this loading vehicle. Strengthening of the bridge to original design capacity may result in inefficient and over-strengthened designs.

2. Incorporate the use of limited destructive testing techniques. In order to determine an accurate structural capacity assessment for load rating, the existing section properties and steel reinforcement layout must be known. Some bridges may not be built according to original design drawings. PennDOT-D3 should incorporate the use of rebar locators and, if necessary, destructive testing techniques to determine the as-built layout of reinforcing steel in the bridge. 
3. Account for varying deterioration levels throughout the beam. BAR7 analysis does not permit varying the reinforcing steel corrosion in different sections of the bridge. The researched bridge exhibited excessive amounts of deterioration and corrosion near the drain pipes. Some of the vertical reinforcing steel had completely corroded through the cross section rendering them completely ineffective as a shear resisting mechanism. These elements need to be accounted for to provide a safer and more reliable load rating analysis and/or FRP strengthening design.

4. Investigate incorporation of techniques and methods used in WVU's analysis and FRP design calculations into BAR7. Several methods to overcome the limitations and difficulties of PennDOT’s BAR7 program have been presented in this thesis. The methods used by WVU researchers provide the user with a simpler method of entering input data and analyzing multiple beams during the same analysis.

\subsection{FUTURE WORK}

The research presented in this thesis covers the necessary preliminary steps towards strengthening of a simply-supported concrete T-Beam bridge. The following recommendations are applicable to PennDOT-D3 and WVU researchers in the continued effort of developing an accurate structural analysis and FRP strengthening design protocol for PennDOT.

1. Investigate heavier loading vehicles as possible required capacities for

strengthening designs. The standard design methodology has changed from Load 
Factor Design (LFD) to Load and Resistance Factor Design (LRFD). The standard design load for LRFD is an HL-93 truck or tandem loading. Both the HL-93 truck and HS-25 truck loadings are heavier than an HS-20 loading. For the span length of the bridge investigated during this project, the HS-25 and HL93 truck loading force effects closely are very similar. Since highway vehicle loads have increased over the years, incorporating a strengthening philosophy that allows for heavier current or anticipated design loading vehicles may offset future repair or rehabilitation costs.

2. Research the effectiveness of setting the desired minimum inventory rating factor greater than 1.0. During the bridge field inspection and subsequent laboratory tests of field samples, it was determined that the reinforcing steel does not have any protection against further corrosion. Wrapping the bridge with FRP laminates may further inhibit the contaminants that seep into the concrete from escaping which would further accelerate deterioration of structural elements. Strengthening to a load rating factor equal to one indicates that any deterioration of any structural element will result in a minimum load rating factor less than 1.0. WVU researchers suggest strengthening based on an HS-25 loading vehicle and reporting a load rating analysis based on an HS-20 truck loading.

3. $\quad$ Update and enhance WVU's simply-supported concrete T-Beam structural analysis, load rating and FRP design program. The design program developed by WVU researchers should be updated to incorporate a more user-friendly program interface. Suggestions should be made by PennDOT-D3 personnel relating to the desired user interface, program capabilities, and analysis results reporting. 
Adapting PennDOT standard program formats may ease adaptation and acceptance of the program to PennDOT-D3 personnel.

\section{Development of a user's manual for WVU's analysis program. Chapter 5} of this thesis is designed to be a preliminary user's manual for the analysis program. An independent user's manual that details all of the aspects of the program should be developed and provided with the program to PennDOT-D3.

5. $\quad$ Investigate other bridges for as-built differences from original design drawings. The structure investigated during this project was supposedly built from a standard set of design drawings for a $45 \mathrm{ft}$ simple-span concrete T-Beam bridge. However, during the concrete repair stages where loose and deteriorated concrete was removed, it was discovered that the as-built steel reinforcement layout did not match the standard design drawings. It is possible that similar $45 \mathrm{ft}$ simple-span bridges were not built according this standard set of design drawings. These types of inaccuracies results in overestimation of structural capacity. Accurate load capacity calculations for every bridge are necessary to assure that PennDOT's bridge inventory is safe for the public. Several bridges based on the same design drawings should be investigated to check the steel reinforcement layout and assure that an accurate load rating is reported.

6. $\quad$ Re-run corrected finite element model. WVU researchers should re-run two updated versions of the finite element model (FEM) developed during PhaseII. The first model should examine the as-built conditions of the deteriorated structure by removing the steel reinforcement that was not included in the as-built bridge. These results should be compared with the load test data and a load rating 
analysis performed based on the computer model. The second FEM should incorporate concrete repair and FRP strengthening design. A load rating analysis should be performed and compared to the results of the first model.

7. Decide definitive strengthening goal. PennDOT-D3 needs to provide a definitive strengthening goal to be included in their FRP strengthening guidelines and specifications. The strengthening philosophy used should be incorporated into all structures requiring FRP strengthening in PennDOT-D3's bridge inventory.

8. Long-term evaluation of FRP effectiveness. The long term effectiveness of the FRP strengthening system applied to PennDOT bridge \#49-4012-02501032 should be investigated. Several load tests over the next $10-20$ years should be performed to determine any loss in the structural capacity of the strengthened bridge and the causes of that loss.

9. Lab-scale side flexural FRP reinforcement studies. The need arose during the FRP flexural strengthening design phase for placing FRP laminates on the side of the beam. This method had not been used in any known previous research. The FRP moment capacity calculations had to be modified to account for the strain gradient developed across the side flexural FRP laminates and the resulting moment arm. Also, placing flexural laminates on the sides of a beam may inhibit the effectiveness of the shear laminates or vice versa. Laboratory studies on side flexural FRP strengthened reinforced concrete T-Beams should be performed to verify the calculation methods developed in this research. Also, the study should 
investigate the interaction between the flexural FRP laminates with the overlapping shear FRP laminates.

10. Work with PennDOT-D3 directly to transfer analysis and design program effectively. WVU researchers will have to work closely with PennDOT-D3 personnel to update and modify the analysis/design program developed by WVU researchers. The user-interface and results reporting should be modified to incorporate PennDOT-D3 personnel suggestions.

11. Re-evaluate FRP rehabilitation cost analysis. The cost analysis completed during Phase-I of this project should be re-evaluated to reflect the actual cost of Phase-III. This cost analysis should include design work, installation, and material costs. 


\section{REFERENCES}

AASTHO, "Manual for Condition Evaluation of Bridges,” $2^{\text {nd }}$ Edition, pp 49-72, 1994.

AASHTO, “Standard Specifications for Highway Bridges,” 16 ${ }^{\text {th }}$ Edition, 760 pp., 1996.

AASHTO. Virtis/Opis Bridge Rating and Design Products. AASHTO BridgeWare. AASHTO, 2003.

ACI 440.2R-02 (2002). Guide for the Design and Construction of Externally Bonded FRP Systems for Strengthening Concrete Structures. American Concrete Institute.

ACI 318-99 (2002), Building Code Requirements for Structural Concrete and Commentary (318R-99), American Concrete Institute, Farmington Hills, MI.

Alkhrdaji, T. and A. Nanni, "Surface Bonded FRP Reinforcement for Strengthening/Repair of Structural Reinforced Concrete,” Proc., ICRI-NRCC Workshop, Baltimore, MD, Oct 30, 1999, 19 pp.

Alkhrdaji, Tarek, Antonio Nanni, Genda Chen, and Michael Barker. Destructive and Non-Destructive Testing of Bridge J857 Phelps County, Missouri- Volume I: Strengthening and Testing to Failure of Bridge Decks. University of MissouriRolla. Center for Infrastructure Engineering Studies, 1999.

Alkhrdaji, T, M Barker, G Chen, H Mu, A Nanni, and X Yang. Destructive and NonDestructive Testing of Bridge J857 Phelps County, Missouri-Volume II: Feasibility Study on Damage Detection of RC Structures Using Dynamic Signature Tests. University of Missouri-Rolla. Rolla, Missouri: University of Missouri-Rolla, 1999.

Bonfiglioli, Barbara, Giovanni Pascale, and Sonia Martinez De Mingo. "Dynamic Testing of Reinforced Concrete Beams Damaged and Repaired with Fiber Reinforced Polymer Sheets." Journal of Materials in Civil Engineering 16 (2004): 400-406.

"Bentley BridgeModeler and Bentley LARS." Bentley. Bentley. 12 May 2008 $<$ www.bentley.com>.

Brayack, Daniel A. Technical and Economic Effectiveness for Repair with FRP of Concrete T-Beam Bridges: Case Study for PennDOT-District 3. Thesis. West Virginia Univ., 2006. Morgantown, WV: West Virginia University, 2006.

Bridge Load Rating, Permitting and Posting. Florida Department of Transportation. 2006. 
Buyukozturk, Oral, and Brian Hearing. "Failure Behavior of Precracked Concrete Beams Retrofitted with FRP." Journal of Composites for Construction 2.3 (1998): 138144.

Catbas, F N., and A E. Aktan. "Condition and Damage Assessment: Issues and Some Promising Indices." Journal of Structural Engineering 128.8 (2002): 1026-1036.

Catbas, F N., Kirk A. Grimmelsman, S K. Ciloglu, Ildefonso Burgos-Gil, and Manuel Coll-Borgo. "Static and Dynamic Testing of a Concrete T-Beam Bridge Before and After Carbon Fiber-Reinforced Polymer Retrofit." Journal of the Transportation Research Board 1976 (2004): 77-87.

Catbas, F N., S K. Ciloglu, and A E. Aktan. "Strategies for Load Rating of Infrastructure Populations: a Case Study on T-Beam Bridges." Structure \& Infrastructure Engineering: Maintenance, Management, Life-Cycle 1.3 (2005): 221-238.

Catbas, F N., S K. Ciloglu, O Hasancebi, J S. Popovics, and A E. Aktan. Re-Qualification of Aged Reinforced Concrete T-Beam Bridges in Pennsylvania. Drexel University. Drexel Intelligent Infrastructure Institute, 2003.

Catbas, Necati, Korhan Ciloglu, Arda Celebioglu, and Emin Aktan. Fleet Health Monitoring of Large Populations: Aged Concrete T-Beam Bridge in Pennsylvania. Drexel University. Drexel Intelligent Infrastructure Institute, 2001.

Chajes, Micheal J., Harry W. Shenton, Iii, and Dennis O'shea. Use of Field Testing in Delaware's Bridge Management System. University of Delaware. Transportation Research Board, 1999.

Davalos, Julio F., Chunfu Lin, Indrajit Ray, Karl E. Barth, George Parish, and William C. Sasher. A Comprehensive Program for Repair with External FRP of Concrete TBeam Bridges in Pennsylvania DOT - USA. West Virginia University. Morgantown, WV: West Virginia University, 2007.

Davalos, Julio F., Chunfu Lin, Karl E. Barth, Indrajit Ray, William C. Sasher, and George Parish. "Material/Structural Evaluation and FRP Retrofit Design of a Concrete T-Beam Bridge." American Concrete Institute (2007).

Davalos, Julio F., Karl E. Barth, Indrajit Ray, Chunfu Lin, and Daniel A. Brayack. District 3-0 Investigation of Fiber-Wrap Technology for Bridge Repair and Rehabilitation (Phase-I). West Virginia University. Morgantown, WV: West Virginia University, 2006.

Davalos, Julio F., Karl E. Barth, Indrajit Ray, Chunfu Lin, William C. Sasher, and George Parish. District 3-0 Investigation of Fiber Wrap Technology for Bridge 
Repair \& Rehabilitation-Phase 2. West Virginia University. Morgantown, WV: West Virginia University, 2007.

Delaware. Delaware Department of Transportation. Bride Design Manual. Delaware Department of Transportation, 2005.

Dey, Gautom. Comparing LFR and LRFR Ratings: Part 1 of FDOT's Two-Part Study. HDR. HDR, 2005.

Dolan, Charles W. Project 12-73 Design Guidelines for Durability of Bonded CFRP Repair/Strengthening of Concrete Beams. National Cooperative Highway Research Board. Transportation Research Board, 2006. 23 June 2006 $<$ www4.trb.org/trb/crp.nsf/All+Projects/NCHRP+12-73> .

El-Sayed, Ahmed, Ehab El-Salakawy, and Brahim Benmokrane. "Shear Strength of OneWay Concrete Slabs Reinforced with Fiber-Reinforced Polymer Composite Bars." Journal of Composites for Construction 9.2 (2004): 147-157.

Elgamal, Ahmed, Joel P. Conte, Linjun Yan, Michael Fraser, Sami F. Masri, Magda El Zarki, Tony Fountain, and Mohan Trivedi. A Framework for Monitoring Bridge and Civil Infrastructure. University of California. San Diego, 2004.

Gordon, Alan. "Bridge Engineering Software-BRIDG for Windows Overview." Washington State Department of Transportation. 23 Aug. 2006. Bridge Office. 12 May $2008<$ http://www.wsdot.wa.gov>.

Griffiths, Jennifer R. Plastic Highway Bridges. CSA, 2000. 23 June 2006 $<$ www.csa.com/discoveryguides/bridge/overview.php>.

Guide for the Selection of Strengthening Systems for Concrete Structures: Guideline NO. 03742. International Concrete Repair Institute. Des Plaines, IL: International Concrete Repair Institute, 2006.

Hag-Elsafi, Osman, Jonathan Kunin, Sreenivas Alampalli, and Timothy Conway. New York. Transportation Research and Development Bureau. New York State Department of Transportation. Strengthening of Route 378 Bridge Over Wynantskill Creek in New York Using FRP Laminates. New York: New York State Department of Transportation, 2001.

Integrated Approach to Load Testing Instruction Manual. Bridge Diagnostics, Inc. Boulder, CO: Bridge Diagnostics, Inc., 2006.

Jaramilla, Becky, and Sharon Huo. Looking to Load and Resistance Factor Rating. U.S. Department of Transportation. Federal Highway Administration, 2005. 10 Aug. $2006<$ www.tfhrc.gov/pubrds/05jul/09.htm>. 
Juntunen, David A. Study of Michigan's Continuous Span Variable Depth T-Beam Bridges. Michigan Department of Transportation. Lansing, MI: MDOT, 2000.

Karbhari, Vistasp M. "Materials Considerations in FRP Rehabilitation of Concrete Structures." Journal of Materials in Civil Engineering 13.2 (2000): 90-97.

Lau, Kin-Tak, Libo Yuan, Li-Min Zhou, Jingshen Wu, and Chung-Ho Woo. "Strain Monitoring in FRP Laminates and Concrete Beams Using FBG Sensors." Composite Structures (2000): 9-20.

Lichtenstein Consulting Engineers, Inc. Manual for Condition Evaluations and Load Rating of Highway Bridges Using Load and Resistance Factor Philosophy. National Cooperative Highway Research Board. Transportation Research Board, 2001.

Lopez, Alexis, and Antonio Nanni. "Composite Strengthening Technologies." Concrete International (2006): 74-80.

Lopez, Alexis, Antonio Nanni, and Eli S. Hernandez. Preservation of Missouri Transportation Infrastructure - Validation of FRP Composite Technology Through Field Testing. University of Missouri. RB2C, 2005.

Lwin, M M. Bridge Load Ratings for the National Bridge Inventory. U.S. Department of Transportation. Federal Highway Administration, 2006. 12 May 2008 $<$ www.fhwa.dot.gov/BRIDGE.nbis.103006.cfm\#tab1>.

Malek, Amir M., and Hamid Saadatmanesh. "Analytical Study of Reinforced Concrete Beams Strengthened with Web-Bonded Fiber Reinforced Plastic Plates or Fabrics." ACI Structural Journal 95.3 (1998): 343-352.

Manual for Condition Evaluations and Load Rating of Highway Bridges Using Load and Resistance Factor Philosophy. AASHTO. AASHTO, 1996. 49-72.

Mayo, R., Nanni, A., Gold, W. and Barker, M., "Strengthening of Bridge G270 with Externally-Bonded CFRP Reinforcement," SP-188, American Concrete Institute, Proc., $4^{\text {th }}$ International Symposium on FRP for Reinforcement of Concrete Structures (FRPRCS4), Baltimore, MD, Nov. 1999, pp.429-440.

Minervino, Charles, Bala Sivakumar, Fred Moses, Dennis Mertz, and William Edberg. "New AASHTO Guide Manual for Load and Resistance Factor Rating of Highway Bridges." Journal of Bridge Engineering 9.1 (2002): 43-54.

Mirmiran, Amir, Mohsen Shahawy, Antonio Nanni, and Vistasp Karbhari. Bonded Repair and Retrofit of Concrete Structures Using FRP Composites: Recommended Construction Specifications and Process Control Manual. National 
Cooperative Highway Research Board. Washington, D.C.: Transportation Research Board, 2004.

Nanni, A., “FRP Reinforcement for Bridge Structures,” Proceedings, Structural Engineering Conference, The University of Kansas, Lawrence, KS, March 16, 2000, 5 pp.

Nanni, Antonio. Fiber Reinforced Polymer Composites for Infrastructure Strengthening From Research to Practice. University of Missouri- Rolla and University of Naples Federico II. Rolla, Missouri: University of Missouri-Rolla, 2005.

Nawy, Edward G. Reinforced Concrete: a Fundamental Approach. 5th ed. Upper Saddle River, NJ: Prentice Hall, 2003.

Ohio Department of Transportation. Ohio Department of Transportation. Section 900Bridge Load Rating. Ohio Department of Transportation, 2005.

Olson, Larry D. US Department of Transportation. Research, Development, and Technology. Federal Highway Administration. Dynamic Bridge Substructure Evaluation and Monitoring. Wheat Ridge, CO: Olson Engineering, Inc., 2005.

Parish, George C. CFRP Repair of Concrete Bridges with Accelerated Ageing by Induced Current. Thesis. West Virginia Univ., 2008. Morgantown, WV: West Virginia University, 2008.

PennDOT. User’s Manual for Computer Program BAR7. Version 7.11.0.9. Bureau of Information Systems Engineering Unit. Dec. 2005.

Phares, Brent M. "Development of Bridge Load Rating Techniques Using Physical Testing." Bridge Engineering Center. Mid-Continent Transportation Symposium. Iowa State University, Iowa. 21 Aug. 2003.

Phares, Brent M., F W. Klaiber, and Ahmad Abu-Hawash. Bride Load Rating Using Physical Testing. Center for Transportation Research and Education. Iowa State University, 2003.

Phares, Brent, Terry Wipf, F W. Klaiber, Ahmad Abu-Hawash, and Scott Neubauer. Implementation of Physical Testing for Typical Bridge Load and Superload Rating. Iowa State University-CTRE. Ames, IA: Iowa State University, 2003.

Potisuk, Tanarat, and Christopher Higgins. "Field Testing and Analysis of CRC Deck Girder Bridges." Journal of Bridge Engineering 12.1 (2005): 53-63.

Rahimi, Hamid, and Alan Hutchinson. "Concrete Beams Strengthened with Externally Bonded FRP Plates." Journal of Composites for Construction 5.1 (2001): 44-56. 
Reed, Michael W., Robert W. Barnes, Anton K. Schindler, and Hwan-Woo Lee. "FiberReinforced Polymer Strengthening of Concrete Bridges That Remain Open to Traffic." ACI Structural Journal 102.6 (2005): 823-831.

Riggs, H R., Si-Hwan Park, Ian N. Robertson, and Gregor Fisher. Sate of Hawaii Department of Transportation. College of Engineering. University of Hawaii. Final Report: Use of Advanced Composites for Hawaii Bridges. Manoa: University of Hawaii, 2004.

Rizkalla, Sami, Tarek Hassan, and Nahla Hassan. Design Recommendations for the Use of FRP for Reinforcement and Strengthening of Concrete Structures. North Carolina State University. John Wiley \& Sons, 2003. 16-28.

Ross, Allen, David M. Jerome, Joseph W. Tedesco, and Mary L. Hughes. "Strengthening of Reinforced Concrete Beams with Externally Bonded Composite Laminates." ACI Structural Journal 96.2 (1999): 212.

Saadatmanesh, H, and A M. Malek. "Design Guidelines for Flexural Strengthening If RC Beams with FRP Plates." Journal of Composites for Construction 2.4 (1998): $158-164$.

Samali, B, J Li, K I. Crews, and M Al-Dawod. Load Rating of Impaired Bridges Using Dynamic Method. University of Technology Sydney. Sydney, Australia: University of Technology Sydney, 2006.

Sargand, Shad M., and Ryan Ball. Special Students Study: Experimental Analysis of Composite Reinforced Bridge - Field Study. Diss. Ohio Univ., 2000.

Schiff, Scott D., Joseph J. Piccirilli, Christopher M. Iser, and Kevin J. Anderson. Load Testing for Assessment and Rating of Highway Bridges. Clemson University. Clemson, SC: Clemson University, 2006.

Shahrooz, Bahram M., and Serpil Boy. "Retrofit of a Three-Span Slab Bridge with Fiber Reinforced Polymer Systems - Testing and Rating." Journal of Composites for Construction 8.3 (2004): 241-247.

Shahrooz, Bahram M., and Serpil Boy. Ohio Department of Transportation. College of Engineering. University of Cincinnati. Retrofit of Existing Reinforced Concrete Bridges with Fiber Reinforced Polymer Composites. Federal Highway Administration, 2001.

Starnes, Monica A., Nicholas J. Carino, and Eduardo A. Kausel. "Preliminary Thermography Studies for Quality Control of Concrete Structures Strengthened with Fiber-Reinforced Polymer Composites." Journal of Materials in Civil Engineering 15.3 (2003): 266-273. 
Taljsten, B, and Skanska Teknik. CFRP Strengthening and Monitoring of the Grondals Bridge in Sweden. Lulea University of Technology. Lulea, SWEDEN, 2004.

Taljsten, Bjorn. FRP Strengthening of Concrete Structures - Design Guidelines in Sweden. Columbia University. New York: ASCE, 2002. 


\section{Appendix A: Penndot 45 ft SPan Concrete T-Beam BRIDGE SHOP DRAWINGS}




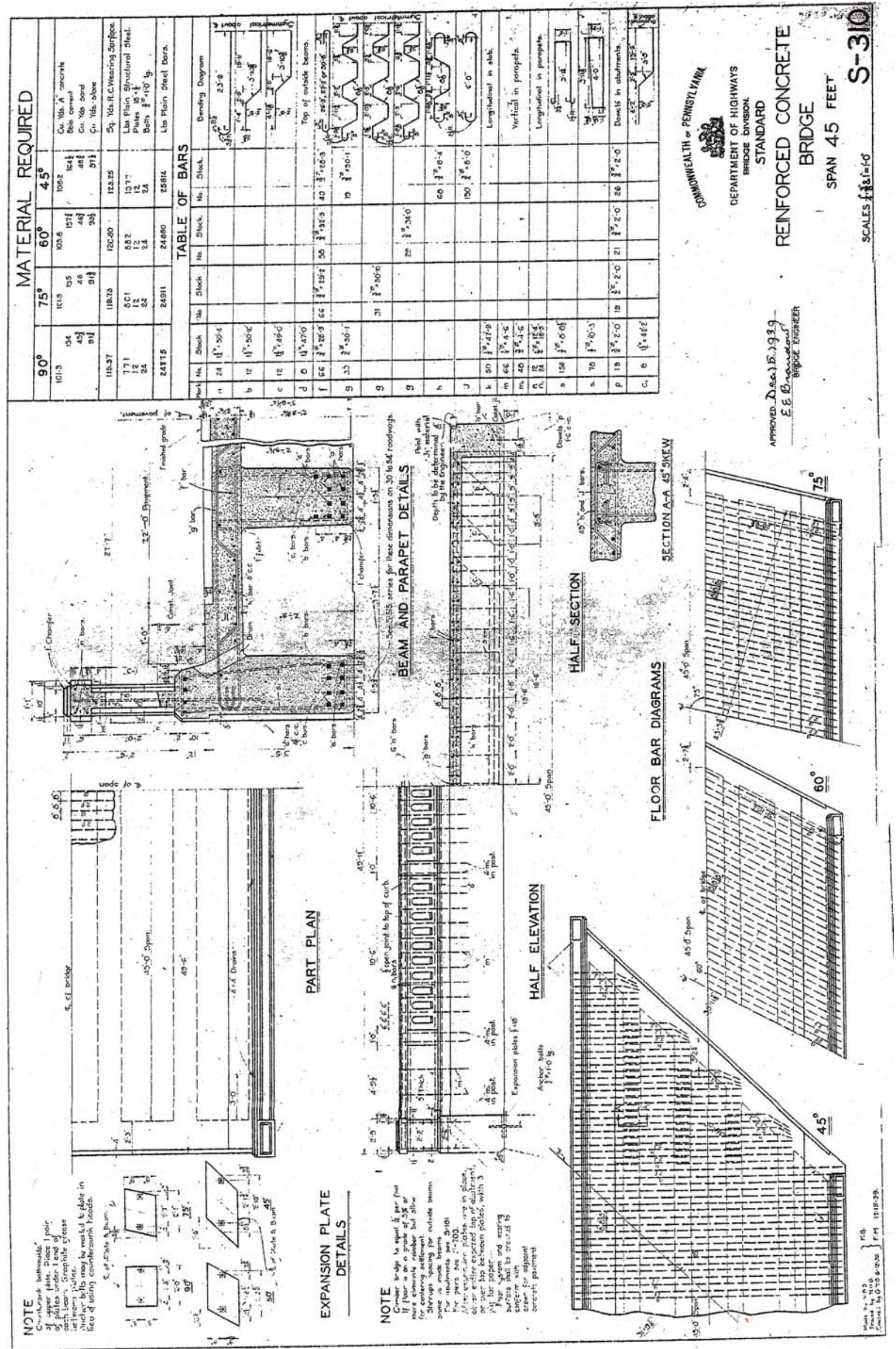




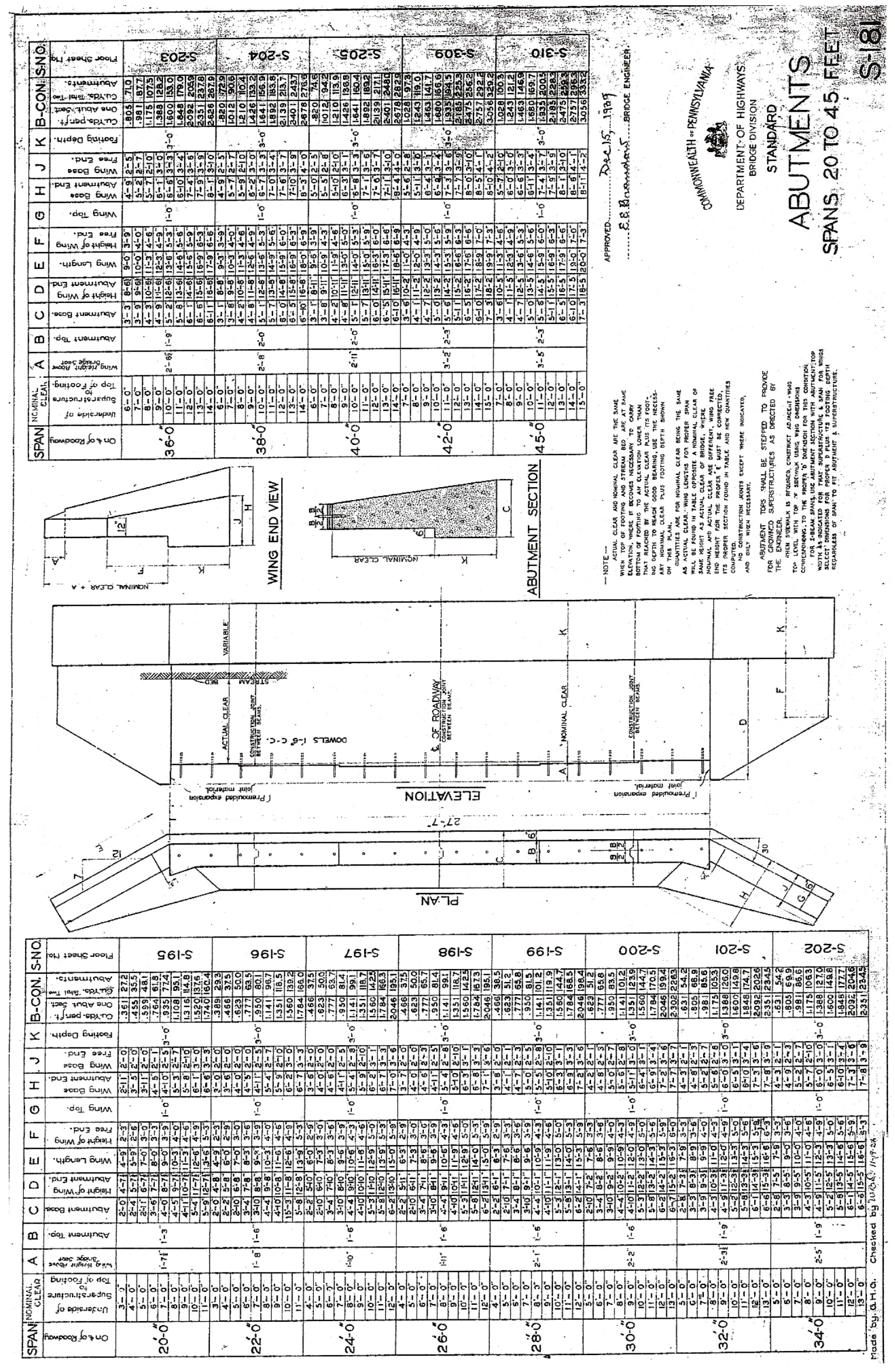




\section{APPENDiX B: MATERIAL Evaluation TeSt Results}


Table B.1 Concrete Compression Test Results

\begin{tabular}{|c|c|c|c|}
\hline & \multicolumn{2}{|c|}{ Deck Core } \\
\hline & & $\# 1$ & $\# 2$ \\
\hline Diameter & (in) & 4.125 & 4.125 \\
\hline Length & (in) & 4.5 & 4.25 \\
\hline Weight & (lbs) & 5.2 & 5 \\
\hline Ultimate Load & (kips) & 75 & 100 \\
\hline Clear Cover & (in) & 0.25 & 0.25 \\
\hline Diamter of Rebar & (in) & 0.75 & 0.75 \\
\hline Concrete Density & $\left(\mathrm{lb} / \mathrm{ft}^{3}\right)$ & 149.4 & 152 \\
\hline Length/Diameter Ratio & & 1.09 & 1.03 \\
\hline $\begin{array}{l}\text { AASTM C } 42 \text { Strength } \\
\text { Correction Factor }\end{array}$ & & 0.892 & 0.877 \\
\hline Compressive Strength & (psi) & 5005 & 6560 \\
\hline
\end{tabular}

Table B.2 Ultra Sonic Pulse Velocity Test Values

\begin{tabular}{|c|l|c|c|c|}
\hline \multicolumn{2}{|c|}{} & \multicolumn{3}{|c|}{ Distance from South Abutment (ft) } \\
\cline { 3 - 5 } \multicolumn{2}{|c|}{} & $\mathbf{4 . 5}$ & $\mathbf{5}$ & $\mathbf{5 . 5}$ \\
\hline \hline \multirow{2}{*}{$\begin{array}{c}\text { Visually Bad } \\
\text { Concrete Surface }\end{array}$} & Beam 1 & - & 58.2 & 53.6 \\
\cline { 2 - 5 } $\begin{array}{c}\text { Visually Good } \\
\text { Concrete Surface }\end{array}$ & Beam 3 & 166.4 & 320 & 216 \\
\cline { 2 - 5 } & Beam 4 & 99.2 & 97.7 & 115.4 \\
\hline
\end{tabular}

Table B.3 Rebound Hammer Test Values

\begin{tabular}{|c|l|c|c|}
\hline \multicolumn{2}{|c|}{} & $\begin{array}{c}\text { Horizontal Readings from } \\
\text { Right Side of Beam }\end{array}$ & $\begin{array}{c}\text { Vertical Readings from } \\
\text { Bottom Face of Beam }\end{array}$ \\
\hline \hline $\begin{array}{c}\text { Visually Bad } \\
\text { Concrete Surface }\end{array}$ & Beam 1* & $39,43,44,52,51,52,50,48$ & - \\
\cline { 2 - 4 } $\begin{array}{c}\text { Visually Good } \\
\text { Concrete Surface }\end{array}$ & Beam 2 & $52,32,56,58,56,56,50,48$ & $43,48,46,43,45,47,46$ \\
\cline { 2 - 4 } & Beam 4 & $56,51,55,50,48,46,52,48$ & $64,54,59,56,60,57,58,58$ \\
\hline
\end{tabular}

*Diagonal Measurement 
Table B4 summarizes the area calculation for each of the 6 steel tension test samples fabricated from the removed section of rebar. The diameter measurements (D1, D2, D3) were taken from three points along the length of each specimen. The average of the three diameter measurements was used for the cross sectional area calculation (A). This area was used to calculate stress values from the raw load data.

Table B.4 Steel Tension Test Sample-Area Calculation

\begin{tabular}{|c|c|c|c|c|c|c|}
\hline Scan Session: & "no1" & "no2" & "no3" & "no4" & "no5" & "no6" \\
\hline Test Date: & $6 / 23 / 2006$ & $6 / 23 / 2006$ & $6 / 23 / 2006$ & $6 / 23 / 2006$ & $6 / 23 / 2006$ & $6 / 23 / 2006$ \\
\hline Start Time: & $5: 10: 57 P M$ & $5: 26: 31 P M$ & $5: 46: 18 P M$ & $5: 58: 49 P M$ & $6: 12: 51 P M$ & $6: 22: 35 P M$ \\
\hline \hline D1 & 0.4965 & 0.5045 & 0.4925 & 0.5005 & 0.4975 & 0.5060 \\
\hline D2 & 0.4970 & 0.5015 & 0.5015 & 0.5010 & 0.4985 & 0.5030 \\
\hline D3 & 0.4995 & 0.5005 & 0.5000 & 0.5040 & 0.4995 & 0.5015 \\
\hline Average D & 0.4977 & 0.5022 & 0.4980 & 0.5018 & 0.4985 & 0.5035 \\
\hline Area & 0.1945 & 0.1981 & 0.1948 & 0.1978 & 0.1952 & 0.1991 \\
\hline
\end{tabular}


ApPendix C: Structural Analysis Calculations 


\section{Structural Analysis Notation:}

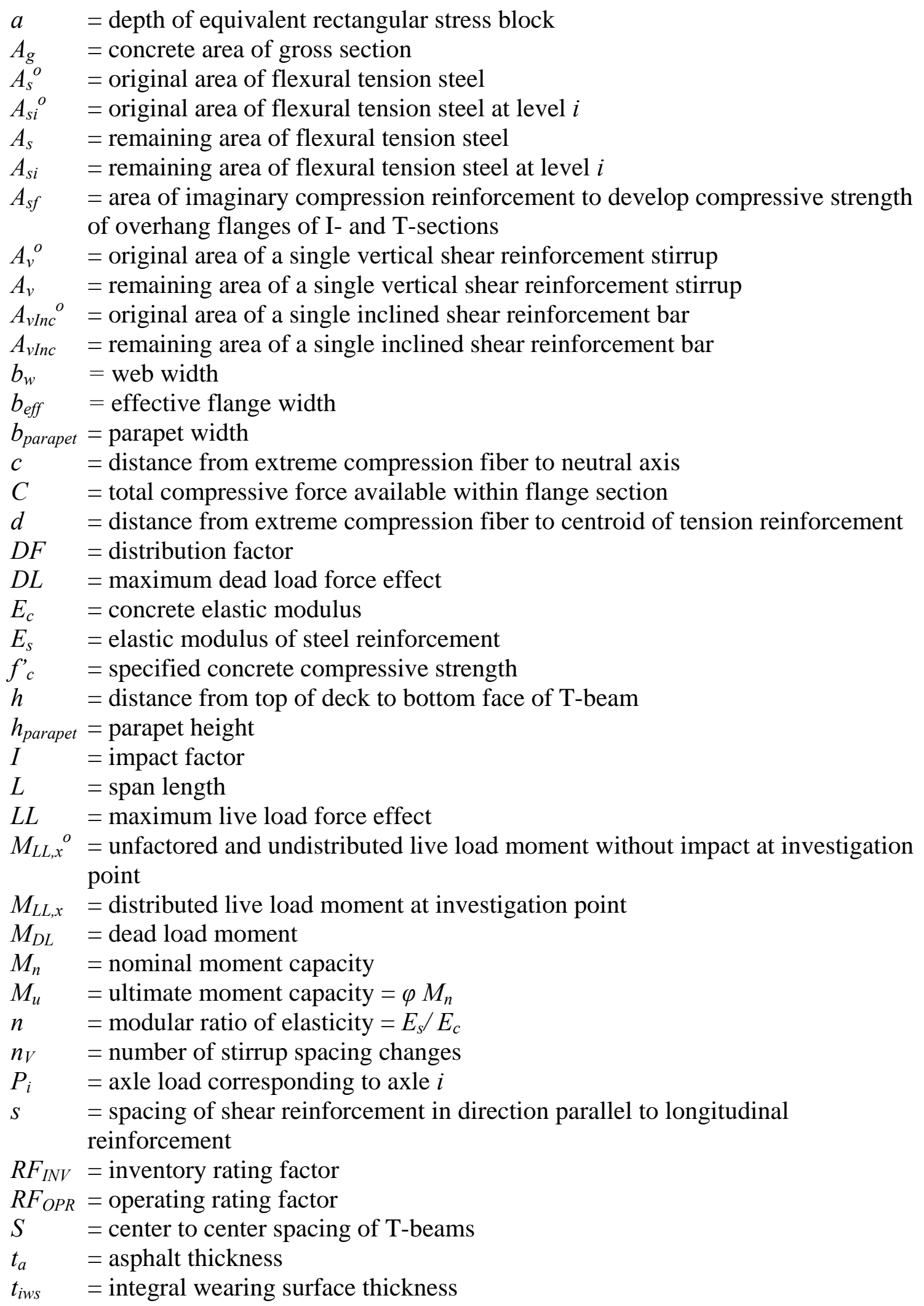




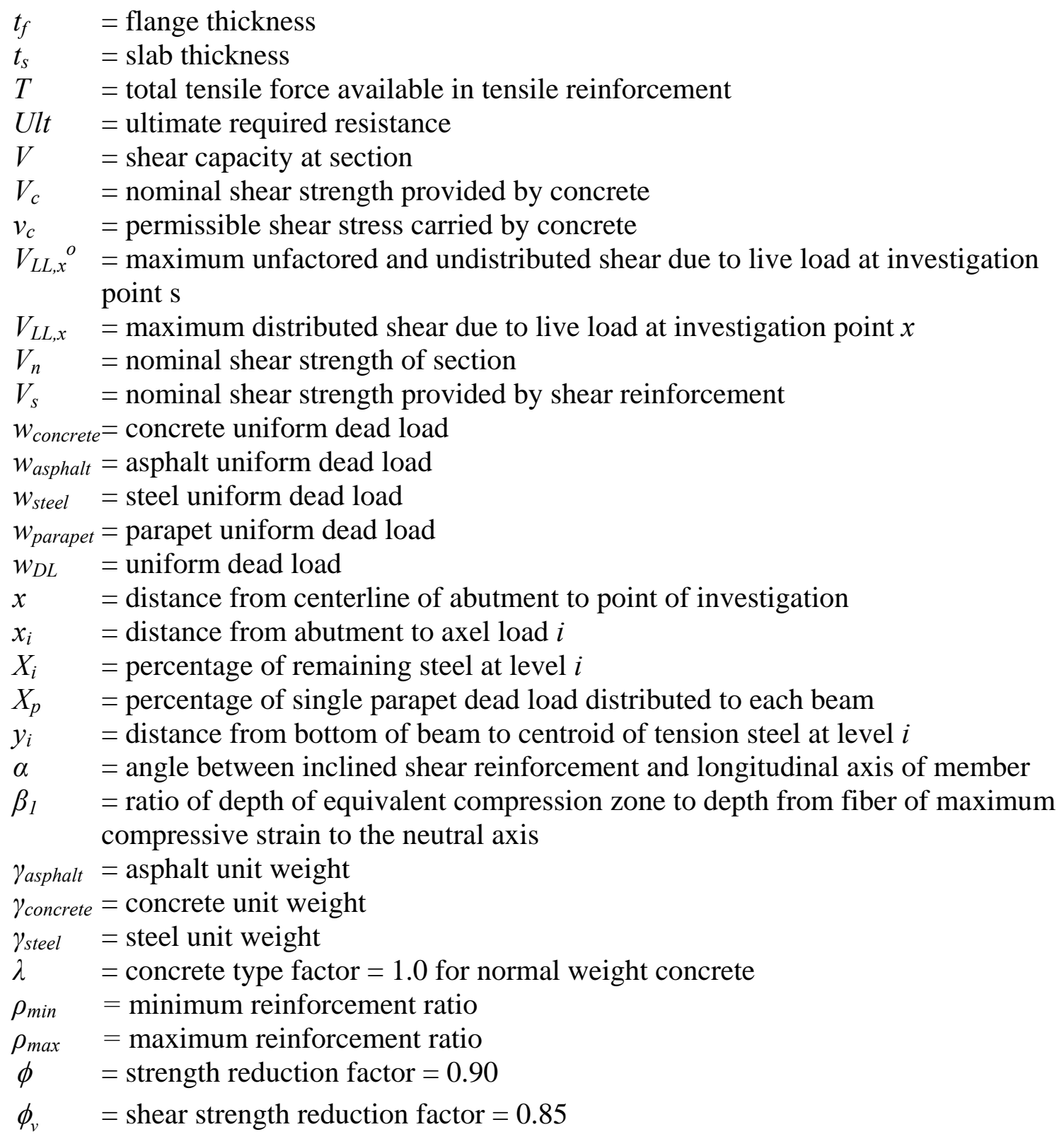




\section{Section Properties:}

Flange Thickness $=t_{f}=t_{s}-t_{i w s}$

Tension Steel Remaining at Level $i=A_{s i}=A_{s i}{ }^{o} \times \%$ remaining

Total Original Tension Steel Area $=A_{s}^{o}=\sum_{i=1}^{3} A_{s i}{ }^{o}$

Total Remaining Tension Steel Area $=A_{s}=\sum_{i=1}^{3} A_{s i}$

Total Percentage of Remaining Tension Steel $=\frac{A_{s}}{A_{s}{ }^{o}} \times 100 \%$

Depth to Centroid of Original Tension Steel $=d=h-\frac{\sum_{i=1}^{3} y_{i} A_{s i}{ }^{o}}{A_{s}{ }^{\circ}}$

Depth to Centroid of Tension Steel $=d=h-\frac{\sum_{i=1}^{3} y_{i} A_{s i}}{A_{s}}$

Effective Flange Width =

$$
b_{\text {eff }}=\left\{\begin{array}{c}
\text { Interior Beam }=\min \left\{\begin{array}{c}
L / 4 \\
S \\
12 t_{s}
\end{array}\right. \\
\text { Exterior Beam }=\min \left\{\begin{array}{c}
L / 12 \\
6 t_{s} \\
\frac{\left(S-b_{w}\right)}{2}
\end{array}\right.
\end{array}\right.
$$

Beta Factor $=\beta_{1}$

$$
0.65 \leq \beta_{1}=1.05-.05 \frac{f^{\prime}{ }_{c}}{1000} \leq 0.85
$$


Maximum Reinforcement Ratio Check =

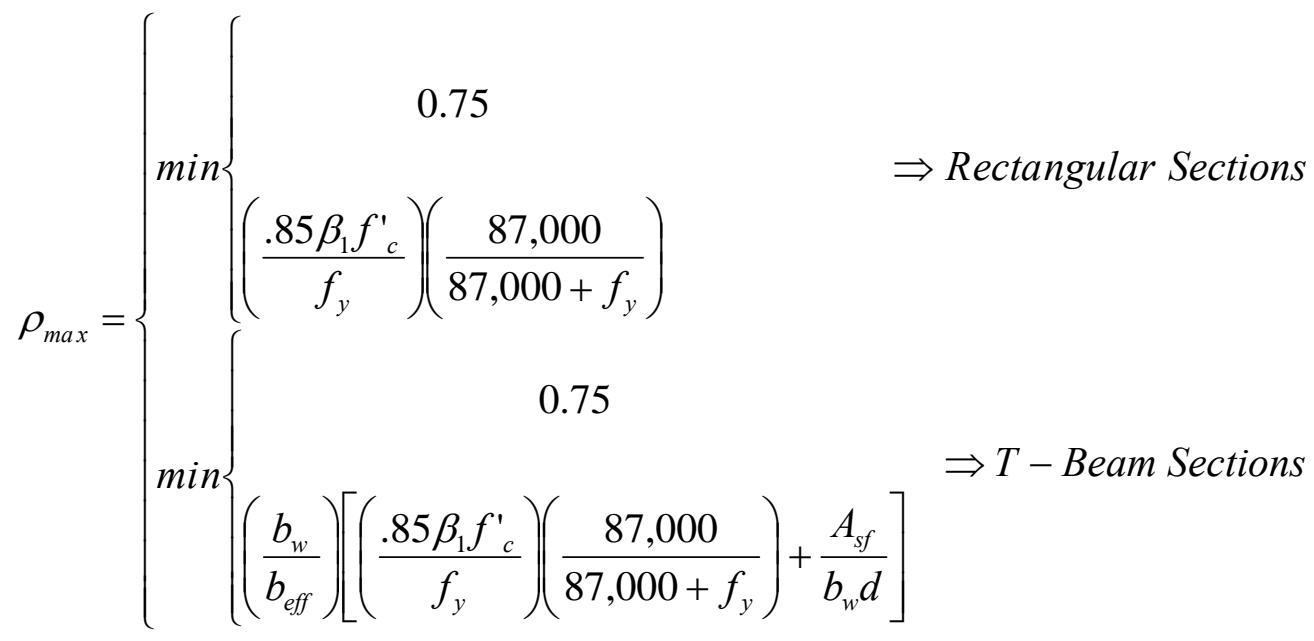

Minimum Reinforcement Ratio Check $=\rho_{\min }=\max \left\{\begin{array}{l}\frac{3 \sqrt{f_{c}^{\prime}}}{f_{y}} \\ \frac{200}{f_{y}}\end{array}\right.$

Area of Imaginary Compression Steel for T-Beam Analysis $=A_{s f}=\frac{0.85 f^{\prime}{ }_{c}\left(b_{e f f}-b_{w}\right) t_{f}}{f_{y}}$

Modulus of Elasticity of Concrete $=E_{c}=57,000 \sqrt{f^{\prime}}$ 


\section{Flexural Capacity Calculations:}

Tension Force Capacity $=T=A_{s} f_{y}$

Compression Force Capacity $=C=0.85 f^{\prime}{ }_{c} b_{e f f} t_{f}$

T-Beam Behavior Possibility $=$ if $\left\{\begin{array}{l}C<T \Rightarrow T-\text { Beam Behavior } \\ T<C \Rightarrow \text { Rectangular Beam Behavior }\end{array}\right.$

Neutral Axis Depth $=c=\frac{1.18 A_{s} f_{y} d}{\beta_{1} b_{e f f} d f^{\prime}{ }_{c}}$

Compression Block Length $=a$

$$
\begin{aligned}
& a=\frac{\left(A_{s}-A_{s f}\right) f_{y}}{0.85 f_{c}^{\prime} b_{w}} \Rightarrow T-\text { Beam Behavior } \\
& a=\frac{A_{s} f_{y}}{0.85 f^{\prime}{ }_{c} b_{\text {eff }}} \Rightarrow \text { Rectangular Beam Behavior }
\end{aligned}
$$

Ultimate Moment Capacity =

$$
\begin{aligned}
& M_{u}=\phi\left[\left(A_{s}-A_{s f}\right) f_{y}\left(d-\frac{a}{2}\right)+A_{s f} f_{y}\left(d-\frac{t_{f}}{2}\right)\right] \Rightarrow T \text {-Beam Behavior } \\
& M_{u}=\phi A_{s} f_{y}\left(d-\frac{a}{2}\right) \Rightarrow \text { Rectangular Beam Behavior }
\end{aligned}
$$




\section{Shear Capacity Calculations:}

Maximum Concrete Shear Stress Limit $=v_{c}=\lambda \times 2.0 \sqrt{f^{\prime}{ }_{c}} b_{w} d$

Original Area of Single Vertical Stirrup $=A_{v}^{o}=\frac{2 \pi \phi_{v}^{2}}{4}$

Remaining Area of Single Vertical Stirrup $=A_{v}=A_{v}^{o} \times \%$ remaining

Remaining Area of Single Inclined Bar $=A_{v I n c}=A_{v I n c}{ }^{o} \times \%$ remaining

Steel Reinforcement Shear Capacity $=\frac{2 A_{v} f_{y}}{s}+A_{v I n c} f_{y} \sin (\alpha) \cot (\alpha)+\cot (\alpha)$

Concrete Shear Capacity $=V_{c}=v_{c} b_{w} d$

Ultimate Shear Capacity $=\phi_{v}\left(V_{s}+V_{c}\right)$ 


\section{Appendix D: Structural Analysis Calculation RESULTS}




\section{Input Data:}

Table D.1 Universal Structural Analysis Input Data Variables

\begin{tabular}{|c|c|c|c|}
\hline Span Length & $\mathrm{L}$ & (ft.) & 45 \\
\hline c/c spacing & $\mathrm{s}$ & (in.) & 58 \\
\hline Yield Stress for Steel & $\mathrm{f}_{\mathrm{y}}$ & (psi) & 36000 \\
\hline Original Design Concrete Compressive Strength & $\mathrm{f}_{\mathrm{co}}^{\prime}$ & $(\mathrm{psi})$ & 3000 \\
\hline Existing Concrete Compressive Strength & $\mathrm{f}_{\mathrm{c}}^{\prime}$ & $(\mathrm{psi})$ & 3000 \\
\hline Integral Wearing Surface & $\mathrm{t}_{\mathrm{iws}}$ & (in.) & 0.5 \\
\hline Slab Thickness & $\mathrm{t}_{\mathrm{s}}$ & (in.) & 8.5 \\
\hline Flange Thickness & $\mathrm{t}$ & (in.) & 8 \\
\hline Concrete Unit Weight & $\overline{g_{c}}$ & $\left(\mathrm{k} / \mathrm{ft}^{3}\right)$ & 0.150 \\
\hline Asphalt Unit Weight & $\mathrm{ga}_{\mathrm{a}}$ & $\left(\mathrm{k} / \mathrm{ft}^{3}\right)$ & 0.150 \\
\hline Asphalt Thickness & $\mathrm{t}_{\mathrm{a}}$ & (in.) & 4.5 \\
\hline Parapet Height & $\mathrm{h}_{\mathrm{p}}$ & (in.) & 44.0 \\
\hline Parapet Width & $b_{p}$ & (in.) & 18.5 \\
\hline Analyze Universal Girder only? & \multicolumn{2}{|c|}{ (YES or NO) } & NO \\
\hline Inclined Stirrup Angle with Respect to Horizontal & \multicolumn{2}{|c|}{ (degrees) } & 45 \\
\hline Diameter of Vertical Stirrups & $f_{V}$ & (in.) & 0.5 \\
\hline Original Area of Single Inclined Stirrup & $\mathrm{A}_{\mathrm{vi1}}{ }^{0}$ & $\left(\right.$ in. $\left.^{2}\right)$ & 1.563 \\
\hline Remove Clear Cover on Web for Shear Calcs? & \multicolumn{2}{|c|}{ (YES or NO) } & NO \\
\hline \multicolumn{3}{|l|}{ \# of Sections of Vertical Stirrup Spacing Changes for the 1 Girder } & 8 \\
\hline \multicolumn{3}{|l|}{ \# of Sections of Vertical Stirrup Spacing Changes for the 6 Girder } & 8 \\
\hline \multicolumn{3}{|c|}{$\begin{array}{l}\text { Select Desired Load Rating Method: Enter } 1 \text { for Allowable Stress Design Rating, Enter } 2 \text { for Load Factor } \\
\text { Design Rating, Enter } 3 \text { for Load and Resistance Factor Design Rating }\end{array}$} & 2 \\
\hline \multicolumn{3}{|c|}{$\begin{array}{l}\text { Select Required Capacity for Design of FRP Strengthening: Enter } 1 \text { for Original Design Capacity, Enter } 2 \text { for } \\
\text { Loading Vehicle Capacity, Enter } 3 \text { for Maximum of Design Vehicle Loading or Original Design Capacity, } \\
\text { Enter } 4 \text { for Design Based on Minimum Rating Factor }\end{array}$} & 4 \\
\hline
\end{tabular}


Table D.2 Beam Specific Input Data Variables

\begin{tabular}{|c|c|c|c|c|c|c|c|c|}
\hline \multicolumn{3}{|l|}{ Girder Specific Input Data } & \multicolumn{6}{|c|}{ Beam \# } \\
\hline Beam Number & & & 1 & $\overline{2}$ & $\overline{3}$ & $\overline{4}$ & $\mathbf{5}$ & $\overline{6}$ \\
\hline Analyze as Interior Girder? & \multicolumn{2}{|c|}{ (YYES or NO) } & $\mathrm{PNO}$ & YYES & IYES & $\overline{Y Y E S}$ & IYES & $\mathrm{NOO}$ \\
\hline Width & b & (in.) & 17.75 & 17.5 & 17.5 & 17.5 & 17.5 & 17.75 \\
\hline \begin{tabular}{|l|} 
Depth of Girder \\
\end{tabular} & $\mathbf{h}$ & (in.) & 41.50 & 42.25 & 42.25 & 42.25 & 42.25 & 41.50 \\
\hline Compression Steel & $\mathbf{A}_{\mathrm{s}}^{\prime}$ & (in. $^{2}$ ) & 0.00 & 0 & 0 & 0 & 0 & 0.00 \\
\hline Original Flexural Tension Steel & $\mathbf{A}_{\mathrm{s}}^{0}$ & $\left(\right.$ in. $\left.^{2}\right)$ & 9.375 & 15.625 & 15.625 & 15.625 & 15.625 & 9.375 \\
\hline Estimate of \% of Remaining Flexural Steel & & $(\%)$ & 69 & 72.4 & 72 & 72 & 59.0016 & 76 \\
\hline Flexural Tension Steel Remaining & $\overline{\mathbf{A}_{\mathrm{s}}}$ & (in. $^{2}$ ) & 6.441 & 11.3125 & 11.25 & 11.25 & 9.219 & 7.116 \\
\hline$\%$ of Single Parapet DL distribution & & $(\%)$ & 33.0 & 33 & 33 & 33 & 33 & 33.0 \\
\hline Centroid Distance of Tension Steel at $1^{\text {st }}$ level, from bottom of girder & $\mathrm{y}_{1}$ & (in.) & 2.6 & 2.625 & 2.625 & 2.625 & 2.625 & 2.6 \\
\hline Original Area of Tension Steel at $1^{\text {st }}$ level, from bottom of girder & $\mathbf{A}_{\mathbf{s 1}}{ }^{0}$ & $\left(\right.$ in. $\left.^{2}\right)$ & 6.3 & 6.25 & 6.25 & 6.25 & 6.25 & 6.3 \\
\hline Estimate of $\%$ of Remaining Flexural Steel at $1^{\text {st }}$ level, from bottom & & $(\%)$ & 68.7 & 90.5 & 90 & 90 & 73.752 & 75.9 \\
\hline Flexural Tension Steel Remaining at $1^{\text {st }}$ level, from bottom & $\mathbf{A}_{\mathrm{s} 1}$ & $\left(\right.$ in. $\left.^{2}\right)$ & 4.3 & 5.65625 & 5.625 & 5.625 & 4.6095 & 4.7 \\
\hline Centroid Distance of Tension Steel at $2^{\text {nd }}$ level, from bottom of girder & $\mathbf{y}_{2}$ & (in.) & 6.6 & 6.625 & 6.625 & 6.625 & 6.625 & 6.6 \\
\hline Original Area of Tension Steel at $2^{\text {nd }}$ level, from bottom of girder & $\mathbf{A}_{\mathrm{s} 2}{ }^{0}$ & (in. $\left.^{2}\right)$ & 3.1 & 6.25 & 6.25 & 6.25 & 6.25 & 3.1 \\
\hline Estimate of $\%$ of Remaining Flexural Steel at $2^{\text {nd }}$ level, from bottom & & $(\%)$ & 68.7 & 90.5 & 90 & 90 & 73.752 & 75.9 \\
\hline Flexural Tension Steel Remaining at $2^{\text {nd }}$ level, from bottom & $\mathbf{A}_{\mathbf{s} 2}$ & (in. $^{2}$ ) & 2.1 & 5.65625 & 5.625 & 5.625 & 4.6095 & 2.4 \\
\hline Centroid Distance of Tension Steel at $3^{\text {rd }}$ level, from bottom of girder & $\mathbf{y}_{3}$ & (in.) & 0.0 & 10.625 & 10.625 & 10.625 & 10.625 & 0.0 \\
\hline Original Area of Tension Steel at $3^{\text {rd }}$ level, from bottom of girder & $\mathbf{A}_{\mathrm{s} 3}{ }^{0}$ & $\left(\right.$ in. $\left.^{2}\right)$ & 0.0 & 3.125 & 3.125 & 3.125 & 3.125 & 0.0 \\
\hline Estimate of $\%$ of Remaining Flexural Steel at $3^{\text {rd }}$ level, from bottom & & $(\%)$ & 0.0 & 0 & 0 & 0 & 0 & 0.0 \\
\hline Flexural Tension Steel Remaining at $3^{\text {rd }}$ level, from bottom & $\mathbf{A}_{\mathrm{s} 1}$ & $\left(\right.$ (in. $\left.^{2}\right)$ & 0.0 & 0 & 0 & 0 & 0 & 0.0 \\
\hline Original Ext. Comp. Fiber- $\mathbf{A}_{\mathrm{s}}$ Centroid Dist. & d & (in.) & 37.54 & 36.425 & 36.425 & 36.425 & 36.425 & 37.54 \\
\hline As Built Ext. Comp. Fiber- $A_{\mathrm{s}}$ Centroid Dist. & d & (in.) & 37.54 & 37.625 & 37.625 & 37.625 & 37.625 & 37.54 \\
\hline Section 1 Distance & 1 & (in.) & 4 & 4 & 4 & 4 & 4 & 4 \\
\hline Section 1 Spacing & 1 & (in.) & 4 & 4 & 4 & 4 & 4 & 4 \\
\hline Section 2 Distance & $\mathbf{0}$ & (in.) & 27 & 27 & 27 & 27 & 27 & 27 \\
\hline Section 2 Spacing & 2 & (in.) & 9 & 9 & 9 & 9 & 9 & 9 \\
\hline Section 3 Distance & 3 & (in.) & 27 & 27 & 27 & 27 & 27 & 27 \\
\hline Section 3 Spacing & & (in.) & 9 & 9 & 9 & 9 & 9 & 9 \\
\hline Section 4 Distance & A & (in.) & 12 & 12 & 12 & 12 & 12 & 12 \\
\hline Section 4 Spacing & 4 & (in.) & 12 & 12 & 12 & 12 & 12 & 12 \\
\hline Section 5 Distance & 5 & (in.) & 36 & 36 & 36 & 36 & 36 & 36 \\
\hline Section 5 Spacing & $\mathbf{5}$ & (in.) & 12 & 12 & 12 & 12 & 12 & 12 \\
\hline Section 6 Distance & 6 & (in.) & 72 & 72 & 72 & 72 & 72 & 72 \\
\hline Section 6 Spacing & 6 & (in.) & 18 & 18 & 18 & 18 & 18 & 18 \\
\hline Section 7 Distance & 7 & (in.) & 20 & 20 & 20 & 20 & 20 & 20 \\
\hline Section 7 Spacing & $f$ & (in.) & 20 & 20 & 20 & 20 & 20 & 20 \\
\hline Section 8 Distance & 8 & (in.) & 72 & 72 & 72 & 72 & 72 & 72 \\
\hline Section 8 Spacing & 8 & (in.) & 24 & 24 & 24 & 24 & 24 & 24 \\
\hline & & 1 & 0 & 0 & 0 & 0 & 0 & 0 \\
\hline & & 2 & 2 & 2 & 2 & 2 & 2 & 2 \\
\hline & & 3 & 0 & 2 & 2 & 2 & 2 & 0 \\
\hline Nut & & 4 & 0 & 2 & 2 & 2 & 2 & 0 \\
\hline Number of Inclined Stirrups Effective in Section & & 5 & 0 & 2 & 2 & 2 & 2 & 0 \\
\hline & & 6 & 0 & 0 & 0 & 0 & 0 & 0 \\
\hline & & 7 & 0 & 0 & 0 & 0 & 0 & 0 \\
\hline & & 8 & 0 & 0 & 0 & 0 & 0 & 0 \\
\hline & & 1 & $\mathrm{NO}$ & $\mathrm{NO}$ & $\mathrm{NO}$ & $\mathrm{NO}$ & $\mathrm{NO}$ & $\mathrm{NO}$ \\
\hline & & 2 & $\mathrm{NO}$ & $\mathrm{NO}$ & $\mathrm{NO}$ & $\mathrm{NO}$ & $N O$ & $\mathrm{NO}$ \\
\hline & & 3 & $N O$ & $\mathrm{NO}$ & $N O$ & $N O$ & $\mathrm{NO}$ & $\mathrm{NO}$ \\
\hline Is there sovere diogon crocling in section? & & 4 & NO & $N O$ & $N O$ & $N O$ & $N O$ & NO \\
\hline Is there severe diagonal cracking in section? & & 5 & $N O$ & $N O$ & $N O$ & $N O$ & $N O$ & NO \\
\hline & & 6 & $\mathrm{NO}$ & $\mathrm{NO}$ & $\mathrm{NO}$ & $\mathrm{NO}$ & $\mathrm{NO}$ & NO \\
\hline & & 7 & $\mathrm{NO}$ & $\mathrm{NO}$ & $\mathrm{NO}$ & $N O$ & $\mathrm{NO}$ & $\mathrm{NO}$ \\
\hline & & 8 & $\mathrm{NO}$ & $\mathrm{NO}$ & $\mathrm{NO}$ & $\mathrm{NO}$ & $\mathrm{NO}$ & $\mathrm{NO}$ \\
\hline Section 1 Estimate of Remaining Vertical Stirrup Steel & & $(\%)$ & 90 & 90 & 90 & 90 & 90 & 90 \\
\hline Section 2 Estimate of Remaining Vertical Stirrup Steel & & (\%) & 90 & 90 & 90 & 90 & 90 & 90 \\
\hline Section 3 Estimate of Remaining Vertical Stirrup Steel & & $(\%)$ & 90 & 90 & 90 & 90 & 90 & 90 \\
\hline Section 4 Estimate of Remaining Vertical Stirrup Steel & & $(\%)$ & 90 & 90 & 90 & 90 & 90 & 90 \\
\hline Section 5 Estimate of Remaining Vertical Stirrup Steel & & $(\%)$ & 90 & 90 & 90 & 90 & 90 & 90 \\
\hline Section 6 Estimate of Remaining Vertical Stirrup Steel & & (\%) & 90 & 90 & 90 & 90 & 90 & 90 \\
\hline Section 7 Estimate of Remaining Vertical Stirrup Steel & & $(\%)$ & 90 & 90 & 90 & 90 & 90 & 90 \\
\hline Section 8 Estimate of Remaining Vertical Stirrup Steel & & $(\%)$ & 0 & 0 & 0 & 0 & 0 & 0 \\
\hline Section 1 Estimate of Remaining Inclined Stirrup Steel & & $(\%)$ & & & & & & \\
\hline Section 2 Estimate of Remaining Inclined Stirrup Steel & & $(\%)$ & 90 & 90 & 90 & 90 & 90 & 90 \\
\hline Section 3 Estimate of Remaining Inclined Stirrup Steel & & $(\%)$ & & 90 & 90 & 90 & 90 & \\
\hline Section 4 Estimate of Remaining Inclined Stirrup Steel & & $(\%)$ & & 90 & 90 & 90 & 90 & \\
\hline Section 5 Estimate of Remaining Inclined Stirrup Steel & & $(\%)$ & & 0 & 0 & 0 & 0 & \\
\hline Section 6 Estimate of Remaining Inclined Stirrup Steel & & $(\%)$ & & & & & & \\
\hline Section 7 Estimate of Remaining Inclined Stirrup Steel & & $(\%)$ & & & & & & \\
\hline Section 8 Estimate of Remaining Inclined Stirrup Steel & & $(\%)$ & & & & & & \\
\hline Load Rating/FRP Design Vehicle & & & $H S-20$ & $H S-20$ & $H S-20$ & $H S-20$ & $H S-20$ & $H S-20$ \\
\hline
\end{tabular}




\section{Moment Capacity Variable Results:}

Table D.3 Moment Capacity Calculation Variable Results

\begin{tabular}{|c|c|c|c|c|c|c|c|}
\hline & & Beam 1 & Beam 2 & Beam 3 & Beam 4 & Beam 5 & Beam 6 \\
\hline$E_{c}$ & (psi) & 33321000 & 33321000 & 33321000 & 3321000 & 3321000 & 3321000 \\
\hline$E_{s}$ & (psi) & 29000000 & 29000000 & 29000000 & 29000000 & 29000000 & 29000000 \\
\hline$\beta$ & & 0.85 & 0.85 & 0.85 & 0.85 & 0.85 & 0.85 \\
\hline$n$ & & 9 & 9 & 9 & 9 & 9 & 9 \\
\hline$d$ & (in) & 37.54 & 37.63 & 37.63 & 37.63 & 37.63 & 37.54 \\
\hline $\boldsymbol{b}_{\text {eff }}$ & (in) & 20.13 & 58.00 & 58.00 & 58.00 & 58.00 & 20.13 \\
\hline$\rho_{\max }$ & & $O K$ & $O K$ & $O K$ & $O K$ & $O K$ & $O K$ \\
\hline$\rho_{\min }$ & & $O K$ & $O K$ & $O K$ & $O K$ & $O K$ & $O K$ \\
\hline$A_{s f}$ & $\left(\mathrm{in}^{2}\right)$ & 1.35 & 22.95 & 22.95 & 22.95 & 22.95 & 1.35 \\
\hline$T$ & (lbs) & 231863 & 407250 & 405000 & 405000 & 331884 & 256163 \\
\hline$C$ & (lbs) & 410550 & 1183200 & 1183200 & 1183200 & 1183200 & 410550 \\
\hline $\begin{array}{c}\text { T-Beam Behavior } \\
\text { Possibility? }\end{array}$ & & $N O$ & $\mathrm{NO}$ & $N O$ & $\mathrm{NO}$ & $N O$ & $\mathrm{NO}$ \\
\hline$w$ & & 0.102 & 0.062 & 0.062 & 0.062 & 0.051 & 0.113 \\
\hline$c$ & (in) & 5.331 & 3.249 & 3.231 & 3.231 & 2.648 & 5.890 \\
\hline Analysis Approach & & $\begin{array}{c}\text { Rectangular } \\
\text { Beam }\end{array}$ & $\begin{array}{c}\text { Rectangular } \\
\text { Beam }\end{array}$ & $\begin{array}{l}\text { Rectangular } \\
\text { Beam }\end{array}$ & $\begin{array}{l}\text { Rectangular } \\
\text { Beam }\end{array}$ & $\begin{array}{c}\text { Rectangular } \\
\text { Beam }\end{array}$ & $\begin{array}{c}\text { Rectangular } \\
\text { Beam }\end{array}$ \\
\hline $\bar{a}$ & (in) & 4.52 & 2.75 & 2.74 & 2.74 & 2.24 & 4.99 \\
\hline$M_{U}$ & (kip·ft) & 613.6 & 1107.2 & 1101.3 & 1101.3 & 908.6 & 673.3 \\
\hline
\end{tabular}




\section{Shear Capacity Variable Results:}

Table D.4 Shear Capacity Calculation Variable Results

\begin{tabular}{|c|c|c|c|c|c|c|c|}
\hline & & Beam 1 & Beam 2 & Beam 3 & Beam 4 & Beam 5 & Beam 6 \\
\hline$v_{c}$ & (psi) & 71.20 & 71.20 & 71.20 & 71.20 & 71.20 & 71.20 \\
\hline$\alpha$ & (rad) & 0.785 & 0.785 & 0.785 & 0.785 & 0.785 & 0.785 \\
\hline$A_{v}{ }^{o}$ & $\left(i^{2}\right)$ & 0.393 & 0.393 & 0.393 & 0.393 & 0.393 & 0.393 \\
\hline$\varphi_{v}$ & & 0.85 & 0.85 & 0.85 & 0.85 & 0.85 & 0.85 \\
\hline$V_{c}$ & (lbs) & 72997 & 72128 & 72128 & 72128 & 72128 & 72997 \\
\hline$A_{v}{ }^{o}$ & (in2) & 0.393 & 0.393 & 0.393 & 0.393 & 0.393 & 0.393 \\
\hline$D F_{S}$ & & 0.210 & 0.586 & 0.586 & 0.586 & 0.586 & 0.210 \\
\hline$A_{v 1}$ & $($ in2) & 0.353 & 0.353 & 0.353 & 0.353 & 0.353 & 0.353 \\
\hline$A_{\text {vIncI }}$ & (in2) & 0 & 0 & 0 & 0 & 0 & 0 \\
\hline$V_{s 1}$ & (lbs) & 119000 & 120000 & 120000 & 120000 & 120000 & 119000 \\
\hline$V_{n 1}$ & (lbs) & 163000 & 163000 & 163000 & 163000 & 163000 & 163000 \\
\hline$A_{v 2}$ & (in2) & 0.353 & 0.353 & 0.353 & 0.353 & 0.353 & 0.353 \\
\hline$A_{v I n c 2}$ & (in2) & 2.8134 & 2.8134 & 2.8134 & 2.8134 & 2.8134 & 2.8134 \\
\hline$V_{s 2}$ & (lbs) & 196000 & 196000 & 196000 & 196000 & 196000 & 196000 \\
\hline$V_{n 2}$ & (lbs) & 229000 & 228000 & 228000 & 228000 & 228000 & 229000 \\
\hline$A_{v 3}$ & (in2) & 0.353 & 0.353 & 0.353 & 0.353 & 0.353 & 0.353 \\
\hline$A_{v \operatorname{Inc} 3}$ & (in2) & 2.8134 & 2.8134 & 2.8134 & 2.8134 & 2.8134 & 2.8134 \\
\hline$V_{s 3}$ & (lbs) & 196000 & 196000 & 196000 & 196000 & 196000 & 196000 \\
\hline$V_{n 3}$ & (lbs) & 229000 & 228000 & 228000 & 228000 & 228000 & 229000 \\
\hline$A_{v 4}$ & (in2) & 0.353 & 0.353 & 0.353 & 0.353 & 0.353 & 0.353 \\
\hline$A_{v I n c 4}$ & (in2) & 2.8134 & 2.8134 & 2.8134 & 2.8134 & 2.8134 & 2.8134 \\
\hline$V_{s 4}$ & (lbs) & 183000 & 183000 & 183000 & 183000 & 183000 & 183000 \\
\hline$V_{n 4}$ & (lbs) & 218000 & 217000 & 217000 & 217000 & 217000 & 218000 \\
\hline$A_{v 5}$ & (in2) & 0.353 & 0.353 & 0.353 & 0.353 & 0.353 & 0.353 \\
\hline$A_{v \operatorname{Inc5}}$ & (in2) & 0 & 0 & 0 & 0 & 0 & 0 \\
\hline$V_{s 5}$ & (lbs) & 40000 & 40000 & 40000 & 40000 & 40000 & 40000 \\
\hline$V_{n 5}$ & (lbs) & 96000 & 95000 & 95000 & 95000 & 95000 & 96000 \\
\hline$A_{v 6}$ & (in2) & 0.353 & 0.353 & 0.353 & 0.353 & 0.353 & 0.353 \\
\hline$A_{\text {vInc6 }}$ & (in2) & 0 & 0 & 0 & 0 & 0 & 0 \\
\hline$V_{s 6}$ & (lbs) & 27000 & 27000 & 27000 & 27000 & 27000 & 27000 \\
\hline$V_{n 6}$ & (lbs) & 85000 & 84000 & 84000 & 84000 & 84000 & 85000 \\
\hline$A_{v 7}$ & (in2) & 0.353 & 0.353 & 0.353 & 0.353 & 0.353 & 0.353 \\
\hline$A_{v I n c 7}$ & (in2) & 0 & 0 & 0 & 0 & 0 & 0 \\
\hline$V_{s 7}$ & (lbs) & 20000 & 20000 & 20000 & 20000 & 20000 & 20000 \\
\hline$V_{n 7}$ & (lbs) & 79000 & 78000 & 78000 & 78000 & 78000 & 79000 \\
\hline$A_{v 8}$ & (in2) & 0 & 0 & 0 & 0 & 0 & 0 \\
\hline$A_{v \operatorname{Inc} 8}$ & (in2) & 0 & 0 & 0 & 0 & 0 & 0 \\
\hline$V_{s 8}$ & (lbs) & 0 & 0 & 0 & 0 & 0 & 0 \\
\hline$\overline{V_{n 8}}$ & (lbs) & 62000 & 61000 & 61000 & 61000 & 61000 & 62000 \\
\hline
\end{tabular}




\section{APPENDIX E: DEAD/LIVE LOAD GENERATOR EQUATIONS}




\section{Dead Load Calculations:}

Concrete Area of Gross Section $=A_{g}=b_{\text {eff }} t_{s}+\left(h-t_{s}\right) b_{w}-A_{s}$

Uniform Concrete Dead Load $=w_{\text {concrete }}=A_{g} \gamma_{\text {concrete }}$

Uniform Asphalt Dead Load $=w_{\text {asphalt }}=b_{\text {eff }} t_{a} \gamma_{\text {asphalt }}$

Uniform Steel Dead Load $=w_{\text {steel }}=A_{s} \gamma_{\text {steel }}$

Uniform Parapet Dead Load $=w_{\text {parapet }}=h_{\text {parapet }} b_{\text {parapet }} \gamma_{\text {concrete }} \times(\%$ Parapet Distribution $)$

Uniform Dead Load $=w_{D L}=w_{\text {concrete }}+w_{\text {asphalt }}+w_{\text {steel }}+w_{\text {parapet }}$

Dead Load Moment at $x=M_{D L, x}=\frac{w_{D L} x}{2}(L-x)$

Maximum Dead Load Moment $=M_{D L}=\frac{w_{D L} L^{2}}{8}$ 


\section{Live Load Moment Calculations:}

Impact Factor $=I=\frac{50}{L+125} \leq 0.3$

Moment Distribution Factor

- Interior Beam

$$
\begin{aligned}
& D F_{I N T, M}=\text { Interior Girder Moment Distribution Factor } \\
& D F_{I N T, M}=\frac{S}{6 f t}=D F_{I N T, M, \text { Wheel Lines }} \Rightarrow \frac{D F_{\text {Whel Lines }}}{2 \text { Wheel Lines / Axle }}=D F_{I N, M, A x l e s}
\end{aligned}
$$

- Exterior Beam

$$
\begin{aligned}
D F_{E X T, M} & =\text { Exterior Girder Moment Distribution Factor } \\
D F_{E X T, M} & =1-\frac{b_{\text {parapet }}+24 \text { in }-\left(b_{w} / 2\right)}{S}=D F_{E X T, M, \text { WheelLines }} \\
\Rightarrow & \frac{D F_{\text {WheelLines }}}{2 \text { Wheel Lines / Axle }}=D F_{E X T, M, \text { Axles }}
\end{aligned}
$$

Unfactored and Undistributed Live Load Moment at Investigation Point $=M_{L L, x}{ }^{o}$

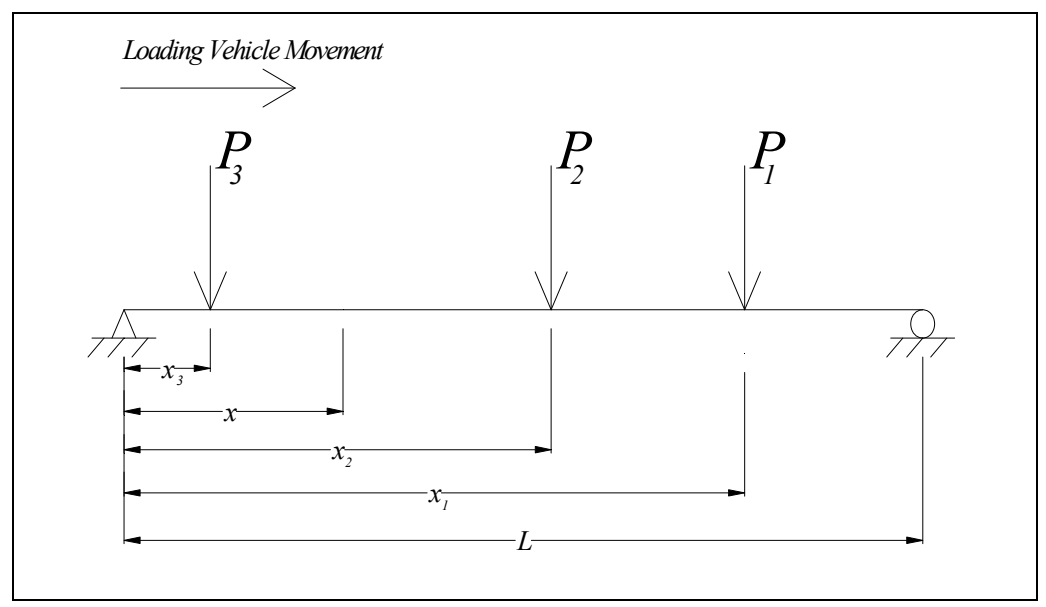

Figure E.1 Loading Vehicle Calculation Diagram

$$
M_{L L, x}^{o}=\sum_{i=1}^{m} \begin{cases}\frac{P_{i}\left(L-x_{i}\right) x}{L}, & \text { when } x<x_{i} \\ \frac{P_{i}(L-x) x_{i}}{L}, & \text { when } x>x_{i}\end{cases}
$$

Distributed Live Load Moment at Investigation Point $=M_{L L, x}=M_{L L, x}{ }^{o} \times D F_{M}$ 


\section{Live Load Shear Calculations:}

Impact Factor $=I=\frac{50}{L+125} \leq 0.3$

Shear Distribution Factor $=D F_{S}$

- Interior Beam

$$
\begin{aligned}
& D F_{I N T, S}=\text { Interior Girder Shear Distribution Factor } \\
& D F_{I N T, S}=1+\left(\frac{S-48 \text { in }}{S}\right)=D F_{I N T, S, \text { Wheel Lines }} \\
& D F_{I N T, S}=\frac{D F_{I N T, S, \text { Wheel Lines }}}{2 \text { Wheel Lines / Axle }}=D F_{I N T, S, \text { Axles }}
\end{aligned}
$$

- Exterior Beam

$$
\begin{aligned}
& D F_{E X T, S}=\text { Exterior Girder Shear Distribution Factor } \\
& D F_{E X T, S}=1-\frac{\left(b_{\text {parapet }}+24 \text { in }-\left(b_{w} / 2\right)\right)}{S}=D F_{E X T, S, \text { Wheel Lines }} \\
& D F_{E X T, S}=\frac{D F_{E X T, S, \text { Wheel Lines }}}{2 \text { Wheel Lines / Axle }}=D F_{E X T, S, A x l e s}
\end{aligned}
$$

Unfactored and Undistributed Live Load Shear $=V_{L L}$

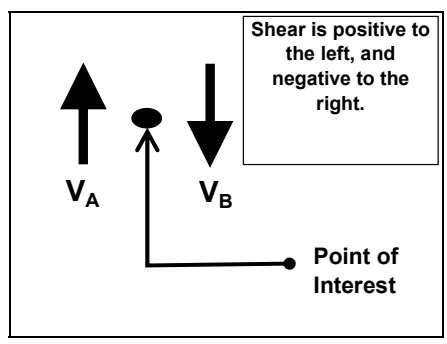

\section{Figure E.2 Shear Force Designation}

Shear to the Left of Investigation Point $=V_{A, x}$

$$
V_{A, x}=\sum_{i=1}^{m} \begin{cases}\frac{P_{i}\left(L-x_{i}\right)}{L} \Rightarrow & \text { when } x<x_{i} \\ \frac{-P_{i} x_{i}}{L} \Rightarrow & \text { when } x>x_{i}\end{cases}
$$


Shear to the Right of Investigation Point $=V_{B, x}$

$$
V_{B, x}=\sum_{i=1}^{m}\left\{\begin{array}{ccc}
P_{i}\left(1-\frac{x_{i}}{L}\right) & \Rightarrow & \text { when } x<x_{i} \\
-P_{i}\left(1-\frac{\left(L-x_{i}\right)}{L}\right) & \Rightarrow & \text { when } x>x_{i}
\end{array}\right.
$$

Maximum Unfactored and Undistributed Live Load Shear at Investigation Point $=\mathrm{V}_{\mathrm{LL}, \mathrm{x}}{ }^{\mathrm{o}}$

$$
V_{L L, x}{ }^{o}=\max \begin{cases}\left|V_{A, x}\right| & \left|V_{A, L-x}\right| \\ \left|V_{B, x}\right| & \left|V_{B, L-x}\right|\end{cases}
$$

Distributed Live Load Shear at Investigation Point $=V_{L L, x}=V_{L L, x}{ }^{o} \times D F_{S}$

\begin{tabular}{|c|c|c|c|c|c|c|c|}
\hline & & Beam 1 & Beam 2 & Beam 3 & Beam 4 & Beam 5 & Beam 6 \\
\hline$A_{\text {T-Beam }}$ & $\left(\mathrm{in}^{2}\right)$ & 901.2 & 1072.3 & 1072.4 & 1072.4 & 1074.4 & 900.6 \\
\hline$A_{A C}$ & $\left(\mathrm{in}^{2}\right)$ & 90.56 & 261.00 & 261.00 & 261.00 & 261.00 & 90.56 \\
\hline$w_{A}$ & (kip/ft) & 0.09 & 0.27 & 0.27 & 0.27 & 0.27 & 0.09 \\
\hline$w_{C}$ & (kip/ft) & 0.94 & 1.12 & 1.12 & 1.12 & 1.12 & 0.94 \\
\hline$w_{D L}$ & (kip/ft) & 1.33 & 1.71 & 1.71 & 1.71 & 1.71 & 1.33 \\
\hline$I$ & & 0.29 & 0.29 & 0.29 & 0.29 & 0.29 & 0.29 \\
\hline$D F_{M}$ & & 0.21 & 0.40 & 0.40 & 0.40 & 0.40 & 0.21 \\
\hline$M_{D L}$ & (kip·ft) & 337.9 & 432.1 & 432.1 & 432.1 & 432.7 & 337.7 \\
\hline$M_{L L}{ }^{0}$ & (kip·ft) & 531.2 & 531.2 & 664.0 & 664.0 & 531.2 & 531.2 \\
\hline$M_{L L+I}$ & (kip·ft) & 144.5 & 276.9 & 346.1 & 346.1 & 276.9 & 144.5 \\
\hline
\end{tabular}

Table E.1 Dead/Live Load Calculation Variable Results 


\section{APPENDIX F：FRP DESIGN CALCULATIONS}




\section{Strengthening Analysis Notation:}

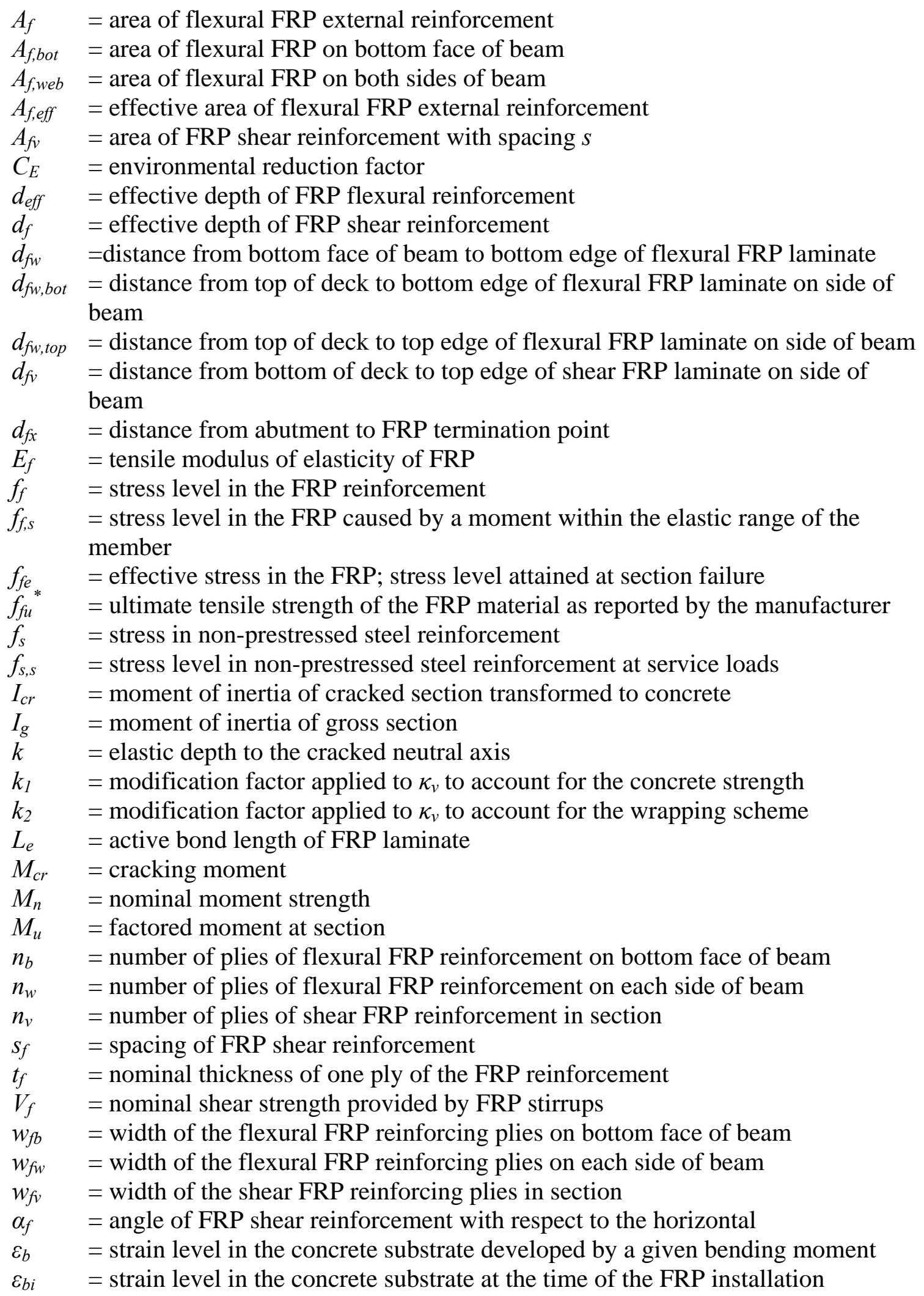


$\varepsilon_{f} \quad=$ strain level in the FRP reinforcement

$\varepsilon_{\text {bottom }}=$ strain level in the FRP reinforcement on the bottom face of the beam

$\varepsilon_{f e} \quad=$ effective strain level in the FRP reinforcement; strain level attained at section

failure

$\varepsilon_{f u_{*}} \quad=$ design rupture strain of FRP reinforcement

$\varepsilon_{f u}{ }^{*} \quad=$ ultimate rupture strain of the FRP reinforcement

$\varepsilon_{w e b, b o t}=$ strain level at the bottom edge of the FRP reinforcement on the sides of the beam

$\varepsilon_{\text {web,top }}=$ strain level at the top edge of the FRP reinforcement on the sides of the beam

$\varepsilon_{s} \quad=$ strain level in the nonprestressed steel reinforcement

$\gamma \quad=$ multiplier on $f_{c}{ }_{c}$ to determine the intensity of an equivalent rectangular stress distribution for concrete

$\kappa_{m} \quad=$ bond dependent coefficient for flexure

$\kappa_{v} \quad=$ bond dependent coefficient for shear

$\rho_{f} \quad=$ FRP reinforcement ratio

$\psi_{f} \quad=$ additional FRP strength-reduction factor 


\section{Design FRP Material Properties:}

Design Ultimate Tensile Strength $=f_{f u}=C_{E} f_{f u}^{*}$

Design Rupture Strain $=\varepsilon_{f u}=C_{E} \varepsilon_{f u}^{*}$

FRP Modulus of Elasticity $=E_{f}=\frac{f_{f u}}{\varepsilon_{f u}}$

\section{Strengthened Flexural Capacity Calculations:}

Strengthening Limit $=\left(\phi R_{n}\right)_{\text {existing }} \geq\left(1.2 M_{D L}+0.85 M_{L L}\right)_{\text {new }}$

Total Area of Flexural FRP Reinforcement $=A_{f}=A_{f, b o t}+A_{f, \text { web }}$

Area of Flexural FRP Reinforcement of Bottom Face of Beam $=A_{f, b o t}=n_{b} t_{f} w_{f b}$

Area of Flexural FRP Reinforcement of Both Sides of Beam $=A_{f, w e b}=2 n_{w} t_{f} w_{f w}$

Distance from the Top of the Deck to the Top of the Flexural FRP on the Sides of the

$$
\text { Beam }=d_{f w, t o p}=h-d_{f w}-w_{f w}
$$

Distance from Top of the Deck to Bottom Edge of Flexural FRP Laminate on Side of

$$
\text { Beam }=d_{f w, b o t}=h-d_{f w}
$$

Effective Area of Flexural FRP Reinforcement $=A_{\text {eff }}$

$$
A_{\text {eff }}=\frac{1}{\varepsilon_{\text {bottom }}}\left[\left(\frac{A_{f, \text { bottom }}}{A_{f, \text { total }}}\right)+A_{f, \text { web }}\left(\varepsilon_{\text {web }, \text { top }}+\frac{\left(\varepsilon_{\text {web bottom }}-\varepsilon_{\text {web }, \text { top }}\right)}{2}\right)\right]
$$

Effective Moment Arm of FRP Reinforcement $=d_{\text {eff }}$

$$
d_{e f f}=\frac{h A_{f, b o t} \varepsilon_{b o t}+\left(h-d_{f, w e b}-\frac{b_{f, w e b}}{2}\right)\left(A_{f, w e b} \varepsilon_{w e b, t o p}\right)+\left(h-d_{f, w e b}-\frac{b_{f, w e b}}{3}\right)\left(A_{f, w e b} \frac{\left(\varepsilon_{\text {web }, b o t}-\varepsilon_{\text {web }, \text { top }}\right)}{2}\right)}{A_{f, b o t} \varepsilon_{b o t}+h \varepsilon_{\text {web }, \text { top }}+h\left(\frac{\varepsilon_{\text {web }, \text { bot }}-\varepsilon_{\text {web }, \text { top }}}{2}\right)}
$$


FRP Reinforcement Ratio $=\rho_{f}=\frac{A_{f}}{b_{w} d}$

Cracked Moment of Inertia $=I_{c r}$

$$
\begin{aligned}
& k=\sqrt{\left(\rho_{s} n_{s}\right)^{2}+2\left(\rho_{s} n_{s}\right)}-\left(\rho_{s} n_{s}\right) \\
& c_{1}=k d \\
& \gamma=\left(h_{f}^{2} b+2 A_{s} n_{s} d-b_{w} h_{f}^{2}\right) \\
& \lambda=\left(h_{f} b-h_{f} b_{w}+A_{s} n_{s}\right) \\
& c_{2}=\frac{-\lambda+\sqrt{\lambda^{2}+b_{w} \gamma}}{b_{w}} \\
& I_{c r}=\frac{b h_{f}^{3}}{12}+b h_{f}\left(c-\frac{h_{f}}{2}\right)^{2}+\frac{\left(c-h_{f}\right)^{3}}{3}+n_{s} A_{s}(d-c)^{2}
\end{aligned}
$$

Existing State of Strain on Bottom Face of Beam $=\varepsilon_{b i}=\frac{M_{D L}(h-k d)}{I_{c r} E_{c}}$

Bond Dependent Coefficient $=\kappa_{m}$

$$
\kappa_{m}=\left\{\begin{array}{c}
\frac{1}{60 \varepsilon_{f u}}\left(1-\frac{n E_{f} t_{f}}{2,000,000}\right) \leq 0.90 \text { for } n E_{f} t_{f} \leq 1,000,000 \\
\frac{1}{60 \varepsilon_{f u}}\left(\frac{500,000}{n E_{f} t_{f}}\right) \leq 0.90 \text { for } n E_{f} t_{f}>1,000,000
\end{array}\right.
$$

Effective Level of Strain in the FRP $=0.003\left(\frac{h-c}{c}\right)-\varepsilon_{b i} \leq \kappa_{m} \varepsilon_{f u}$

Note: Concrete crushing is the failure mode if $0.003\left(\frac{h-c}{c}\right)-\varepsilon_{b i}$ controls

this equation. FRP failure controls if $\kappa_{m} \varepsilon_{f u}$ controls the equation.

Strain in Existing Reinforcing Steel $=\varepsilon_{s}=\left(\varepsilon_{f e}+\varepsilon_{b i}\right)\left(\frac{d-c}{h-c}\right)$

Strengthened Stress Level in the Reinforcing Steel $=f_{s}=E_{s} \varepsilon_{s} \leq f_{y}$ 
Stress Level in the FRP $=f_{f e}=E_{f} \varepsilon_{f e}$

Neutral Axis Depth $=c=\frac{A_{s} f_{s}+A_{\text {eff }} f_{f e}}{\not f^{\prime}{ }_{c} \beta_{1} b_{\text {eff }}}$

Design Strengthened Flexural Capacity $=\phi M_{n}=\phi\left[A_{s} f_{s}\left(d-\frac{\beta_{1} c}{2}\right)+\psi A_{\text {eff }} f_{f e}\left(d_{\text {eff }}\right)\right]$

Elastic Depth to the Cracked Neutral Axis $=k$

$$
k=\sqrt{\left(\rho_{s} \frac{E_{s}}{E_{c}}+\rho_{f} \frac{E_{f}}{E_{c}}\right)^{2}+2\left(\rho_{s} \frac{E_{s}}{E_{c}}+\rho_{f} \frac{E_{f}}{E_{c}}\left(\frac{h}{d}\right)\right)}-\left(\rho_{s} \frac{E_{s}}{E_{c}}+\rho_{f} \frac{E_{f}}{E_{c}}\right) \text { for rectangular section }
$$

Service Stresses in Reinforcing Steel $=f_{s, s}$

$$
f_{s, s}=\frac{\left\lfloor M_{s}+\varepsilon_{b i} A_{e f f} E_{f} d_{e f f}\right\rfloor(d-k d) E_{s}}{A_{s} E_{s}\left(d-\frac{k d}{3}\right)(d-k d)+A_{e f f} E_{f} d_{e f f}(h-k d)} \leq 0.80 f_{y}
$$

Service Stress Level in FRP $=f_{f, s}$

$$
f_{f, s}=f_{s, s}\left(\frac{E_{f}}{E_{s}}\right)\left(\frac{h-k d}{d-k d}\right)-\varepsilon_{b i} E_{f} \leq 0.55 f_{f u} \quad \text { for Carbon FRP }
$$

Side Flexural FRP Contribution Derivation:

The equation for flexural FRP contribution to the nominal moment capacity suggested by ACI 440.2R-02 guidelines had to be modified to include the strain gradient developed in the side flexural FRP laminates. The method used to include the strain gradient developed in the side flexural FRP laminates calculates the strains at the top and bottom of the side FRP laminates. The areas shown in Figure F1 arbitrarily demonstrate how the side flexural laminate contribution is divided up due to the strain gradient. The forces developed in each area are defined as follows: 


$$
\begin{aligned}
& T_{1}=E_{f} A_{f, b o t} \varepsilon_{b o t t o m} \\
& T_{2}=E_{f} A_{f, w e b} \varepsilon_{w e b, t o p} \\
& T_{3}=E_{f} A_{f, w e b}\left(\frac{\varepsilon_{w e b, b o t}-\varepsilon_{w e b, t o p}}{2}\right) \\
& T_{F R P}=T_{1}+T_{2}+T_{3} \\
& T_{s}=A_{s} f_{y}
\end{aligned}
$$

The forces for each area act at the centroid of each area. The force resultant, $T_{F R P}$, acts at the centroid of loading of all of the forces. This distance is also used to calculate the moment arm for the flexural FRP contribution to the nominal moment strength.

The ratio of the total force developed by the flexural FRP with the strain gradient over the total FRP area at the maximum strain value is used to reduce the total flexural FRP area to the effective FRP area. The effective area of flexural FRP is calculated by the following equation:

$$
A_{\text {eff }}=A_{f} \frac{T_{F R P}}{E_{f} A_{f} \varepsilon_{\text {bottom }}}=\frac{T_{F R P}}{E_{f} \varepsilon_{\text {bottom }}}
$$

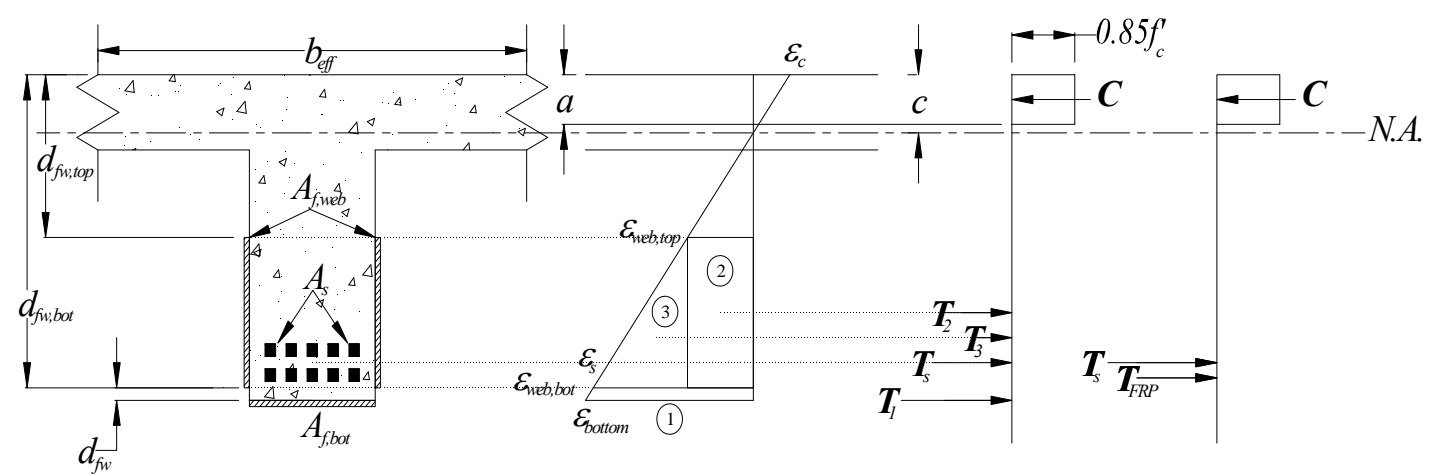

\footnotetext{
1 = Strain section corresponding to bottom face FRP laminate

2 = Strain section corresponding to side face FRP laminate at $\varepsilon$ throughout the cross section

3 = Strain section corresponding to side face FRP laminate with strain gradient
}
$\boldsymbol{T}_{1} \quad$ = Tension force developed by strain section
corresponding to bottom face FRP laminate
$\boldsymbol{T}_{2}$ = Tension force developed by strain section corresponding to side face FRP laminate at $\varepsilon_{\text {web,top }}$ throughout the cross section
$T_{3}=$ Tension force developed by strain section corresponding to side face FRP laminate with strain gradient
$\boldsymbol{T}_{S}=$ Tension force developed by strain section corresponding to side face FRP laminate with strain gradient

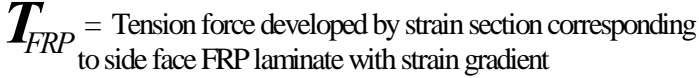

Figure F.1 Side Flexural FRP Laminate Contribution Diagram 


\section{Strengthened Shear Capacity Calculations:}

Strengthening Limit $=\left(\phi R_{n}\right)_{\text {existing }} \geq\left(1.2 V_{D L}+0.85 V_{L L}\right)_{\text {new }}$

Effective Depth of FRP Shear Reinforcement $=d_{f}=d-t_{s}-d_{f v}$

Active Bond Length $=L_{e}=\frac{2,500}{\left(n_{v} t_{f} E_{f}\right)^{0.58}}$

Bond-Reduction Coefficient Compressive Strength Modification Factor $=k_{1}=\left(\frac{f^{\prime}{ }_{c}}{4,000}\right)^{2 / 3}$

Bond-Reduction Coefficient Wrapping Scheme Modification Factor $=k_{2}$

$$
k_{2}= \begin{cases}\frac{d_{f}-L_{e}}{d_{f}} & \text { for } U-\text { wraps } \\ \frac{d_{f}-2 L_{e}}{d_{f}} & \text { for two sides bonded }\end{cases}
$$

Bond-Reduction Coefficient $=\kappa_{v}=\frac{k_{1} k_{2} L_{e}}{468 \varepsilon_{f u}} \leq 0.75$

Effective Strain $=\varepsilon_{f e}=\kappa_{v} \varepsilon_{f u} \leq 0.004$

Area of FRP Shear Reinforcement $=A_{f v}=2 n_{v} t_{f} w_{f v}$

Effective Stress in FRP Reinforcement $=f_{f e}=\varepsilon_{f e} E_{f}$

Shear Contribution of FRP Reinforcement $=V_{f}=\frac{A_{f v} f_{f e}(\sin (\alpha)+\cos (\alpha)) d_{f}}{s_{f}}$

Ultimate Shear Strength of Section $=\phi V_{n}=\phi\left(V_{c}+V_{s}+\psi_{f} V_{f}\right)$

Shear FRP Reinforcement Limit $=V_{s}+V_{f} \leq 8 \sqrt{f_{c}^{\prime}} b_{w} d$ 
APPENDIX G: FRP DESIGN CALCUlation VARIABLE Results 


\section{Manufacturer Guaranteed FRP Material Properties:}

Table G.1 Manufacturer's Reported FRP System Properties

\begin{tabular}{|l|c|c|}
\hline Thickness per ply, $\boldsymbol{t}_{\boldsymbol{f}}$ & (in) & 0.0065 \\
\hline Ultimate Tensile Strength, $\boldsymbol{f}_{\boldsymbol{f} \boldsymbol{u}}{ }^{*}$ & (ksi) & 550 \\
\hline Rupture Strain, $\boldsymbol{\varepsilon}_{\boldsymbol{f} \boldsymbol{u}}{ }^{*}$ & (in/in) & 0.0167 \\
\hline Modulus of Elasticity of FRP Laminate & (ksi) & 33000 \\
\hline
\end{tabular}

\section{$\underline{\text { Strengthened Moment Capacity Variable Results: }}$}

Table G.2 Flexural FRP Design Variable Summary

\begin{tabular}{|c|c|c|c|c|c|c|c|}
\hline \multirow{2}{*}{\multicolumn{2}{|c|}{ FRP Flexural Reinforcement Design Details }} & \multicolumn{6}{|c|}{ Beam } \\
\hline & & 1 & 2 & 3 & 4 & 5 & 6 \\
\hline Desired Minimum Rating Factor & & 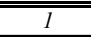 & 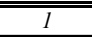 & 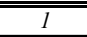 & 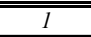 & 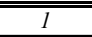 & 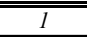 \\
\hline Existing Inventory Rating Factor & & 0.72 & 0.91 & 0.90 & 0.90 & 0.58 & 0.91 \\
\hline Existing Operating Rating Factor & & 1.20 & 1.52 & 1.50 & 1.50 & 0.96 & 1.52 \\
\hline Existing Moment Capacity & (kip·ft) & 613.6 & 1107.2 & 1101.3 & 1101.3 & 908.6 & 673.3 \\
\hline Required Moment Capacity for Inv RF = 1 & (kip·ft) & 701.0 & 1162.6 & 1162.6 & 1162.6 & 1163.3 & 700.8 \\
\hline Require Strengthening? & & YES & $Y E S$ & $Y E S$ & $Y E S$ & $Y E S$ & YES \\
\hline Eligible for FRP Strengthening? & & $Y E S$ & $Y E S$ & $Y E S$ & $Y E S$ & $Y E S$ & $Y E S$ \\
\hline Inventory Rating Factor with FRP & & 1.00 & 1.01 & 1.00 & 1.00 & 1.00 & 1.01 \\
\hline Operating Rating Factor with FRP & & 1.68 & 1.69 & 1.67 & 1.67 & 1.67 & 1.69 \\
\hline Environmental Reduction Factor, $\mathrm{C}_{\mathrm{E}}$ & & 0.85 & 0.85 & 0.85 & 0.85 & 0.85 & 0.85 \\
\hline$\#$ of plies on bottom face of girder, $n_{b}$ & (plies) & 1 & 1 & 1 & 1 & 3 & 1 \\
\hline Width of FRP plies on bottom face, $w_{f b}$ & (in) & 14 & 9 & 9 & 9 & 14 & 5 \\
\hline$\#$ of plies each web face of girder, $n_{w}$ & (plies) & 0 & 0 & 0 & 0 & 0 & 0 \\
\hline Width of FRP plies on webs, $w_{f w}$ & (in) & 0 & 0 & 0 & 0 & 0 & 0 \\
\hline Distance from bottom of girder to bottom edge of FRP laminate on & (in) & 0 & 0 & 0 & 0 & 0 & 0 \\
\hline Distance from bottom of deck to top edge of FRP laminate on web & (in) & 0 & 0 & 0 & 0 & 0 & 0 \\
\hline Total Area of FRP & $\left(\right.$ in $\left.^{2}\right)$ & 0.091 & 0.0585 & 0.0585 & 0.0585 & 0.273 & 0.033 \\
\hline Effective Area of FRP & $\left(\right.$ in $\left.^{2}\right)$ & 0.091 & 0.0585 & 0.0585 & 0.0585 & 0.273 & 0.033 \\
\hline Controling Failure Mode? & & $\begin{array}{c}\text { FRP } \\
\text { Failure } \\
\end{array}$ & $\begin{array}{c}\text { FRP } \\
\text { Failure } \\
\end{array}$ & $\begin{array}{c}\text { FRP } \\
\text { Failure } \\
\end{array}$ & $\begin{array}{c}\text { FRP } \\
\text { Failure } \\
\end{array}$ & $\begin{array}{c}\text { FRP } \\
\text { Failure } \\
\end{array}$ & $\begin{array}{c}F R P \\
\text { Failure } \\
\end{array}$ \\
\hline Distance from Extreme Compression Fiber to Neutral Axis, c & (in) & 6.195 & 3.436 & 3.418 & 3.418 & 3.45 & 6.187 \\
\hline Nominal Moment Strength, $\Phi M_{n}$ & (kip·ft) & 702.1 & 1168.7 & 1162.9 & 1162.9 & 1164.8 & 704.7 \\
\hline Required Resisting Moment Strength, $\Phi \mathrm{M}_{\mathrm{req}}$ & (kip·ft) & 701.0 & 1162.6 & 1162.6 & 1162.6 & 1163.3 & 700.8 \\
\hline$\Phi M_{\mathrm{n}}>\Phi M_{\mathrm{req}} ?$ & & $O K$ & $O K$ & $O K$ & $O K$ & $O K$ & $O K$ \\
\hline Steel service level stress check, $\mathrm{f}_{\mathrm{s}, \mathrm{s}}<0.8 \mathrm{f}_{\mathrm{y}}$ ? & & $O K$ & $O K$ & $O K$ & $O K$ & $O K$ & $O K$ \\
\hline Service Level FRP stress check, $\mathrm{f}_{\mathrm{f}, \mathrm{s}}<0.55 * \mathrm{f}_{\mathrm{fu}}$ ? & & $O K$ & $O K$ & $O K$ & $O K$ & $O K$ & $O K$ \\
\hline$c_{\text {initial }}=\mathrm{c} ?$ & & $O K$ & $O K$ & $O K$ & $O K$ & $O K$ & $O K$ \\
\hline FRP Termination Point Distance from Abutment & (ft) & 0.54 & 2.95 & 2.95 & 2.95 & 2.95 & 0.54 \\
\hline \begin{tabular}{|l} 
FRP Anchoring with Transverse Reinforcement? \\
\end{tabular} & & $Y E S$ & $Y E S$ & $Y E S$ & $Y E S$ & $Y E S$ & $Y E S$ \\
\hline Max $\varepsilon_{\text {concrete }}$ & (in/in) & -0.0022 & -0.0011 & -0.0011 & -0.0011 & -0.0010 & -0.0022 \\
\hline Max $\varepsilon_{\text {steel }}$ & (in/in) & 0.0113 & 0.0113 & 0.0113 & 0.0113 & 0.0100 & 0.0113 \\
\hline Max $\varepsilon_{\mathrm{FRP}}$ & (in/in) & 0.0128 & 0.0128 & 0.0128 & 0.0128 & 0.0113 & 0.0128 \\
\hline \begin{tabular}{|l|}
$\varepsilon_{\text {concrete }}$ location \\
\end{tabular} & (in) & 41.5 & 42.25 & 42.25 & 42.25 & 42.25 & 41.5 \\
\hline$\varepsilon_{\text {steel }}$ location & (in) & 3.958 & 4.625 & 4.625 & 4.625 & 4.625 & 3.958 \\
\hline$\varepsilon_{\text {FRP }}$ location & (in) & 0.0 & 0.0 & 0.0 & 0.0 & 0.0 & 0.0 \\
\hline
\end{tabular}




\section{Strengthened Shear Capacity Variable Results:}

Table G.3 FRP Shear Design Variables- Beams 1 and 6

\begin{tabular}{|c|c|c|c|c|c|c|c|c|c|c|c|c|c|c|c|c|c|}
\hline \multirow{3}{*}{\multicolumn{2}{|c|}{\begin{tabular}{|c} 
FRP Shear Reinforcement \\
Design Details
\end{tabular}}} & \multicolumn{8}{|c|}{ Beam 1} & \multicolumn{8}{|c|}{ Beam 6} \\
\hline & & \multicolumn{8}{|c|}{ Section \# } & \multicolumn{8}{|c|}{ Section \# } \\
\hline & & 1 & 2 & 3 & 4 & 5 & 6 & 7 & 8 & 1 & 2 & 3 & 4 & 5 & 6 & 7 & 8 \\
\hline \begin{tabular}{|l} 
Section Distance from Abument \\
\end{tabular} & (ft) & 0.0 & 0.3 & 2.6 & \begin{tabular}{|c|}
4.8 \\
\end{tabular} & 5.8 & 8.8 & $\begin{array}{lll}14.8 \\
\end{array}$ & 16.5 & 0.0 & 0.3 & 2.6 & $\begin{array}{l}4.8 \\
\end{array}$ & 5.8 & 8.8 & 14.8 & 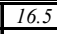 \\
\hline \begin{tabular}{|l|} 
Require FRP Strengthening \\
\end{tabular} & & NO & $N O$ & NO & \begin{tabular}{|l|l|}
$N O$ \\
\end{tabular} & $N O$ & $N O$ & NO & \begin{tabular}{|l|l|}
$N O$ \\
\end{tabular} & \begin{tabular}{|l|l|}
$N O$ \\
\end{tabular} & NO & $N O$ & NO & \begin{tabular}{|l|l|}
$N O$ \\
\end{tabular} & $N O$ & NO & NO \\
\hline \begin{tabular}{|l|l|} 
E Existi \\
\end{tabular} & ps) & 163.2 & 228.6 & 107.1 & 96.0 & 96.0 & 85.0 & 79.0 & 62.0 & 163.2 & 228.6 & 107.1 & 96.0 & 96.0 & 85.0 & \begin{tabular}{|c|}
79.0 \\
\end{tabular} & \begin{tabular}{|c|c|}
62.0 \\
\end{tabular} \\
\hline V Req & & 68.0 & 70.0 & 64.0 & 58.5 & 55.9 & 48.2 & 32.8 & \begin{tabular}{|l|l|}
28.7 \\
\end{tabular} & 68.0 & 70.0 & 64.0 & 58.4 & 55.9 & 48.2 & 32.8 & 28.7 \\
\hline FRP strip l & (in) & & & & & & & & & & & & & & & & \\
\hline \begin{tabular}{|l} 
Number of FRP la \\
\end{tabular} & Layers) & & & & & & & & & & & & & & & & \\
\hline r Orientation & (degrees) & & & & & & & & & & & & & & & & \\
\hline Strip Y & & & & & & & & & & & & & & & & & \\
\hline Center-to-Center spacing of Strips & & & & & & & & & & & & & & & & & \\
\hline $\mathrm{V}_{\mathrm{FRP}} \operatorname{Rec}$ & (kips) & & & & & & & & & & & & & & & & \\
\hline $\mathrm{V}_{\mathrm{FRP}}$ Provided & (kips) & 0.0 & 0.0 & 0.0 & 0.0 & 0.0 & 0.0 & 0.0 & \begin{tabular}{|l|}
0.0 \\
\end{tabular} & 0.0 & 0.0 & 0.0 & 0.0 & 0.0 & 0.0 & 0.0 & 0.0 \\
\hline Strengt & & 3.89 & 5.47 & 2.31 & 2.22 & 2.34 & 2.37 & 3.22 & 2.72 & 3.89 & 5.47 & 2.31 & 2.22 & 2.34 & 2.37 & 3.22 & 2.72 \\
\hline Strengt & & 6.49 & 9.13 & 3.85 & 3.70 & 3.9 & 3.95 & 5.37 & 4.55 & 6.49 & 9.13 & 3.85 & 3.70 & 3.91 & 3.95 & 5.37 & \begin{tabular}{|l}
4.55 \\
\end{tabular} \\
\hline FRP & & & & & & & & & & & & & & & & & \\
\hline FRP Sh & & $O$ & $O K$ & $O K$ & $O K$ & $O K$ & $O K$ & $O K$ & $O K$ & $O K$ & $O K$ & $O K$ & $O K$ & $O K$ & $O K$ & $O K$ & $O K$ \\
\hline Streng & (kips) & 163.2 & 228.6 & 107.1 & 96.0 & 96.0 & 85.0 & 79.0 & 62.0 & 163.2 & 228.6 & 107.1 & 96.0 & 96.0 & 85.0 & 79.0 & 62.0 \\
\hline Stregthened V $>$ V Required? & & $Y E S$ & YES & YES & YES & YES & YES & YES & YES & YES & YES & YES & YES & YES & YES & YES & YES \\
\hline
\end{tabular}

Table G.4 FRP Shear Design Variables- Beams 3 and 4

\begin{tabular}{|c|c|c|c|c|c|c|c|c|c|c|c|c|c|c|c|c|c|}
\hline \multirow{3}{*}{\multicolumn{2}{|c|}{\begin{tabular}{|c} 
FRP Shear Reinforcement \\
Design Details
\end{tabular}}} & \multicolumn{8}{|c|}{ Beam 3} & \multicolumn{8}{|c|}{ Beam 4} \\
\hline & & & & & & & & & & & & & Sec & & & & \\
\hline & & 1 & 2 & 3 & 4 & 5 & 6 & 7 & 8 & 1 & 2 & 3 & 4 & 5 & 6 & 7 & 8 \\
\hline Section Distance from Abument & $\overline{\overline{(\mathrm{ft})}}$ & 0.0 & 0.3 & 2.6 & \begin{tabular}{c|c|}
.8 \\
\end{tabular} & $\begin{array}{c}.8 \\
\end{array}$ & 8.8 & 18.8 & 16.5 & 0.0 & 0.3 & 2.6 & 4.8 & ב5.8 & 8.8 & 14.8 & 10.5 \\
\hline Require FRP Stre & & $\mathrm{NO}$ & $\mathrm{NO}$ & $\mathrm{NO}$ & NO & YES & YES & $N O$ & $Y E S$ & $N O$ & $\mathrm{NO}$ & $\mathrm{NO}$ & $\mathrm{NO}$ & YES & YES & $\mathrm{NO}$ & YES \\
\hline VExi & (ki & 163.3 & 227.9 & 227.9 & 216.9 & 95.3 & 84.3 & 78.3 & 61.3 & \begin{tabular}{|l|}
163.3 \\
\end{tabular} & 227.9 & 227.9 & 216.9 & 95.3 & 84.3 & 78.3 & 61.3 \\
\hline V Required & (kips) & 136.0 & 141.9 & 130.3 & 120.0 & 115.2 & 100.6 & 71.5 & 63.9 & \begin{tabular}{|l|}
136.0 \\
\end{tabular} & 141.9 & 130.3 & 120.0 & 115.2 & 100.6 & 71.5 & 63.9 \\
\hline FRP strip length & (in) & & & & & 35.9 & 71.8 & & 72.0 & & & & & 35.9 & 71.8 & & 72.0 \\
\hline Number & & & & & & 3 & 1 & & 1 & & & & & 3 & 1 & & 1 \\
\hline r Orientation & (degrees & & & & & 45 & 45 & & 90 & & & & & 45 & 45 & & 90 \\
\hline Strip Wid & n) & & & & & 8 & 8 & & 8 & & & & & 8 & 8 & & 4 \\
\hline ng of Strips & & & & & & 22 & 16 & & 24 & & & & & 22 & 16 & & 20 \\
\hline$V_{\text {FRP }}$ Required & (kips) & & & & & 19.9 & 16.4 & & 2.5 & & & & & 19.9 & 16.4 & & 2.5 \\
\hline $\mathrm{V}_{\mathrm{FRP}} \operatorname{Pr}$ & (kips) & 0.0 & 0.0 & 0.0 & 0.0 & 23.9 & 20.0 & 0.0 & 9.4 & 0. & 0.0 & 0.0 & 0.0 & 23.9 & 20.0 & 0.0 & 5.7 \\
\hline Strengt| & & 1.32 & 1.93 & 2.13 & 2.20 & 1.05 & 1.05 & 1.12 & 1.14 & 1.32 & 1.93 & 2.13 & 2.20 & 1.05 & 1.05 & 1.12 & 1.06 \\
\hline Strengtl & & 2.20 & 3.22 & 3.56 & 3.67 & 1.76 & 1.76 & 1.88 & 1.90 & 2.20 & 3.22 & 3.56 & 3.67 & 1.76 & 1.76 & 1.88 & 1.77 \\
\hline FRP Sh & & & & & & 2 & 5 & & 3 & & & & & 2 & 5 & & 4 \\
\hline FRP Sh & & $O K$ & $O K$ & $O K$ & $O K$ & $O K$ & $O K$ & $O K$ & $O K$ & $O K$ & $O K$ & $O K$ & $O K$ & $O K$ & $O K$ & $O K$ & $O K$ \\
\hline Strengt| & (kips) & 163.3 & 227.9 & 227.9 & 216.9 & 119.3 & 104.3 & 78.3 & 70.7 & 163.3 & 227.9 & 227.9 & 216.9 & 119.3 & 104.3 & 78.3 & 67.0 \\
\hline Stregthened V > V Required? & & YES & YES & YES & YES & YES & YES & $Y E S$ & YES & \begin{tabular}{|l|}
$Y E S$ \\
\end{tabular} & YES & YES & YES & YES & YES & $Y E S$ & $Y E S$ \\
\hline
\end{tabular}

Table G.5 FRP Shear Design Variables- Beams 2 and 5

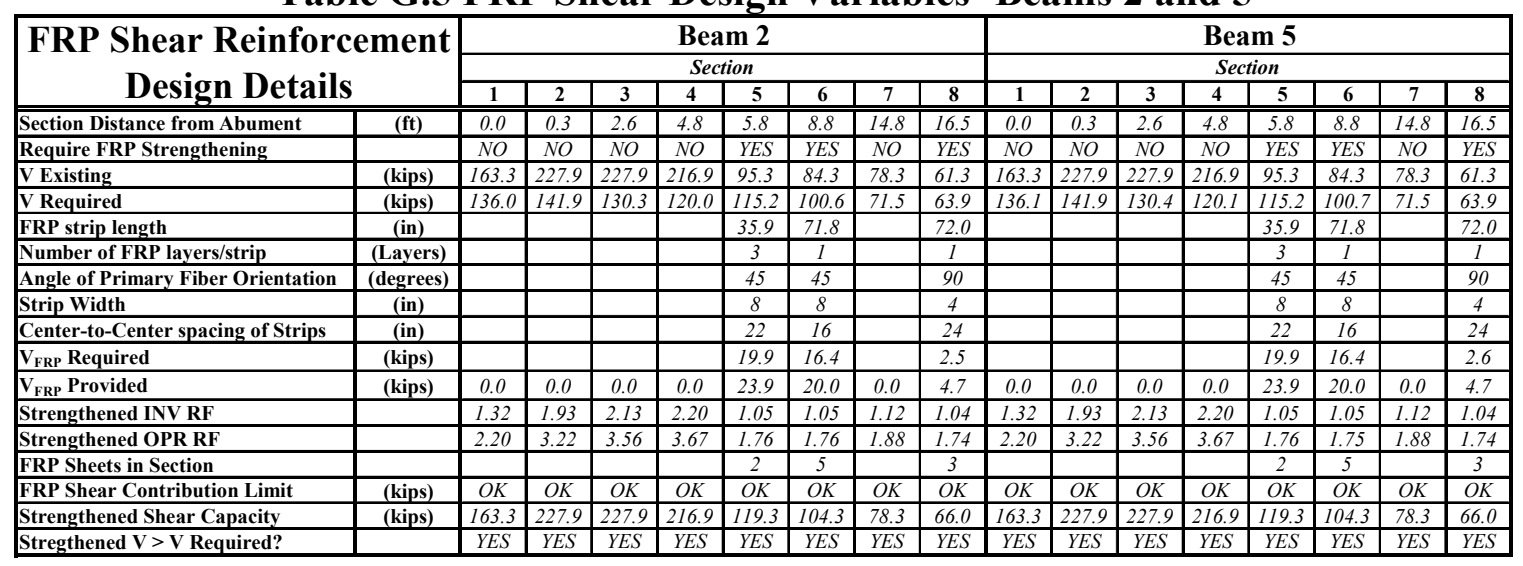




\section{Appendix H: Proposed FRP Strengthening Design DRAWINGS}




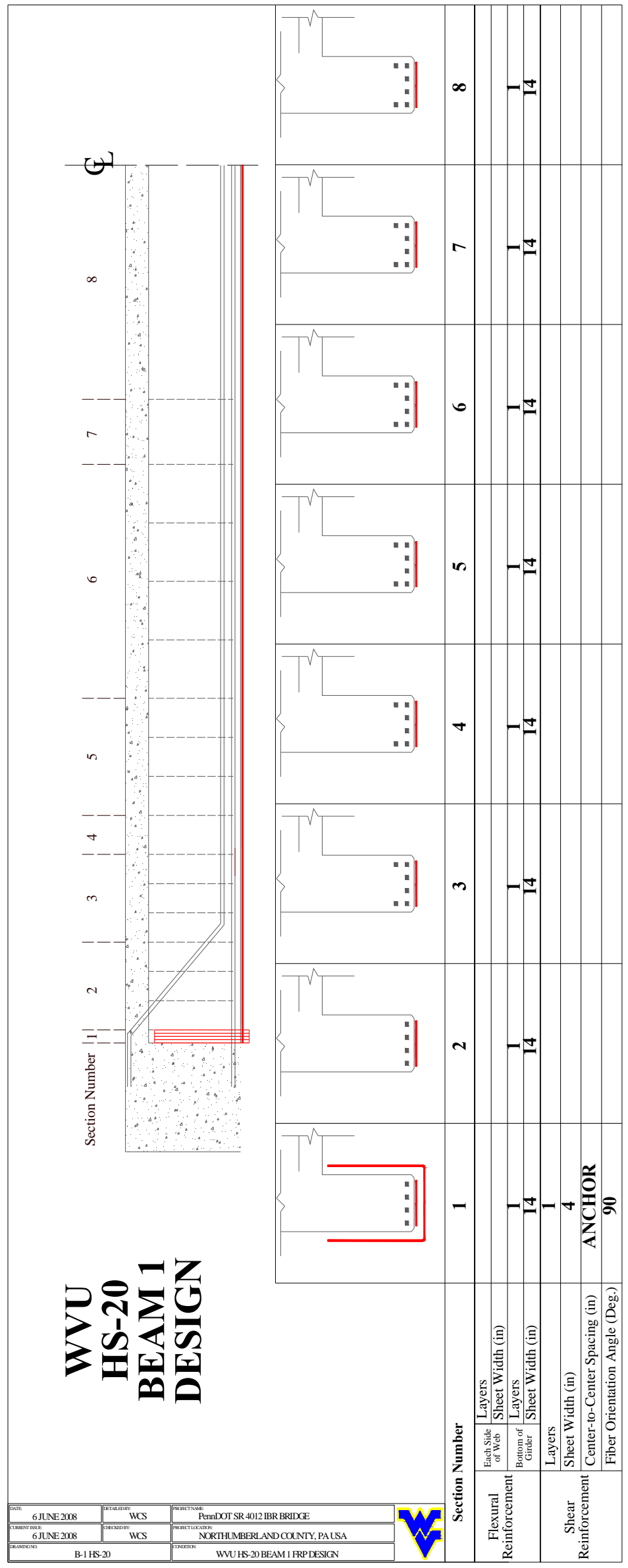

- 172 - 


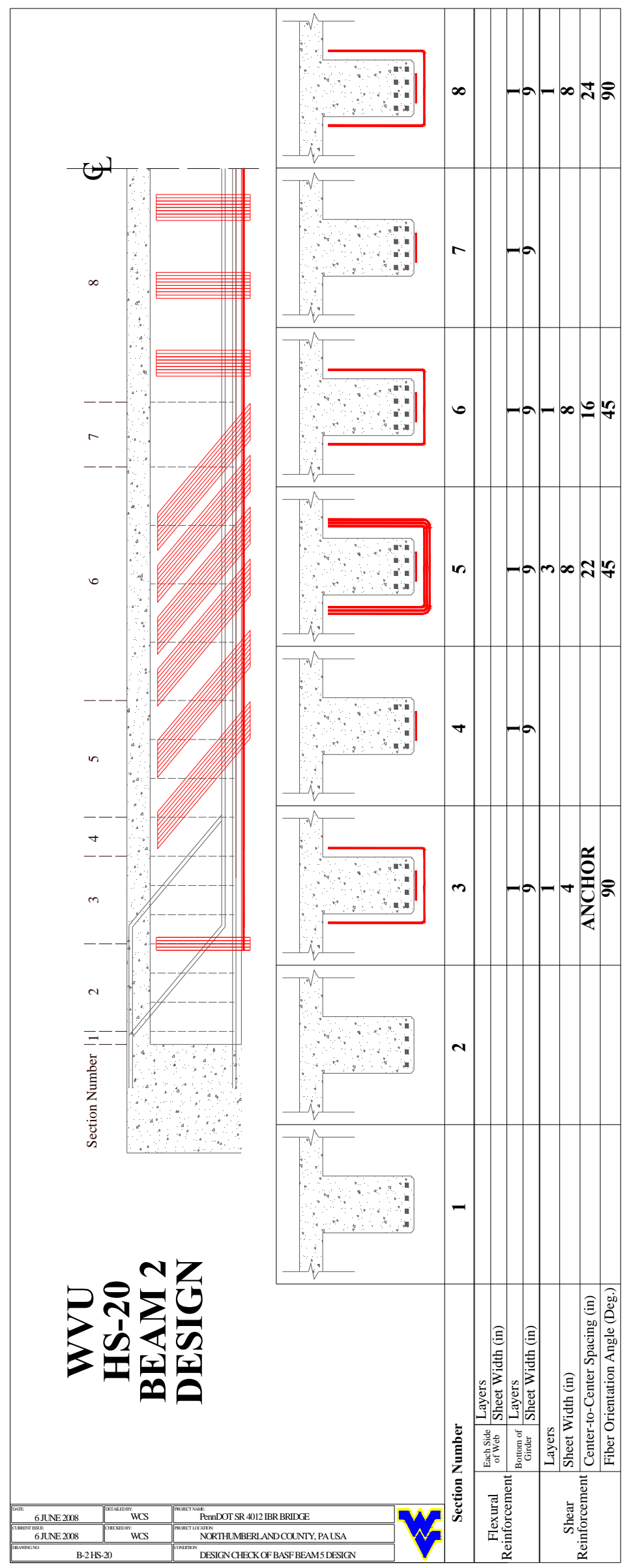




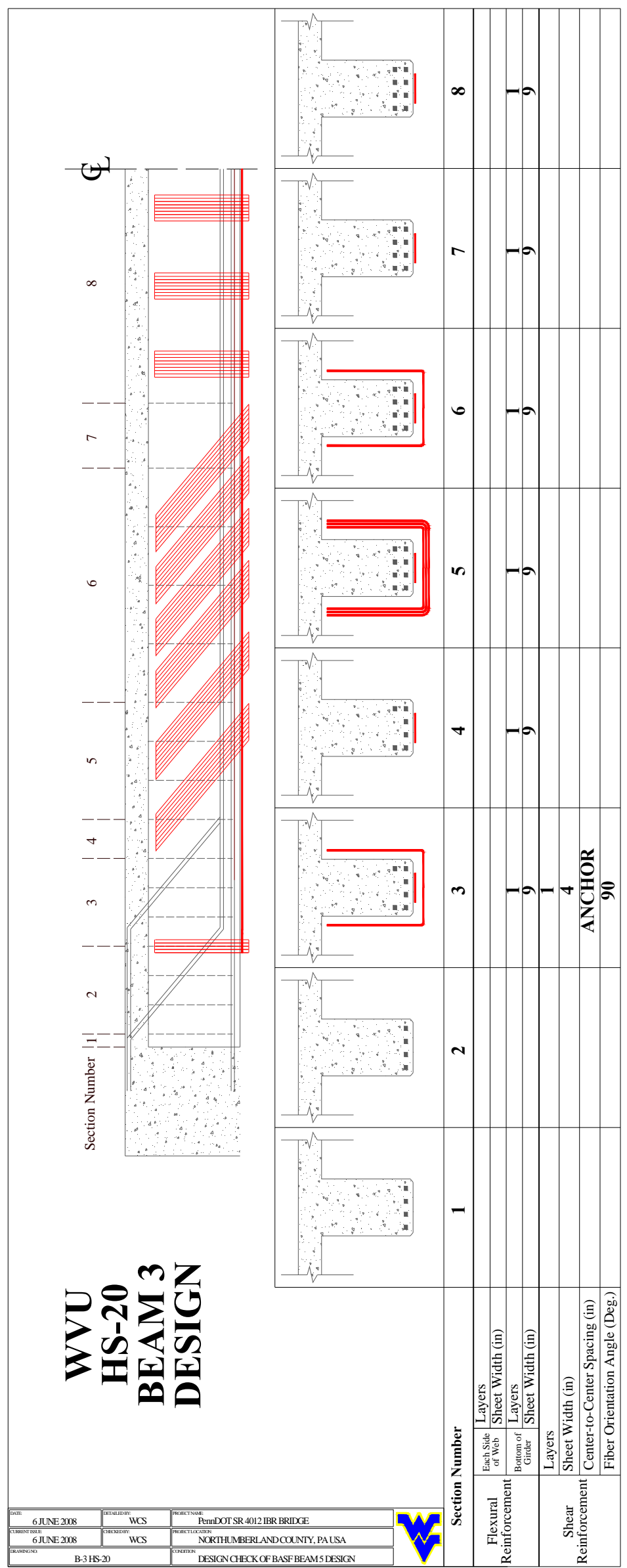

- 174 - 


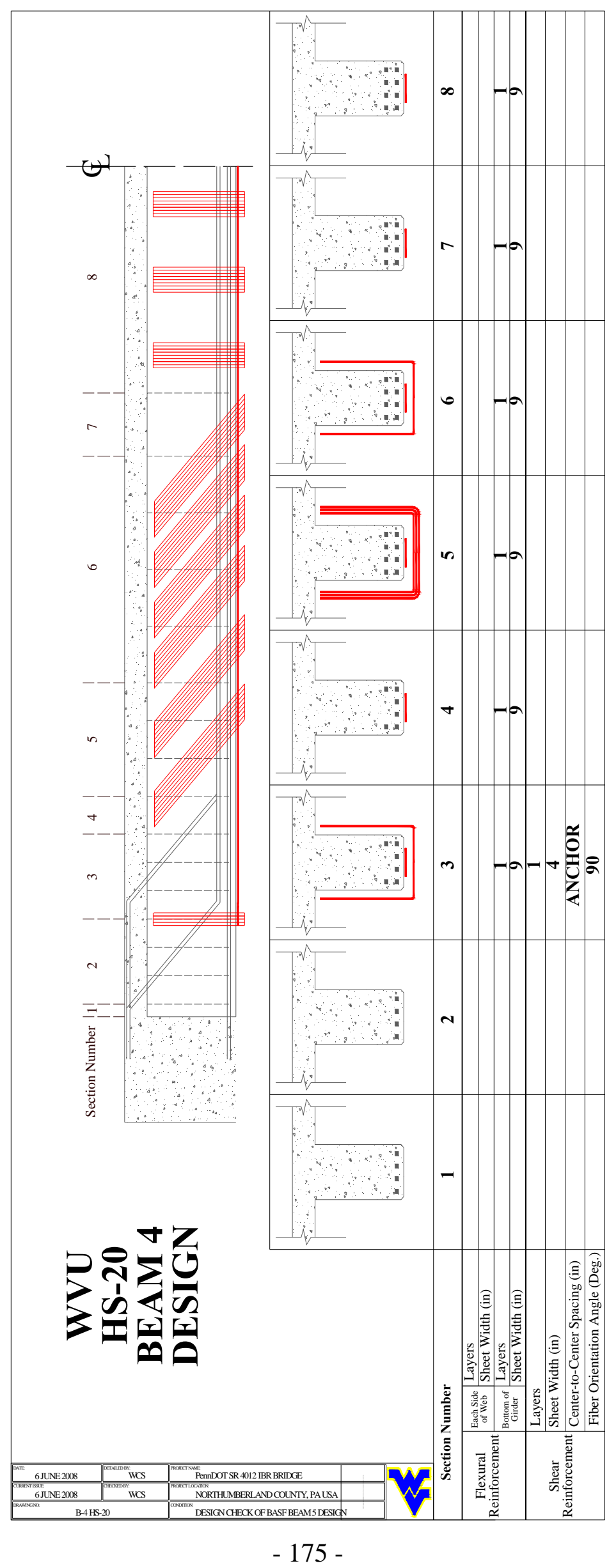




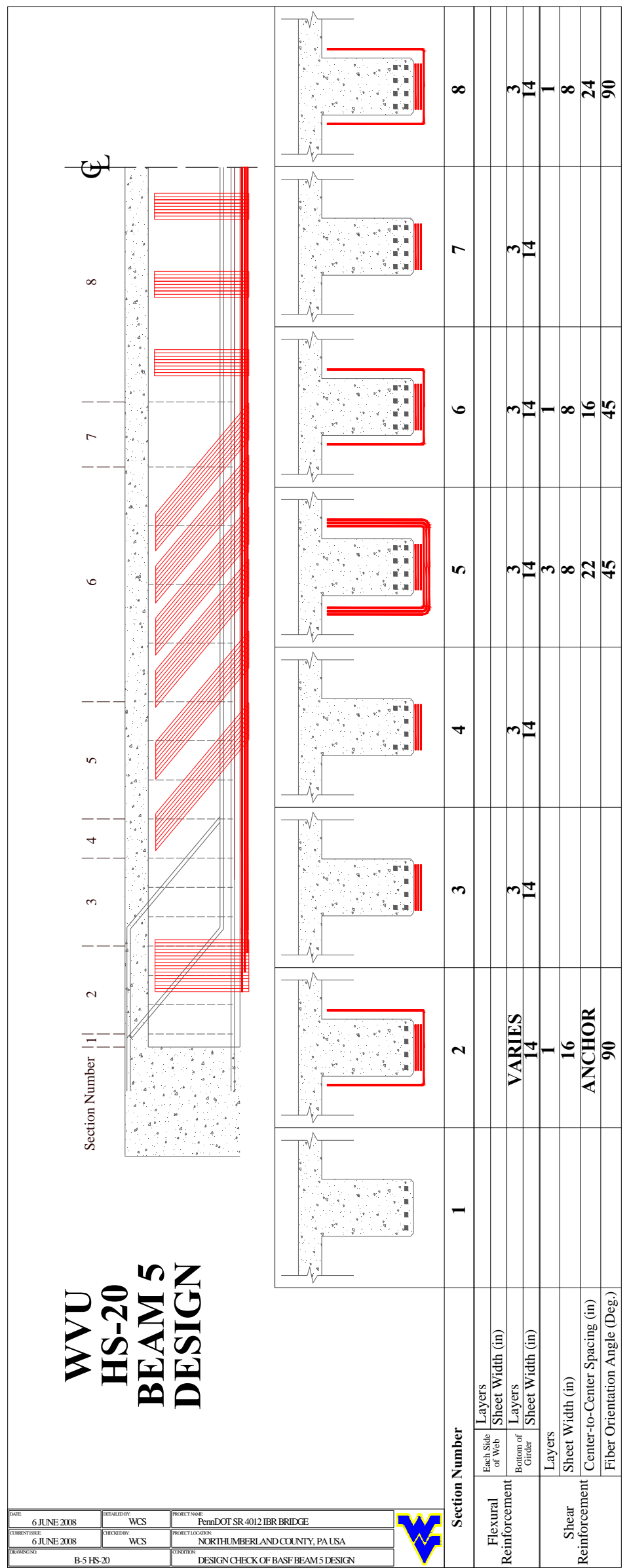




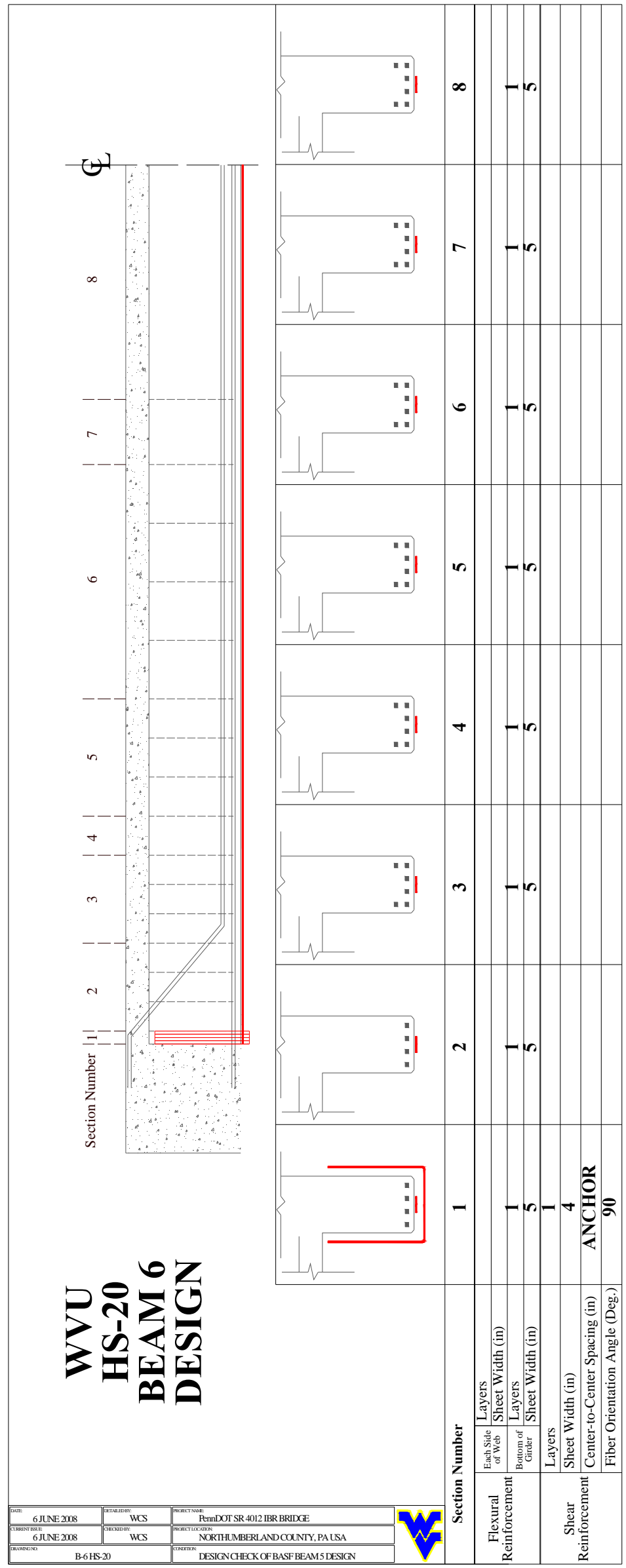

